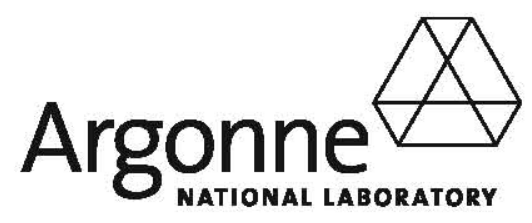

Annotated Bibliography for the
Humpback Chub (Gila cypha) with
Emphasis on the Grand Canyon Population

Environmental Science Division 
About Argonne National Laboratory

Argonne is a U.S. Department of Energy laboratory managed by UChicago Argonne, LLC under contract DE-AC02-06CH11357. The Laboratory's main facility is outside Chicago, at 9700 South Cass Avenue, Argonne, Illinois 60439. For information about Argonne, see www.anl.gov.

\section{Availability of This Report}

This report is available, at no cost, at http://www.osti.gov/bridge. It is also available

on paper to the U.S. Department of Energy and its contractors, for a processing fee, from:

U.S. Department of Energy

Office of Scientific and Technical Information

P.O. Box 62

Oak Ridge, TN 37831-0062

phone (865) $576-8401$

fax (865) $576-5728$

reports@adonis.osti.gov

\section{Disclaimer}

This report was prepared as an account of work sponsored by an agency of the United States Government. Neither the United States Government nor any agency thereof, nor UChicago Argonne, LLC, nor any of their employees or officers, makes any warranty, express or implied, or assumes any legal liability or responsibility for the accuracy, completeness, or usefulness of any information, apparatus, product, or process disclosed, or represents that its use would not infringe privately owned rights. Reference herein to any specific commercial product, process, or service by trade name, trademark, manufacturer, or otherwise, does not necessarily constitute or imply its endorsement, recommendation, or favoring by the United States Government or any agency thereof. The views and opinions of document authors expressed herein do not necessarily state or reflect those of the United States Government or any agency thereof, Argonne National Laboratory, or UChicago Argonne, LLC. 


\section{Annotated Bibliography for the Humpback Chub (Gila cypha) with Emphasis on the Grand Canyon Population}

prepared for

Western Area Power Administration

Colorado River Storage Project Management Center

Salt Lake City, Utah

prepared by

C.T. Goulet and K.E. LaGory

Environmental Science Division, Argonne National Laboratory

September 2009 
This page intentionally left blank. 


\section{CONTENTS}

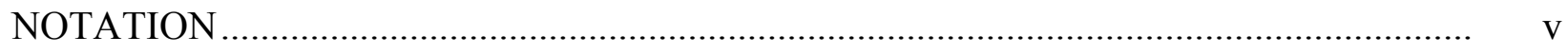

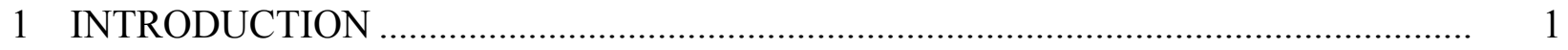

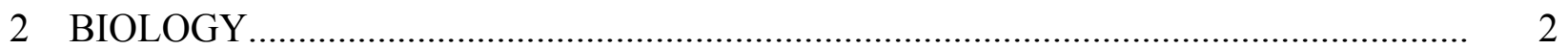

2.1 Anatomy and Physiology ..................................................................................... 2

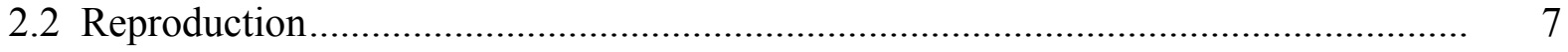

2.3 Genetics and Systematics................................................................................ 9

2.4 Supporting Articles ...................................................................................... 15

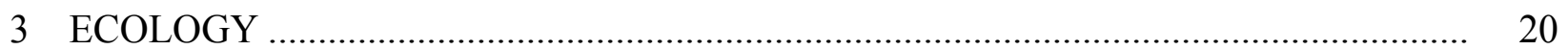

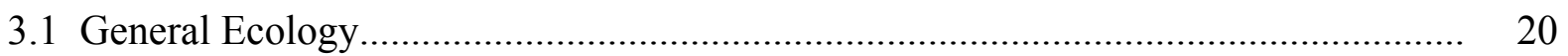

3.2 Distribution and Abundance …………………................................................. 27

3.3 Habitat Selection.............................................................................................. 41

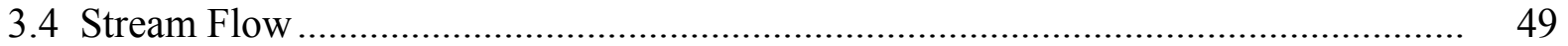

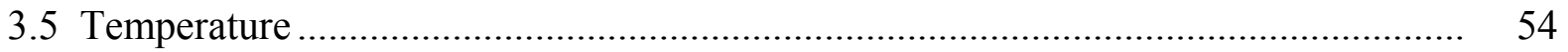

3.6 Foraging and Diet ……………….............................................................. 56

3.7 Supporting Articles ............................................................................................. 58

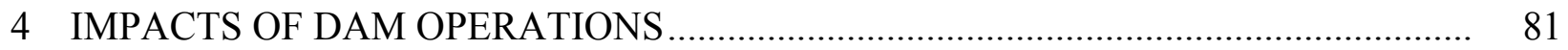

4.1 Effects on Flow ........................................................................................... 81

4.2 Effects on Sediment and Debris Deposition ........................................................ 107

4.3 Effects on Temperature ................................................................................. 123

4.4 Effects on Food Availability ............................................................................. 124

4.5 Supporting Articles ........................................................................................ 129

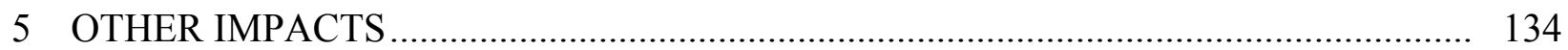

5.1 Nonnative Species........................................................................................... 134

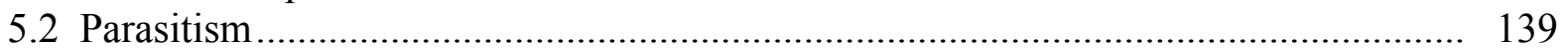

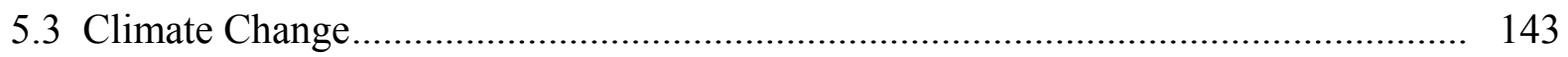

5.4 Supporting Articles ........................................................................................ 145

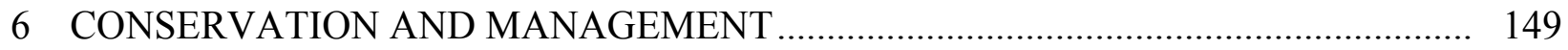

6.1 Habitat and Species Management ....................................................................... 149

6.2 Monitoring Techniques ................................................................................. 196

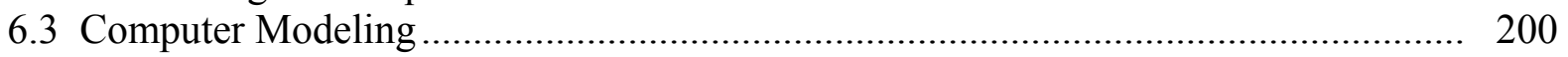

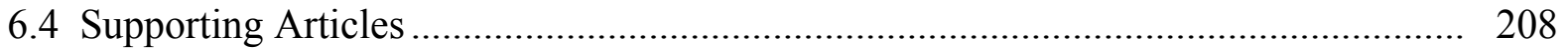

7 CITATIONS INCLUDED IN BIBLIOGRAPHY ..................................................... 211 
This page intentionally left blank. 


\section{NOTATION}

The following is a list of the acronyms, initialisms, and abbreviations (including units of measure) used in this document.

\section{ACRONYMS, INITIALISMS, AND ABBREVIATIONS}

\begin{tabular}{|c|c|}
\hline AFDM & ash-free dry mass \\
\hline AGFD & Arizona Game and Fish Department \\
\hline AMP & Adaptive Management Program \\
\hline B-F & Baker and Fraser method \\
\hline BHBF & Beach Habitat-Building Flow \\
\hline BNT & brown trout \\
\hline BO & biological opinion \\
\hline CFR & Code of Federal Regulations \\
\hline CI & confidence interval \\
\hline CL & confidence limit \\
\hline CPE & catch per effort \\
\hline CPUE & catch per unit effort \\
\hline $\mathrm{CV}$ & coefficient of variation \\
\hline $\mathrm{CY}$ & calendar year \\
\hline DOI & Department of the Interior \\
\hline DPS & distinct population segment \\
\hline $\mathrm{EF}$ & electrofishing \\
\hline EIS & Environmental Impact Statement \\
\hline FR & Federal Register \\
\hline GCD & Glen Canyon Dam \\
\hline GCDAMP & Glen Canyon Dam Adaptive Management Program \\
\hline GCES & Glen Canyon Environmental Studies \\
\hline GCMRC & Grand Canyon Monitoring and Research Center \\
\hline GCM & General Circulation Model \\
\hline $\begin{array}{l}\text { GEMSS } \\
\text { GIS }\end{array}$ & Generalized Environmental Modeling System for Surface Waters \\
\hline $\mathrm{HBC}$ & humpback chub \\
\hline ICS & Intentionally Created Surplus \\
\hline ISMP & Interagency Standardized Monitoring Program \\
\hline
\end{tabular}




\begin{tabular}{|c|c|}
\hline LCR & Little Colorado River \\
\hline LSSF & low summer steady flow \\
\hline mtDNA & mitochondrial DNA \\
\hline msat & microsatellite \\
\hline MLFF & modified low fluctuating flow \\
\hline MSCP & Multispecies Conservation Plan \\
\hline $\mathrm{N}$ & sample size \\
\hline $\mathrm{N}_{\mathrm{b}}$ & effective number of breeders per year \\
\hline $\mathrm{N}_{\mathrm{e}}$ & effective population size per generation \\
\hline NWR & National Wildlife Refuge \\
\hline $\mathrm{P}$ & $\begin{array}{l}\text { probability of obtaining a result at least as extreme as that observed, assuming the } \\
\text { null hypothesis is true. }\end{array}$ \\
\hline PCE & primary constituent elements \\
\hline PHABSIM & physical habitat simulation model \\
\hline PIT & passive integrated transponder \\
\hline PSD & proportional stock density \\
\hline $\mathrm{r}$ & correlation coefficient \\
\hline $\mathrm{R}^{2}$ & coefficient of regression \\
\hline RBT & rainbow trout \\
\hline Reclamation & Bureau of Reclamation \\
\hline RIP & Recovery Implementation Program \\
\hline RK & river kilometer \\
\hline RM & river mile \\
\hline ROD & Record of Decision \\
\hline SWS & selective withdrawal system \\
\hline TL & total length \\
\hline USC & United States Code \\
\hline USFWS & U.S. Fish and Wildlife Service \\
\hline USGS & U.S. Geological Survey \\
\hline VIC & Variable Infiltration Capacity \\
\hline ww & wet weight \\
\hline YOY & young-of-the-year \\
\hline
\end{tabular}




\section{UNITS OF MEASURE}

\begin{tabular}{|c|c|}
\hline$\mu \mathrm{g}$ & microgram \\
\hline $\begin{array}{l}\mathrm{cfs} \\
\mathrm{cm}\end{array}$ & $\begin{array}{l}\text { cubic feet per second } \\
\text { centimeter(s) }\end{array}$ \\
\hline $\mathrm{d}$ & $\operatorname{day}(\mathrm{s})$ \\
\hline $\mathrm{ft}$ & foot (feet) \\
\hline $\begin{array}{l}\mathrm{h} \\
\mathrm{ha}\end{array}$ & $\begin{array}{l}\text { hour(s) } \\
\text { hectare(s) }\end{array}$ \\
\hline in. & $\operatorname{inch}(e s)$ \\
\hline $\mathrm{kg}$ & kilogram(s) \\
\hline $\mathrm{km}$ & kilometer(s) \\
\hline $\begin{array}{l}\mathrm{L} \\
\mathrm{lb}\end{array}$ & $\begin{array}{l}\operatorname{liter}(\mathrm{s}) \\
\operatorname{pound}(\mathrm{s})\end{array}$ \\
\hline $\begin{array}{l}\mathrm{m} \\
\mathrm{maf} \\
\mathrm{mg} \\
\mathrm{mL} \\
\mathrm{mi} \\
\mathrm{min} \\
\mathrm{mm} \\
\mathrm{mo}\end{array}$ & $\begin{array}{l}\text { meter(s) } \\
\text { million acre-feet } \\
\text { milligram(s) } \\
\text { milliliter(s) } \\
\text { mile(s) } \\
\text { minute(s) } \\
\text { millimeter(s) } \\
\text { month(s) }\end{array}$ \\
\hline S & second(s) \\
\hline wk & week(s) \\
\hline$y r$ & year(s) \\
\hline
\end{tabular}


This page intentionally left blank. 


\title{
ANNOTATED BIBLIOGRAPHY FOR THE HUMPBACK CHUB (GILA CYPHA) WITH EMPHASIS ON THE GRAND CANYON POPULATION
}

\author{
Prepared by \\ Celine Goulet and Kirk LaGory \\ Environmental Science Division \\ Argonne National Laboratory
}

September 2009

\section{INTRODUCTION}

Glen Canyon Dam is a hydroelectric facility located on the Colorado River in Arizona that is operated by the U.S. Bureau of Reclamation (Reclamation) for multiple purposes including water storage, flood control, power generation, recreation, and enhancement of fish and wildlife. Glen Canyon Dam operations have been managed for the last several years to improve conditions for the humpback chub (Gila cypha) and other ecosystem components.

An extensive amount of literature has been produced on the humpback chub. We developed this annotated bibliography to assist managers and researchers in the Grand Canyon as they perform assessments, refine management strategies, and develop new studies to examine the factors affecting humpback chub. The U.S. Geological Survey recently created a multispecies bibliography (including references on the humpback chub) entitled Bibliography of Native Colorado River Big Fishes (available at www.fort.usgs.gov/Products/data/COFishBib). That bibliography, while quite extensive and broader in scope than ours, is not annotated, and, therefore, does not provide any of the information in the original literature.

In developing this annotated bibliography, we have attempted to assemble abstracts from relevant published literature. We present here abstracts taken unmodified from individual reports and articles except where noted. The bibliography spans references from 1976 to 2009 and is organized in five broad topical areas, including: (1) biology, (2) ecology, (3) impacts of dam operations, (4) other impacts, and (5) conservation and management, and includes twenty subcategories. Within each subcategory, we present abstracts alphabetically by author and chronologically by year. We present relevant articles not specific to either the humpback chub or Glen Canyon Dam, but cited in other included reports, under the Supporting Articles subcategory. We provide all citations in alphabetical order in Section 7. 


\section{BIOLOGY}

\subsection{ANATOMY AND PHYSIOLOGY}

\section{Berry, C.R. and R. Pimentel. 1985. Swimming performances of three rare Colorado River fishes. Transactions of the American Fisheries Society 114:397-402.}

A stamina tunnel was used to determine the prolonged swimming performance of age-0 humpback chubs Gila cypha, bonytail chubs G. elegans, and Colorado squawfish Ptychocheilus lucius and of subadult Colorado squawfish. The "fatigue velocity" in body lengths per second at which $50 \%$ of the test fish were fatigued (FV50) was determined at 14,20 , and $26^{\circ} \mathrm{C}$. The ranges of FV50 values for the three fishes (average total length in parentheses) were humpback chubs (95 mm), 4.4-5.7; bonytail chubs (99 mm), 4.7-5.8; small Colorado squawfish (104 mm), 4.04.5; large Colorado squawfish (432 mm), 2.0-2.3. Absolute speed of large Colorado squawfish was about 2.4 times that of small Colorado squawfish. Swimming ability of the sub-yearlings increased with increased water temperature. These rare fish had prolonged-swimming abilities similar to other fish species.

\section{Berry, D.R. 1984. Hematology of four rare Colorado River fishes. Copeia 3:790-793.}

The razorback sucker (Xyrauchen texanus), Colorado squawfish (Ptychocheilus lucius), humpback chub (Gila cypha) and bonytail chub (G. elegans) are native to the Colorado River system. Fish culture and stocking can be aided by use of clinical tests to determine fish health, but hematology of healthy fish must be known. Reported here are hematological characteristics for certain life stages of the four Colorado River fishes.

\section{Didenko, A.V., S.A. Bonar and W.J. Matter. 2004. Standard weight $\left(W_{s}\right)$ equations for four rare desert fishes. American Journal of Fisheries Management 24(2):697-703.}

Standard weight $\left(\mathrm{W}_{\mathrm{s}}\right)$ equations have been used extensively to examine body condition in sport fishes. However, development of these equations for nongame fishes has only recently been emphasized. We used the regression-line-percentile technique to develop standard weight equations for four rare desert fishes: flannelmouth sucker Catostomus latipinnis, razorback sucker Xyrauchen texanus, roundtail chub Gila robusta, and humpback chub G. cypha. The $\mathrm{W}_{\mathrm{s}}$ equation for flannelmouth suckers of 100-690 mm total length (TL) was developed from 17 populations: $\log _{10} \mathrm{~W}_{\mathrm{s}}=-5.180+3.068 \log _{10} \mathrm{TL}$. The $\mathrm{W}_{\mathrm{s}}$ equation for razorback suckers of 110 $885 \mathrm{~mm}$ TL was developed from 12 populations: $\log _{10} \mathrm{~W}_{\mathrm{s}}=-4.886+2.985 \log _{10} \mathrm{TL}$. The $\mathrm{W}_{\mathrm{s}}$ equation for roundtail chub of 100-525 mm TL was developed from 20 populations: $\log _{10} \mathrm{~W}_{\mathrm{s}}=-5.065+3.015 \log _{10} \mathrm{TL}$. The $\mathrm{W}_{\mathrm{s}}$ equation for humpback chub of $120-495 \mathrm{~mm} \mathrm{TL}$ was developed from 9 populations: $\log _{10} \mathrm{~W}_{\mathrm{s}}=-5.278+3.096 \log _{10} \mathrm{TL}$. These equations meet criteria for acceptable standard weight indexes and can be used to calculate relative weight, an index of body condition. 


\section{Douglas, M.E. 1993. An analysis of sexual dimorphism in an endangered cyprinid fish (Gila cypha Miller) using video image technology. Copeia 1993:334-343.}

Univariate and multivariate techniques were used to evaluate sexual dimporphism in 53 morphometric measures taken from 63 adult specimens of endangered cyprinid, the humpback chub (Gila cypha). Specimens were filmed and released unharmed after their capture in the Colorado and Little Colorado rivers of the Grand Canyon (Arizona). Morphometric data were later extracted from film using a microcomputer and image analysis software. Because of the unique morphology of this fish, analyses emphasized its anterodorsal hump. Only two of 53 characters $(3.8 \%)$ revealed significant sexual dimorphism in an analysis of covariance; approximately what one would expect from chance alone (i.e., one in 20, or 5\%). A discriminant analysis correctly classifies specimens by sex only $60 \%$ of the time, which is not significantly different from random expectations. Multiple group principal components analysis (MGPCA) and sheared PCA using all 53 characters also failed to delineate significant sexual dimorphism. Morphological shape differences among individuals, regardless of sex, were clearly apparent from character loadings onto both principal component 2 and sheared principal component 2. These differences were due to extent and development of the nuchal hump and to concomitant changes in concavity and length of the head which accompany development. These differences appear ontogenetically based and are unrelated to either sexual or seasonal variation.

\section{Douglas, M.E., M.R. Douglas, J.M. Lynch, and D.M. McElroy. 2001. Use of geometric morphometrics to differentiate Gila (Cyprinidae) within the Upper Colorado River basin. Copeia 2:389-400.}

Video images of 215 adult Gila robusta and 148 endangered Gila cypha were collected from May 1991-October 1992 at eight Colorado River basin localities (seven upper basins and one lower basin). The two species were sympatric at five of these locations; G. robusta was absent at one site, whereas G. cypha was missing at two others. Saggital views of each individual were videotaped and 25 morphological points (15 anatomical landmarks and 10 helping points) identified. Bookstein shape coordinates were calculated from Cartesian coordinates of these landmarks and points, whereas centroid size was used as a measure of body size. Shape differences were evaluated among populations of each species using MANOVA and canonical variates analysis. In G. cypha, variation encompassed three aspects: nuchal hump (most pronounced in Grand Canyon forms), relative head size (larger in Cataract Canyon forms), and caudal peduncle dimensions (shorter with a tapering depth in Cataract Canyon forms but longer and uniformly deeper in those from Desolation Canyon). Nuchal development in G. robusta is slight, hence only head and peduncle dimensions distinguished populations. Those individuals from Cataract Canyon had relatively shorter peduncles that (again) tapered in depth from anterior to posterior, whereas $G$. robusta from Desolation Canyon possessed peduncles that were much longer and of uniform depth. Specimens from Debeque and Rifle Canyons had proportionally smaller heads. Variation among all 13 populations (i.e., both species together) was evaluated using relative warp analysis, with $G$. cypha and G. robusta clearly separated at all sympatric locations except those from Desolation and Caratact Canyons. Here, body shapes of the two species converged. Overall, shape variation in both species is clinal. Although results from our geometric morphometric analysis were statistically similar to those based on distances derived 
from a truss analysis, the geometric approach visually demonstrated phenotypic differences among populations and species and this, in turn, has management implications.

\section{Hendrickson, D.A. and E.B. Brothers. 1994. Utility of otoliths of Grand Canyon humpback chub Gila cypha for age determinations and as indicators of ecological history of individuals. Proceedings of the Desert Fishes Council 25:30-31.}

Otoliths of teleosts are crystalline structures of the inner ear, the micro- structure and chemistry of which have been found in other species to contain detailed growth and temperature histories of individuals. We have verified the daily periodicity of increment formation in hatchery populations of the surrogate bonytail chub Gila elegans, and have used daily increments in one of the three otoliths (lapillus) to age young of the year humpback chubs taken in 1990 and 1991 from both the mainstream Colorado River and the Little Colorado River (LCR). Spawning in the LCR appears to correlate with decreasing discharge in that river in spring or early summer. Growth is rapid in the LCR, whereas, all fish taken from the mainstream Colorado (a cold, nearconstant temperature river comprised almost entirely of hypolimnetic releases from Glen Canyon dam) are much smaller than individuals of equal age captured in the LCR. Growth in the mainstream is extremely slow, but otoliths indicate that young-of-the-year (YOY) occasionally encounter warmer, diurnally cycling, temperature regimes, perhaps tributary mouths or backwaters, where they remain for periods of up to a week and grow at much higher rates. In some individuals taken from the mainstream Colorado, abrupt transitions from periods of rapid to very slow growth are interpreted to equate to movement from the LCR to the much colder mainstream. Ages, otolith structure, and locations of some YOY taken from the mainstream almost certainly preclude an origin in the LCR. At least limited spawning and recruitment to at one or two months of age does appear to have occurred in the mainstream or closely associated habitats outside of the LCR, both up- and downstream of the LCR.

\section{Lorenzen, K. 1996. The relationship between body weight and natural mortality in fish: a comparison of natural ecosystems and aquaculture. Journal of Fish Biology 49:627-647.}

The relationship between body weight and natural mortality in juvenile and adult fish was analysed for different aquatic ecosystems: lakes, rivers, the ocean, and pond, cage and tank aquaculture systems. Mortality was modelled as a power function of weight, and the parameters $b$ (exponent) and $M_{u}$ (mortality at the unit weight of $1 \mathrm{~g}$ ) estimated for fish in the six ecosystems, as well as within selected populations, species and families. At the ecosystem level, no significant differences in parameters were found between lakes, rivers and the ocean and a joint mortality-weight relationship for all natural ecosystems was estimated with parameters $b=$ -0.288 (90\% confidence limit [CL; -0.315, -0.261]) and $M_{u}=3.00(90 \% \mathrm{CL}[2.70,3.30])$ per year. Among the culture systems, mortality-weight relationships in ponds and cages were not significantly different and a joint relationship was estimated. The weight exponents of mortality in ponds/cages and tanks were very similar at about $b=-0.43$, and significantly more negative than in natural ecosystems. Mortalities at unit weight were significantly lower in tanks $(0.91 / \mathrm{yr})$ than in ponds/cages (2.24/yr), and both were significantly lower than in natural ecosystems. No systematic differences were found between the mortality-weight relationships determined for individual populations, species or families, and fish in the respective ecosystems. It is hypothesized that aquaculture mortality-weight relationships indicate the allometric scaling of non-predation mortality, which is therefore more strongly size dependent than predation 
mortality. If non predation mortality in natural ecosystems shows a similar scaling with body weight, then the allometric exponent of predation mortality must be less negative than that observed for total natural mortality. Implications of the established mortality-weight relationships for aquaculture and culture-based fisheries are discussed.

Meretsky, V.J., R.A. Valdez, M.E. Douglas, M.J. Brouder, O.T. Gorman, and P.C. Marsh. 2000. Spatiotemporal variation in length-weight relationships of endangered humpback chub: implications for conservation and management. Transactions of the American Fisheries Society 129:419-428.

The largest population of endangered humpback chub Gila cypha inhabits the lower LCR and the main-stem Colorado River near its confluence with the LCR in Grand Canyon, Arizona. At present, fish in both rivers spawn almost exclusively in the LCR. Flows in the main-stem Colorado River are regulated by Glen Canyon Dam, and water temperature approximates predam winter temperatures year-round. The LCR continues to provide a relatively natural hydrograph and seasonal warming patterns. Length-weight relationships among adult humpback chub from the lower Colorado River basin showed a seasonal pattern of declining condition during spring spawning season followed by recovery of condition during summer through early winter. Fish from the main stem recovered condition more rapidly after reproduction than did fish from the LCR and may have benefited from dam-mediated environmental changes. Grand Canyon Colorado River fish had the greatest weight at length of eight locations sampled in the upper and lower basins. Records since 1978 indicate a decline in condition of lower basin humpback chub coincident with a reported decline in population size in Grand Canyon. We recommend increased monitoring of all populations, including mark-recapture studies to provide population estimates during the spawning season and condition monitoring during OctoberNovember to determine more subtle changes in fish health.

\section{Portz, D. and H. Tyus 2004. Fish humps in two Colorado River fishes: a morphological response to cyprinid predation? Environmental Biology of Fishes 71(3):233-245.}

Extant fishes endemic to the upper Colorado River of the American southwest include only cyprinids and catostomids. A curious attribute in species of both groups is the presence of a large nuchal hump. Largest cyprinid humps occur in humpback chub, Gila cypha, and largest catostomid humps occur in razorback sucker, Xyrauchen texanus. Several authors have suggested the humps confer a hydrodynamic advantage to life in fast flow, but this premise has not been confirmed with experimental work. To test the role of humps in Colorado River fishes, the authors subjected whole-body casts of preserved specimens with humps and with humps removed to controlled flows in an experimental tank. These tests confirmed that humps increased drag coefficients for $X$. texanus and $G$. cypha with no additional lift component. High energetic costs of locomotion and position-holding with a large hump, and the additional metabolic expense of forming large humps, suggest that the humps are not relict structures. Instead, the authors argue that these large humps represent convergent evolution prompted by predation from a cyprinid piscivore. Colorado pikeminnow, Ptychocheilus lucius, top piscivore in the Colorado River system, is the only native fish capable of consuming large $X$. texanus and G. cypha, and it also is sympatric with them. However, lack of jaw teeth and a relatively small jaw gape limit the maximum prey size that $\mathrm{P}$. lucius can consume. Based on gape size, about $55 \%$ of $X$. texanus and 
$71 \%$ of $G$. cypha could be consumed by even the largest $P$. lucius. However, vulnerability would increase to 73 and $83 \%$ respectively if these species did not have humps. Co-evolution tends to favor predator defense mechanisms in prey most vulnerable to such a voracious predator.

Development of a large nuchal hump provides a deep body that is difficult or impossible for $P$. lucius to ingest.

\section{Robinson, A.T. and M.R. Childs. 2001. Juvenile growth of native fishes in the Little Colorado River and in a thermally modified portion of the Colorado River. North American Journal of Fisheries Management 21:809-815.}

We estimated juvenile growth rates of four native fish species using the von Bertalanffy growth equation and length data from fish captured in 1991-1994 in the Little Colorado River, a tributary to the Colorado River in Arizona in the Grand Canyon. We compared growth rates to water temperatures for all four species and modeled the effects of warming the Colorado River (through proposed retrofit of the Glen Canyon Dam) on the growth of age-0 emigrants from the tributary. Juvenile growth rates in the Little Colorado River were faster for flannelmouth sucker Catostomus latipinnis, slowest for speckled dace Rhinichthys osculus, and intermediate for humpback chub Gila cypha and bluehead sucker Catostomus discobolus. Our model indicates that native fish immigrating into the cold Colorado River $\left(8-12^{\circ} \mathrm{C}\right)$ from the relatively warm Little Colorado River during their first 3 months of life will grow very little by the end of their first year. According to other studies, older, larger fish that disperse into the Colorado River are more likely to survive than those that migrate as larvae. Growth, and possibly survival, of native fish larvae that drift from tributaries into the Colorado River could be increase if water released from Glen Canyon Dam is warmed during the period of larval drift.

\section{Snyder, D.E. 1976. Terminologies for intervals of larval fish development. Pages 41-60 in J. Boreman, editor. Great Lakes fish egg and larvae identification, proceedings of a workshop. U.S. Fish and Wildlife Service FWS/OBS-76/23.}

Several terminology systems for larval fish phases are reviewed, and a new standardized system is recommended, based on four phases: (1) larva, (2) protolarva, (3) mesolarva, and (4) metalarva. The phases are based on the morphogenesis of the median finfold and fin elements (spines, and rays); paired fins are included in the definition of the last phase. The larval phase is characterized by obvious fin morphogenesis following hatching or parturition, ending immediately before: (1) the last finfold and atrophying fins are adsorbed beyond recognition; (2) the full complement of distinct fin elements (spines and rays) become apparent in all fins; and (3) principal ray segmentation becomes apparent in all fins. This phase may be absent in some fish. In the protolarval phase distinct median fin elements (dorsal, anal, or caudal spines or rays) are not yet apparent. In the mesolarval phase at least one but not the full complement is present and the adult possesses pelvic fins, the pelvic buds or fins are not yet apparent. The metalarval phase is characterized by the presence of the full complement of distict principal rays in the median fins and, if the adult possesses pelvic fins, the pelvic buds or fins are apparent. Thirteen terminology systems are reviewed in this paper, and a term frequency table is given. 


\subsection{REPRODUCTION}

\section{Gorman, O.T. and D.M. Stone. 1999. Ecology of spawning humpback chub, Gila cypha, in the Little Colorado River near Grand Canyon, Arizona. Environmental Biology of Fishes 55:115-133.}

The morphologically unique and endangered humpback chub, Gila cypha, is found in canyon-bound reaches of the Colorado River and its tributaries. Now limited to six isolated reproducing populations, this species is believed to have been once distributed over a large portion of the mainstem river. Because the species inhabits remote canyon areas, little is known about its spawning ecology. The largest remaining population occurs in the lower Little Colorado River (LCR) near Grand Canyon, where we conducted a three-year study of spawning ecology during spring (March-June) 1993-1995. We analyzed seasonal patterns of movement, population density, relative condition, spawning scores, and frequency of ripe condition and fin abrasions and compared these data with seasonal discharge and water temperature to determine spawning phenology and ecology. Spawning commenced in late March, peaked in mid-April, and waned in mid-May. A high proportion of males remained ripe over this period, whereas ripe females were relatively abundant only in April. Increased densities of adult fish in March-April and rapid declines in May-June coupled with recaptures of $18.4 \%$ of these adults in the Colorado River suggest that portion of the population migrated from the Colorado River into the LCR to spawn and then returned. Ripe males aggregated in areas of complex habitat structure with high angular variation in bottom profiles (matrix of large boulders, travertine masses combined with chutes, runs, and eddies, 0.5-2.0 m deep) and were associated with deposits of clean gravel. Ripe females appeared to move to these male aggregations to spawn. Near-spawning (including gravid) females and non-spawning fish used similar habitats and were segregated but close $(<50$ $\mathrm{m})$ to habitats occupied by aggregations of ripe males. Abrasions on anal and lower caudal fins of males and females suggest that spawning involves contact with gravel substrates, where semiadhesive eggs are deposited and females fertilized. The findings of this study should aid recovery efforts for humpback chub by identifying spawning habitat within the historic distributional range where additional spawning stocks could be established.

\section{Hamman, R.L. 1982. Spawning and culture of humpback chub. Progressive Fish- Culturist 44:213-216.}

During 1981, humpback chub (Gila cypha) were spawned and cultured at Willow Beach (Arizona) National Fish Hatchery. This species is listed as endangered by the U.S. Fish and Wildlife Service. Seventeen wild females ovulated after injection with $4 \mathrm{mg}$ acetone-dried carp pituitary per kilogram of body weight. Eight females were stripped manually, whereas the remaining nine injected females spawned naturally in a trout raceway. Mean fecundity of eight females was 2,523. Incubation periods ranged from 102 to $146 \mathrm{~h}$ at water temperatures of 21$22^{\circ} \mathrm{C}, 115$ to $160 \mathrm{~h}$ at $19-20^{\circ} \mathrm{C}, 167$ to $266 \mathrm{~h}$ at $16-17^{\circ} \mathrm{C}$, and 340 to $475 \mathrm{~h}$ at $12-13^{\circ} \mathrm{C}$. Survival of eggs was $79 \%$ at $21-22^{\circ} \mathrm{C}, 84 \%$ at $19-20^{\circ} \mathrm{C}, 62 \%$ at $16-17^{\circ} \mathrm{C}$, and $12 \%$ at $12-13^{\circ} \mathrm{C}$. At hatching, total length and weight of fry ranged from 6.7 to $7.4 \mathrm{~mm}$ and 2.8 to $4.2 \mathrm{mg}$. The survival of swim-up fry was $99 \%$ at $21-22^{\circ} \mathrm{C}, 95 \%$ at $19-20^{\circ} \mathrm{C}, 91 \%$ at $16-17^{\circ} \mathrm{C}$, and $15 \%$ at 12 $13^{\circ} \mathrm{C}$. The length of fry placed in raceways had doubled by 21 to 28 days, and fingerlings attained a range of 36.9 to $47.5 \mathrm{~mm}$ and 586.5 to $887.4 \mathrm{mg}$ by day 56 after hatching. 
Kaeding, L.R., B.D. Burdick, P.A. Schrader and C.W. McAda. 1990. Temporal and spatial relations between the spawning of humpback chub and roundtail chub in the upper Colorado River. Transactions of the American Fisheries Society 119:135-144.

Gonadosomatic indices $(100 \times$ gonad weight/whole-body weight $)$ and the occurrence of expressible gametes indicated a temporal overlap in the spawning of humpback chub Gila cypha and roundtail chub G. robusta at Black Rocks, a turbulent, deepwater reach of the upper Colorado River, Colorado $\left(39^{\circ} \mathrm{N}, 109^{\circ} \mathrm{W}\right)$. Radiotelemetry showed that roundtail chub moved throughout the upper Colorado River during the spawning season, whereas humpback chub were restricted almost entirely to the 1.8-km Black Rocks reach; however, spatial isolation of the species during spawning was not demonstrated. A principal component analysis of morphologic measurements taken from live fish supported taxonomic assignments made in the field and suggested that most of the few specimens considered hybrids or intergrades by field personnel were actually humpback chub; however, an analysis based on fin ray counts indicated that this group included roundtail chub, hybrids, or backcross individuals. The strong affinity of humpback chub for the unique habitat conditions created by water flowing rapidly among large, angular boulders and shoreline rock outcrops at Black Rocks and elsewhere suggests that the unusual morphology of this species is an adaptation to life in such habitats. The limited availability of such habitats might be an important factor controlling the distribution and relative abundance of the humpback chub, a species now listed as endangered.

Stone, D.M. and O.T. Gorman. 2005. Ontogenesis of endangered humpback chub (Gila cypha) in the Little Colorado River, Arizona. The American Midland Naturalist 155:123135.

The largest population of endangered humpback chub Gila cypha inhabits the Colorado River below Glen Canyon Dam and the lower $14 \mathrm{~km}$ of the Little Colorado River (LCR), Arizona. Currently, adults from both rivers spawn and their progenies grow and recruit to adulthood primarily within the LCR, where we studied G. cypha's life history using hoop net capture data. Humpback chub undergo an ontogenesis from diurnally active, vulnerable, nearshore-reliant YOY (30-90 mm total length) into nocturnally active, large-bodied adults ( $\geq 180 \mathrm{~mm}$ TL). During the day, adults primarily resided in deep midchannel pools; however, at night they dispersed inshore amongst the higher densities of YOY conspecifics. Many YOY G. cypha shifted to nocturnal habitats that provided greater cover, possibly, to avoid inshore invading adults. These findings mirror predator-prey scenarios described in other freshwater assemblages, but do not refute other plausible hypotheses. Gila cypha piscivorous activity may escalate in hoop nets, which can confine fish of disparate sizes together; adults were significantly associated with YOY conspecifics and small dead fish in hoop nets at night and eight G. cypha (156-372 $\mathrm{mm} \mathrm{TL}$ ) regurgitated and/or defecated other fish body parts during handling following capture. Gila cypha can definitely be piscivorous given the opportunity, but the magnitude of their piscivorous activity in the wild is debatable. 


\subsection{GENETICS AND SYSTEMATICS}

\section{DeMarais, B.D. and T.E. Dowling. 1993. Introgressive hybridization and evolution of Colorado River basin Gila (Teleostei: Cyprinidae). Proceedings of the Desert Fishes Council 24:67.}

Allozymes and mitochondrial DNA (mtDNA) were used to assess population and phylogenetic relationships among Gila elegans, Gila cypha, and stocks of Gila robusta from the Colorado River basin. Admixture of molecular markers diagnostic for these three species in stocks of G. robusta and discordance of phylogenetic topologies for allozymes and mtDNA resulted from introgressive hybridization. Examples of relatively recent as well as evolutionary old hybridization have been identified; therefore, interspecific gene flow have been an important evolutionary force that has contributed to morphological diversity in these fishes.

\section{Douglas, M.E., W.L. Minckley and H.M. Tyus. 1989. Qualitative characters, chubs of the genus Gila (Pisces: Cyprinidae) and the "art of seeing well". Copeia 3:653-662.}

Qualitative scoring is frequently overlooked in preference to counts or measurements of individual characters, particularly for species whose overlap in morphology makes clear separation difficult. Quantitative measurements and counts of single characters were compared to qualitative rankings of selected morphological features of chubs from the Yampa River, Colorado. Data were collected by technicians with no specialized training in systematics. A high degree of morphological variability confounded identification using the quantitative data set, while principal components analysis of qualitative data clearly separated Gila cypha (humpback chub) and G. robusta (roundtail chub). Totals of 32 G. cypha and 336 G. robusta were identified; no intermediates were indicated. We thus demonstrate that scoring of complex characteristics is useful for endangered fishes that must be minimally handled to insure uninjured release. The clean separation of syntopic G. cypha and G. robusta supports protection of the lower Yampa River, the only location in the upper Colorado River basin in which apparent hybridization.

\section{Douglas, M.E., W.L. Minckley and H.M. Tyus. 1998. Multivariate discrimination of Colorado Plateau Gila spp.: the art of seeing well revisited. Transactions of the American Fisheries Society 127:163-173.}

Fishery managers have long been troubled by phenotypic variation within and among Colorado Plateau Gila. The problem is twofold. From an historical perspective, there was reticence to investigate fishes long considered as "undesirable." In a taxonomic sense, there is confusion over within- and among-species variability. We document the former, then clarify the latter by applying discriminant analysis to meristic and morphometric data collected from museum specimens. We test three hypotheses: roundtail chub G. robusta, humpback chub $G$. cypha, and bonytail G. elegans are morphologically indistinguishable; juveniles are assignable to species based upon adult characters; and putative hybrids are morphologically intermediate between parental forms. Through the use of meristic characters in nonparametric discriminate analysis, over $95 \%$ of all adults were segregated to species. By using morphometric characters, $97 \%$ could be allocated to species. Gila robusta was easily separated from G. cypha and G. elegans. The latter were most difficult of all species-pairs to discriminate, yet field characters 
still segregated them at better than 95\%. A discriminant function, based upon five morphometric characters, will allocate unknowns to species. Juvenile G. elegans were often misidentified as G. robusta. Putative hybrids were generally assigned to one or the other parental form; thus, hybrid intermediacy could not be rejected. However, paucity of hybrids weakened the test. We conclude that factors most important in segregating these species are character selection, adequate analyses, and the "art of seeing well."

\section{Douglas, M.R. and M.E. Douglas. 2007. Genetic structure of humpback chub Gila cypha and roundtail chub $G$. robusta in the Colorado River ecosystem. Final report, Department of Fish, Wildlife and Conservation Biology, Colorado State University, Fort Collins, Colorado.}

Humpback chub, Gila cypha, and roundtail chub, G. robusta, are found in the Upper Colorado River drainage (Green and Colorado rivers and their tributaries, in the states of Colorado, New Mexico, Utah, Wyoming). The former species is also found in Marble and Grand Canyons (Arizona) of the lower basin Colorado River. Natural populations of a third species, Bonytail, G. elegans have been mostly extirpated from the wild. All three species have been affected by anthropogenic modifications of the Colorado River ecosystem, with two (G. cypha and G. elegans) listed as federally endangered, and the third considered for listing, as well as state-designated 'of concern' throughout its range. We evaluated molecular genetic diversity across four mtDNA regions (total 1,869 base pairs) for 336 specimens representing four upper basin populations of G. cypha, seven upper basin populations of G. robusta, and nine lower basin Marble/ Grand canyon "aggregates" of G. cypha. In addition, using larger sample sizes, we also surveyed these same populations and species at 16 microsatellite (msat) DNA loci for a total of 643 specimens.

Neither G. cypha nor G. robusta could be discriminated using mtDNA, although this marker was successful in separating both from $G$. elegans at $4.7-4.8 \%$ sequence divergence $( \pm 0.0-0.1 \%)$. The recent coalescence of lineages in G. cypha / G. robusta is unusual, especially given (a) fossil history, (b) the broad geographic sampling conducted in this study, and (c) the number (and evolutionary rate) of the mtDNA regions examined.

The most parsimonious explanation for these data is that both species were reduced to very small populations by an end-of-Pleistocene warming event and were subsequently forced together into refugial (and shrinking) riverine habitat, thus becoming syntopic with one another. They then hybridized, possibly backcrossing (progeny to parental forms) over an extended temporal span. Eventually, pluvial conditions returned, the aquatic environment subsequently expanded, and both species returned to familiar and exclusive niches within the river where they reproduced with like kind. Nevertheless, the large-scale population reduction would have re-set their mtDNA evolutionary clocks, and hybridization event(s) would have provided both species with the same mtDNA haplotype(s).

These data are also congruent with shallow mtDNA diversity uncovered in a basinwide study of Flannelmouth sucker (Catostomus latipinnis), giving credence to the fact that the aforementioned perturbation at end-of-Pleistocene was ecosystem-wide and thus affected more than a single species of fish. Two interesting points emerged from the G. cypha / G. robusta 
mtDNA data analysis. One is a lack of haplotype differentiation in Desolation Canyon, a location previously identified in a morphological analysis as exhibiting a 'locality effect' for G. cypha and G. robusta, where individuals of both species resembled one another more closely than either resembled conspecific populations elsewhere in the basin. Desolation Canyon specimens also reflected the lowest mtDNA k-value (i.e., an estimate of how much on average two random haplotypes differ), thus indicating that $G$. cypha and $G$. robusta are more similar to one another on the mtDNA level at this site than they are at other sites. These mtDNA results mirror the morphological results at Desolation Canyon.

Haplotype trees generated for all specimens graphically display the admixture of individuals with regard to mtDNA haplotype. This confusion extends not only across populations in each basin, but across upper and lower basins, and most importantly, across species as well. Although mtDNA is not well suited for hybrid analysis, our data nevertheless uncovered seven G. cypha with a G. elegans haplotype (with six of these in Marble and Grand canyons, the other in Desolation Canyon), whereas but a single G. robusta was found to possess a G. elegans haplotype (also from Desolation Canyon).

Analysis of nuclear DNA offered additional perspectives. Microsatellite DNA provided sufficient resolution to discriminate among populations and basins when $G$. cypha and $G$. robusta were evaluated. However, one difficulty with our msat analysis is that upper basin $G$. cypha and $G$. robusta are too similar to one another to adequately differentiate them. This problem is particularly manifest in upper basin G. cypha. Different software algorithms provide separate perspectives on the number of discrete populations within the upper basin and lower basin, and across both species.

We elect to take a conservative approach to delineating subgroups based on our msat data and select the analyses that recognize six groups. These six-clusters are: (1) G. elegans; (2) all Grand Canyon G. cypha 'aggregates'; (3) Desolation Canyon G. cypha and G. robusta; (4) upper basin G. cypha (excluding G. cypha from Desolation Canyon); (5) upper basin G. robusta (excluding G. robusta from Desolation Canyon and Yampa River); and (6) upper basin G. robusta from the Yampa River.

Within Marble and Grand canyons, the northern and southern extremities of the distribution of $G$. cypha represent populations with greatest admixture overall. All other Grand Canyon aggregates (from HLCR through HHAV) are linked via gene flow, and this has kept them relatively homogeneous amongst themselves. It has also contributed to the high scores they reflect in our admixture evaluations. Marble and Grand canyon aggregates of G. cypha are relatively homogeneous amongst themselves (save for the populations at the upper and lower end of the canyon), yet as a group they are differentiated from upper basin G. cypha. However, the two extrema populations (30- mile and Western Grand Canyon) reflect very small sample sizes (eleven and ten, respectively). Given this, there is little statistical basis for making any claims with regard to supposed uniqueness.

Conclusions 1: Our data support the recognition of six 'Management Units' (MUs). The Marble/ Grand Canyon aggregates of G. cypha would represent a distinct MU, as would Desolation Canyon G. cypha and G. robusta (as a group). Another MU would consist of 
G. robusta from the Yampa River. In addition, G. robusta from upper basin locations (save Desolation Canyon and Yampa River) could be recognized as an MU, as could G. cypha from upper basin locations (save Desolation Canyon). In addition, bonytail would represent the sixth MU.

Conclusions 2: Marble and Grand canyon 'aggregates' of G. cypha were not overly distinct at the msat level. Aggregates appeared to be connected by gene flow, suggesting downstream drift of larvae and juveniles as a likely scenario. The Little Colorado River population would be the primary source, but contribution from occasional local reproduction by mainstem aggregates cannot be excluded.

Conclusions 3: The G. cypha population at 30-mile in Marble Canyon was recorded as having two individuals with $G$. elegans haplotypes, and the msat profile for this population is intermediate between genotypes found in Desolation Canyon (a hypothesized hybrid population) and Grand Canyon. Although reproduction has been documented for the 30-mile population, it suffers from chronic low numbers (at least chronic low numbers of catchable fish). However, this is the only population in Grand Canyon that is upstream from the Little Colorado River and is least likely to receive migrants from downstream locations. Due to its potential distinctiveness it should be further studied.

Conclusions 4: Upper basin G. robusta are seemingly more distinct than are upper basin G. cypha, and G. robusta from the Yampa River fall out as distinct in the five- and six-cluster models. Only the four-cluster model groups upper basin G. robusta with upper basin G. cypha. While G. robusta in the Yampa River certainly appears distinct and potentially unique, our data are inconclusive about status of Yampa River G. cypha. Additional studies must be conducted on G. cypha from the Yampa River, in that only seven individuals were available to us. Such chronic low numbers preclude any statistically valid conclusions. Management decision should not be based on the assumption of Yampa River G. cypha being distinct, simply because this is neither supported nor rejected by our data.

Conclusions 5: Our last conclusion centers on G. elegans. The individuals we evaluated in this study were hatchery-derived, but in some analyses, they were grouped with the unique G. cypha/ G. robusta populations of Desolation Canyon. We identified a single individual from this population that retained both a mtDNA haplotpye and a msat DNA genotype of G. elegans. Given the propensity for Colorado River native fishes to hybridize throughout their long history, it is not surprising that alleles characteristic for G. elegans apparently persist in wild populations of G. cypha and G. robusta. Similarly, alleles considered characteristic for the latter two species were occasionally detected in G. elegans we examined. Albeit historic, admixture among the Colorado River Gila species should be taken into account when G. elegans are reintroduced into the wild, particularly in locations where the other two species still persist.

\section{Dowling, T.E. and B.D. DeMarais. 1993. Evolutionary significance of introgressive hybridization in cyprinid fishes. Nature 362:444-446.}

Botanists have long recognized introgressive hybridization as important in the evolution of plants1, 2. Hybridization among animals is also common3, yet few zoologists have considered it evolutionarily important4-6. We report here that in the genus Gila, a morphologically diverse 
group of minnows from western North America7, we have discovered a pervasive influence of hybridization throughout their evolutionary histories. Gene exchange among distinctive forms has contributed to existing diversity, supporting the hypothesis that introgressive hybridization can play a significant role in evolution of vertebrates.

\section{Garrigan, D., P.C. Marsh and T.E Dowling. 2002. Long-term effective population size of three endangered Colorado River fishes. Animal Conservation 5(2):95-102.}

The extant genetic variation of a population is the legacy of both long-term and recent population dynamics. Most practical methods for estimating effective population size are only able to detect recent effects on genetic variation and do not account for long-term fluctuations in species abundance. The utility of a maximum likelihood estimator of long-term effective population size based upon the coalescent theory of gene genealogies is examined for three endangered Colorado River fishes: humpback chub (Gila cypha), bonytail chub (Gila elegans) and razorback sucker (Xyrauchen texanus). Extant mtDNA variation in humpback chub suggests this species has retained its historical equilibrium genetic variation despite recent declines in abundance. The mtDNA variation in razorback suckers indicates the population was quite large and expanding prior to recent declines and that rare alleles still survive in the remnant populations. The remaining mtDNA variation in bonytail chub indicates that dramatic, recent declines may have already obliterated a substantial portion of any historical variation. The results from long-term effective population size analyses are consistent with known natural history and illustrate the utility of the analysis for endangered species management.

\section{Hamman, R.L. 1981. Hybridization of three species of chub in a hatchery. Progressive Fish Culturist 43(3):140-141.}

A study was undertaken to determine whether the bonytail chub (Gila elegans) could hybridize with the roundtail chub (G. robusta) and the humpback chub (G. cypha). Of 12,000 bonytail $\mathrm{x}$ roundtail hybrids and 8000 bonytail $\mathrm{x}$ humpback hybrids obtained, 7 months after hatching, some 500-1000 from each cross survived. Embryos in eggs of both crosses died after 110 hours in low temperatures, indicating a possible reason for the decline of this endangered species in the upper Colorado River Basin. Both hybrids failed to spawn naturally, but it is suggested that alterations in the upper basin of the river may increase the potential hybridization and the decline of genetically pure stock.

\section{Holden, P.B. and C.B. Stalnaker. 1970. Systematic studies of the cyprinid genus Gila in the Upper Colorado River Basin. Copeia 1970:409-420.}

Three hundred and nine specimens of Gila from the Colorado River basin were studied by taximetrics analysis. Results of the study indicate that the concept of ecosubspecies or ecological subspecies does not fit Colorado basin Gila. The roundtail and bonytail chubs, G. robusta and G. elegans respectively, currently treated as subspecies, are well separated morphologically, ecologically, and apparently reproductively, and therefore, are better considered two species. The relationship between G. cypha, the humpback chub, and G. elegans is clouded by the presence of intergrade forms. Future investigations are needed to resolve this problem. Insufficient material was available to make any conclusions on taxonomic status of the 
Virgin River population. However, the subspecies name seminude Cope and Yarrow should be restricted to Gila of Virgin River.

Hurt, C. and P. Hedrick. 2004. Conservation genetics in aquatic species: general approaches and case studies in fishes and springsnails of arid lands. Aquatic Sciences 66(4):402-413.

Many aquatic species have become endangered because of the elimination and fragmentation of their habitat, human alteration of the environment, and introduced species. New applications and insights from genetic studies of endangered species are being used to formulate management plans to prevent extinction of endangered taxa. Here we discuss three applications of genetic techniques to the conservation of endangered aquatic species in the desert Southwest, USA. First, we discuss estimation of long-term effective population size in three endangered big-river fishes, bonytail chub (Gila elegans), humpback chub (G. cypha) and razorback suckers (Xyrauchen texanus), of the lower Colorado River. For all three species, the current census number is much smaller than the estimated effective population size in which these species evolved. Second, we discuss the determination of species, ESUs, and MUs in the endangered Sonoran topminnow. Molecular genetic data show that the Gila and Yaqui topminnows are different species. Experimental examination of pre-mating and postmating reproductive isolation demonstrates that some reproductive isolation has already developed between these two species. Finally, springsnails (Pyrgulopsis) of the lower Colorado River basin exist only in remote and isolated springs. Examination of molecular variation generally supports the morphological designation of 16 different species, although a few species have several ESUs. There does not appear to be a correlation of genetic and geographic distance between species, suggesting that they are quite old. These genetic studies provide insight into the conservation of these rare aquatic species. Although mitigating ecological factors may be most significant in preventing extinction, genetic studies can provide the evolutionary context for endangered species and identify what units are most in need of conservation.

\section{Keeler-Foster, C.L., I.B. Spies, V. Bondu-Hawkins and P. Bentzen. 2004. Development of microsatellite markers in bonytail (Gila elegans) with cross-species amplification in humpback chub (Gila cypha). Molecular Notes 4(1):23-25.}

Bonytail, Gila elegans, is an endangered species of fish native to the Colorado River. Primers are presented for 17 microsatellites cloned from bonytail as well as the results of test amplifications in bonytail and humpback chub, G. cypha. Bonytail exhibited three to 18 alleles per locus across the 17 microsatellites and a mean expected heterozygosity of 0.58 among 10 loci used to screen 160 broodstock. Humpback chub exhibited one to six alleles and a mean expected heterozygosity of 0.69 among 10 loci that were successfully amplified in that species.

\section{Minckley, W.L. and B.D. DeMarais. 2000. Taxonomy of chubs (Teleostei, Cyprinidae, genus Gila) in the American Southwest with comments on conservation. Copeia (1):251- 256.}

Chubs of the Gila River basin have been variously classified as nominal species, subspecies of Gila robusta, or a "complex." Three full species, robusta, intermedia, and nigra 
are here recognized, the last possibly arising through more than one hybridization event between robusta and intermedia. Following resolution of a nomenclatural problem, G. nigra is characterized in a key for species identification. Listing under the Endangered Species Act is suggested for all species of Gila in the Colorado River basin.

\section{Rosenfeld, M.J. and J.A. Wilkinson. 1989. Biochemical genetics of the Colorado River Gila complex (Pisces: Cyprinidae). Southwestern Naturalist 34:232-244.}

Protein variation in members of the cyprinid genus Gila endemic to the Colorado River drainage (Gila cypha, Gila elegans, Gila robusta robusta, and G. r. seminuda) was examined through electrophoresis of 23 presumptive loci. Fixation of loci for different alleles between morphologically recognized taxa was not found. Allelic differentiation was incomplete, with some variation distributed in a specific or subspecific fashion. Although now extremely reduced in numbers, G. elegans may have retained a significant fraction of its original variability. In contrast, G. cypha in the Upper Colorado River Basin may have experienced substantial allelic loss in recent years. Considerable hybridization may have occurred between G. cypha and G. r. robusta in the Upper Basin. The origin of G. r. seminuda may have included hybridization between G. elegans and G. r. robusta or their progenitors. Sample sizes were sometimes small, and tissues were obtained over a 4-year period from localities often hundreds of kilometers apart; consequently, sampling error, temporal shifts in allele frequencies, and isolation by distance as well as local differentiation remain unresolved factors.

\subsection{SUPPORTING ARTICLES}

\section{Berry, C.R. 1988. Effects of cold shock on Colorado River squawfish larvae. Southwestern Naturalist 33(2):193-197.}

Larvae of Colorado squawfish (Ptychocheilus lucius) acclimated to $22^{\circ} \mathrm{C}$ were subjected to water temperature decreases of 5,10 , or $15^{\circ} \mathrm{C}$ within 5 min or within 240 to $300 \mathrm{~min}$. Most mortality due to shock occurred in the first $48 \mathrm{~h}$. The $15^{\circ} \mathrm{C}$ shock in 5 min caused significant mortality of 14-day old larvae but did not affect 40-day olds. In addition to causing this direct mortality, shocks of 10 or $15^{\circ} \mathrm{C}$ min caused behavioral changes in 14-day olds that could result in indirect mortality of wild fish.

\section{Bozek, M.A., L.J. Paulson and G.R. Wilde. 1990. Effects of ambient Lake Mohave temperatures on development, oxygen consumption and hatching success of the razorback sucker. Environmental Biology of Fishes 27:255-263.}

Spawning of razorback suckers, Xyrauchen texanus, in Lake Mohave occurred from 10$22^{\circ} \mathrm{C}$ and larvae were collected at water temperatures from $10-15^{\circ} \mathrm{C}$ in 1982 and 1983 . In the laboratory, hatching success was similar from $12-20^{\circ} \mathrm{C}$, but reduced hatching success was found at $10^{\circ} \mathrm{C}$ while none hatched a $8^{\circ} \mathrm{C}$. Development rate and oxygen consumption were positively related to incubation temperature. Direct effects of ambient Lake Mohave water temperatures on hatching success of razorback sucker embryos are considered minimal. Historical spawning temperatures for the species are hypothesized based upon successful incubation temperatures and comparison to the white sucker, Catostomus commersoni. 
Chart, T. E., D. P. Svendson and L. D. Lentsch. 1999. Investigation of potential razorback sucker (Xyrauchen texanus) and Colorado pikeminnow (Ptychocheilus lucius) spawning in the lower Green River, 1994 and 1995. Final report of Utah Division of Wildlife Resources to Upper Colorado River Endangered Fish Recovery Program, Lakewood, Colorado.

Colorado pikeminnow spawn in the lower $210 \mathrm{~km}$ of the Green River. Based on the infrequent collections of adults in the past ten years, sampling efforts for razorback sucker were focused around the mouth of the San Rafael River at Green River kilometer (RK) 156. Investigations of Colorado pikeminnow spawning were centered on a cobble bar at the mouth of Millard Canyon (RK 53.9). Electrofishing and trammel nets were used to sample adults; larval light traps and seines were used to sample the early life stages. One adult razorback sucker was collected while conducting Interagency Standardized Monitoring Program (ISMP) electrofishing in 1995 near Mineral Bottom RK 83.7). This fish $(\mathrm{TL}=559 \mathrm{~mm}, \mathrm{Wt}=2150 \mathrm{~g}$, PIT \# = 1F74374E68) was caught 69 km below the San Rafael River at RK 86; on 16 May, 1995. No adult razorback suckers were collected as result of specific project efforts near the mouth of the San Rafael River. A total of 48 larval razorback suckers were collected during this study, with the majority $(91.7 \% ; N=44)$ of those collected in 1994 near the mouth of the San Rafael River. Twenty-eight larvae were collected in the mouth of the San Rafael River and the remaining larvae were collected in habitats immediately downstream. No larvae were collected in habitats upstream of the San Rafael River/Green River confluence. Incorporating the results of this study with those of concurrent efforts in the middle Green River, Muth et al. (1998) determined that larval razorback suckers collected in the lower Green River were likely spawned there. Water temperatures warm earlier each spring in the lower Green River than the middle Green River. The thermal regimes of the Green River at Jensen, Utah, and at Green River, Utah, are discussed in light of razorback sucker spawning time. Further investigation into the timing, magnitude, and specific location of razorback sucker spawning in the lower Green River is recommended. No evidence was found of Colorado pikeminnow spawning in the lower $60 \mathrm{~km}$ of the Green River. Based on the results of other project efforts it was determined that the timing of sampling for adults at the Millard Canyon bar was likely better in June, 1994, than in June, 1995.

Pikeminnow spawning was delayed throughout the upper Colorado River basin until the latter part of July in 1995. Further investigations into pikeminnow spawning in the lower Green should be more intensive than this effort and should occur within the next five years.

\section{Converse, Y.K., L.D. Lentsch and R.A. Valdez. 1999. Evaluation of size-dependent overwinter growth and mortality of age-0 Colorado squawfish. Final report of Utah Division of Wildlife Resources to Upper Colorado River Endangered Fish Recovery Program, Lakewood, Colorado.}

This report encompasses two important aspects of age-0 Colorado pikeminnow life history. First, we investigated usefulness of scale analysis and length-frequency distributions for evaluating overwinter mortality and growth of age-0 Colorado pikeminnow. Second, we examined associations of age- 0 fish length and relative abundance in fall and spring with spatial and temporal degree-day accumulation and flow regimes in the Green River system. 
Using the relationship between total number of circuli and total length of young Colorado pikeminnow, we estimated maximum number of circuli formed in the first year for 1) fish that formed a first year growth check and 2) for those that did not. We found that most age-0 Colorado pikeminnow (49\%) collected in fall of 1991 (only year scales were collected from age0 fish) were too small ( $<40 \mathrm{~mm}$ TL) to form a first year growth check but that a first year growth check was present on scales of most adults (75\%) collected between 1978-1989.

We then examined length frequency information collected over eight winter seasons (1987 to 1994). In the middle Green River, 45 to $75 \%$ of age- 0 fish were less than 40 min in fall for years examined (1989 to 1993); in the lower Green River, 50 to $90 \%$ of fish were less than 40 min TL in fall for years examined (1987 to 1993). This information suggests that some size dependent mechanism, such as mortality or growth, favored larger Colorado pikeminnow.

To assess size-selective mechanisms (growth or mortality) affecting survival of age-0 Colorado pikeminnow, we examined shifts in length-frequency data, plotted as quantiles, from fall to spring over the 8 year period. In the middle Green River, all years showing a significant effect of a size-selective overwinter mechanism indicated mortality was dominant. In the lower Green River, mortality was dominant in five years, but two years showed dominant size-selective growth. We were not able to discern the interaction between growth and mortality. The relative importance of these size-dependent mechanisms most likely varies from year to year depending on biological and environmental factors like nonnative predation, competition, and degree day accumulation in the first growing season.

These results lead us to explore relationships between physical variables of temperature and flow with size of age-0 Colorado pikeminnow in fall. If degree-day accumulation influenced size of fish in fall, we would have expected to see differences among middle and lower river reaches for both size of age-0 fish entering winter and consequently, their overwinter survival assuming they were hatched during the same period. We calculated degree-day accumulation for pre- and post-dam periods to determine large-scale changes due to Flaming Gorge Dam and then for individual winter and summer seasons that corresponded with fall and spring age-0 fish sampling (1987 to 1994). We found that mean daily water temperatures of the Green River near Jensen, Utah, and near Green River, Utah, were higher on average at the downstream Green River station than the upstream Jensen station, and total degree day accumulation was $37 \%$ greater at the downstream station during the period of record. However, no change was found to be associated with dam operations. We also found that degree day accumulation for summer and winter periods was consistently and substantially greater in the lower Green River during the study period. Despite the differences in degree-day accumulation between sites, age-0 Colorado pikeminnow were not larger in the lower Green River in fall.

Furthermore, analysis showed that overwinter degree-day accumulation did not appear to be associated with different size-selective overwinter mechanisms between the middle and lower reaches or among years. One exception to this was a dominant mechanism of size-selective growth occurring only in the lower Green River where temperatures were warmer (1987-88 and 1990-91). Fish growth did not appear to be related to mainstem degree-day accumulation which suggests limitations of age-0 Colorado pikeminnow growth may have been due to differences in specific habitat type quantity or quality between the two areas or possibly differential food, 
predation or competition pressure. This contention is further supported by a lack of a detectable association between age-0 year class size and length in fall and physical flow attributes, such as timing and magnitude of peak flows, average summer flows, and summer degree-day accumulation. A notable but insignificant association between degree-day accumulation and size of age-0 fish in fall in the lower Green river (which did not show up in the middle Green River) suggests limiting factors of early life-stage survival may be different at different sites. In fact, age- 1 year class size and length in spring was best predicted by age- 0 year class size and length in the fall and was not related to average winter flows or winter degree-day accumulation. The largest and most abundant fall year classes were also the largest and most abundant spring year classes. Such a finding lead us to the conclusion that limiting factors on age- 0 Colorado pikeminnow recruitment to age-1 generally occurs before fall of their first year, not overwinter as has been previously hypothesized.

We recommend further investigations between size-dependent overwinter growth and mortality to quantify limitations on age- 0 Colorado pikeminnow survival and more information on factors limiting pre-winter recruitment of age- 0 Colorado pikeminnow.

\section{Haines, G.B. 1995. Effects of temperature on hatching success and growth of razorback sucker and flannelmouth sucker. Final report of U.S. Fish and Wildlife, Vernal, Utah, to Upper Colorado River Endangered Fish Recovery Program, Lakewood, Colorado.}

Laboratory experiments were conducted to assess the effects of water temperature on the developmental rate and hatching success of embryos and growth of larvae of the endangered razorback sucker (Xyrauchen texanus) and the sympatric and common flannelmouth sucker (Catostomus latipinnis). Embryos and larvae were reared at 12,16 , or $20^{\circ} \mathrm{C}$ for $45 \mathrm{~d}$ postfertilization. Mean number of days between fertilization and peak hatching of embryos decreased as water temperature increased for both species; $6.5 \mathrm{~d}\left(20^{\circ} \mathrm{C}\right)$ to $12.5 \mathrm{~d}\left(12^{\circ} \mathrm{C}\right)$ for razorback sucker and $6.0 \mathrm{~d}\left(20^{\circ} \mathrm{C}\right)$ to $16.5 \mathrm{~d}\left(12^{\circ} \mathrm{C}\right)$ for flannelmouth sucker. The period from first to last hatch averaged $2.0 \mathrm{~d}$ longer for razorback sucker than flannelmouth sucker over all temperatures. Percent hatch of flannelmouth sucker embryos was independent of water temperature and, at each water temperature, was higher for flannelmouth sucker (83-91\%) than for razorback sucker (48-67\%); hatching success of razorback sucker embryos increased as water temperature increased. At $20^{\circ} \mathrm{C}$ on each sampling day, embryos and larvae of flannelmouth sucker were substantially larger than those of razorback sucker.

\section{Waples, R.S. 1990. Conservation genetics of Pacific salmon. II. Effective population size and the rate of loss of genetic variability. Journal of Heredity 81:267-276.}

A simulation model for genetic change in Pacific salmon (Oncorhynchus spp.) populations is extended to examine the loss of genetic variability. The study was designed to address three major questions: 1) What is the rate of loss of genetic variability from Pacific salmon populations as a consequence of finite population size? 2) How can existing population genetics theory be used to predict patterns of genetic change in Pacific salmon? and 3) What do the concepts "effective population size" and "generation length" mean with respect to Pacific salmon? Results indicate that effective population size per generation $\left(\mathrm{N}_{\mathrm{e}}\right)$ is equivalent to the effective number of breeders per year $\left(\mathrm{N}_{\mathrm{b}}\right)$ times the average age at spawning, or generation 
length (g), and that the use of $\mathrm{N}_{\mathrm{e}}=\mathrm{g} \mathrm{N}$ in standard equations for the variance of allele frequencies, loss of heterozygosity, and loss of alleles over time accurately predicts the rate of genetic change in the population as a whole. With Pacific salmon, however, genetic data are seldom gathered for a population as a whole; instead, data are typically taken from individual brood years, which represent only a portion of the individuals comprising a generation. The magnitude of genetic change among brood years is larger than predicted using standard equations. In addition, uniting of progeny from different brood years in each year's spawning population creates a Wahlund effect that slightly reduces the observed proportion of heterozygotes. Formulas are provided to adjust standard population genetics equations for the effects of measuring change among subsets of the population. It is shown that low frequency alleles are subject to rapid extinction in Pacific salmon populations with $\mathrm{N}_{\mathrm{b}}$ less than about 100 per year, and the implications of this result for the conservation genetics of wild and cultured populations is discussed.

\section{Waples, R.S., G.A. Winans, F.M. Utter and C. Mahnken. 1990. Genetic approaches to the management of Pacific salmon. Fisheries 15(5):19-25.}

The complex problems involved in managing Pacific salmon (Oncorhynchus spp.) are largely a consequence of the unusual life history features of these species. The strong homing instinct leads to the formation of discrete, locally-adapted spawning populations, each of which has the potential to evolve as an independent evolutionary unit. It is important, therefore, that the genetic consequences of different management policies be carefully evaluated. If current management goals (e.g., doubling the abundance of anadromous salmonids in the Columbia River basin through increased hatchery production and supplementation of natural populations) are realized, genetic issues will assume even greater importance in the future. To date, however, genetic concerns have not been adequately incorporated into the management process. We identify three genetic approaches, primarily based on easily obtained electrophoretic data, that can provide valuable information on which to base management decisions: (1) Using the Genetic Stock Identification method for identifying stocks contributing to oceanic, mixed-stock fisheries. Genetic Stock Identification has several advantages over traditional tagging methods, including cost-effectiveness and easy access to wild as well as hatchery stocks. (2) Monitoring genetic changes in hatchery stocks. Analysis of the nature and magnitude of such changes is the best means of identifying stocks in which potentially dangerous levels of inbreeding may be occurring. (3) Detecting mixtures of gene pools. The ability to detect hybridization and introgression is necessary for an evaluation of the genetic consequences of releasing artificially propagated fish into the wild. 


\section{ECOLOGY}

\subsection{GENERAL ECOLOGY}

Kaeding, L.R. and M.A. Zimmerman. 1983. Life history and ecology of the humpback chub in the Little Colorado and Colorado Rivers of the Grand Canyon. Transactions of the American Fisheries Society 112:577-594.

The loss of habitat for some native fishes of the Colorado River drainage coincided with the closure of Flaming Gorge Dam on the Green River. Humpback chubs in the Little Colorado River grew rapidly to about $250-300 \mathrm{~mm}$ in length at $3 \mathrm{yr}$ of age, the onset of reproductive maturity for the female. Annual reproductive success was greatest when spawning coincided with seasonal river runoff. Use of the physical habitat by age- 0 and juvenile humpback chubs was affected by light intensity. Shallow littoral areas were used during darkness, but during daylight only when the water was turbid. Year-round low temperatures in the Colorado River did not inhibit seasonal gonadal maturation of humpback chubs. However, lab studies indicate that such low temperatures result in nearly complete mortality of embryonic and larval humpback chubs. Persistence of the fish in the Little Colorado River could be attributable, in part, to the unsuitability of that environment, and that of the Colorado River, for potential competitor or predator species in the drainage.

Karp, C.A. and H.M. Tyus. 1990. Humpback chub (Gila cypha) in the Yampa and Green Rivers, Dinosaur National Monument, with observations on roundtail chub (G. robusta) and other sympatric fishes. Great Basin Naturalist 50:257-264.

We evaluated distribution, habitat use, spawning, and species associations of the endangered humpback chub (Gila cypha) in the Yampa and Green rivers, Dinosaur National Monument, from 1986 to 1989. Adult and juvenile humpback chub were captured in highgradient reaches of Yampa and Whirlpool canyons where they were rare $(N=133,<1 \%$ of all fish captured). The fish was primarily captured in eddy habitats in association with 7 native and 12 nonnative fish species. Roundtail chub (G. robusta) were widely distributed in eddies, pools, runs, and riffles. Humpback chub $(N=39)$ and roundtail chub $(N=242)$ in reproductive condition were sympatric in eddy habitats during the 5-6-week period following highest spring runoff. River temperatures at this time averaged about 20 degree C. Nonnative channel catfish (Ictalurus punctatus) were abundant in eddies yielding humpback and roundtail chubs, suggesting a potential for negative interactions between the native and introduced fishes.

Kubly, D.M. 1990. The endangered humpback chub (Gila cypha) in Arizona: a review of past studies and suggestions for future research. Arizona Game and Fish Department, Phoenix, Arizona. Abstract excerpted from report objectives.

Much of the available information on the endangered humpback chub (Gila cypha) population in the Grand Canyon region of Arizona lies in the confines of fisheries biologists' field notes or government agency and contract reports. This body of "grey literature" is difficult to access for even the most persistent investigator, and it has seldom been subjected to critical 
evaluation as part of the peer review process involved in publishing in scientific journals. During the course of the ongoing Section 7 Consultation on the Operation of Glen Canyon Dam (2-ZL57-F-23), a decision was made to gather together the available data and literature on humpback chub in the Grand Canyon, including data gathered by the Arizona Game and Fish Department (Department) during 1987-1989. The objectives of this effort were threefold:

(1) Review the literature, both published and unpublished on the ecology of the species in the study area;

(2) Compile in a computerized relational database the existing data and, where necessary, sample (or resample) and interpret these data; and

(3) Determine what areas of our knowledge are lacking and needful of further research to help ensure the sustained presence of Gila cypha in the Colorado River and its tributaries below Glen Canyon Dam.

Although this report is limited in scope to consideration of the endangered humpback chub, this limitation does not indicate a lack of concern by the Department for other threatened and endangered species of wildlife in the Colorado River and its tributaries below Glen Canyon Dam. Department concerns for these species in Grand Canyon are being addressed through provisions of the Fish and Wildlife Coordination Act and the National Environmental Policy Act as they pertain to compliance with the October 27, 1989, directive by the Secretary of the Interior to evaluate the effects of the operation of Glen Canyon Dam.

Minckley, C.O. 1996. Observations on the biology of the humpback chub in the Colorado River Basin, 1908-1990. Doctoral Dissertation. Northern Arizona University, Flagstaff, Arizona.

The humpback chub is listed as a federally endangered species primarily as the result of the impacts of hydroelectric dam operations and the introduction of nonnative fishes.

Geographic distribution of the humpback chub in the Colorado River basin is well documented, occurring in the major tributaries of the upper basin including the Green, White, Yampa, and Little Snake Rivers. Currently there are five upper basin populations to include: the Green, Yampa, and Colorado River (at Black Rocks, Westwater Canyon and Cataract Canyon). In the lower basin distribution is from Glen Canyon Dam into Lake Mead. In Grand Canyon, the largest population occurs in the Little Colorado River although fish occur consistently at five other areas along the river.

The habitats used by the humpback chubs are similar throughout the basin, varying with the life stage. Generally, larvae and fry occupy shoreline backwater habitats in slowly moving eddies and adjacent backwaters. Juveniles live in deeper water such as low-velocity eddies and backwaters $<10 \mathrm{~m}$ deep. Adults are in deep eddies and backwaters, presumably including depths $>10 \mathrm{~m}$.

Adult humpback chubs are considered sedentary, occurring in canyon-bound reaches of the Colorado River Basin. However, there are exceptions when some individuals move further. 
The diet of this species consists of a variety of aquatic and terrestrial invertebrates, and occasionally fish. Reproduction has been confirmed throughout the basin but spawning has not been observed. Humpback chub host several parasites but only two present potential threats, the anchorworm and Asian tapeworm. These parasites have been found in the lower basin and may have negative impacts $n$ the future.

A recovery plan is in place for this species addressing the upper basin population. No specific plan is extant for the lower basin.

\section{Stone, D.M. 1999. Ecology of humpback chub (Gila cypha) in the Little Colorado River, near Grand Canyon, Arizona. Master's thesis, Northern Arizona University, Flagstaff.}

Within the Colorado River and its major tributaries, a unique assemblage of fish species began to evolve during the Miocene that were morphologically and physiologically capable of surviving periods of drought intermingled with stochastic flood events, high sediment loads, and fluctuations in the types and quantity of food resources. Within the last century, anthropogenic disturbances have decimated much of this original ichthyofauna. The lower $141 \mathrm{~km}$ of the LCR is the last holdout where humpback chub (Gila cypha) numerically dominate over other piscine species. Moreover, the other most common fishes are native species and include speckled dace (Rhinichthys osculus), bluehead sucker (Catostomus discobolus), and flannelmouth sucker (C. latipinnis). We found evidence that adult humpback chub, which are considered opportunistic feeders, can be highly piscivorous and may structure the life history of smaller fish in the LCR. Regardless of water clarity, all small native fish in this system were diurnally active including dace and all YOY fish; whether this was a result of undeveloped sensory abilities or a behavioral response is unknown. In contrast, adult humpback chubs (>180 $\mathrm{mm}$ TL) were predominately nocturnally active. During nighttime, adult chubs shifted habitat use to nearshore areas where they could forage on small fish. Piscivory by adult chubs is supported by observations of dead small fish being found in miniature hoopnets during the nighttime and cases where adults regurgitated or defecated undigested fish while being handled. Also, in clear water conditions ( $<30$ NTUs), when adults moved inshore at night, YOY chubs ( $<90 \mathrm{~mm}$ TL) shifted to areas of greater cover, while juvenile chubs (110-160 mm TL) and dace shifted to midchannel habitats. At night in turbid water conditions ( $>30$ NTUs), the two smaller size classes of chubs and dace appeared to avoid habitats occupied by adult chub spawning aggregations. During daytime irrespective of water clarity, habitats used by chubs were delineated by fish size, such that increasingly larger chubs were captured progressively further midchannel, at greater depths, and in faster currents. Patterns of diel activity and habitat use documented in this study are consistent with predator-prey interactions found in other freshwater fish assemblages.

\section{Suttkus, R.D. and G.H. Clemmer. 1977. The humpback chub, Gila cypha, in the Grand Canyon area of the Colorado River. Occasional Papers of the Tulane University Museum of Natural History, New Orleans, Louisiana 1:1-30.}

The humpback chub, Gila cypha, is redefined from specimens taken in the Colorado River in the Grand Canyon. Specimens from 24'6 ' 320 mm are depicted, and notes on growth 
and development, sexual dimorphism, breeding tubercles and coloration, and reproduction are presented with standard meristic and morphometric data.

Valdez, R.A. and R.J. Ryel. 1995. Life history and ecology of the humpback chub (Gila cypha) in the Colorado River, Grand Canyon, Arizona. Final report of Bio/West, Inc., Logan, Utah, to U.S. Bureau of Reclamation, Salt Lake City, Utah. Abstract was excerpted from report.

The life history and ecology of the humpback chub (Gila cypha) in the Colorado River in the Grand Canyon was studied from October 1990 through November 1993, as part of the Glen Canyon Environmental Studies (GCES). The purpose of the investigation was to describe the ecological requirements of the species and evaluate the effects of Glen Canyon Dam operations on the various life stages. The objectives of the study were to describe and identify limiting factors to distribution, abundance, survivorship, movement, habitats, food habits, and reproductive capacity. Important biotic interactions and the life history schedule for the species were also described. This life history information was used to identify management options and recommendations for core research and monitoring with respect to dam operations. The investigation was designed to integrate with other companion studies and provide the framework for an integrated scientific report by GCES.

The physical, chemical, and biological nature of the Colorado River in the Grand Canyon was changed dramatically after it was impounded by Glen Canyon Dam in March 1963. Since impoundment, water has been released through the dam under six operational scenarios, each with unique characteristics, but all with common features. The dam eliminated spring floods and increased low base flows in later summer, fall, and winter. Daily fluctuations for hydropower generation became a normal feature of the hydrograph, and flows of over 31,500 cfs and below 1,000 cfs were eliminated.

Key findings of each objective were as follows:

- The present distribution of humpback chub in the Grand Canyon is related to mainstem temperature, locations of warm tributaries and springs, occurrence of suitable adult habitat, and food availability;

- The largest and only self-sustaining population of humpback chub in the canyon was located in the lower reaches of the LCR and adjacent mainstem Colorado River;

- The present distribution of the humpback chub in the Grand Canyon is believed to be the remnant of a more dispersed historic distribution. Pre-dam humpback chub in the Grand Canyon probably spawned in the mainstem, and likely occurred in higher concentrations in areas of more suitable habitat or greater food supplies;

- Fish populations of the Colorado River have been affected in numerous ways by land use practices, water diversions, and non-native fishes starting in the late $1800 \mathrm{~s}$. 
- The combined estimates for the nine mainstem aggregations were about 3,300 to 3,800 adults;

- Survival of humpback chub in the mainstem is probably limited by cold temperatures, suitable habitat, food availability, and predation. Parasites are not believed to be a significant factor to survival in the mainstem, although an increased incidence of Asian tapeworms could affect the health of individual fish under stress;

- Adult humpback chub in Grand Canyon exhibited strong spatial fidelity for specific river sites, which was similar to the behavior observed in other populations;

- Adults in the mainstem moved very little during non-spawning periods, in summer, fall, and winter, when local movement was primarily influenced by time of day, turbidity, flow magnitude, and ramping rate;

- Sub-adult humpback chub used primarily shallow sheltered shorelines, while adults used primarily large recirculating eddies;

- Adult humpback chub in the Colorado River in the Grand Canyon ate primarily simuliids, introduced freshwater amphipods, chironomids, other aquatic invertebrates, and terrestrial insects. The algae, Cladophora glomerata, also made up a significant portion of the gut volume, but it was not determined if this was consumed incidentally or selected by the fish;

- Cold releases from the Glen Canyon Dam have disrupted life cycles of aquatic invertebrates and greatly affected fish food diversity and availability;

- Average lengths of sub-adult humpback chub at the first three scale annuli formations were 96,144 , and $186 \mathrm{~mm}$ TL;

- The only self-sustaining population of humpback chub in the Grand Canyon was found in the lower $14.9 \mathrm{~km}$ of the LCR and the adjacent $13.5 \mathrm{~km}$ of the mainstem Colorado River; and

- Fourteen species of fish were sympatric with humpback chub, including 3 native species and 11 non-natives. These interacted with humpback chub as known or potential predators, competitors, and vectors for parasites and diseases.

\section{Valdez, R.A. and R.J. Ryel. 1997. Life history and ecology of the humpback chub in the Colorado River in Grand Canyon, Arizona. Final report TR-250-08. BIO/WEST, Inc., Logan, Utah.}

The endangered humpback chub (Gila cypha) is found as six populations in the Colorado River Basin. The largest is in Grand Canyon, Arizona, where in 1990-1993, fish were distributed as nine aggregations in $307 \mathrm{~km}$ of the Colorado River, as well as in the lower $14.9 \mathrm{~km}$ of the LCR, a seasonally warmed tributary. An estimated 3,700 adults inhabited the mainstem in 
1993, with 3,480 adults in the largest aggregation near the LCR. The LCR was the only area with significant spawning and recruitment of fish to the mainstem, but it was used only by the mainstem aggregation and a resident LCR population. Year-round release of $8-10^{\circ} \mathrm{C}$ water from Glen Canyon Dam precluded successful mainstem reproduction and limited growth of young chubs. Adults exhibited a high degree of spatial fidelity for specific river locales, mean net movement was $1.49 \mathrm{~km}$ (range $=0-6.11 ; \mathrm{SD}=1.50$ ) for 69 radiotagged fish and $1.64 \mathrm{~km}$ (range $=0-9.8 ; \mathrm{SD}=1.72$ ) for 238 passive integrated transponders (PIT)-tagged fish. Annual survival of chubs during the first 3 years of life was estimated at 0.10 , while estimated annual survival of adults (age3+) was 0.93 . A major source of subadult mortality was predation by brown trout (Salmo trutta) and channel catfish (Ictalurus punctatus), which together potentially consumed about 228,850 chubs annually. Adult chubs inhabited primarily large recirculating eddies ( $88 \%$ captures, $74 \%$ radio contacts), whereas subadults used shorelines with vegetation, talus, and debris fans as well as eddy return channels (i.e., backwaters). Diet by volume of mainstem adults neat the LCR consisted of Gammarus lacustris (freshwater amphipods, 45\%). Simuliidae (blackflies, 40\%) terrestrial invertebrates (9\%), Chironomidae (midges, 5\%), and other aquatic invertebrates(1\%). Adults from more downstream aggregations consumed a lower proportion of $G$. lacustris and a higher proportion of terrestrial invertebrates. External parasitic copepods (Lernaea cyprinacea) were on 8 of $6,294(<1 \%)$ chubs examined and Asian tapeworms (Bothriocephalus acheilognathi) were in guts of 6 of $168(4 \%)$ adults flushed with a stomach pump.

\section{Valdez, R.A. and T.L. Hoffnagle. 1999. Movement, habitat use and diet of adult humpback chub. Pages 297-307 in R.H. Webb, J.C. Schmidt, G.R. Marzolf and R.A. Valdez (eds.). The controlled flood in Grand Canyon. Geophysical Monograph 110. American Geophysical Union, San Francisco, California.}

The humpback chub (Gila cypha) is a big-river cyprinid fish endemic to the Colorado River, where river regulation has contributed to its endangerment. Flooding is essential to reshaping its habitat, redistributing nutrients, flushing terrestrial insects for food, and, in the postdam river, controlling non-native competitors and predators. Effects of the 1996 controlled flood on movement and habitat use of adults were monitored with radiotelemetry, and diet was evaluated with a non-lethal stomach pump. Movement of 9 radio-tagged adults during the flood (mean, $0.40 \mathrm{~km}$; range, $0-1.24 \mathrm{~km})$ was not significantly different $(\mathrm{P} \leq 0.05)$ from movement in the month preceding the flood (mean, $1.26 \mathrm{~km}$; range, $0.1-2.95 \mathrm{~km}$ ), indicating no unusual movement or displacement of fish by the flood. Habitat used during the flood, as a percentage of radio-contacts (i.e., 73\% eddies, 19\% runs, $8 \%$ tributary inflows), was similar to that used under normal operations by 69 fish tracked during 1990-1992 (i.e., 74\% eddies, $12 \%$ runs, 7\% backwaters, $6 \%$ tributary inflows, $1 \%$ pools, $<1 \%$ riffles). Diet of 43 adults showed dramatic shifts to items scoured by the flood. Simuliidae ( $68 \%$ ash-free dry weight) and Chironomidae (15\%) dominated pre-flood diets; Amphipoda (31\%), Simuliidae (25\%), and terrestrial insects (i.e., beetles, ants, grasshoppers, $20 \%$ ) were ingested during the flood; and Simuliidae (62\%) and Amphipoda (18\%) were eaten post-flood. While composition of the diet changed, biomass consumed was not significantly affected by the flood $(\mathrm{P}=0.9157)$. The controlled flood had no detrimental effects on movement, habitat use, or diet of adult humpback chub. Effects of habitat reshaping and nutrient redistribution can only be evaluated through long-term monitoring. Floods of higher magnitude or at a different time of year may have different effects on this endangered 
species and should be investigated before implementing controlled floods as an element of dam operations.

Valdez, R.A., W.J. Masslich, W. Leibfried, A. Wasowicz, B. Cowdell, R. VanHaverbeke, M. Yard, T.M. Trinca and L.I. Brown. 1992. Characterization of the life history and ecology of the humpback chub in the Grand Canyon. Annual report TR 250-05 of BIO/WEST, Inc. to U.S. Bureau of Reclamation, Salt Lake City, Utah.

Investigations of the endangered humpback chub were initiated in the mainstem Colorado River of the Grand Canyon on September 1. 1990 by BIO/WEST, Inc, of Logan, Utah. The first month of the project was dedicated to training personnel, assimilating field equipment, defining standard sampling methods, and developing standardized data collection procedures and forms. Five Achilles sport boats were outfitted as research boats including two for electrofishing and three for netting and radiotracking. Equipment for fish sampling radiotelemetry, water quality, and habitat mapping was also assembled. A Data Collection Plan was developed together with a Fish Sampling Protocol, Fish Handling Protocol, and Database Management Protocol. These documents detail the methodologies to be employed by BIO/WEST in this investigation and were made available to agencies and individuals involved in the Glen Canyon Environmental Studies (GCES).

The study area was defined as 170 miles of river from Kwagunt rapid (river mile [RM] 56) to Diamond Creek (RM 226). The region was divided into three sample reaches designated as the Little Colorado (LCR) Reach, Granite Gorge Reach, and Havasu Creek Reach. Sampling was conducted monthly in October, November, and December with field trips of 10, 20, and 10days durations, respectively. The 10-day field trips were designed for one team of 6 people to sample the LCR Reach only, while the 20-day trips were designed for two similar teams to sample with approximately equal effort in all three sample reaches.

Six gear types were used to sample humpback chub in 1990, including 1 and $1.5 \mathrm{in.} \mathrm{mesh}$ trammel nets, $1.5 \mathrm{in}$. and 2 in. gill nets, experimental gill nets, and electrofishing. The 1 in. and 1.5 in. mesh trammel nets and the 1.5 in. gill nets produced the greatest numbers of chubs (26, 30 , and 28 , respectively) with approximately equal catch rates of $1.49,1.57$, and 1.45 fish/100 feet/10 hours respectively. Electrofishing yielded 6 fish with a catch rate of 4.03 fish/10 hours. Gear efficiency will continue to be evaluated in 1991.

Ten species of fish representing five families were captured during the three field trips in 1990. The most abundant species were rainbow trout and carp. A total of 94 humpback chub were captured and released alive; 83 were PIT tagged and 17 were radiotagged (16 with PIT tags). Of the 94 fish captured, 10 had been previously tagged with Floy or Carlin tags by other investigators, 2 were previously PIT tagged by other investigators, and 3 were fish previously PIT tagged during the investigation. Morphometric measurements and meristics were recorded on 46 humpback chub.

$\mathrm{BIO} / \mathrm{WEST}$ initiated a radiotelemetry study to evaluate its use in the Grand Canyon for assessing habitat use and movement of humpback chub. Preliminary results show that radiotelemetry will be a useful tool in monitoring movement and habitat use of fish in the Grand 
Canyon and for evaluating the impacts of Glen Canyon Dam operations. Use of radiotelemetry will be further evaluated in a 5-mile section of the LCR Reach; 10 fish were Radiotagged in October and 7 I November. In November, 8 of the 10 October fish were recontacted, and in December 11 of the 17 fish were recontacted for a recontact rate of $80 \%$ and $65 \%$, respectively. The position of each fish was determined several times daily to monitor both horizontal and vertical movement (radiosignals are extinguished at about $4 \mathrm{~m} \mathrm{depth}$ ). Radiotagged fish were monitored for 24-hour periods and for 2-hour periods. Movement and habitat was recorded on standard data sheets and maps, and relative changes in river stage were recorded during these monitoring modes. Eight temporary bench marks established in the LCR Reach that will eventually be surveyed to permanent U.S. Geological Survey (USGS) bench marks so that all relative stage readings can be tied to absolute stage changes and to the operation of Glen Canyon Dam.

Movement and change in macrohabitat use were noted for Radiotagged fish relative to changes in flow, turbidity, and time of day. These variables will continue to be measured and closely monitored during this investigation in order to describe their relationships to fish movement and habitat use. Macrohabitat mapping of area occupied by humpback chub as well as areas not used by the fish will also continue in order to evaluate the availability of habitat and changes in flow.

A food habits pilot study using non-lethal stomach pumping will be initiated in January 1991 to evaluate the diet of the humpback chub in the mainstem Colorado River. Drift samples will be collected and data gathered from other investigators on benthic invertebrate communities in order to assess the availability of food resources.

Plans were developed for the 1991 investigation including establishing remote radiotelemetry stations to monitor fish movement into the LCR, establishing temporary bench marks to monitor river stage change during radiotelemetry observations, identifying relationships for measuring river turbidity, procuring appropriate maps for macrohabitat mapping, interfacing macrohabitat mapping with development of depth and velocity isopleths to stage relationships being developed by other investigators, and coordinating efforts near tributary inflows and in backwaters with other investigators.

\subsection{DISTRIBUTION AND ABUNDANCE}

Ackerman, M.W., D. Ward, T. Hunt, R.S. Rogers, D.R. Van Haverbeke, A. Morgan and C. Cannon. 2006. 2006 Grand Canyon long-term fish monitoring in the Colorado River, Diamond Creek to Lake Mead. Annual report to the U.S. Geological Survey, Grand Canyon Monitoring and Research Center, Flagstaff, Arizona. Abstract excerpted from report.

The 2006 Trip Report for Trip ID:GC20060523 provides a summary of methods and preliminary observations from the 2006 Diamond Creek to Lake Mead monitoring. May 2006 was the third long-term monitoring trip for fish downriver of Diamond Creek since 1996. These trips are part of an ongoing, long-term monitoring program designed to determine trends in 
relative density and distribution of fish within the Colorado River between Lake Powell and Lake Mead. Monitoring below Diamond Creek was initiated in 2004 as an extension to the current monitoring program for Grand Canyon fishes. With recent higher river temperatures in the Colorado River, it has become increasingly important to understand the distribution and potential sources of warm-water non-native fish species within the Colorado River ecosystem including the area from Diamond Creek to Lake Mead. In 2006, catch by trammel netting and electrofishing saw an observed increase in comparison to 2005. It is important that flow and season remain similar among sampling periods as these factors are known to influence catch rates, and catchability can have significant effects on catch rates used for index monitoring. The ability to compare data between 2005 and 2006 due to similar sampling conditions seems to be an important tool that will be useful during long-term monitoring.

\section{Badame, P.V. 2008. Population estimates for humpback chub (Gila cypha) in Cataract Canyon, Colorado River, Utah, 2003-2005. Final report of Utah Division of Wildlife Resources to Upper Colorado River Endangered Fish Recovery Program, Lakewood, Colorado.}

Humpback chub (Gila cypha) are listed under the Endangered Species Act of 1973, as amended. In accordance with recovery goals finalized in 2002, population estimates were completed for adult humpback chub in Cataract Canyon on the Colorado River. The sampling was conducted from 2003 to 2005 with the objective of obtaining annual point estimates for humpback in the canyon. Sampling occurred between mid September and early November each of the three years of the study. Three sites were sampled for two nights on three occasions each year with approximately one week between sampling occasion. Approximately 28\% (1.9 river miles) of the available habitat in Cataract Canyon was sampled on each occasion. The primary method of capture was trammel netting with supplemental electrofishing on one pass per year.

Population estimates were generated from mark-recapture data using closed population models calculated with program CAPTURE. Separate estimates were generated for each year of the study. Results indicated a non-significant decline in the adult humpback chub population during the 2003 - 2005 sampling period. The adult point estimates were 126 (2003), 91 (2004), and 70 (2005). The interpretation of these estimates relative to the amount of available habitat in Cataract Canyon depends on how movement, or lack thereof, effects the assumptions of the estimator. Every annual and intra-annual recapture of a humpback occurred in the individuals original capture site. No movement implies that mixing between the sample areas does not occur and that fall point estimates would relate only to the area sampled ( 2 river miles); therefore, the density estimates for the sampling period would be 63-35 fish/mile (no mixing model). If the density estimates are applied to the total available habitat in the canyon (approximately 7 river miles) the total population size would have varied between 468-262 adult humpbacks during the

sampling period. Relative to other upper basin humpback chub populations; the density is similar to that of Desolation/Gray Canyons, and significantly less than found in Westwater Canyon.

Growth of humpback chub in Cataract Canyon was slow relative to other upper basin populations. In addition, the relative size structure of this population is small and is within a narrow range. In three years of sampling, the smallest humpback captured was $195 \mathrm{~mm}$. Results from Desolation and Westwater trammel netting suggest our inability to capture smaller 
juveniles in Cataract is likely a limitation of net size used. Electrofishing has been the preferred method for finding juvenile chubs in other canyons; however, none were captured using this technique in Cataract Canyon. It is unclear if they are not present or if they are utilizing habitats which are unreachable with electrofishing.

Analysis of catch per unit effort (CPUE) totals for the period of 2003 to 2005 has shown no statistically significant changes for humpback chub. The average trammel net CPUE for humpback chubs in Cataract Canyon was lower than both Desolation Canyon and Westwater Canyon. Mean CPUE for bonytail chub declined quickly from 2003 to 2004 and 2005.

The small size of this population suggests a need to reassess how it is monitored. Although there are not enough adult individuals to consider this a core population, it is still considered an integral part of the overall upper basin population recovery. The persistence of stocked adult bonytail within Cataract Canyon also warrants continued monitoring.

Chart, T. E., and L. D. Lentsch. 2000. Reproduction and recruitment of Gila spp. and Colorado pikeminnow (Ptychocheilus lucius) in the middle Green River 1992-1996. Report $\mathrm{C}$ in Flaming Gorge Studies: Reproduction and recruitment of Gila spp. and Colorado pikeminnow (Ptychocheilus lucius) in the middle Green River. Final report of Utah Division of Wildlife Resources to Upper Colorado River Endangered Fish Recovery Program, Lakewood, Colorado.

This report presents data collected from five annual monitoring trips in Desolation and Gray (Deso/Gray) canyons of the Green River, Utah; 1992-1996. Pre-project data, in some cases as early as 1985 , is incorporated in long term comparisons of catch data. Low velocity habitats were sampled throughout the canyon (two habitats $/ 8 \mathrm{~km}$ ) with seines. Main channel habitats were sampled with trammel nets, hoop nets, and electrofishing. Main channel sampling occurred at four trend sites (Cedar Ridge, RK 295.7; Surprise Canyon/Rock Creek area, RK 280.5; Joe Hutch, RK 256; and Coal Creek, RK 232.8) each year. Additional sites were sampled each year to determine if Colorado pikeminnow spawned there. Nonnative cyprinids, most importantly Cyprinella lutrensis, dominated the catch in low velocity habitats. Low velocity habitat sampling during August, 1993, resulted in the greatest catch $(N=162)$ of YOY chubs (approximately $0.1 \mathrm{fish} / \mathrm{m}^{2}$ ). YOY chubs were collected in relatively low numbers every other year of the study. Annual YOY chub CPE was weakly correlated with Green River peak flow $\left(R^{2}=0.1\right)$. Back calculated spawning dates indicate chubs spawned in Deso/Gray under a wide range of flows $(1,650-25,800 \mathrm{cfs})$. Adult and juvenile Gila spp. net catch rates at the four monitoring sites remained below 0.2 fish $/ 23 \mathrm{~m}$ net-hour throughout this five year period and dropped below 0.1 the final year of study, 1996. Considering pre-project data, adult Gila spp. catch rates have been declining since 1989. The 1993 chub cohort was sampled in 1994 as Age 1+ fish and offers the strongest evidence of recruitment since pre-project monitoring in 1989. Juvenile chubs (likely the 1993 and 1994 cohorts) were collected again in 1995. Kolmogorov-Smirnov tests for differing distributions indicated population structure (as characterized in length frequency analysis) of Deso/Gray chubs are dynamic and recently (incorporating 1997 data) were comprised of smaller (younger) individuals. Colorado pikeminnow trammel net CPE remained low at the four trend sites, with the greatest catch (0.065 and 0.08) collected at RK 280.5 in 1994 and 1995. Concentrations of ripe male pikeminnow were found at Rabbit Valley RK 238) in 
1994 and 1995. Concentrations of spawning pikeminnow were also found at Joe Hutch RK 256) in 1997. The Three Fords spawning area was determined to be an $18 \mathrm{~km}$ stretch of river between RK 256 and 238, with the focus of spawning shifting within that stretch through time. Netting catch rates for native catostomids have been in general decline since 1989, however rebounded in recent years. Electrofishing has provided a relatively strong sample of both Catostomus latipinnis and C. discobolus since 1994 including some strong evidence of recent recruitment. Native catastomid recruitment appears to be more successful since 1993 than was observed in 1992 and during pre-project monitoring years. Channel catfish (Ictalurus punctatus) was the most abundant species collected in main channel habitat each year of study. The only apparent lapse in channel catfish recruitment was observed in 1994 after the higher flows of 1993. We recommend incorporating Deso/Gray fish community monitoring into the Interagency Monitoring Program and targeting flows of 7,000-8,000 cfs to maximize sampling efficiency. Population estimates at the four trend sampling sites would help validate CPE values collected in this canyon since 1986. If a more intensive study to estimate chub population size is initiated, incorporation of a catfish control component at the trend sites should be considered. This monitoring data set does not lend itself to developing flow recommendations. However, the 1993 cohort of chubs appeared to overwinter better than the 1994 cohort. Overwinter flows averaged 3,250 cfs from Oct 1993-Feb 1994 opposed to 2,250 cfs the next winter.

\section{Coggins, L.G. 2007. Abundance trends and status of the Little Colorado River population of humpback chub: an update considering 1989-2006 data. United States Geological Survey open file report $2007-1402$.}

The abundance of the LCR population of federally listed humpback chub Gila cypha in Grand Canyon has been monitored since the late 1980s by means of catch rate indices and capture-recapture-based abundance estimators. Analyses of data from all sources using various methods are consistent and indicate that the adult population has declined since monitoring began. Intensive tagging led to a high proportion ( $>80 \%)$ of the adult population being marked by the mid-1990s. Analysis of these data using both closed and open abundance estimation models yields results that agree with catch rate indices about the extent of the decline. Survival rates for age- 2 and older fish are age dependent but apparently not time dependent. Backcalculation of recruitment using the apparent 1990s population age structure implies periods of higher recruitment in the late 1970s to early 1980s than is now the case. Our analyses indicate that the U.S. Fish and Wildlife Service recovery criterion of stable abundance is not being met for this population. Also, there is a critical need to develop new abundance indexing and tagging methods so that early, reliable, and rapid estimates of humpback chub recruitment can be obtained to evaluate population responses to management actions designed to facilitate the restoration of Colorado River native fish communities.

\section{Coggins, L., C. Walters, C. Paukert and S. Gloss. 2003. An overview of status and trend information for the Grand Canyon population of the humpback chub, Gila cypha. U.S. Geological Survey, Grand Canyon Monitoring and Research Center, Flagstaff, Arizona. Abstract excerpted from report.}

Recent analyses of historical data on humpback chub in Grand Canyon have caused considerable consternation, because of uncertainties about the current size of the population and 
because of the strong probability that the population has been declining steadily for at least a decade. Our most recent assessment models indicate that the current spawning population is probably somewhere between 2,000 and 4,000 age 4 and older fish, We remain quite uncertain about the absolute population size because of uncertainties about whether field procedures have met some assumptions of the main method used to estimate absolute abundance (mark-recapture sampling) and because of limited sample sizes, but all the assessment methods are in clear agreement about the population being in decline. One assessment model (called "Supertag") resulted in a considerably lower estimate for recent adult abundance (1,100-1,200 fish in 2001), but we now believe that estimate was biased downward because of using two inappropriate assumptions in the calculations: the population was assumed to have a stable age structure in the early 1990s, and older chubs were assumed to be equally vulnerable to sampling programs. There are two strategic options for monitoring and population assessment in Grand Canyon: (1) make independent population (and/or trend index) estimates each year using multiple-trip mark-recapture experiments (mark fish on successive trips and measure the proportion of the population made up by these "known" marked numbers) along with index catch-per-effort sampling; and/or (2) use more elaborate stock assessment models to integrate current and past information into more complex estimators of current abundance. In Grand Canyon adaptive management, a really key issue is whether various management policies can improve humpback chub juvenile survival and recruitment. Integrated stock assessment methods are particularly critical for recruitment assessments.

\section{Converse, Y.K. 1995. Use of geomorphology to predict subadult humpback chub distribution in the Colorado River. Proceedings of the Desert Fishes Council.}

Subadult (less than $200 \mathrm{~mm}$ TL) humpback chub (Gila cypha) densities were examined for 16 miles of the Colorado River below the confluence of the Little Colorado River. Geology and surficial hydraulic criteria were used to describe geomorphic reaches. Geomorphic processes were used to describe shoreline types within geomorphic reaches. Narrow reaches with greater total eddy area had higher densities than wider reaches with greater total riffle area. Vegetation, talus and debris fan shorelines with greater fish densities, had lower velocities, were deeper and offered more cover than bedrock, cobble and sand shorelines. Stability of these conditions for the range of Interim Flow Operations of Glen Canyon Dam was also examined.

\section{Douglas, M.E. and P.C. Marsh. 1993. Monthly population estimates of endangered humpback chub (Gila cypha) in the Little Colorado River of Arizona. Proceedings of the Desert Fishes Council 24:65-66.}

Gila cypha (the humpback chub) is restricted in distribution to tight, canyon-bound reaches of the Colorado River and its tributaries. This fish achieves greatest abundance in the lower basin where it utilizes the LCR (a tributary of the Colorado River in the northern Grand Canyon) for spring reproduction and summer residence. However, the onset of its reproductive movements within this important river and its seasonal variance in population density remain unquantified and anecdotal. An understanding of these factors is clearly imperative for proper management of this endangered species. To remedy this, humpback chub were captured by hoop and trammel nets at monthly intervals from July 1991 to present in three study reaches of the LCR: the Confluence (from 0.0 to $1.4 \mathrm{~km}$ upriver); Powell Canyon (1.5 to $7.0 \mathrm{~km}$ above 
confluence on the Navajo Indian Reservation); and Salt Canyon (8.0 to $15.0 \mathrm{~km}$ above confluence on the Navajo Indian Reservation). Fish were PIT-tagged and standard monitoring data collected. Monthly population estimates were derived from tag/recapture data applying the best-fitting of 7 different models, using the computer program CAPTURE. For computational purposes, fish collected within each reach were considered to be from closed populations (i.e., with no immigration or emigration). This assumption is valid given the brevity of monthly sampling periods (i.e., from 6-8 days). During 1992, chub density peaked at the confluence during early March when adults staged for movement upriver but declined by May. Density at Powell Canyon peaked in late March and gradually declined into July, while density at Salt Canyon peaked in April and remained high through summer months. These data indicate that chubs migrate into the LCR during spring and remain in residence within upper reaches throughout summer.

Douglas, M.E. and P.C. Marsh. 1996. Population estimates/population movements of Gila cypha, an endangered cyprinid fish in the Grand Canyon region of Arizona. Copeia 1996:15-28.

Gila cypha (the humpback chub) is a unique but endangered cyprinid fish endemic to the Colorado River system in western North America. Its distribution within the system is patchy; occurrence is restricted primarily to narrow, canyon-bound reaches of these rivers. Greatest abundance is achieved at the confluence of the Colorado and Little Colorado rivers in northern Grand Canyon (Coconino County, AZ). This study defines the nature and extent of G. cypha's movements within the LCR, and tests the hypothesis that its duration of stay within that river is restricted to the reproductive period.

During 1991-1992, adult G. cypha were captured and tagged during 19 6-14 day sampling periods in three separate reaches of the LCR. From these data, population estimates were derived for each reach on a monthly basis, by month for the entire LCR, and over the entire study period. Results indicate an upriver migration by some individuals in early spring, followed by a slow, protracted post-reproductive movement downstream. Localized stasis by adults in the LCR, particularly summer through winter, is also strongly supported by the data. Movements by G. cypha in the LCR thus appears to be amalgam of two processes: upriver movement in spring coupled with localized movements by overwintering adults. The latter suggests a possible alteration in life-history strategy for the species and is discussed in the context of Glen Canyon Dam, built in 1963 to impound Lake Powell at the northern extent of Grand Canyon.

Douglas, M.E. and P.C. Marsh. 1996. Survivability of an endangered species (Gila cypha) within the Grand Canyon region of Arizona. Section 4 in M.E. Douglas and P.C. Marsh, eds. Ecology and Conservation Biology of Humpback Chub (Gila cypha) in the Little Colorado River. Bureau of Reclamation, Salt Lake City, Utah.

The primary focus of this paper is development of Cormack-Jolly-Seber (CJS) open population estimates for $G$. cypha during each of the 50 months, 16 seasons, and four years of this study. From these data, probabilities of yearly survival are then estimated for five different adult size-classes. The hypothesis under test is that overall survival rate is low for this species, particularly given massive anthropogenic modifications of the mainstem Colorado River. 
Fagan, W.F., C. Aumann, C.M. Kennedy and P.J. Unmack. 2005. Rarity, fragmentation, and the scale of dependence of extinction risk in desert fishes. Ecology 86(1):34-41.

Attributes of a species' spatial distribution, such as the number of occurrences and the spatial distribution of those occurrences, can affect extinction risk. Extinction risk, however, is scale dependent, and it is unclear how scale dependency affects linkages between species' distributions and extinction risk. Here, we evaluate the relationships between number of occurrences, distributional fragmentation, and extinction risk for a diverse assemblage of desert fishes across multiple spatial scales. We used the SONFISHES biodiversity database, which details occurrence patterns of 25 native fishes to contrast the species' historical distributions with their much-reduced modern distributions. Defining occurrences (and losses to extinction) at each of five scales $(5,25,100,500$, and $2500 \mathrm{~km}$ of stream reach), we found that range fragmentation was a stronger predictor of extinction risk than the number of occurrences for all scales of analysis. Furthermore, we detected scale dependence in the strength of the predictive relationship between fragmentation and extinction, with loss of occurrences at intermediate scales $(\sim 100 \mathrm{~km}$ of stream reach) being most closely tied to range fragmentation. Importantly, our results proved insensitive to our definition of the historical and modern periods. These findings highlight the value of multi-scale analyses to investigations of extinction in species assemblages.

Gorman, O.T., R.G. Bramblett, R.M. Hervin, D.R. Van Haverbeke and D.M. Stone. 2005. Distribution and abundance of native and non-native fishes of the Colorado River Ecosystem in Grand Canyon, Arizona. Page 78-94 in Proceedings of two symposia: restoring native fish to the lower Colorado River: interaction of native and non-native fishes. July 13-14, 1999. Las Vegas, Nevada. U.S. Fish and Wildlife Service, Southwest Region, Albuquerque, New Mexico.

The Colorado River ecosystem in Grand Canyon is strongly impacted by operation of Glen Canyon Dam. Fluctuating releases of cold, hypolimnetic water from Lake Powell $\left(\sim 8^{\circ} \mathrm{C}\right)$ for peak hydroelectric power generation has had a profound impact on the formerly warm, silty Colorado River. Clear, cold stenothermal conditions preclude successful reproduction and recruitment of most native fishes in the mainstem and introduced trout have become dominant species in the fish community. To assess the effects of dam operations on the native fish assemblage, the distribution and abundance of native and non-native fishes of the Colorado River ecosystem in Grand Canyon were assessed in the first year of a two-year research and monitoring program funded by the Grand Canyon Monitoring and Research Center. Study sites were located along 159 miles of the Colorado River from the Paria River to below Havasu Creek. An intensive area of study was established from just above the confluence of the Little Colorado River (LCR) at RM 60 to Tanner Rapid at RM 68.6 (LCR inflow reach). Additional sampling was conducted in major tributaries (LCR, Bright Angel, Shinumo, Kanab, Havasu). Mini-hoopnets, minnow traps, electrofishing, trammel nets, and seines were used to sample fish during 120 days of fieldwork spread over four seasons between March 1998 and February 1999. Some 4,618 fish were captured in the Colorado River mainstem and tributaries. Non-native species dominated the catch in the mainstem Colorado River $(1,515 / 2,565,59 \%)$ and rainbow trout Oncorhynchus mykiss was the most common non-native species ( $\mathrm{N}=955,37 \%)$. Of 1,050 native fish captured in the mainstem, speckled dace Rhinichthys osculus $(\mathrm{N}=463,18 \%)$ and humpback chub Gila cypha $(\mathrm{N}=395,15 \%)$ were the most abundant. The use of mini-hoopnets to 
sample fish in mainstem habitats revealed a relative abundance of humpback chub in the 100-200 mm TL size class, a population feature not observed in previous studies. In the smaller tributaries (Bright Angel, Shinumo, Kanab, Havasu), native species dominated the catch $(739 / 847,87 \%)$. Speckled dace $(\mathrm{n}=370,44 \%)$ and humpback chub $(\mathrm{n}=133,16 \%)$ were the most abundant native fishes. The LCR assemblage was dominated by native species $(963 / 1206,80 \%)$ with humpback chub $(\mathrm{N}=515,43 \%)$ and speckled dace $(\mathrm{n}=308,19 \%)$ dominating. The pattern of appearance, distribution, and abundance of YOY humpback chub in the mainstem Colorado River observed in our study was consistent with a "source-sink" model of downstream dispersal from the LCR coupled with high mortality from predation in the mainstem Colorado River. The abundance of adult rainbow trout in the LCR inflow reach of the Colorado River coupled with their complementary distribution with juvenile humpback chub in January 1999 strongly suggests that predation by rainbow trout may have been responsible for the near disappearance of YOY humpback chub between late summer and early winter. Mortality rates for small fish are likely exacerbated by fluctuating flows, which disrupt habitat associations and increase the probability of downstream movement and dispersal. Fluctuating flows also reduce the suitability of river edge habitats and food resources needed for rearing small fish. The rarity of small humpback chub downstream of the LCR inflow coupled with high abundance of trout and cold fluctuating flows suggest that conditions for recruitment of YOY humpback chub in the Colorado River in Grand Canyon are extremely poor. In order to provide opportunities for increased survivorship of small humpback chub in Grand Canyon, resource managers should consider ways to stabilize flows and increase temperature in the mainstem Colorado River. Implementation of more natural flow and temperature conditions will increase the stability of shoreline habitat and cover, and likely result in increased food resources and growth rates in small fishes, and decrease mortality associated with piscivory.

\section{Hoffnagle, T.L., R.A. Valdez and D.W. Speas. 1999. Fish abundance, distribution, and habitat use. Pages 273-287 in R.H. Webb, J.C. Schmidt, G.R. Marzolf and R.A. Valdez, eds. The Controlled Flood in Grand Canyon. Geophysical Monograph 110, The American Geophysical Union, Washington, D.C.}

The 1996 controlled flood in the Colorado River, Grand Canyon, was designed, in part, to improve conditions for juvenile native fishes by reshaping habitat and displacing non-native fishes. We examined changes in abundance and distributions of native and non-native fishes immediately before and after the controlled flood and recovery of affected species 2.5 and 6 months after. CPUE of humpback chub and flannelmouth sucker did not differ in pre- versus post-flood periods. CPUE of plains killifish, bluehead sucker and fathead minnow decreased following the flood, and CPUE of speckled dace and rainbow trout increased. Juvenile humpback chub remained primarily along talus shorelines at all discharges, while at higher discharges, speckled dace shifted from mid-channel riffles to debris fans and talus and fathead minnows used primarily vegetated shorelines. There was evidence of some downstream displacement of plains killifish, fathead minnows and rainbow trout. Catch rates of all species showed seasonal variation following the flood, with summer recruitment of YOY, particularly fathead minnows and plains killifish. Although short-term reductions in catch rates of fathead minnows and plains killifish occurred, these populations returned to pre-flood densities by 6 months after the flood. Catch rates of all species before and after the flood were similar to those 
recorded in previous years. We determined that the controlled flood did not significantly alter native fish distributions or abundances through Grand Canyon.

Jackson, J.A. 2008. Population estimate for the humpback chub (Gila cypha) and roundtail chub (Gila robusta) in Western Canyon, Colorado River, Utah 2003-2005. Draft report Utah Division of Wildlife Resources, Moab, Utah.

Humpback chub population estimates were determined for Desolation and Gray canyons (Deso/Gray), on the Green River, by conducting multiple pass capture-recapture sampling. Three sampling passes were conducted in 2001 and 2003, and two passes were conducted in 2002 due to low water. In 2003, sampling was moved to the fall to avoid capturing Colorado pikeminnow that use Desolation Canyon for spawning. Twelve sites were sampled throughout the two canyons. Included within these sites, were four long-term sites sampled annually by Utah Division of Wildlife Resources, since 1989. Analysis of point estimates generated by capture-recapture data demonstrated that the adult humpback chub populations was composed of 1,254 individuals in 2001, 2,612 individuals in 2002, and 937 individuals in 2003. Many factors were at play during the three-year period that may have contributed in the variation in point estimates among years. Non-biological factors complicating the validity of the estimates include moving sampling from summer to fall and low water conditions at the time of sampling. Factors that may have directly affected the humpback chub population biologically include: the Rattle Complex fire and subsequent fish kill in late summer 2002, and the apparent increase in smallmouth bass occupying Deso/Gray. The authenticity of the point estimates will be more clearly analyzed when population estimates are conducted consistently during the fall months of 2006-2008.

Population estimates for the juvenile portion of the population could not be determined since very few individuals were collected each year. Numbers of humpback chub juveniles collected by all methods during the study period were: 5 in 2001, 24 in 2002, and 4 in 2003. To determine mean recruitment for juveniles into the adult population, we assumed that individuals from 200-220 mm would be first year adults. Point estimates for this size class were derived by taking the proportion of these fish relative to the total numbers used in the adult population estimates. Therefore, estimates of first year adults were 163 (95\% CI=149-192) for 2001, 297 $(95 \% \mathrm{CI}=275-343)$ for 2002, and $134(95 \% \mathrm{CI}=123-159)$ for 2003 . In order to increase the catch of juvenile humpback chub we recommend the continuation of electrofishing to the extent possible, utilizations of hoop nets and minnow traps, and incorporation of smaller mesh trammel nets.

Catch rate data incorporated to analyze changes over time at four long-term sites illustrated that catch rates for humpback chub have not changed substantially since 1989 . Furthermore, examination of pre-study and study period data suggest that catch rates can be extremely variable and possibly dependent on environmental factors during sampling.

This study represents the first sampling period since finalization of the amended recovery goals for humpback chub in 2002 and is valuable in the initial evaluation of population size of humpback chub in Deso/Gray. Furthermore, it serves to illuminate any necessary adjustments to 
the sampling design before population estimate sampling for humpback chub in Deso/Gray resumes in 2006.

Olden, J.D., L. Poff and K.R. Bestgen. 2008. Trait synergisms and the rarity, extirpation, and extinction risk of desert fishes. Ecology 89(3):847-856.

Understanding the causes and consequences of species extinctions is a central goal in ecology. Faced with the difficult task of identifying those species with the greatest need for conservation, ecologists have turned to using predictive suites of ecological and life-history traits to provide reasonable estimates of species extinction risk. Previous studies have linked individual traits to extinction risk, yet the non-additive contribution of multiple traits to the entire extinction process, from species rarity to local extirpation to global extinction, has not been examined. This study asks whether trait synergisms predispose native fishes of the Lower Colorado River Basin (USA) to risk of extinction through their effects on rarity and local extirpation and their vulnerability to different sources of threat. Fish species with "slow" life histories (e.g., large body size, long life, and delayed maturity), minimal parental care to offspring, and specialized feeding behaviors are associated with smaller geographic distribution, greater frequency of local extirpation, and higher perceived extinction risk than that expected by simple additive effects of traits in combination. This supports the notion that trait synergisms increase the susceptibility of native fishes to multiple stages of the extinction process, thus making them prone to the multiple jeopardies resulting from a combination of fewer individuals, narrow environmental tolerances, and long recovery times following environmental change. Given that particular traits, some acting in concert, may differentially predispose native fishes to rarity, extirpation, and extinction, we suggest that management efforts in the Lower Colorado River Basin should be congruent with the life-history requirements of multiple species over large spatial and temporal scales.

Paukert, C.P., L.G. Coggins, Jr. and C.E. Flaccus. 2006. Distribution and movement of humpback chub in the Colorado River, Grand Canyon, based on recaptures. Transactions of the American Fisheries Society 135:539-544.

Mark-recapture data from the federally endangered humpback chub Gila cypha in the Colorado River, Grand Canyon, were analyzed from 1989 to 2002 to determine large-scale movement patterns and distribution. A total of 14,674 recaptures from 7,127 unique fish were documented; $87 \%$ of the recaptures occurred in the same main-stem river reach or tributary as the original captures, suggesting restricted distribution of most fish. A total of $99 \%$ of all recaptures were from in and around the Little Colorado River (LCR), a tributary of the Colorado River and primary aggregation and spawning location of humpback chub in Grand Canyon. Time at liberty averaged $394 \mathrm{~d}$, but some fish were recaptured near their main-stem capture location over 10 years later. Proportionally fewer large $(>300 \mathrm{~mm})$ humpback chub exhibited restricted distribution than small $(<200 \mathrm{~mm})$ fish. However, several fish did not move more than $154 \mathrm{~km}$ throughout Grand Canyon between capture and recapture, suggesting that limited movement occurs throughout Grand Canyon. The majority of the recaptured fish remained in or returned to the LCR or the Colorado River near the LCR. Although many large-river fishes exhibit extensive migrations to fulfill their life history requirements, most of the humpback chub in Grand Canyon appear to remain in or come back to the LCR and LCR confluence across 
multiple sizes and time scales. Detecting trends in the overall abundance of this endangered fish in Grand Canyon can probably be accomplished by monitoring the area in and around the LCR.

Program Director's Office. 2006. Evaluation of population estimates for Colorado pikeminnow and humpback chub in the Upper Colorado River Basin. Upper Colorado River Endangered Fish Recovery Program, Lakewood, Colorado.

The Upper Colorado River Endangered Fish Recovery Program (UCRRP) coordinates population estimates for the endangered Colorado pikeminnow (Ptychocheilus lucius) and humpback chub (Gila cypha) in the Colorado River Basin. Reliable and precise estimates are needed by the U.S. Fish and Wildlife Service as part of recovery and demographic criteria provided in species recovery goals approved in August 2002. Population estimates are being conducted in eight regions of the Upper Colorado River Basin by state and federal agencies with assistance from universities and private individuals. Mark-recapture estimates are being obtained from field sampling of populations in each region for 3 consecutive years with 2 years off to minimize over-handling of fish. Estimates of Colorado pikeminnow began in 1992 in the Upper Colorado River Subbasin and in 2000 in the Green River Subbasin. Numbers of wild fish in the San Juan River Subbasin are currently too low for formal mark-recapture estimates, and hatchery augmentation is expected to increase population size for estimates by about 2006.

Estimates of humpback chub began in 1998 in Black Rocks and Westwater Canyon; 2000 in Yampa Canyon; 2001 in Desolation/Gray Canyons; and 2003 in Cataract Canyon. Annual reports are submitted by respective researchers for each of the population estimates to the UCRRP and the San Juan River Basin Recovery Implementation Program, and findings are presented and discussed at the Annual Upper Basin Researchers Meeting. Two workshops of species experts and statisticians have been convened by the UCRRP to improve reliability and precision of population estimates, and an ad hoc committee of species experts and researchers has been established to ensure ongoing communication and evaluation of field sampling protocols and analytical methods. Precision criteria of capture probability (P-hat $\geq 0.10)$ and coefficient of variation $(\mathrm{CV} \leq 0.15)$ are not being consistently met in all estimates. Researchers are refining field sampling protocols and analytical methods to improve precision but environmental variables, particularly flow, are uncontrolled and affect capture efficiency and hence, precision. Estimates will continue to be evaluated, but maximum achievable precision may be reflected in current estimates.

\section{Robinson, A.T. D.M. Kubly, R.W. Clarkson and E.D. Creef. 1996. Factors limiting the distributions of native fishes in the Little Colorado River, Grand Canyon, Arizona. Southwestern Naturalist 41(4):378-387.}

Native fishes are not distributed evenly in the terminal $21 \mathrm{~km}$ of the Little Colorado River (Blue Spring to the mouth); speckled dace (Rhinichthys osculus) are present throughout the $21 \mathrm{~km}$; humpback chub (Gila cypha), bluehead sucker (Pantosteus discobolus), and flannelmouth sucker (Catostomus latipinnis) are restricted to the $14.2 \mathrm{~km}$ below chute Falls. Water chemistry (primarily carbon dioxide concentration) and food resources have been hypothesized to limit fish distribution in the Little Colorado River. We sampled algae, invertebrates, and water chemistry in reaches above and below Chute Falls to determine if native 
fish distributions were limited by these parameters. Chlorophyll $a$ content of algae samples collected from fine substrates was greatest above Chute Falls. Densities and biomasses of invertebrates known to be food items for native fishes were also greatest in that reach. Longitudinal water chemistry gradients were consistent across seasons; dissolved oxygen, $\mathrm{pH}$, and conductivity generally decreased. To determine if native fishes other than speckled dace could survive in the waters above Chute Falls, we captured age- 0 and age- 1 humpback chub, and age-1 bluehead suckers near $10.5 \mathrm{~km}$, relocated subsets to $12.5,15,17.5$, and $20 \mathrm{~km}$, and held them for three days. All age- 1 humpback chub and bluehead suckers survived three days of relocation at all sites. Age-0 humpback chub and bluehead suckers survived three days of relocation at all sites. Age- 0 humpback chub experienced significantly more mortality, and exhibited more stress behaviors at the $20 \mathrm{~km}$ relocation site than at any other site. Longitudinal food resource patterns and the results of the relocation experiment suggest that neither food resources nor water chemistry prohibit humpback chub and bluehead sucker from inhabiting the reach above Chute Falls. We believe that during base flow, Chute Falls is a physical barrier to upstream movement of fishes. If humpback chub and the two sucker species could transgress Chute Falls during high discharge, or if these species were artificially reintroduced above the falls, we believe that sufficient habitat and food resources are available to sustain populations.

\section{Robinson, A.T., R.W. Clarkson and R.E. Forrest. 1998. Dispersal of larval fishes in a regulated river tributary. Transactions of the American Fisheries Society 127:722-786.}

We investigated longitudinal distributions, near-shore movements, and drift of larval native fishes (humpback chub Gila cypha, speckled dace Rhinichthys osculus, bluehead sucker Catostomus discobolus, and flannelmouth sucker Catostomus latipinnis) in the Little Colorado River, a tributary to the regulated Colorado River in Grand Canyon, Arizona, to determine spawning sites, larval dispersal patterns, and amount of drift into the mainstem Colorado River. Larval distributions and drift indicated native fishes spawned throughout the terminal $14.2 \mathrm{~km}$ of the Little Colorado River. In addition, distribution, drift, and trap data suggest an active component to dispersal for all four native species. Drift of larval native fish was greater near shore than mid-channel, and except for speckled dace larvae, which were prone to drift at night, larval native fish did not exhibit diel periodicity in drift. During a 46-d period in 1993, we estimated that over 370,000 native fish larvae drifted out of the Little Colorado River into the Colorado River. Regulated discharge from Glen Canyon Dam has all but eliminated springsummer ponding of tributary mouths that occurred when ascending flows in the Colorado River coincided with descending and base flows in tributaries; thus, drifting larvae are allowed to pass directly into the Colorado River. Survival of larvae now transported into the Colorado River is probably poor because of perennially cold water temperatures and instability of near-shore habitats.

U.S. Geological Survey. 2006. Grand Canyon humpback chub population stabilizing. U.S. Geological Survey Fact Sheet 2006-3109. Abstract was excerpted from report introduction and results.

A number of factors have contributed to the decline of humpback chub and other native Colorado River fish. In 1967, the humpback chub was added to the federal list of endangered species and is today protected under the Endangered Species Act of 1973. Only six populations 
of humpback chub are currently known to exist, five in the Colorado River Basin above Lees Ferry, Arizona, and one in Grand Canyon, Arizona. Monitoring and research of the Grand Canyon population of humpback chub is overseen by the U.S. Geological Survey's Grand Canyon Monitoring and Research Center (GCMRC) under the auspices of the Glen Canyon Dam Adaptive Management Program (GCDAMP). Recently collected data indicate that the number of adult (age-4+) humpback chub in the Grand Canyon stabilized between 2001 and 2005 after more than a decade of decline.

Since scientists began monitoring efforts in 1989, the population of adult humpback chub in the Grand Canyon has declined steadily until recently. The death of 15 to $20 \%$ of adult fish each year and a low rate of juvenile fish surviving into adulthood contributed to the decline. Adult mortality rates and the failure of juvenile fish to reach adulthood have been attributed to changes in Little Colorado River and Colorado River hydrology, the weakening of young fish by the nonnative Asian tapeworm (Bothriocephalus acheilognathi), and competition with and predation by nonnative fish species.

Between 2001 and 2005, however, conditions appear to have improved, and the number of adult fish stabilized at an estimated 5,000 fish. Additionally, near the confluence of the Colorado and Little Colorado Rivers, catch-rate data from the monitoring program indicate an increased abundance of juvenile humpback chub between 2003 and 2005. Increases in juvenile fish during the same period were also apparent for other native species found near the confluence, including bluehead sucker (Catostomus discobolus), flannelmouth sucker (Catostomus latipinnis), and speckled dace (Rhinichthys osculus).

Elsewhere in the Grand Canyon, catch rates for humpback chub produced in 2005 were higher than previous years in middle and lower Marble Canyon. Higher than average catch rates at these locations were unexpected because they are up to 25 river miles above the confluence of the Colorado and Little Colorado Rivers where spawning usually occurs. These findings suggest that more favorable conditions for spawning and incubation existed in the Colorado River main channel during 2005.

\section{U.S. Geological Survey. 2007. Grand Canyon humpback chub population improving. U.S. Geological Survey Fact Sheet 2007-3113. Abstract excerpted from report.}

The U.S. Geological Survey's (USGS) Grand Canyon Monitoring and Research Center oversees monitoring and research activities for the Grand Canyon population under the auspices of the Glen Canyon Dam Adaptive Management Program (GCDAMP). Analysis of data collected through 2006 suggests that the number of adult (age 4+ years) humpback chub in Grand Canyon increased to approximately 6,000 fish in 2006, following an approximate 40-50\% decline between 1989 and 2001 (Coggins 2007). Increasing numbers of adult fish appear to be the result of steadily increasing numbers of juvenile fish reaching adulthood beginning in the mid- to late-1990s and continuing through at least 2002.

Humpback chub have been affected not only by changes in hydrology since the construction of the dam but also by competition with and predation by nonnative fishes. Fishes originating in many parts of the world are currently found in the Colorado River, including 
introduced species of trout, catfish, carp, and bass. Nonnative fish parasites, such as the Asian tapeworm (Bothriocephalus acheilognathi) and anchor worm (Lernaea cyprinacea), which infect some humpback chub, have also found their way into the Colorado River.

Since 1989, when scientists began repeated monitoring efforts, the population of adult humpback chub in Grand Canyon has declined steadily until about 2001, when the population appeared to stabilize. More recently, the population appears to have increased, reaching an estimated 6,000 adult fish in 2006. Current estimates suggest that there has been an approximate increase of 20-25 percent in adult fish abundance since 2001. This increase in adult fish numbers since 2001 appears to be the result of increasing recruitment that began in the mid- to late-1990s and has continued through at least 2002.

USGS scientists have been working to improve their ability to estimate the status and trends of the Grand Canyon population of humpback chub. They evaluated the age-structured mark-and-recapture models used to estimate adult humpback chub numbers and made refinements to ensure that current estimates are most consistent with the data. Model innovations included accounting for the impacts of seasonal and spatial variation in water temperature on fish growth. A new method was also developed for estimating the relation between fish age and length. Scientists also concluded that only large changes in recruitment caused by management actions can be readily detected, given the uncertainty in current assessment procedures.

\section{Valdez, R.A., W.J. Masslich and W. Leibfried. 1993. Present distribution of humpback chub Gila cypha in the mainstem Colorado River, Grand Canyon, Arizona. Proceedings of the Desert Fishes Council 24:66.}

Ninety-five percent $(1,324)$ of 1,392 humpback chub Gila cypha captured from the mainstem Colorado River in Grand Canyon, form October 1990 through June 1992, were found in a 13-km reach between RM 57 and 65, about equidistance upstream and downstream of the confluence with the Little Colorado River (LCR, RM 61.3). Bimonthly sampling conducted between RM 56 and 226 revealed that chubs were distributed between RM 57.0 and 221.8. Concentrations of chubs downstream of the LCR were encountered at Bright Angel Creek inflow (RM 87-88), Shinumo Creek inflow (RM 108-109), above Blacktail Canyon RM 119-120) Middle Granite Gorge (RM 126-127), Havasu Creek inflow (RM 155-157), and Pumpkin Spring (RM 213-214). Present distribution of humpback chub in the mainstem Colorado River is compared with historic distribution.

\section{Wasowicz, A. and R.A. Valdez. 1995. Historic and present distribution and abundance of humpback chub in Grand Canyon, Arizona. Proceedings of the Desert Fishes Council 26:57.}

Archaeological and historic records indicate that the endangered humpback chub (Gila cypha) was once distributed throughout the Colorado River and its major tributaries in Grand Canyon. Following completion of Glen Canyon Dam in 1963 and until 1970, mainstem distribution of the species was reported as $412 \mathrm{~km}$, from the tailwaters of the dam to Separation Canyon. Present distribution is $359 \mathrm{~km}$, from RM 30 (South Canyon) to RM 253 (Maxson Canyon), with 88 percent of adults in an 11-km area, from RM 58.3 to RM 65.4. This population 
center for humpback chub in Grand Canyon is associated with the LCR, where the majority of mainstem adults and the LCR population component spawn. Limited mainstem spawning success is suspected, as indicated by ripe and gravid fish away from the LCR and few larval chubs. Distribution of humpback chub in the mainstem Colorado River in Grand Canyon is limited by cold, hypolimnetic releases from Glen Canyon Dam $\left(8-10^{\circ} \mathrm{C}\right.$, which also limit reproduction), low food availability, large numbers of predators, and possibly habitat instability from dam operations. The species was reported in low numbers from lower areas of Bright Angel Creek, Shinumo Creek, Kanab Creek, Tapeats Creek, and Havasu Creek, where it is still found in very small numbers. The population component inhabiting the LCR, and spawners ascending from the mainstem, occur only in the lower $13 \mathrm{~km}$ of stream. Although the distribution of humpback chub in Grand Canyon has contracted since Glen Canyon Dam was built, changes in species abundance are difficult to assess. Historic records indicate higher abundances throughout the canyon, but it appears that densities may be higher within the LCR.

\subsection{HABITAT SELECTION}

Childs, M.R., R.W. Clarkson and A.T. Robinson. 1998. Resource use by larval and early juvenile native fishes in the Little Colorado River, Grand Canyon, Arizona. Transactions of the American Fisheries Society 127:620-629.

We investigated resource use by early life stage ( $\leq 30 \mathrm{~mm}$, total length) humpback chub Gila cypha, speckled dace Rhinichthys osculus, bluehead suckers Catostomus discobolus, and flannelmouth suckers C. latipinnis in the Little Colorado River, a tributary to the Colorado River in Grand Canyon, Arizona. Significant logistic regression models for habitat use were developed for all species pairwise combinations except flannelmouth sucker-humpback chub and flannelmouth sucker-speckled dace; correct classification probabilities ranged from $54 \%$ to $81 \%$. Parameters used in discriminating among habitat use included depth, distance from shore, cover, and substrate. Logistic models were also developed to compare habitat use among larval stages within species, and most combinations produced significant models. Classification probabilities ranged from $60 \%$ to $95 \%$ in these models with the variables of depth, distance from shore, current velocity, cover, and substrate contributing to the various models. Behavioral observations revealed significant differences in vertical use of the water column and feeding locations among bluehead suckers and the two cyprinids. Diet analysis supported differences observed in feeding location and also identified some differences in diel feeding patterns. These differences in habitat use, behavioral time budgets, and diet indicate that some resource partitioning occurs among larval fishes in the Little Colorado River. Further laboratory study is needed to verify the mechanisms that sustain differential resource use in this system.

\section{Converse, Y.K., C.P. Hawkins and R.A. Valdez. 1998. Habitat relationships of subadult humpback chub in the Colorado River through Grand Canyon: spatial variability and implications of flow regulation. Regulated Rivers: Research and Management 14(3):267- 284.}

We examined subadult humpback chub densities along $24 \mathrm{~km}$ of the Colorado River in the Grand Canyon to: (1) identify geomorphic conditions in the study area; (2) determine 
associations between subadult humpback chub $(<200 \mathrm{~mm}$ TL) habitat use and geomorphic differences; and (3) determine how discharge, during base flow conditions, was related to subadult humpback chub habitat conditions.

Habitat was categorized at two nested spatial scales: geomorphic reach and shoreline type. Within reaches, shoreline types were categorized according to geomorphology. We measured water depth, velocity and cover attributes along all shoreline types over a range of discharges to determine if habitat quality of reaches and shoreline types varied with discharge. Reaches 1 and 3 had narrow, deep corridors, whereas Reach 2 was a wide, shallow reach. Among shoreline types, depth, velocity and cover varied; however, differences were not consistent between reaches. Fish densities also varied among shoreline types and reaches. Vegetation, talus and debris fan shorelines had the highest densities of subadult humpback chub in a pattern similar to that of cover. In addition, subadult humpback chub presence was associated with a high frequency of cover regardless of shoreline designation. However, these relationships explained little of the overall variation in subadult densities.

Lack of a strong association between fish density and geomorphology may be partially due to effects of discharge on habitat quality. The overall trend among shorelines (without regard to type) showed that cover decreased with increasing discharge, whereas depth and velocity increased. However, no consistent pattern between discharge and depth, velocity and cover among individual shoreline types was evident.

Vegetated shorelines, consisting mainly of non-native tamarisk (Tamarix chinensis), had nearly twice the fish densities of talus and debris fan. Reasons are discussed as to why subadult humpback chub occupy naturalized habitat like vegetated shorelines in greater densities than natural habitats. The relationships observed in this study have important implications for humpback chub recovery and management of the Colorado River through Grand Canyon.

Day, K. S., K. D. Christopherson and C. Crosby. 2000. Backwater use by young-of-year chub (Gila spp.) and Colorado pikeminnow (Ptychocheilus lucius) in Desolation and Gray Canyons of the Green River, Utah. Report B in Flaming Gorge studies: reproduction and recruitment of Gila spp. and Colorado pikeminnow (Ptychocheilus lucius) in the middle Green River. Final report of Utah Division of Wildlife Resources to Upper Colorado River Endangered Fish Recovery Program, Lakewood, Colorado.

Backwater nursery habitat characteristics used by chubs (Gila spp.) and Colorado pikeminnow (Ptychocheilus lucius) were studied in Desolation and Gray canyons of the Green River, Utah, during 1994 and 1996. This study was conducted as part of the Recovery Implementation Program (RIP) for the Endangered Fish Species in the Upper Colorado River Basin, Scope-of-Work number FG-39. The Flaming Gorge Investigations are a five year program begun in 1992 to provide pertinent information on endangered fishes in the Green River and the effects of flow regulation by the dam. Results of the numerous studies conducted during this period will be used to develop a new Biological Opinion on the future operation of Flaming Gorge Dam. There were a total of ten project objectives, six dealt with biological component and four dealt with geomorphic component. Several of the objectives were handled by more than one research team and the results are reported in more than one final report. The specific tasks of this 
report were to: 1. determine reproductive success, growth rates, and backwater habitat use of early life stages of Gila spp. and Colorado pikeminnow; 2. continue PIT tagging all juvenile and adult Gila spp.; and 3. monitor apparent trends in the non-target fish community. A total 729 backwater and low velocity flow habitats of Desolation and Gray canyons were sampled four times each year between 1994 through 1996 for the presence of endangered fish. Each backwater sampled was first categorized by physical type, and physical measurements were made after fish communities were sampled with a $3 \mathrm{~mm}$ mesh seine. Several statistical analyses were conducted to help interpret significant relationships. Linear regression was performed on four flow parameters peak flow, date of peak flow, flow and duration against backwater numbers, volume and area. Contingency table and $X^{2}$ analysis were preformed to test preference for use of habitat classes. The Wilcoxon rank-sum tested the significant differences $(P<0.05)$ of habitat variables between occupied and unoccupied backwaters. Discriminant function analysis was also used to determine if Colorado pikeminnow use of nursery habitats could be predicted by a model of habitat characteristics. Models were developed for each season of each year, for each season for all years, for each year and for all seasons and years pooled. Numbers of backwaters sampled varied between years and seasons. The predominant backwater class was shoreline eddy. Correlations between backwater numbers and flow events could not be rigorously tested because this study represents only three years of flow data. Correlation analyses were run to determine if backwater types were influenced by flow events. Strong negative correlations were seen between the number of migrating sand wave backwaters sampled and annual peak flow and the duration of flow above $50 \%$ of the peak, when all sampling periods were included in the analysis. Secondary channel backwaters were negatively associated with duration of flows above $75 \%$ of the peak. Although shoreline eddy habitats were not significantly correlated with peak flow events, there was a negative correlation with flows during sampling periods. Chubs did not show a preference for backwater habitats based on method of formation. Backwaters containing chubs were significantly larger (length, area, depth, volume) and more turbid than unused backwaters, but preferences varied between months. Habitat selection by chubs showed considerable variability. Recent studies from the Grand Canyon indicate that chubs use in-channel shoreline habitats more than backwaters. Other studies show that chubs are often found in main channel habitats and are capable of movement into and through flow. Therefore, this study is likely insufficient for describing characteristics of chub recruitment and nursery habitat use in Desolation and Gray canyons. Colorado pikeminnow used scour-formed and migrating sandwave backwaters and avoided constricted reach eddies and shoreline eddies. Selection for scour backwaters matched patterns seen in floodplain reaches. Colorado pikeminnow chose larger (length, width, area, volume) backwaters with little cover. Habitat use criteria for this species appeared to be more consistent than for chubs.

Discriminant function analyses could not separate backwaters inhabited by chubs and Colorado pikeminnow from those uninhabited. Discriminant models for Colorado pikeminnow were better than those for chubs, another indication of more definite selection patterns, but they were still not powerful enough for application. All sampled habitats were overwhelmingly dominated by nonnative species. Catch-per-unit effort for a few of these species was positively correlated with chubs and Colorado pikeminnow.

Flow regulation alone may not be adequate for control of nonnative fish. It is recommended that additional studies be conducted on chub nursery habitat use. Additional 
studies should be conducted on effects of spring discharge, single year and multiple year interaction, on chubs and Colorado pikeminnow. Habitat associations and flow/recruitment relationships for non-listed native fishes should be analyzed. Nonnative fish recruitment and habitat use, as well as interactions with native fishes should be pursued.

Gorman, O.T. 1995. Habitat use by the endangered humpback chub (Gila cypha) in the Little Colorado River, Grand Canyon. Bulletin of the Ecological Society of America 76 (Suppl. 3):333.

The objective of USFWS research is to determine habitat use by the endangered humpback chub and other native fishes in the LCR and other tributaries of the Colorado River in the Grand Canyon, evaluate the potential for establishing a second spawning aggregation of humpback chub, and from the perspective of habitat requirements, evaluate the impact of Glen Canyon dam on native fishes. Research commenced in the LCR in July 1991 and in January 1992 for other tributaries. Stream habitat in the lower $21 \mathrm{~km}$ of the LCR and lower $8 \mathrm{~km}$ of other tributaries has been mapped and sampled. Habitat use patterns were evaluated from seining, electrofishing, and hoopnetting. In the LCR, humpback chub were the predominant species and maintained a resident population. Preliminary analyses indicate that adult chubs are highly habitat specific and that juvenile chub show a very different pattern of habitat use.

Gorman, O.T. D.M Stone, Z.M. Zdinak and V. Meretsky. 1995. Habitat use by the endangered humpback chub (Gila cypha) in the Little Colorado River, Arizona near Grand Canyon. Proceedings of the Desert Fishes Council 26:53.

During the spring months (March, April, May) of 1993, 1994, and 1995, the Service conducted field studies to describe the habitat used by spawning humpback chub in the Little Colorado River. During the spring spawning season, ripe males congregated in shallow to moderately deep runs and eddies below travertine dam/reef complexes. These habitats had slow currents, complex structure and were associated with the presence of gravel substrates. Most ripe females appeared to be solitary and were captured in deeper downstream pool habitats. Capture of single ripe females in aggregations of ripe males indicated putative spawning sites. This pattern of spawning habitat use and behavior is concordant with published studies of minnow spawning ecology. The results of our work will serve as a model of habitat use by humpback chub and will be useful in efforts to establish additional spawning populations.

\section{Gorman, O.T., S.C. Leon and O.E. Maughan. 1993. Habitat use by humpback chub, Gila cypha, in the Little Colorado River and other tributaries of the Colorado River. Proceedings of the Desert Fishes Council 24:20-21.}

The objective of USFWS research is to determine habitat use by the endangered humpback chub and other native fishes in the LCR and other tributaries of the Colorado River in the Grand Canyon, evaluate the potential for establishing a second spawning aggregation of humpback chub, and from the perspective of habitat requirements, evaluate the impact of Glen Canyon dam on native fishes. Research commenced in the LCR in July 1991 and in January 1992 for other tributaries. Stream habitat in the lower $21 \mathrm{~km}$ of the LCR and the lower $8 \mathrm{~km}$ of other tributaries has been mapped and sampled. Habitat use patterns were evaluated from 
seining, electrofishing, and hoopnetting. In the LCR, humpback chub were the predominant species and maintained a resident population. Preliminary analyses indicate that adult chubs are highly habitat specific and that juvenile chub show a very different pattern of habitat use.

\section{Hoffnagle, T.L., W.R. Persons and G. Doster. 1994. Use of backwater areas by juvenile} native fishes in the Colorado River. Proceedings of the Desert Fishes Council 25:33-34.

Use of backwater habitats in the Colorado River, Grand Canyon, by juvenile native fishes was studied over the past year. Comparisons of relative abundances within reaches revealed that speckled dace (Rhinichthys osculus) (48.5\%) and flannelmouth sucker (Catostomus latipinnis) $(32.5 \%)$ were the more common species in Reach 20 [Lee's Ferry (RM 0) to the LCR (RM 61.5)]. Humpback chub (Gila cypha) (33.3\%) was the most common species in Reach 30 [LCR to Bright Angel Creek (RM 87.6)]. In Reach 40 [Bright Angel Creek to National Canyon (RM 166.4)], bluehead sucker (Catostomus discobolus) (35.7\%) was most abundant. Speckled dace (33.8\%) and bluehead sucker (24.6\%) were the more common species in Reach 50 [National Canyon to Diamond Creek (RM 225.6)]. Comparisons among reaches showed that most bluehead suckers $(66.5 \%)$, flannelmouth suckers $(52.4 \%)$ and speckled dace $(67.9 \%)$ were collected in Reach 50, whereas most humpback chubs (87.6\%) were taken in Reach 30. Humpback chubs caught in backwaters at night were significantly larger than those taken during the day. No significant relationships were found for comparisons of catch rates with water temperature, substrate, depth, turbidity, or ambient light. Juvenile native fishes were more common in areas near known spawning areas for these species, and it appears that the measured environmental variables had little effect on their use of backwaters.

Orchard, K.L. and J.C. Schmidt. 2000. A geomorphic assessment of the availability of potential humpback chub habitat in the Green River in Desolation and Gray Canyons, Utah. Report A in Flaming Gorge studies: reproduction and recruitment of Gila spp. and Colorado pikeminnow (Ptychocheilus lucius) in the middle Green River. Final report of Utah Division of Wildlife Resources to Upper Colorado River Endangered Fish Recovery Program, Lakewood, Colorado.

The size and number of low-velocity eddies that may be preferred habitat for the endangered humpback chub (Gila cypha) in the Green River in Desolation and Gray Canyons changes with discharge and has changed since the early 1900's. We determined the present extent and distribution of these habitats by mapping low-velocity eddies at a scale of 1:5000 at 5 or 6 discharges between 2,100 and $27,000 \mathrm{cfs}$ in four $8-\mathrm{km}$ reaches that are regularly sampled by the Utah Division of Wildlife Resources. We also mapped the surficial geology of these study reaches and the distribution of bed substrate that are emergent at 2,000 cfs. We analyzed the distribution of these areas within a geographic information system. The availability of habitat prior to completion of Flaming Gorge Dam was estimated by matching old oblique photographs, analyzing old aerial photos, and recomputing habitat availability prior to channel change. The total area of low-velocity eddies, when summed for the 4 study reaches, does not change with discharge, but the relative distribution of these eddies among the 4 study reaches does change. Also, the type of eddies changes with discharge. At low discharge, the greatest proportion of the total area of low-velocity eddies occurs as small shoreline eddies, but the greatest proportion occurs in a few large eddies at higher discharges. At low discharge, the river bank is highly 
contorted and is dominantly bare sand and gravel. At high discharge, the river bank has a simpler shape, and much of the shoreline is inundated vegetation.

The Green River channel is $19 \%$ narrower today than it was in the 1920's, and riparian vegetation has established itself at low elevations and on formerly active mid-channel islands. We estimate that the substrate of most nearshore habitats was sand or gravel prior to channel narrowing. For purposes of developing flow recommendations, our results must be integrated with the results of ecological studies which identify the relative importance of the different habitats in the life history of the target species.

Pimentel, R. and R.V. Bulkley. 1983. Concentrations of total dissolved solids preferred or avoided by endangered Colorado River fishes. Transactions of the American Fisheries Society 112(5):595-600.

Juveniles (age 0 -1) of three endangered River Colorado fishes were subjected to a gradient of total dissolved solids (TDS) to determine the concentrations that they preferred or avoided. Preferred and avoided TDS concentrations, respectively, for juveniles of each species were: Colorado squawfish Ptychocheilus lucius, 560-1, 1,150 mg/liter and greater than 4,400 mg/liter; humpback chub Gila cypha, 1,000-2,500 mg/liter and greater than 5,100 mg/liter; and bonytail Gila elegans, 4,100-4,700 mg/liter and less than $560 \mathrm{mg} /$ liter or greater than 6,600 $\mathrm{mg} /$ liter. Colorado squawfish and humpback clubs selected TDS concentrations that were similar to those in waters they now inhabit, but bonytail selected concentrations four times higher.

Seals, J.M., O.T. Gorman and S.C. Leon. 1994. Stream fish habitat studies in the Little Colorado River: a microhabitat approach. Proceedings of the Desert Fishes Council 25:1415.

The objective of USFWS research is to determine habitat use by the endangered humpback chub (Gila cypha) and other native fishes in the LCR. High conductivity, low visibility, extensive travertine structures, and prolonged periods of flooding prohibited conventional approaches to determining habitat use by fishes in the LCR. We developed an experimental passive sampling methodology that would allow us to determine microhabitat use by all adult and YOY fishes and to detect diurnal patterns of activity and habitat use. Our passive sampling was complemented with seining surveys, and when conditions permitted, observational surveys. Microhabitat use patterns determined from these other sampling methods corroborated the results of our passive sampling methodology. Our sampling methods have been used in studies of other tributaries in the Grand Canyon to evaluate their potential to support additional reproducing populations of humpback chub.

Thieme, M.L., C.C. Mivor, M.J. Brouder and T.L. Hoffnagle. 2001. Effects of pool formation and flash flooding on relative abundance of young-of-year flannelmouth suckers in the Paria River, Arizona.

Flannelmouth sucker, Catostomus latipinnis, a fish endemic to the Colorado River basin in the western United States, appears to experience poor recruitment to adult size in the Colorado River, downstream of Glen Canyon Dam. Lack or impermanence of rearing areas for YOY fish 
is hypothesized to be the problem. Knowing the importance of tributary mouths as rearing areas in other river systems, we studied use of the mouth of the Paria River, a tributary of the Colorado River, by YOY flannelmouth suckers, and the availability of rearing area in the mouth at different flow levels in the Colorado River in 1996 and 1997. We also examined the relationship between flash floods in the Paria River and catch-per-unit-effort (CPUE) of YOY in the Paria River between 1991 and 1996.

Maximum mean daily discharge in the Paria River was inversely correlated with CPUE of YOY flannelmouth suckers (Spearman rho $=-0.9856, p=0.0003$ ) during their critical rearing period (15 March-30 June). Thus, it appears that YOY flannelmouth suckers rear longer in the Paria River in years when flash flooding is minimal.

Recruitment of YOY flannelmouth suckers at the Paria River may also be improved by enhancing pool formation during spring and summer rearing seasons. YOY flannelmouth sucker was captured in a pool created by high Colorado River flows $\left(336 \mathrm{~m}^{3} / \mathrm{s}\right)$ that inundated the mouth of the Paria River during spring and summer, 1996. In 1997, high flows (about $550-750 \mathrm{~m}^{3} / \mathrm{s}$ ) in the Colorado River during winter and spring initially inundated the Paria River and formed a pool in the mouth. However, these high flows eventually caused $0.5-1.0 \mathrm{~m}$ of suspended sediment from the incoming Paria River to deposit in the mouth. Thus, despite higher flows than 1996, the slackwater area formed only occasionally in 1997. Differences in pool formation between 1996 and 1997 demonstrate that pool formation cannot be inferred solely from Colorado River flows.

Tyus, H.M. and C.A. Karp. 1989. Habitat use and streamflow needs of rare and endangered fishes, Yampa River, Colorado and Utah. U.S. Fish and Wildlife Service Biological Report 89:1-27.

In the Yampa River, stream habitat needs and life history requirements of Colorado squawfish (Ptychocheilus lucius), humpback chub (Gila cypha), razorback sucker (Xyrauchen texanus), and other native Colorado River fishes are presently maintained by flow regimens approximating natural conditions. Yampa River flows are also important in reducing adverse water management practices in the downstream Green River. Management for recovery of endangered fishes in the Yampa River will require specific flows to provide seasonal requirements at different locations: high spring flows associated with the initiation of Colorado squawfish spawning migrations, humpback chub and razorback sucker spawning, and maintenance of spawning bars and eddy habitats; descending summer flows associated with Colorado squawfish spawning, downstream transport of larvae, and creation of nursery habitat; stable winter flows to remove the threat of ice damage to shoreline areas used by many species. Acquisition of Yampa River water rights may be the decisive factor in conservation of endangered fish species in the Green River basin.

Valdez, R.A., P.B. Holden and T.B. Hardy. 1990. Habitat suitability index curves for humpback chub of the Upper Colorado River Basin. Rivers 1:31-42.

Habitat suitability index (SI) curves were developed for the endangered humpback chub (Gila cypha) using previously-collected microhabitat data from the Upper Colorado River Basin. 
Data selection, partitioning and pooling, as well as curve development were decided by consensus by a panel of species experts during two week-long workshops. The result was a total of 14 riverine SI curves associating four life stages (larvae, YOY, juvenile, and adult) with three microhabitat parameters (water depth, velocity, and substrate). The SI curves were developed to best fit actual field data, and modified by the experts according to biological judgment. The species experts classified these as "interim SI curves" and recommended application of only the adult curve set, recognizing that much information still needs to be gathered on the rare fishes of the upper basin. The process by which these SI curves were developed is recommended in dealing with large volumes of pre-existing microhabitat information scattered through many literature sources and reports. The concept of assimilating the data for evaluation by a panel of species experts was sound in that it allowed for a joint review by the experts without each investing large amounts of time to independently research the data. The idea of open workshops, in which experts and participants were given equal opportunity to express opinions, also worked well, although a third workshop was recommended to allow the experts to participate in generation of weighted usable area and evaluation of the streamflow to habitat relationships.

\section{Wick, E.J., J.A. Hawkins and T.P. Nesler. 1991. Occurrence of two endangered fishes in the Little Snake River, Colorado. Southwestern Naturalist 36:251-254.}

The Little Snake River (Colorado) delivers significant amounts of water and sediments to the Yampa River yet generally has been disregarded as a potential habitat for endangered fishes. Collection of humpback-like chubs of the Gila complex led to funding of studies to determine the extent of use of the lower Little Snake River by endangered and other native fishes. Two radiotagged Colorado squawfish were contacted by radiotelemetry in the Little Snake River. Sampling for adult fishes in the Little Snake River was initiated during spring runoff and continued into baseflow periods in July and October. Among the 308 adult and large juvenile fish collected were seven suspected humpback chub, two suspected hybrids of humpback chub $\mathrm{x}$ Colorado roundtail chub, and one Colorado squawfish. Numerically dominant species collected were Colorado roundtail chub (53\%), flannel-mouth sucker $(20 \%)$, common carp (11\%), and channel catfish $(9 \%)$. Species collected in small numbers $(<3 \%)$ included bluehead sucker, black bullhead, and white sucker. Collections with fine-mesh seine and dipnet yielded 1,260 young fish, of which $82 \%$ were flannel-mouth sucker and $17 \%$ were bluehead sucker. Other species collected in small numbers included sand shiner, speckled dace, and Colorado roundtail chub. The Little Snake River provided habitat for Colorado squawfish and humpback chub during the spring, when high discharge provided suitable habitat. It appeared that Colorado squawfish left the Little Snake River prior to spawning. Occurrence of suspected humpback chub in the canyon section of the Little Snake River also appears to be restricted to the spring runoff period. 


\subsection{STREAM FLOW}

\section{Muth, R.T., L.W. Crist, K.E. LaGory, J.W. Hayse, K.R. Bestgen, T.P. Ryan, J.K. Lyons and R.A. Valdez. 2000. Flow and temperature recommendations for endangered fishes in the Green River downstream of Flaming Gorge Dam. Final report to Upper Colorado River Endangered Fish Recovery Program, Lakewood, Colorado.}

The Green River system of the upper Colorado River basin in Utah and Colorado supports populations of three endangered fishes - humpback chub Gila cypha, Colorado pikeminnow Ptychocheilus lucius, and razorback sucker Xyrauchen texanus - and it historically supported the endangered bonytail Gila elegans. Bonytails are almost unknown in recent collections. Humpback chubs still reproduce and recruit in the Green River system, but their long-term viability in the system is uncertain. System-wide reductions in spatial and temporal components of habitat complexity, attributed to past and ongoing alterations in river flow and temperature, have been implicated as major factors contributing to the decline of all the endangered fishes.

Operation of Flaming Gorge Dam, which is located on the upper main-stem Green River, strongly influences downstream flow and temperature regimes and the ecology of riverine biota, including native fishes. The USFWS, in its 1992 Biological Opinion on Operation of Flaming Gorge Dam (Biological Opinion), concluded that continuation of historic operations at Flaming Gorge Dam was likely to further reduce the distribution and abundance of these federally protected species and thus jeopardize their continued existence. The Biological Opinion identified a reasonable and prudent alternative containing several related elements. These elements included (1) refine the operation of Flaming Gorge Dam so that flow and temperature regimes more closely approximate historic conditions; (2) conduct a 5-year research program ("Flaming Gorge Flow Recommendations Investigation") to include implementation of winter and spring "research flows" beginning in 1992, to allow for potential refinement of flows for those seasons; (3) determine the feasibility and effects of releasing warmer water during the late spring through summer period and investigate the feasibility of retrofitting river bypass tubes to include power generation capability, thereby facilitating higher spring releases; (4) legally protect Green River flows from Flaming Gorge Dam to Lake Powell; and (5) initiate discussions with the USFWS after conclusion of the Flaming Gorge Flow Recommendations Investigation to examine further refinement of flows and temperatures for the endangered fishes.

The Flaming Gorge Flow Recommendations Investigation, which began in 1992 but also included research conducted in 1990 and 1991 (while the Biological Opinion was being prepared), was conducted under the auspices of the Upper Colorado River Endangered Fish Recovery Program. The purpose of the investigation was to evaluate and refine the original flow and temperature recommendations given in the Biological Opinion as part of the reasonable and prudent alternative. Specifically, the Flaming Gorge Flow Recommendations Investigation was intended to determine the biological and physical responses of the Green River system to seasonal flow modifications, develop data for refinement of flow recommendations, and investigate the potential effects of increasing the temperature of water released from Flaming Gorge Dam. Specific objectives of the investigation were to (1) track reproduction of the endangered fishes and determine relationships among seasonal flows, water temperatures, and 
reproductive success; (2) evaluate recruitment of the endangered fishes from age- 0 to subsequent life-history stages and determine relationships among seasonal flows, water temperatures, and survival of young fish; (3) monitor the relative abundance and population structure of the endangered fishes in order to acquire information on interactions among fish species and how flows may differentially affect populations; and (4) determine how releases from Flaming Gorge Dam and flows from tributaries affect the formation and maintenance of important habitats for the endangered fishes throughout the Green River. To accomplish these objectives, a series of long-term studies was conducted to track changes in populations, reproductive success, and habitats. In addition, shorter-duration studies were conducted to examine specific hypotheses and flow relationships. This report summarizes and synthesizes the results of the Flaming Gorge Flow Recommendations Investigation as well as other relevant information to provide recommended flow and temperature regimes that would benefit the endangered fishes in the Green River.

Data gathered during the Flaming Gorge Flow Recommendations Investigation and other studies were used to develop descriptions of the basic life history, habitat use, and population status of the Colorado pikeminnow, razorback sucker, and humpback chub in the Green River system downstream of Flaming Gorge Dam. Reproduction and recruitment of humpback chubs occur in Desolation and Gray Canyons in Reach 3. A few humpback chubs occur in Whirlpool and Split Mountain Canyons of upper Reach 2, but the current abundance and life history of chubs in those areas are unknown. High spring flows prepare spawning habitats and provide the fish with cues for spawning, which occurs as runoff declines in late spring. Young fish inhabit low-velocity shorelines and backwater habitats as flow decreases during summer. Older juveniles inhabit deeper offshore eddies, often in association with boulders or other cover. Large eddies form at high flow and provide habitat in which humpback chubs spawn and feed on entrained allochthonous materials. Complex shoreline habitats used by larvae and juveniles are available at relatively low base flows during summer and autumn.

Information on each endangered fish species was used to develop integrated flow and temperature recommendations for the Green River downstream of Flaming Gorge Dam. The goal of the recommendations is to provide the annual and seasonal flow and temperature patterns in the Green River that would enhance populations of the endangered fishes. Six objectives were developed to achieve this goal: (1) provide appropriate conditions that allow gonadal maturation and environmental cues for spawning movements and reproduction; (2) form low-velocity habitats for pre-spawning staging and post-spawning feeding and resting areas; (3) inundate floodplains and other off-channel habitats at the appropriate time and for an adequate duration to provide warm, food-rich environments for fish growth and conditioning and to provide river floodplain connections for the restoration of natural ecosystem processes; (4) restore and maintain the channel complexity and dynamics needed for the formation and maintenance of high-quality spawning, nursery, and adult habitats; (5) provide base flows that promote favorable conditions in low-velocity habitats during summer, autumn, and winter; and (6) minimize differences in water temperature between the Green River and Yampa River in Echo Park to prevent temperature shock and possible mortality to larval Colorado pikeminnow transported from the Yampa River and into the Green River during summer. 
To achieve these objectives, Flaming Gorge Dam releases should provide a wide range of peak and base flows, and daily fluctuations in downstream reaches due to hydropower generation should be moderated. Providing greater inter-annual flow variability would maintain and restore important geomorphic and biological processes and improve the spatial and temporal habitat complexity in the system, which is required by the endangered fishes. Such inter-annual variability should be achieved by providing flows consistent with hydrologic conditions in the upper Green River basin in a given year. Flow recommendations were based on the following information or assumptions: (1) populations of the endangered fishes and habitats required by all life stages are concentrated in Reaches 2 and 3 of the Green River; (2) habitat for endangered fishes in Reach 1 is limited to Lodore Canyon because the summer water temperatures upstream are too cold; (3) providing suitable habitat conditions through flow and temperature management at Flaming Gorge Dam will enhance endangered fish populations in the Green River; (4) current hydrology of the upper Green River basin, including inflows to Flaming Gorge Reservoir and available release volumes from Flaming Gorge Dam, will remain largely unaltered; and (5) changes in flow, temperature, and sediment regimes in Green River tributaries (particularly the Yampa and White Rivers) will be consistent with known or pending biological opinions.

\section{Stanford, J.A. 1994. Instream flows to assist the recovery of endangered fishes of the Upper Colorado River basin: review and synthesis of ecological information, issues, methods and rationale. U.S. Fish and Wildlife Service, Denver, Colorado. FLBS Open File Report 130-93. Abstract excerpted from results and conclusions.}

The purpose of this study was to review the science pertaining to the issue of flow provision, to identify critical uncertainties and to provide recommendations for determining the instream flow needs of the endangered fishes. Studies to date strongly indicate that truncation of peak flows and higher fluctuating base flows (loss of seasonality) resulting from river regulation have altered complex biophysical processes (detailed herein) that form and maintain low velocity habitats required for survival of the various life history stages of the fishes. An ecological tradeoff apparently exists: very high flows are needed occasionally to produce habitats that the fish need to survive, but at the expense of reproductive success. Based on review of the ecological information and recognizing the problems in the methodological approaches that were used to derive flow recommendations, several key uncertainties appear to be critical to the goal of establishing flow regimes that will ultimately recover the endangered fishes:

- Flow seasonality and its correlates (e.g., temperature and physical habitat) may not be the factor(s) limiting recovery of the native fishes.

- Given the high societal value placed on tailwater trout fisheries, and the high priority placed on meeting entitlements under the Colorado compact and current water law (i.e., the "law of the river"), water volume in the Colorado and Green Rivers may be insufficient to produce flows required to recover the fishes.

- Channel and floodplain morphology in time and space is not a simple flow-area relationship, and complex interactions not yet fully understood may emerge that will compromise recovery of the fish. 
- What is the tradeoff between the propensity of endangered fish larvae to drift downstream and the need for high flows to maintain connectivity between the channel and backwaters and wetlands?

- Can food webs reestablish in key low velocity habitats (backwaters) to the extent needed to recover the fishes, given the windows permitted or needed for hydropower operations?

- Can the endangered fishes expand their range and productivity, given the downstream extension of cold water environments caused by regulation, and is the locality of the transition zone between cold and warm reaches likely to stay constant as deregulated flow regimes are implemented?

- Interactions with nonnative fishes may limit recovery of endangered fishes regardless of flow provisions.

- The report concludes with recommendations that couple management action (implementation of interim flow regimes) with additional study to resolve the uncertainties presented above. The suite of recommendations constitute an ecosystem approach to resolution of flows needed to protect and enhance the endangered fishes of the upper Colorado River basin. In essence, these recommendations constitute a new, holistic instream flow methodology.

- Implement interim flows that reestablish seasonality with spring peaks that approach the amplitude and frequency of preregulation events and summer and winter base flows with daily changes (not daily volume) limited to near preregulation conditions (likely no more than about $5 \%$ per day).

- Provide common understanding of water availability so that interim flows can be provided in relation to precipitation and legal flow abstraction in each sub-basin

- Improve the standardized monitoring program as a mechanism to evaluate the effectiveness of interim flows by adding a community ecology perspective.

- Diversify the research program to resolve critical uncertainties associated with interim flows.

- Implement a peer review process to insure that research and monitoring objectives are based on solid science and are responsive to the need to resolve uncertainties associated with the interim flows.

- Implement a management plan that can adaptively change the interim flows as new implications from monitoring and research are forthcoming.

The recommended methodology needs unambiguous endorsement to be successful. Success or failure will be judged by long-term trends in the populations of the endangered fishes. 
Tyus, H.M. and C.A. Karp. 1991. Habitat use and streamflow needs of rare and endangered fishes, Green River, Utah. U.S. Fish and Wildlife Service, Vernal, Utah.

In the Yampa River, stream habitat needs and life history requirements of Colorado squawfish (Ptychocheilus lucius), humpback chub (Gila cypha), razorback sucker (Xyrauchen texanus), and other native Colorado River fishes are presently maintained by flow regimens approximating natural conditions. Yampa River flows are also important in reducing adverse water management practices in the downstream Green River. Management for recovery of endangered fishes in the Yampa River will require specific flows to provide seasonal requirements at different locations: high spring flows associated with the initiation of Colorado squawfish spawning migrations, humpback chub and razorback sucker spawning, and maintenance of spawning bars and eddy habitats; descending summer flows associated with Colorado squawfish spawning, downstream transport of larvae, and creation of nursery habitat; stable winter flows to remove the threat of ice damage to shoreline areas used by many species. Acquisition of Yampa River water rights may be the decisive factor in conservation of endangered fish species in the Green River basin.

Valdez, R.A., T.L. Hoffnagle, C.D. McIvor, T. McKinney and W.C. Leibfried. 2001. Effects of a test flood on fishes of the Colorado River in Grand Canyon, Arizona. Ecological Applications 11:686-700.

A beach/habitat-building flow (i.e., test flood) of $1,274 \mathrm{~m}^{3} / \mathrm{s}$, released from Glen Canyon Dam down the Colorado River through Grand Canyon, had little effect on distribution, abundance, or movement of native fishes, and only short-term effects on densities of some nonnative species. Shoreline and backwater catch rates of native fishes, including juvenile humpback chub (Gila cypha), flannelmouth suckers (Catostomus latipinnis), and bluehead suckers (C. discobolus), and all ages of speckled dace (Rhinichthys osculus), were not significantly different before and after the flood. Annual spring spawning migrations of flannelmouth suckers into the Paria River and endangered humpback chub into the LCR took place during and after the flood, indicating no impediment to fish migrations. Pre-spawning adults staged in large slack water pools formed at the mouths of these tributaries during the flood. Net movement and habitat used by nine radio-tagged adult humpback chub during the flood were not significantly different from prior observations. Diet composition of adult humpback chub varied, but total biomass did not differ significantly before, during, and after the flood, indicating opportunistic feeding for a larger array of available food items displaced by the flood. Numbers of nonnative rainbow trout (Oncorhynchus mykiss) $<152 \mathrm{~mm}$ total length decreased by $-8 \%$ in electrofishing samples from the dam tailwaters $(0-25 \mathrm{~km}$ downstream of the dam) during the flood. Increased catch rates in the vicinity of the LCR (125 km downstream of the dam) and Hell's Hollow (314 km downstream of the dam) suggest that these young trout were displaced downstream by the flood, although displacement distance was unknown since some fish could have originated from local populations associated with intervening tributaries. Abundance, catch rate, body condition, and diet of adult rainbow trout in the dam tailwaters were not significantly affected by the flood, and the flood did not detrimentally affect spawning success; catch of YOY increased by $20 \%$ in summer following the flood. Post-flood catch rates of nonnative fathead minnows (Pimephales promelas) in shorelines and backwaters, and plains killifish (Fundulus zebrinus) in backwaters decreased in the vicinity of the LCR, and fathead 
minnows increased near Hell's Hollow, suggesting that the flood displaced this nonnative species. Densities of rainbow trout and fathead minnows recovered to pre-flood levels eight months after the flood by reinvasion from tributaries and reproduction in backwaters. We concluded that the flood was of insufficient magnitude to substantially reduce populations of nonnative fishes, but that similar managed floods can disadvantage alien predators and competitors and enhance survival of native fishes.

\section{Van Steeter, M.M. and J. Pitlick. 1998. Geomorphology and endangered fish habitats of the upper Colorado River, 1. Historic changes in streamflow, sediment load and channel morphology. Water Resources Research 34:287-302.}

The hydrologic, geomorphic, and ecologic effects of reservoir operations are thought to be key factors in the decline of native fishes in the upper Colorado River basin. The present paper examines the extent to which changes in streamflow and sediment loads have affected alluvial reaches of the Colorado River near Grand Junction, Colorado. The analysis shows that since 1950, annual peak discharges of the Colorado River and its major tributary, the Gunnison River, have decreased by $29-38 \%$. The total volume of runoff delivered to the study area has not changed significantly over the period of record, but the annual hydrograph has been modified greatly by reductions in peak flows and augmentation of base flows. Annual suspended sediment loads of the Colorado River and Gunnison River have likewise decreased. This was particularly apparent during the period from 1964 to 1978, when annual sediment loads were 40-65\% less than the long-term average. Analysis of aerial photographs indicates that between 1937 and 1993 the main channel of the Colorado River has narrowed by an average of $20 \mathrm{~m}$ and about $1 / 4$ of the area formed by side channels and backwaters has been lost.

\subsection{TEMPERATURE}

Gloss, S.P. and L.G. Coggins. 2005. Fishes of Grand Canyon. Pages 33-49 in Gloss, S.P., J.E. Lovich and T.S. Melis, eds., The state of the Colorado River ecosystem in Grand Canyon. A report of the Grand Canyon Monitoring and Research Center 1991-2004. USGS Circular 1282. U.S. Geological Survey, Flagstaff, Arizona.

Fishes of the Colorado River vary from coldwater trout species found in the river's mountainous headwaters to uniquely adapted desert river species found at lower elevations. Within the study area, the Colorado River corridor between Glen Canyon Dam and the western boundary of Grand Canyon National Park (hereafter Grand Canyon), the Colorado River was a seasonally warm and turbid river characterized by large seasonal variations in flow before it was altered by the closure of Glen Canyon Dam in 1963. Although water temperatures fluctuated between $32^{\circ} \mathrm{F}\left(0^{\circ} \mathrm{C}\right)$ during winter to a high approaching $86^{\circ} \mathrm{F}\left(30^{\circ} \mathrm{C}\right)$ during late summer, several warmwater native fish species successfully inhabited this stretch of the river. Because of the harsh environment created by dramatic seasonal fluctuations in the river's pre-dam flow and temperature, only 8 of the 32 species of native fish historically found in the Colorado River were common in the Grand Canyon reach of the river. Other native fishes within the study area were restricted to small tributary streams or occurred only in transient or seasonal numbers. Of the 
eight fish species that were originally common to the study area, only four species are known to persist today.

\section{Korman, J., M. Kaplinski and J. Buszowski. 2006. Effects of air and mainstem water temperatures, hydraulic isolation and fluctuating flows from Glen Canyon Dam on water temperatures in shoreline environments of the Colorado River in Grand Canyon. Final report to U.S. Geological Survey, Grand Canyon Monitoring and Research Center, Flagstaff, Arizona.}

Backwater and other shoreline environments are preferentially used by native juvenile fish for rearing. The objective of this study was to better determine the extent to which daily variation in flow from Glen Canyon Dam effects water temperature regimes in shoreline environments. Continuously recording temperature loggers were deployed at -3.5 mile (Glen Canyon), 44.6 mile (Eminence), and 64.5 mile (Salt Mines). Loggers were deployed along chains extending from the shoreline towards the thalweg, allowing us to record the gradient in temperatures between backwaters and the mainstem, and in mainstem shoreline environments. Temperature loggers were deployed in 3 habitat types: backwaters; low angle mainstem shorelines; and talus mainstem shoreline. Loggers were deployed in mid-August and retrieved in early-November, 2004.

Maximum warming in low angle shorelines was observed in August in Glen Canyon when the difference between mainstem water temperatures and air temperatures was greatest. Across the three habitat types, the extent of warming depended on the extent of isolation from the mainstem, with backwaters showing the greatest warming, low angle shorelines showing moderate warming, and virtually no warming seen in well mixed steep talus environments. Greater fluctuations in flow reduced the extent of warming in backwaters due to increased exchange with mainstem water. The extent of this effect was variable and depended on the timing of daily maximum and minimum flows and the topography of the backwater. With the exception of backwater temperatures at Eminence in September, shoreline temperatures were a maximum of $2-3^{\circ} \mathrm{C}$ (Celsius) warmer than the mainstem and typically these larger differences only occurred in the fluctuating zone. Vertical stratification in water temperature was observed in all backwaters. Stratification patterns were dynamic and varied over a $24 \mathrm{hr}$. period with changes in flow and air temperature. Surface waters in backwater and talus environments were a maximum of $3-7^{\circ} \mathrm{C}$ and $1^{\circ} \mathrm{C}$ warmer than bottom water, respectively.

\section{Marsh, P.C. 1985. Effect of incubation temperature on survival of embryos of native Colorado River fishes. Southwestern Naturalist 30:129-140.}

Razorback sucker (Xyrauchen texanus), bonytail (Gila elegans) and humpback ( $G$. cypha) chubs, and Colorado squawfish (Ptychocheilus lucius) comprise the endemic "big river" fish fauna of the Colorado River, western North America. All are near extirpated in the wild. Effects of incubation temperature upon embryo hatch success were experimentally examined to evaluate potential impacts of cold hypolimnetic reservoir releases upon species reproductive success. Eggs were spawned and fertilized at $18^{\circ} \mathrm{C}$, and embryos incubated at 5, 10, 15, 20, 25, and $30^{\circ} \mathrm{C}$. Total mortality of embryos of all species occurred in $12-96$ hours at 5,10 , and $30^{\circ} \mathrm{C}$; and in $48-60$ hours at $15^{\circ} \mathrm{C}$ for $P$. luscious only. Survival and percentage hatch were highest at 
15 and $20^{\circ} \mathrm{C}$ (G. elegans) or $20^{\circ} \mathrm{C}$ (all others). Hatched prolarvae were $0.2-1.3 \mathrm{~mm}$ TL longer at $20^{\circ} \mathrm{C}$ than at 15 or $25 \mathrm{C}$. Spinal or other anomalies were more frequent at 15 and $25^{\circ} \mathrm{C}$ than at $20^{\circ} \mathrm{C}$. Development rates (V) were similar for all species, $4.4-6.1\left(15^{\circ} \mathrm{C}\right), 8.4-9.9\left(20^{\circ} \mathrm{C}\right)$, and $12.4-18.8\left(25^{\circ} \mathrm{C}\right)$. Because of lower survival and higher incidence of anomalies at 15 and $25^{\circ} \mathrm{C}$, optimal temperatures for development and hatching are probably neat $20^{\circ} \mathrm{C}$. Reproduction may thus be limited in the wild by low water temperatures, although successful hatching is certainly not precluded. Other hypotheses to explain the demise of these fishes in thermally suitable portions of the Colorado River, such as predation among young, should be examined.

\subsection{FORAGING AND DIET}

\section{Clarkson, R.W. 1993. Foods of young-of-year native fishes in the Little Colorado River, Arizona, and infestation patterns by Asian fish tapeworm Bothriocephalus acheilognathi. Proceedings of the Desert Fishes Council 24:27.}

Foods and tapeworm infestation rates were examined from stomachs of larvae, early post-larvae, and juvenile speckled dace (Rhinichthys osculus), bluehead sucker (Pantosteus discobolus), and humpback chub (Gila cypha) from the LCR in 1990-1991. Chironomidae was an important food item for all three species, with the two cyprinids reducing their utilization of this component with age, and bluehead sucker increasing its use with age. Ostracods were used most often by larval and early-larval dace, and by juvenile chub. Vascular plant material was noteworthy in stomachs of younger dace and chub, while bluehead sucker frequently contained inorganic materials. Asian fish tapeworm suddenly appeared in chub stomachs in 1990. Three larvae, 11 early post-larvae, and 47 adult and sub-adult chub examined from 1989 did not contain tapeworms, while chub larvae collected from May-June $1990(\mathrm{~N}=24)$ exhibited a 91.7\% infestation rate, older 1990 YOY specimens $(\mathrm{N}=15)$ exhibited a 100\% infestation rate, and 44\% of 18 adults examined from 1990 were infested. In contrast, tapeworms did not appear in 1991 YOY chub stomachs until they exceeded $50 \mathrm{~mm}$ in length beginning in September. A low incidence in speckled dace was noted in 1991. Effects of the tapeworm on its hosts are well studied, but may include reduced growth, depressed swimming ability via elevated muscle fatigue, other debilitating effects, and elevated mortality.

\section{Leibfried, W.C. and R.A. Valdez. 1995. Food habits and electivity indices of the endangered humpback chub, Gila cypha form the Colorado River in Grand Canyon National Park. Proceedings of the Desert Fishes Council, Flagstaff, Arizona.}

The diets of humpback chub from the Colorado River in Grand Canyon National Park were analyzed from three locations along the river during 1991, 1992, and 1993. A total of 168 chub were pumped and variation between season and location determined for stomach contents both by volume and abundance. The amphipod, Gammarus lacustris, chironomids, simuliids, terrestrial invertebrates, and the green alga, Cladophora glomerata dominated stomach contents. Significant variation in invertebrate numbers and volume of gut contents occurred between locations sampled. Significant seasonal variation within locations was also determined for some food items. Chub stomachs sampled from locations away from the Little Colorado River (LCR) had significantly greater numbers and volumes of terrestrial and other forms of aquatic 
invertebrates. Electivity indices (Ivlev 1961) were calculated to compare food habits of humpback chub to food availability from instream drift. Chub above the LCR showed a more generalized feeding strategy than below the LCR which selected for Gammarus. Chub from the Middle Granite Gorge tended to select terrestrial and other aquatic invertebrates.

Robinson, A.T. 1993. Feeding behavior and ecology of young-of-the-year native fish in the Little Colorado River of the Grand Canyon. Proceedings of the Desert Fishes Council 24:39.

The feeding behavior and ecology of three YOY native fish species (Gila cypha, Rhinichthys osculus, Catostomus discobolus) was studied in the Little Colorado River of the Grand Canyon. Feeding behavior was recorded within four general habitat localities: bottom, plants, water column, and surface. A habitat variable, vertical positioning in the water column, was noted as individuals began new behaviors. Specimens of each species were collected and preserved, and their stomach contents were analyzed in the laboratory. Drift samples were collected and analyzed for invertebrate composition.

Foraging humpback chubs partitioned their habitat by feeding extensively off of the vegetation. Bluehead suckers on the other hand feed primarily on the bottom, and to a lesser extent on algae and aquatic macrophytes. Humpback chub and speckled dace YOY utilize the upper pelagic and surface zones preferentially to other vertical zones. Humpback chubs and speckled dace had diets that did not differ significantly from each other, however, both species differed from bluehead suckers. Humpback chubs had diets that were most similar in invertebrate composition to what occurred in the drift samples. The behavioral, spatial use, and diet differences may help to reduce any possible competition between species.

\section{Shannon, J.P., D.W. Blinn, G.A. Haden, E.P. Benenati and K.P. Wilson. 2001. Food web implications of $\sigma 13 \mathrm{C}$ and $\sigma 15 \mathrm{~N}$ variability over $370 \mathrm{~km}$ of the regulated Colorado River USA. Isotopes in Environmental and Health Studies 37(3):179-191.}

Dual stable isotope analysis in the regulated Colorado River through Grand Canyon National Park, USA, revealed a food web that varied spatially through this arid biome. Downriver enrichment of $\delta^{13} \mathrm{C}$ data was detected across three trophic levels resulting in shifted food webs. Humpback chub $\delta^{13} \mathrm{C}$ and $\delta^{15} \mathrm{~N}$ values from muscle plugs and fin clips did not differ significantly. Humpback chub and rainbow trout trophic position is positively correlated with standard length indicating an increase in piscivory by larger fishes. Recovery of the aquatic community from impoundment by Glen Canyon Dam and collecting refinements for stable isotope analysis within large rivers are discussed.

Stone, D.M. 2004. Differential detection of ingested items evacuated from genus Gila cyprinids by two nonlethal alimentary tract lavage techniques. Journal of Freshwater Ecology 19:559-565.

Two nonlethal alimentary tract lavage techniques were conducted on ten bonytail chub (Gila elegans, 211-241 mm TL) that had previously ingested 2-4 rainbow trout (Oncorhynchus mykiss, apprx $40 \mathrm{~mm}$ TL) to evaluate their capabilities of detecting piscivory in the field. Each fish was initially lavaged with water down its buccal cavity and out its anal vent using the 
Wasowicz and Valdez (W-V) technique and then immediately flushed in the opposite direction with the Baker and Fraser (B-F) method. Microscopic examination of evacuated material revealed only three identifiable rainbow trout scales and other assorted clumps of presumably well-digested body material. Overall, $30 \%$ of bonytail chub expelled rainbow trout scales and/or other body material during the initial W-V lavage, and $60 \%$ expelled material during the B-F flush. Dissections of four bonytail, seven humpback (G. cypha), and four roundtail chubs ( $G$. robusta) revealed that their intestines were similarly curved and tapered to 1toreq $50 \%$ of the anterior widths. Whereas the B-F method pushes ingested items backwards through the increasingly larger intestinal circumferences in these Gila fishes, it is more apt to retrieve greater quantities of food items. Food preference studies based on findings from a highly size-selective lavage technique will likely be biased in favor of smaller, less-digestible prey items, such as invertebrates with chitinous exoskeletons. Use of the B-F rather than W-V technique should lessen this bias.

Tyus, H.M. and W.L. Minckley. 1988. Migrating Mormon crickets, Anabrus simplex (Orthoptera: Tettigoniidae), as food for stream fishes. Great Basin Naturalist 48:25-30.

Migrating bands of Mormon crickets (Anabrus simplex ) were observed crossing the Green and Yampa rivers in Dinosaur National Monument, Colorado and Utah, in 1986 and 1987. Swimming cricket were swept downstream and eaten by four endemic and seven introduced fish species. Included were two endangered fishes, Colorado squawfish (Ptychocheilus lucius) and humpback chub (Gila cypha). Direct and indirect effects to aquatic food webs associated with application of pesticides for Mormon cricket control may pose a threat to these fishes and to man.

\subsection{SUPPORTING ARTICLES}

Bartley, D., M. Bagley, G. Gall and B. Bentley. 1992. Use of linkage disequilibrium data to estimate effective size of hatchery and natural fish populations. Conservation Biology 6:365-375.

A primary parameter in the assessment of the viability of a population is its effective population size $(\mathrm{Ne})$. Allozyme analysis of four groups of fishes provided data on linkage disequilibrium, which were then used to estimate Ne. The groups included hatchery samples of juvenile rainbow trout, Oncorhynchus mykiss, from Shasta hatchery, and juvenile Chinook salmon, O. tshawytscha, from Coleman National Fish hatchery. The fourth sample consisted of juvenile Chinook salmon from the threatened winter run in the upper Sacramento River. The groups of fish were chosen to represent different applications of the methodology to conservation of fishes. For a variety of reasons, Ne may considerably lower than census counts of fish present in the parental populations. The Ne of the hatchery broodstock that produced the sample of juvenile white seabass was estimated to be approximately 10, although 25 adult white seabass were present in a mass spawning tank. Ne estimates for the Shasta and Coleman Hatchery samples were 35.8 and 132.5, respectively. The actual number of fish spawned at the Shasta hatchery was approximately 40, where nearly 10,000 salmon spawned at the Coleman Hatchery. The threatened winter run of Chinook salmon had estimated $\mathrm{Ne}$ of 85.5 and approximate run size 
of 2000 salmon. The method estimating effective population size from linkage disequilibrium data appears to result in realistic estimates of effective population size when adequate sample size and sufficient number of polymorphic loci are available.

\section{Bestgen, K.R. 1996. Growth, survival and starvation resistance of Colorado squawfish larvae. Environmental Biology of Fishes 46:197-209.}

Growth and survival of Colorado squawfish, Ptychocheilus lucius, larvae under fluctuating 18,22 , and $26^{\circ} \mathrm{C}\left(5^{\circ} \mathrm{C}\right.$ diel fluctuations) and constant $18,22,26^{\circ} \mathrm{C}$, and $30^{\circ} \mathrm{C}$ temperature conditions and ration size corresponding to $12.5,28,64,142,320$ brine shrimp nauplii/fish/day was determined from laboratory experiments. Growth was optimal at $31^{\circ} \mathrm{C}$ and high at temperatures of $26^{\circ} \mathrm{C}$ to $30^{\circ} \mathrm{C}$, at the highest food abundance. Lowest growth was under lowest food rations and highest temperatures. Growth of Colorado squawfish larvae declined substantially at temperatures $<22^{\circ} \mathrm{C}$. Neither growth nor survival was significantly different between fluctuating or constant regimes. Survival of Colorado squawfish larvae was highest $(95 \%)$ at $26.2^{\circ} \mathrm{C}$ and 235 nauplii/fish/day and high at temperatures of 20 to $30^{\circ} \mathrm{C}$ with food abundance $>180$ nauplii/fish/day. Survival was lowest when food abundance was low and temperature was high. Highest mortality occurred more than 20 days after experiments began and mortalities occurred sooner in higher than lower temperatures. Colorado squawfish larvae denied food for 5, 10, or $15 \mathrm{~d}$ after first feeding could have begun ( $6 \mathrm{~d}$ ), had survival greater than $87 \%$ which was equivalent to continuously fed controls. Survival of fish denied food for $17.5 \mathrm{~d}$ after feeding could have begun declined from $84 \%$ before feeding to $57 \%$ after feeding. Point of no return was estimated between 17.5 and $20 \mathrm{~d}$. Colorado squawfish have relatively high starvation resistance. Low, stable flows that simulate natural hydrographs may enhance growth, survival, and recruitment of early life stages of Colorado squawfish by increasing water temperature and food abundance in regulated rivers of the Colorado River basin.

\section{Bestgen, K.R. 1997. Interacting effects of physical and biological processes on recruitment of Colorado squawfish. Doctoral Dissertation, Chapter 4. Colorado State University, Fort Collins.}

Recruitment is central to population ecology because the abundance of young individuals often drives dynamics of subsequent life stages. Recruitment variation of age- 0 Colorado squawfish Ptychocheilus lucius in the Green River, Colorado River basin, was related to physical and biological factors that were important at both intra-annual and annual time scales. Distributions of squawfish hatching dates derived from otolith increment analyses in 1991 and 1992 indicated that larvae in cohorts that hatched early survived poorly to fall. Growth rate comparisons suggested that the few early-hatched fish that survived were a fast-growing subset of the fish present in the same cohort in summer. I attributed this to a biological factor, sizeselective predation mortality by nonnative fishes. In contrast, larvae that hatched late grew relatively slowly but survived at higher rates due to environmental factors and to declines in abundance of predaceous red shiners Cyprinella lutrensis by mid-summer. An independent individual-based computer simulation model which had gape-limited red shiners as predators and Colorado squawfish larvae as prey produced similar size-selective survival patterns. Model simulations also showed that fish with moderate growth rates survive at twice the rate of fish with low-growth rates. Growth reductions caused by competition with non-native fishes or 
starvation would extend the time that Colorado squawfish were susceptible to predation but by themselves would not explain the size-selective patterns observed. Reduced growth rates of Colorado squawfish, which were temporally correlated with a stochastic physical factor, flooding from summer thunderstorms, may have combined with size-selective predation to cause very low recruitment in the lower Green River in 1992. Otherwise, recruitment was not correlated with discharge and temperature regimes in the summers of 1991 and 1992. Over a 17-year record, mean July-August discharge had no effect on annual abundance of Colorado squawfish juveniles in backwaters in the fall except at relatively high discharge. Low abundance of juvenile Colorado squawfish in 1991 and 1992 when size-selective patterns were evident suggested that predation may regulate recruitment in most years. Therefore, discharge management that emphasizes habitat enhancement should be supplemented with strategies to reduce effects of nonnative fishes.

\section{Bestgen, K.R., D.W. Beyers, J.A. Rice and G.B. Haines. 2006. Factors affecting recruitment of young Colorado pikeminnow: Synthesis of predation experiments, field studies and individual-based modeling. Transactions of the American Fisheries Society 135:1722-1742.}

Predation experiments, field studies, and individual-based models (IBM) simulations revealed that factors that affected the survival of early life stages of endangered Colorado pikeminnow Ptychocheilus lucius in the Green River basin, Utah and Colorado. Small-bodied, non-native red shiners Cyprinella lutrensis attacked Colorado pikeminnow larvae an average of once per minute, and predation success approached $30 \%$ in laboratory aquaria. Attack rate was also high in mesocosm experiments; turbidity and alternative prey reduced predation success. Distributions of hatching dates derived from otolith daily increment analysis showed that large cohorts of Colorado pikeminnow larvae that hatched in the Green River in early summer had low survival to autumn and that the few survivors were fast growing. Larvae hatched in midsummer or later had higher survival. Autumn juveniles grew 12-73 and faster than summer juveniles, which suggested differential mortality of slow-growing fish. The IBM simulations integrated size-dependent pikeminnow growth, Green River predator size-structure dynamics, seasonally variable Green River water temperatures, and turbidity and alternative prey availability effects; the simulations showed that red shiner predation interacting with environmental variables may significantly reduce age- 0 pikeminnow recruitment in autumn. Recruitment and growth patterns from simulations and field observations were consistent and suggested that the IBM is useful in evaluating management scenarios. Experiments, field studies, and predictive modeling provided consistent evidence that interacting effects of predation and environmental variables, including flow fluctuations, may structure intra-annual growth and recruitment patterns of age- 0 Colorado pikeminnow. Flow management to benefit growth and survival of young pikeminnow, particularly early hatching ones, and reduced nonnative predator abundance in Green River backwaters may enhance the Colorado pikeminnow populations. 
Bestgen, K.R. and J.M. Bundy. 1998. Environmental factors affect daily increment deposition and otolith growth in young Colorado squawfish. Transactions of the American Fisheries Society 127:105-117.

Otolith microstructure of endangered Colorado squawfish Ptychocheilus lucius was investigated to determine patterns of otolith growth and to validate daily deposition of increments. Sagittae and lapilli formed prior to hatching. After fish hatched, otolith increments were deposited daily whether larvae were reared at a constant $22^{\circ} \mathrm{C}$ temperature or subjected to fluctuating temperatures $\left( \pm 2.5^{\circ} \mathrm{C}\right.$ d) centered at 18,22 , or $26^{\circ} \mathrm{C}$. Otolith increments were clearer and counts of increments were more accurate for fish reared at fluctuating than at constant temperatures. Otolith growth was lower at $18^{\circ} \mathrm{C}$ than at 22 or $26^{\circ} \mathrm{C}$, but evidence of a direct effect of temperature on otolith growth was inconclusive. Lapillus diameters of slow-growing Colorado squawfish were larger than those of similar-sized but fast-growing fish, indicating that fish and otolith growth rates were not proportional. When larvae were starved, growth in body length generally ceased immediately but otolith growth continued for up to $15 \mathrm{~d}$. Otolith growth was reduced for up to $5 \mathrm{~d}$ after starved fish began to feed. Timing of starvation and reduced growth may not be accurately recorded by reduced otolith increment spacing. Low-contrast otolith increments in wild fish may indicate periods of low food abundance and starvation. Increased otolith growth early in life could reflect the start of exogenous feeding by Colorado squawfish larvae, a habitat shift to warmer water, or both. Otolith analysis will be useful for elucidating age, growth, and recruitment patterns of young Colorado squawfish.

Bestgen, K.R., R.T. Muth and M.A. Trammell. 1998. Downstream transport of Colorado squawfish larvae in the Green River drainage: temporal and spatial variation in abundance and relationships with juvenile recruitment. Final report of Colorado State University Larval Fish Laboratory to Upper Colorado River Endangered Fish Recovery Program, Lakewood, Colorado.

This study was initiated in 1990 and was part of the Five-Year Flaming Gorge Flow Recommendations Investigations, 1992-1996. It was designed to assess aspects of reproduction, recruitment, and status of Colorado squawfish in the Green and Yampa Rivers. Colorado squawfish reproduced in early to mid-summer in the Green River basin. Initiation of reproduction by Colorado squawfish each year was generally associated with increasing water temperature and diminishing spring runoff. Earlier spawning was associated with earlier occurrence of peak runoff and warmer water temperatures.

No single variable accurately predicted when Colorado squawfish first reproduce among sites or years. Water temperature at initiation of reproduction ranged from 16.0 to $22.3^{\circ} \mathrm{C}$ in the lower Yampa River and was 19.8 to $23.0^{\circ} \mathrm{C}$ in the lower Green River. In the lower Yampa River, Colorado squawfish generally initiated reproduction a few days prior to or within a few days after mean daily water temperature exceeded $18^{\circ} \mathrm{C}$. In contrast, Colorado squawfish in the lower Green River initiated reproduction after mean daily temperature exceeded $18^{\circ} \mathrm{C}$ for 13 to 39 days. Time of year and accumulated degree days were also reasonable predictors of initiation of reproduction by Colorado squawfish. Initiation of reproduction was not closely associated with days post-peak discharge. 
Abundance of larvae was generally higher in the Yampa River than in the lower Green River, and varied widely on diel, spatial, intra-annual and inter-annual scales. High transport abundance of larvae associated with increased turbidity, discharge, and darkness may be due to several factors including loss of orientation. High transport abundance under those conditions may also be a behavioral response to avoid sight-feeding predators. Increased transport abundance during turbidity events may have been caused by increased sediment deposition in interstitial spaces in the substrate, a stress which may have motivated larvae to emerge and drift. Differences in transport abundance of larvae across years and the patterns of abundance within a year may be due to several factors including timing of arrival, condition, and number of reproducing adults at the spawning areas.

Transport abundance appeared to be associated with discharge only during extreme years. High discharge was negatively associated with transport abundance in both the lower Yampa River and the lower Green River while low discharge was negatively associated with transport abundance only at the Yampa River station. Low abundance during either low or high discharge years could be a consequence of low abundance of adults and low production of larvae at spawning areas, high mortality of eggs or larvae at spawning areas or during downstream transport, sampling error, or other factors.

High intra-annual recruitment variation of juvenile Colorado squawfish in both the lower and middle Green River, 1990-1996 was not usually the result of inadequate numbers of larvae produced from spawning areas. Instead, high annual recruitment variation may be a consequence of factors that differentially affect growth and survival of early life stages. Colorado squawfish seem well-adapted to the fluctuating environmental conditions with which they have evolved. Thus, physical factors may regulate recruitment of age-0 Colorado squawfish only in relatively rare instances. Understanding the relative importance of mechanisms regulating recruitment of Colorado squawfish, including effects of discharge, habitat availability, and non-native fish predators, is critical to management and recovery of this species.

\section{Bestgen, K.R. and M.A. Williams. 1994. Effects of fluctuating and constant temperatures on early development and survival of Colorado squawfish. Transactions of the American Fisheries Society 123:574-579.}

A laboratory study was conducted to determine the effects of four constant temperatures $\left(18,22,26\right.$, and $30^{\circ} \mathrm{C}$ ) and three fluctuating temperatures (diel fluctuations of $\pm 2.5^{\circ} \mathrm{C}$ around 18 , 22, and $26^{\circ} \mathrm{C}$ ) on early development and survival of Colorado squawfish Ptychocheilus lucius, which is listed as an endangered species by the U.S. Department of the Interior. Average hatch in constant and fluctuating temperatures was $72 \%$ at $18^{\circ} \mathrm{C}, 67 \%$ at $22^{\circ} \mathrm{C}, 62 \%$ at $26^{\circ} \mathrm{C}$, and $38 \%$ (constant temperature only) at $30^{\circ} \mathrm{C}$. There was no significant difference in hatch between constant and fluctuating temperatures. Average survival of larvae to $7 \mathrm{~d}$ post-hatch in constant and fluctuating temperatures was $68 \%$ at $18^{\circ} \mathrm{C}, 64 \%$ at $22^{\circ} \mathrm{C}, 83 \%$ at $26^{\circ} \mathrm{C}$, and $13 \%$ (constant temperature only) at $30 \mathrm{oC}$. Survival of larvae at $30^{\circ} \mathrm{C}$ may have been confounded by a relatively low hatch of embryos and poor condition of larvae. Survival of larvae was $10-31 \%$ higher in fluctuating than in constant temperatures. Incidence of abnormalities was $2-22 \%$ at $18-26^{\circ} \mathrm{C}$ and $100 \%$ at $30^{\circ} \mathrm{C}$. Differences in abnormality rates were not detectable between constant and fluctuating temperatures. Times to start of hatch, swim bladder inflation, and exogenous feeding 
were shorter at higher temperatures. First feeding occurred about $31 \mathrm{~h}$ earlier in fluctuating temperatures than in constant temperatures. Differences in lengths of larvae at hatching and on day 7 post-hatch at the venous test temperatures were small and not considered ecologically significant. Tolerance of a relatively wide range of high-water temperatures by Colorado squawfish embryos and larvae may reflect the historically variable Colorado River environments in which the species evolved. Low summer water temperatures caused by mainstream dams have eliminated Colorado squawfish from portions of its historic range in the Colorado River basin. Water temperatures that more closely reflect historic regimes are necessary to restore selfsustaining populations of Colorado squawfish in those areas.

\section{Beyers, D.W., R.T. Muth and M.S. Farmer. 1994. Experimental evidence of competition between larvae of Colorado squawfish and fathead minnow. Final report of Colorado State University Larval Fish Laboratory to Upper Colorado River Endangered Fish Recovery Program, Lakewood, Colorado.}

Quantitative study of resource competition has been frustrated by an inability to separate effects of intraspecific and interspecific competition. Two types of experimental design are commonly used to study competition in two- species assemblages (1) replacement designs, and (2) additive designs. We used an experimental design and analysis that incorporated the positive attributes of replacement and additive designs to study resource competition between larvae of federally endangered Colorado squawfish, Ptychocheilus lucius, and a widely distributed nonnative species, the fathead minnow, Pimephales promelas. Effects of competition were inferred by feeding fish known quantities of zooplankton and comparing relative growth in single- and mixed-species assemblages. Effects of intraspecific exploitative competition were accounted for by using regression to describe the density-dependent relation between relative growth and feeding regime in single-species assemblages, and then subtracting these effects from the response of relative growth in mixed-species assemblages. Relative growth of Colorado squawfish and fathead minnow in single- and mixed-species assemblages was compared using a one-sample t-statistic, regression analysis, and an index of competitive ability. Conclusions of statistical analyses were confirmed by study of diet overlap.

The response of each species to competition was consistent with that predicted by ecological theory: relative growth of both fishes was reduced by competition (i.e., -/-). Negative competitive effects were asymmetrical, and quantitatively greater and more frequent for Colorado squawfish than for fathead minnow. Study of diet overlap confirmed conclusions of relative growth analysis. Diet overlap was reduced in the lowest feeding regime where resource competition was intense. Paradoxically, at higher feeding regimes diet overlap increased although analysis of relative growth suggested competition occurred at those feeding regimes as well. The insensitivity of diet overlap at higher feeding regimes may have been due to a lack of alternative prey, or may suggest that the response variable, relative growth, integrated effects of two qualitatively different competitive mechanisms without reflecting a change because intensity of competition remained relatively constant. These results emphasize the need for more detailed ecological investigations of interactions between early life stages of Colorado squawfish and potential non-native competitors. In addition, this study demonstrated that under experimental conditions, effects of intra- and interspecific competition can be separated and the outcome of exploitative resource competition can be determined. 
Bulkley, R.V. and R. Pimental. 1983. Temperature preference and avoidance by adult razorback suckers. Transactions of the American Fisheries Society 112:601-607.

Final thermal preferendum for the razorback sucker Xyrauchen texanus, a rare endemic species of the Colorado River basin, was estimated to lie between 22.9 and $24.8^{\circ} \mathrm{C}$ based on electronic-shuttlebox studies. Estimates of upper and lower avoidance temperature ranged from 27.4 to $31.6^{\circ} \mathrm{C}$ and from 8.0 to $14.7^{\circ} \mathrm{C}$, respectively. Lower, but not upper, avoidance temperature was positively correlated with acclimation temperature. Results indicated that new water-control structures on the upper Colorado River drainage should be designed to provide summer water temperatures between 22 and $25^{\circ} \mathrm{C}$ if preservation of habitat for this species is a consideration.

Chao, A. 1989. Estimating population size for sparse data in capture-recapture experiments. Biometrics 45:427-438.

Estimators of population size under two commonly used models (the time-variation model and the heterogeneity model) for sparse capture-recapture data are proposed. A real data set of Illinois mud turtle (Kinosternon flavescens spooneri) is used to illustrate the methods and to compare them with other estimators. A simulation study was carried out to show the performance and robustness of the proposed estimators.

Collins, K.P. and D.K. Shiozawa. 1996. The effects of fish predation on backwater invertebrate communities of the Green River, Utah (Ouray National Wildlife Refuge reach). Final report of Brigham Young University Department of Zoology to Upper Colorado River Endangered Fish Recovery Program, Lakewood, Colorado.

The potential role of fish predation on the structure of invertebrate communities in backwater habitats of the Green River, a large river in eastern Utah, was examined by placing a series of complete, partial, and no fish exclosures in backwater habitats and sampling benthic and planktonic communities periodically through the summer. The taxa showing the greatest direct treatment effects were the chironomid genus Tanypus, the Corixidae, and the planktonic adult copepod. The benthic densities of the naupliar and copepodite stages of copepods showed a negative response to fish exclusion, probably the result of increased levels of Corixidae and Tanypus, which are known to prey on benthic organisms. This study indicates that backwater fishes may impact food resources, although invertebrate predation may act in a compensatory manner on certain invertebrate species. This suggests that Colorado squawfish Ptychocheilus lucius may undergo resource competition during their post-larval stage. More research is necessary to determine if this is the case. 
Day, K.S., K.D. Christopherson and C. Crosby. 1999. An assessment of young-of-year Colorado pikeminnow Ptychocheilus lucius use of backwater habitats in the Green River, Utah. Report B in Flaming Gorge Studies: Assessment of Colorado pikeminnow nursery habitat in the Green River. Final report to Upper Colorado River Endangered Fish Recovery Program. Utah Division of Wildlife Resources, Salt Lake City, Utah.

Colorado pikeminnow nursery habitat characteristics and selection focusing fall sampling for YOY recruitment in backwater habitats were studied in a $16.1 \mathrm{~km}$ study reach at Ouray National Wildlife Refuge, Utah, from 1990 to 1996 using Interagency Standardized Monitoring Program (ISMP). The information generated by this study was used for development of a model to predict Colorado pikeminnow use of backwaters based on physical parameters, relationships between spring flows, and nursery habitat formation. This report was generated from the Recovery Implementation Program Scope-of-Work number FG-33. The specific task of this project was to study the Green River within the boundaries of Ouray National Wildlife Refuge to: 1) determine the relationship between quantity of nursery habitats available in the summer period to the number of YOY Colorado pikeminnow present in nursery habitats during the autumn period; 2) describe the relationship between nursery habitat availability and fish habitat selection; and 3) compare intensive sampling and standardized monitoring to assess ways of refining standardized monitoring and ways to make greater use of available data.

A total of 1,043 backwaters and low velocity habitats were sampled three times each year from August 1990 through September 1996 for the presence of endangered fishes. Each backwater sampled was first categorized by physical type; which was determined by its method of formation or current condition. To avoid disturbing the fish, all physical measurements were made after fish communities were sampled with a $3 \mathrm{~mm}$ mesh seine. Several statistical analyses were conducted to help interpret significant relationships. Linear regression was performed on four flow parameters peak flow, date of peak flow, flow and duration against backwater numbers, volume and area. Contingency table and $X^{2}$ analysis were preformed to test preference for use of habitat classes. The Wilcoxon rank-sum tested the significant differences $(p<0.05)$ of habitat variables between occupied and unoccupied backwaters. Discriminant function analysis was also used to determine if Colorado pikeminnow use of nursery habitats could be predicted by a model of habitat characteristics. Models were developed for each season of each year, for each season for all years, for each year and for all seasons and years pooled. Correlation analysis on catch-per-unit-effort (CPUE) data for all species to show correlation between species CPUE. No consistent trend was found between native and non-native species.

Findings of this study show that Colorado pikeminnow use large, deep backwaters with high turbidity, and backwaters used by Colorado pikeminnow in the spring were larger and deeper than those used in the summer and fall. Water temperature did not have as much influence on Colorado pikeminnow use of backwaters as expected. Temperature differentials between backwaters and main channel were significant only in the spring. Backwater area and volume available at Ouray NWR was negatively related to peak flows in the preceding spring for all seasons, and no relationship existed between numbers of backwaters available and spring flows. The catch-per-unit-effort of Colorado pikeminnow was positively correlated with bluehead sucker catch, and was not related to spring flows. This was true for most other species captured. 
We recommend that periodic high spring flows are needed to rebuild the river channel and re-establish secondary channel backwaters used by Colorado pikeminnow. This rebuilding event should be followed with several years of variable flow aimed at maintaining channel diversity and secondary channel backwaters. Determination of flow events and timing should be based on geologic and hydrologic studies, concurrently being completed. There are two possible modification that should be considered for ISMP YOY sampling. These include a measure of turbidity and dropping the minimum depth restriction to $0.20-0.25 \mathrm{~m}$. Although not fully addressed here, it is recommended that the final Green River flow regime take into account other species of native fish that show different responses to spring flows and habitats. Variability of the Green River flow regime is likely the best scenario for adequate management of the entire system. Considerable information concerning backwater use by the remaining Green River fish community is still available in this data set, and personnel, time and funding should be dedicated to continue analyses.

\section{Filbert, R.B. and C.P. Hawkins. 1995. Variation in condition of rainbow trout in relation to food, temperature and individual length in the Green River, Utah. Transactions of the American Fisheries Society 124:824-835.}

We examined how condition (weight at length) of rainbow trout Oncorhynchus mykiss varied in relation to availability of drifting invertebrates and temperature at two locations over four seasons in the Green River, Utah. Food availability (daytime drift density) varied more than 17-fold across sites and seasons, and rainbow trout experienced an $11^{\circ} \mathrm{C}$ range in mean monthly temperature. Both rainbow trout gut fullness and condition increased as joint, nonlinear functions of increasing food availability and increasing temperature. Variation in condition decreased with fish size, although condition of intermediate sized fish was most strongly related to variation in food and temperature. Observed relationships between rainbow trout condition, drift abundance, and temperature were qualitatively consistent with bioenergetic models that predict fish growth should vary as a joint function of food and temperature. However, the inferred temperature optima for rainbow trout seemed to be significantly higher than predicted. Our results support a growing body of evidence that stream trout may be frequently food-limited in nature.

Freeman, M.C., Z.H. Bowen, K.D. Bove and E.R. Irwin. 2001. Flow and habitat effects on juvenile fish abundance in natural and altered flow regimes. Ecological Applications 11(1):179-190.

Conserving biological resources native to large river systems increasingly depends on how flow-regulated segments of these rivers are managed. Improving management will require a better understanding of linkages between river biota and temporal variability of flow and instream habitat. However, few studies have quantified responses of native fish populations to multiyear ( $>2 \mathrm{yr}$ ) patterns of hydrologic or habitat variability in flow-regulated systems. To provide these data, we quantified YOY fish abundance during four years in relation to hydrologic and habitat variability in two segments of the Tallapoosa River in the southeastern United States. One segment had an unregulated flow regime, whereas the other was flowregulated by a peak-load generating hydropower dam. We sampled fishes annually and explored how continuously recorded flow data and physical habitat simulation models (PHABSIM) for 
spring (April-June) and summer (July- August) preceding each sample explained fish abundances. Patterns of YOY abundance in relation to habitat availability (median area) and habitat persistence (longest period with habitat area continuously above the long-term median area) differed between unregulated and flow-regulated sites. At the unregulated site, YOY abundances were most frequently correlated with availability of shallow-slow habitat in summer (10 species) and persistence of shallow-slow and shallow-fast habitat in spring (nine species). Additionally, abundances were negatively correlated with 1-h maximum flow in summer (five species). At the flow-regulated site, YOY abundances were more frequently correlated with persistence of shallow-water habitats (four species in spring; six species in summer) than with habitat availability or magnitude of flow extremes. The associations of YOY with habitat persistence at the flow-regulated site corresponded to the effects of flow regulation on habitat patterns. Flow regulation reduced median flows during spring and summer, which resulted in median availability of shallow-water habitats comparable to the unregulated site. However, habitat persistence was severely reduced by flow fluctuations resulting from pulsed water releases for peak-load power generation. Habitat persistence, comparable to levels in the unregulated site, only occurred during summer when low rainfall or other factors occasionally curtailed power generation. As a consequence, summer-spawning species numerically dominated the fish assemblage at the flow-regulated site; five of six spring-spawning species occurring at both study sites were significantly less abundant at the flow-regulated site. Persistence of native fishes in flow-regulated systems depends, in part, on the seasonal occurrence of stable habitat conditions that facilitate reproduction and YOY survival.

\section{Gido, K.B., D.L. Propst and M.C. Molles. 1997. Spatial and temporal variation of fish communities in secondary channels of the San Juan River, New Mexico and Utah. Environmental Biology of Fishes 49:417-434.}

Spatial and temporal variation of fish communities in four secondary channels of the San Juan River between Shiprock, NM and Bluff, UT were investigated from July 1993 through November 1994. Fish abundance and habitat availability data were collected to determine if physical attributes of sites influenced spatial and temporal variation in their fish communities. Stability of habitat was shown to positively influence the stability of the fish community. Analysis of variance revealed greater spatial than temporal variation in the abundance of red shiner, Cyprinella lutrensis, fathead minnow, Pimephales promelas, and flannelmouth sucker Catostomus latipinnis, while speckled dace, Rhinichthys osculus showed greater temporal variation. Ordination, using detrended correspondence analysis, revealed variation in fish communities by site, date, and sample year. Spatial variation was greatest during low-flow periods when the greatest differences in habitat among the four sites occurred. Spring runoff had the greatest temporal effect on the fish communities in secondary channels and appeared to ${ }^{i}$ reset ${ }^{3}$ the communities by displacing those species that were less resistant to increased current velocities. This annual event may help maintain native fish species adapted to these conditions in the San Juan River while moderating the abundance of nonnative fish species. 
Haines, G.B., D.W. Beyers and T. Modde. 1998. Estimation of winter survival, movement and dispersal of young Colorado squawfish in the Green River, Utah. Final report of U.S. Fish and Wildlife Service, Vernal, Utah, to Upper Colorado River Endangered Fish Recovery Program, Lakewood, Colorado.

Population estimates for age-0 and age-1 Colorado squawfish in two 32-km reaches of the Green River were made using capture-recapture procedures. Comparisons of autumn and spring population estimates were used to assess overwinter survival and evaluate factors that affect it. Previous research using traditional methodology has demonstrated that estimates obtained using catch per unit effort (CPUE) are unreliable for assessing overwinter survival. Capture-recapture provides a more rigorous basis for estimating abundance of young Colorado squawfish because it can account for variable capture probabilities.

Objectives of this study were to employ capture-recapture methods to (1) compare estimates of abundance from capture-recapture and CPUE methods; (2) estimate overwinter survival of age-0 Colorado squawfish; (3) estimate seining catchability coefficients for autumn and spring sampling; (4) determine extent of downstream movement of marked Colorado squawfish between 1 November and 1 April; and (5) determine the effect of timing and magnitude of spring flows on dispersal of age-1 Colorado squawfish.

We found little evidence that abundance estimates from CPUE accurately reflect the number of young Colorado squawfish in study reaches in the Green River. There was only a weak correlation $(R=0.30, P=0.47)$ between estimates of abundance from CPUE and capturerecapture. On several occasions, CPUE estimates had precision that was comparable to that achieved with capture-recapture, but the estimates differed by as much as $217 \%$. Inaccuracy and greater variability of CPUE was attributed to effects of water temperature on capture probability. Evidence suggests that young Colorado squawfish are less likely to be caught when water temperatures are cool, regardless of their abundance.

Overwinter survival probabilities of age- 0 fish ranged from 0.06 to 0.62 . Three of four estimates were similar and ranged from 0.56 to 0.62 . Low overwinter survival (0.06) during 1995-1996 may have been due to small size of age-0 fish in autumn or relatively high winter discharge.

Recaptures of marked age- 0 and age-1 Colorado squawfish showed that they moved less than $16 \mathrm{~km}$ downstream during sampling periods that ranged from 2 to 21 days Similarly, age- 0 fish that were marked in autumn and recaptured the following spring moved less than $16 \mathrm{~km}$ downstream after being at large for 170 to $200 \mathrm{~d}$. The role of spring flooding in redistribution of age-1 Colorado squawfish remains unclear because few fish were captured during post-runoff surveys conducted in July and August. 


\section{Haines, G.B. and H.M. Tyus. 1990. Fish associations and environmental variables in age-0 Colorado squawfish habitats, Green River, Utah. Journal of Freshwater Ecology 5:427- 436.}

Colorado squawfish (Ptychocheilus lucius), the largest North American minnow, was once abundant and widely distributed. It now exists in less than about $20 \%$ of its historic range, and is classified as an endangered species. The species associations of age- 0 Colorado squawfish were evaluated in the Green River, Utah, from their hatching through the first growing season, and the influence of several variables (i.e. backwater area, depth, and temperature; peak spring and summer discharge) on the relative abundance and distribution of the more common fishes was determined. Drifting larval fish ( $<30 \mathrm{~mm}$ total length (TL) were sampled in the Yampa River and Green River on dates corresponding to larval emergence and downstream drift of Colorado squawfish. The age-0 squawfish were sympatric with seven native and fifteen introduced fishes in the Green River. Larval squawfish was the most abundant fish captured in summer drift (38\%) which included suckers, Catostomus spp. (33\%), speckled dace, Rhinichthys osculus (14\%), and channel catfish, Ictalurus punctatus (3\%). However, ephemeral shoreline embayments used by Colorado squawfish as nursery habitats were dominated by introduced fishes, including red shiner, Notropis lutrensis (87\%) in summer, and red shiner (65\%) and fathead minnow, Pimephales promelas (16\%) in autumn. Abundance of most fishes was highest in years of lower, more historic summer flow. Most fishes in backwaters inhabited a wide range of environmental conditions, but were most abundant in habitats deeper than $15 \mathrm{~cm}$. No segregation in habitat use was detected between young Colorado squawfish and non-native fishes. Hydrologic conditions in the regulated Green River presumably favor the establishment and proliferation of fish invaders from more mesic environments.

\section{Hedrick, P.W., D. Hedgecock and S. Hamelberg. 1995. Effective population size in winter- run chinook salmon. Conservation Biology 9:615-624.}

Winter-run chinook salmon from the Sacramento River, California is federally listed as endangered. Since 1989 there has been a program to augment the natural population by capturing adults, artificially spawning them, raising the young, and releasing the smolt. Here we estimate the effective population size of these captive-raised fish, the natural run, and the combination of both groups over the three-year period from 1991 to 1993 . We find that the most appropriate estimate of the effective population size of the captive-raised progeny is a variance estimate of effective population size standardized so that the number of released smolts returning to spawn was the same as the number of spawners used to produce the smolts originally. We have generated 10,000 random samples to simulate returns from these released progeny. The estimates of the effective population sizes in 1991, 1992, and 1993 were only 7.02, 19.07, and 7.74, respectively. We then determined limits on the effective population size of the natural run based on 0.1 and 0.333 of the run-size estimates. Using estimates of the captive proportion of the run, the minimum estimates of the effective population size of the overall run for the three years were 21.9, 127.3, and 39.0, and the maximum estimates were 61.6, 401.0, and 108.7. It does not appear that the hatchery program has reduced the overall effective population size. The run sizes in each year are extremely low, however, and it is possible that fish will be lost from this run in one of the years in the immediate future, making reestablishment of a healthy run even more difficult. 


\section{Houde, E.D. 1987. Fish early life dynamics and recruitment variability. American Fisheries Society Symposium 2:17-29.}

Tenfold or greater fluctuations in fish recruitment can be precipitated by relatively small variation in mortality rates, growth rates, or stage durations in the early life of fishes. An analysis of dynamics for 5 species in the egg, yolk-sac larva, larva, and juvenile stages, based on field, laboratory, and enclosure data from the literature, demonstrated that growth rate variability and its effect on stage durations can be a major factor affecting recruitment level. Recruitments of anchovy-like species, with high larval growth and mortality rates, and relatively large size at metamorphosis, are probably regulated in the larval stage. Cod-like or herring-like species with slow larval growth, low larval mortality, and relatively small size at metamorphosis could be regulated during the juvenile stage, although control in the larval stage seems more likely. A stage-specific analysis of growth rate variability in early life, which may be more reliable than survey estimation of mortality rates, can provide important insight into fluctuating recruitment levels.

Irving, D. and T. Modde. 2000. Home-range fidelity and use of historical habitat by adult Colorado squawfish (Ptychocheilus lucius) in the White River, Colorado and Utah. Western North American Naturalist 60:16-25.

Twelve wild adult Colorado pikeminnow (Ptychocheilus lucius), captured in the tailwaters of Taylor Draw Dam on the White River, Colorado, were implanted with radio transmitters and their movement patterns monitored from 1992 to 1994. The spawning migration of these fish was extensive. In 1993, the only full year of the study, the fish migrated an average of $658 \mathrm{~km}$ from the White River to spawning sites in the Yampa or Green rivers and back to the White River. Eight of these fish were translocated in the river upstream of the dam in April 1993. These fish and the 4 others below the dam remained in the river until May 1993. All 12 had migrated down the White River to spawning sites in the Green and Yampa rivers by July 1993. The fish that were located above the dam successfully passed over the dam during their downstream migration. Seven fish migrated upstream toward the Yampa River Canyon spawning site and 5 migrated downstream toward the Green River Desolation/Gray Canyon spawning site. Five of 7 Yampa River fish were found at the spawning site. The other 2 were found 5-8 km downstream of the site. One of 5 Green River fish was found at the spawning site, the other 4 between 16 and $62 \mathrm{~km}$ upstream of the site. All fish migrated back to the White River by August 1993 and were found near the dam by October 1993. Two fish were recaptured and translocated above the dam in September 1993. Five fish were located below the dam and 2 above the dam in April 1994. By July 1994 seven of the same fish that had migrated toward the Yampa River in 1993 were found at the Yampa Canyon spawning site. At the same time, 3 of 5 fish that migrated toward the Green River in 1993 were found at the Desolation/Gray Canyon spawning site. This included 2 fish that had been found upstream of the site in 1993.

The 12 fish traveled an average of $6 \mathrm{~km} / \mathrm{d}$ (range: $4-10 \mathrm{~km} / \mathrm{d}$ ) during the migration period from May through October 1993. Generally, fish moved faster to the spawning site than back from the site to the White River. 
These fish moved very little within their home ranges in the White River. Six fish tagged in 1992 moved only $0.1-2.3 \mathrm{~km}$ in the tailwater reach below Taylor Draw Dam from September 1992 through April 1993. All fish, after their spawning runs, had moved up to or near the dam by October 1993. These fish were not tracked again until April 1994. Their movement patterns in April 1994 were similar to those observed in April 1993. The greatest amount of fish movement in the White River was displayed by the 8 fish placed above Taylor Draw Dam in April 1993 and the 2 placed in Kenney Reservoir in September 1993. They moved 1.1-40.6 km in the river before and after their spawning migration in spring and autumn 1993.

These spawning migrations suggest that adult Colorado pikeminnow in the White River were recruited from both Green and Yampa river spawning populations and were presumably imprinted to these respective spawning sites. Those fish placed above Taylor Draw Dam established home ranges in habitats previously occupied by Colorado pikeminnow before the dam was completed. They remained there until they migrated downstream during the spawning period. Although we did not study fish passage, our study demonstrates that adult Colorado pikeminnow will use habitat if access is provided. Translocation of wild adult fish into historic but unoccupied habitats may be a valuable recovery option.

Mabey, L.W. and D.K. Shiozawa. 1993. Planktonic and benthic microcrustaceans from floodplain and river habitats of the Ouray Refuge on the Green River, Utah. Department of Zoology, Brigham Young University, Provo, Utah.

This study compares microcrustacean densities and species occurrence of benthic and planktonic copepods and cladocerans in backwater, river channel, and floodplain habitats of the Green River, Utah. Samples were taken during the summer of 1991. Samples were taken using a $1.27-\mathrm{cm}$ diameter benthic core sampler and vertical plankton tows with a 63 -micron plankton net. In all, 28 species were collected. The copepods are represented by six species of cyclopoids, six species of calanoids, and two species of harpacticoids. Fourteen species of cladocerans were collected. The highest densities were found in the floodplain. Benthic densities ranged from $4,896-23,059 / \mathrm{m}^{2}$ in backwater habitats, $948-6,138 / \mathrm{m} 2$ in river habitats, and $85,812-262,808 / \mathrm{m}^{2}$ in floodplain habitats. Plankton densities ranged from $1,450-63,353 / \mathrm{m}^{3}$ in backwaters, $317-$ $1,312 / \mathrm{m}^{3}$ in the river, and $205,923-690,187 / \mathrm{m}^{3}$ in the floodplain. A comparison of the first sample periods for the floodplain (June), the Ouray backwater (July), and river sites (July) indicate that the density of the benthos was 41 times greater in the floodplain than in the other habitats, and the plankton density in the floodplain was 29 times greater than the backwater and 157 times greater than the river.

McKinney, T. and D.W. Speas. 2001. Observations of size-related asymmetries in diet and energy intake of rainbow trout in a regulated river. Environmental Biology of Fishes 61(4):435-444.

We examined diet and diel energy intake of rainbow trout, Oncorhynchus mykiss, of different lengths captured by electrofishing between 1991 and 1997 in the Lee's Ferry tailwater, Colorado River, below Glen Canyon Dam, Arizona. Trout diets reflected a depauperate food base and indicated limited potential of different fish size-groups to partition food resources. As evidenced by relative stomach volumes of ingested matter, mid-sized and large trout tended to 
consume more algae than did small fish, suggesting that they consumed diets of lower nutritional quality. An energy intake model indicated that median consumers among mid-sized and large fish generally failed annually to surpass estimated maintenance energy requirements and that median consumers among mid-sized trout failed to meet or exceed maintenance requirements during all seasons. In contrast, median consumers among small trout met or surpassed maintenance energy requirements during most years and in summer. Results support a hypothesis that larger rainbow trout in lotic systems are food-limited more often than smaller fish.

Meffe, G.K. and W.L. Minckley. 1987. Persistence and stability of fish and invertebrate assemblages in a repeatedly disturbed Sonoran Desert stream. American Midland Naturalist. 117:177-191.

Persistence, a measure of presence or absence of species, and stability, an estimate of assemblage equilibrium measured as constancy in species ranks or densities, should both be considered when assessing temporal change in natural assemblages. We measured persistence and stability in two distinct animal assemblages frequently disturbed by natural and severe flooding events, the fishes and benthic invertebrates in a Sonoran Desert stream. A persistence index (derived from colonization/extinction analyses) indicates high persistence of fishes for several decades, while benthic invertebrates were persistent except in periods of severe flooding. Stability of taxon rankings (measured by Kendall's W) was high for both assemblages, even though absolute population sizes fluctuated. Fish populations resisted even the most severe flood disturbances, whereas benthic invertebrates were decimated by particular frequent and intensive flooding. The latter were resilient, however, and quickly recovered due to life history characters favoring rapid post-flood recolonization. Although absolute numbers of organisms varied through orders of magnitude, more general aspects of assemblage structure (species' presence or absence, and relative rankings) remained relatively constant despite repeated and potentially devastating natural perturbations.

\section{Mills, L.S. and F.W. Allendorf. 1996. The one-migrant-per-generation rule in} conservation and management. Conservation Biology 10:1509-1518.

In the face of continuing habitat fragmentation and isolation, the optimal level of connectivity between populations has become a central issue in conservation biology. A common rule of thumb holds that one migrant per generation into a subpopulation is sufficient to minimize the loss of polymorphism and heterozygosity within subpopulations while allowing for divergence in allele frequencies among subpopulations. The one-migrant-per-generation rule is based on numerous simplifying assumptions that may not hold in natural populations. We examine the conceptual and theoretical basis of the rule and consider both genetic and nongenetic factors that influence the desired level of connectivity among subpopulations. We conclude that one migrant per generation is a desirable minimum, but it may inadequate for many natural populations. We suggest that a minimum of 1 and a maximum of 10 migrants per generation would be an appropriate general rule for genetic purposes, bearing in mind that factors other than genetics may further influence the ideal level of connectivity. 
Muth, R.T. and D. E. Snyder. 1995. Diets of young Colorado squawfish and other small fish in backwaters of the Green River, Colorado and Utah. Great Basin Naturalist 55:95104.

We compared diet of YOY Colorado squawfish (Ptychocheilus lucius), an endangered cyprinid, with diets of other fish $<75 \mathrm{~mm}$ total length (TL) collected from backwaters of the Green River between river kilometers 555 and 35 during summer and autumn 1987. Species included native Rhinichthys osculus, Catostomus discobolus, and C. latipinnis, and nonnative Cyprinella lutrensis, Notropis stramineus, Pimephales promelas, Ictalurus punctatus, and Lepomis cyanellus. For each species, diet varied with size and between upper and lower river reaches but not between seasons for fish of similar size. Larval chironomids and ceratopogonids were principal foods of most fishes. Copepods and cladocerans were important in diets of $P$. lucius $<21 \mathrm{~mm}$ TL and L. cyanellus $<31 \mathrm{~mm}$ TL. Catostomus discobolus was the only species that ate moderate amounts of algae. Fish (all larvae) were in digestive tracts of only 10 P. lucius (21-73 mm TL), about 1\% of P. lucius analyzed. High diet overlap occurred between some sizereach groups of $P$. lucius and $C$. lutrensis, $R$. osculus, $C$. latipinnis, $L$. punctatus, and $L$. cyanellus. Potential for food competition between YOY P. lucius and other fishes in backwaters appeared greatest with the very abundant $C$. lutrensis.

Muth, R.T. and E.J. Wick. 1997. Field studies on larval razorback suckers in Canyonlands National Park and Glen Canyon National Recreation Area, 1993-1995. Final report of Colorado State University Larval Fish Laboratory to U.S. National Park Service, Rocky Mountain Region, Denver, Colorado.

Field studies on larval razorback suckers (Xyrauchen texanus) were conducted during spring-summer 1993-1995 in reaches of the lower Green River (from Millard Canyon, RK 53.9, downstream to Holeman Canyon, RK 45.1) or middle Colorado River (from the Gooseneck area, RK 58.4, downstream to Lathrop Canyon, RK 37.6) within or bordering Canyonlands National Park and in the lower $47 \mathrm{~km}$ of the Colorado River inflow to Lake Powell within Glen Canyon National Recreation Area. Studies and key findings included:

1. Fish collections using floating quatrefoil light traps and seines in quiet-water flooded or backwater habitats (1993-1995).

- Nonnative minnows (e.g., red shiner Cyprinella lutrensis, sand shiner Notropis stramineus, and fathead minnow Pimephales promelas) dominated all fish collections (76-99\% of total catch from each sampling area over all sampling periods). Native fishes collected included larval razorback suckers (185 total - 122, 47, and 1 from the lower Green River in 1993, 1994, and 1995, respectively; 15 from the Colorado River inflow to Lake Powell in 1993), and larval or early juvenile Colorado squawfish Ptychocheilus lucius (12 larvae and 133 juveniles total - 12 larvae and 6 juveniles in 1993 and 5 juveniles in 1994 from the Colorado River inflow to Lake Powell in 1993; 1, 36, and 82 juveniles from the lower Green River in 1993, 1994, and 1995, respectively; 3 juveniles from the middle Colorado River in 1994). Of all razorback suckers collected, 168 were captured by light traps and 17 (from the lower Green River) by seines. Colorado squawfish larvae were caught in light traps and juveniles were caught in seines. 
- The collection of razorback sucker larvae from the lower Green River suggests localized spawning.

- Collections of razorback sucker and Colorado squawfish larvae from the Colorado River inflow to Lake Powell in 1993 suggest that flowing, lotic conditions throughout the inflow are necessary to transport larvae produced in upstream river reaches into inflow nursery habitats. Larval suckers were efficiently and accurately identified alive in the field, but procedures for successfully transporting wild razorback sucker larvae caught in remote areas (e.g., lower Green River) to rearing facilities require further development.

2. Description of the diet of adult nonnative red shiners captured from the lower Green and middle Colorado rivers (1994).

- Digestive tracts of 22 adult red shiners (5\% of those examined) contained cypriniform fish larvae, most were catostomids. Insects, including parts, chironomid larvae, simuliid pupae, and corixids, were the principal identifiable food items. Adult red shiners may be an important predator on native fishes in the Colorado River basin, especially in habitats with low invertebrate forage during spring and early summer.

3. Initial evaluation of a method to partially block access of adult red shiners into portions of important nursery habitats for larval razorback suckers in the lower Green River using net exclosures (1995).

- Netting effectively blocked access of adult red shiners into exclosed portions of nursery habitats while allowing passage of sucker larvae; results suggest that this method of nonnative fish control could be adapted for broader-scale use.

4. Field marking of sucker larvae using techniques developed in the laboratory for incorporating fluorescent chemicals into otoliths (1995).

- Laboratory techniques for marking otoliths in larval razorback suckers were successfully applied to sucker larvae in the field. Otolith aging of wild-caught razorback sucker larvae can be used to determine growth rates and exact time of spawning, data which can then be used to document environmental parameters associated with spawning and nursery habitats and evaluate factors influencing growth and survival of larvae.

\section{Papoulias, D. and W.L. Minckley. 1992. Effects of food availability on survival and growth of larval razorback suckers in ponds. Transactions of the American Fisheries Society 121:340-355.}

The reasons for consistent failure of razorback sucker Xyrauchen texanus year-classes in Lake Mohave, Arizona-Nevada, are not entirely understood. To date, egg and larval predation by nonnative fishes is considered the most likely explanation, but food limitation may influence larval mortality. Our experiments in rearing razorback sucker larvae in ponds fertilized at three levels ("high," "medium," and "low") with mean invertebrate densities of 43.3, 23.7, and 12.5 
organisms/L, respectively, did not result in significant differences in larval survival $(77.0,89.8$, and $67.4 \%$, respectively). However, total larval growth was greater at the two higher invertebrate densities. Biovolume of food but not numbers of food organisms in guts increased linearly with growth of larvae. Numbers and biovolumes of food items did not differ relative to fertilization treatment. First foods of larval razorback suckers were diatoms, detritus, and algae, Soon thereafter, small rotifers and chironomids were taken, and larger organisms, primarily cladocerans, were selected by larger larvae. Year-class failure of razorback sucker in Lake Mohave may be attributable to nutritional deficiency at the lowest recorded densities of reservoir zooplankton. However, starvation or food-related problems do not seem likely at the higher Lake Mohave zooplankton densities, which are at least as great as the invertebrate densities in our low-fertilization treatment ponds.

Rakowski, C.L. and J.C. Schmidt. 1999. The geomorphic basis of Colorado pikeminnow nursery habitat in the Green River near Ouray, Utah. Report A in Flaming Gorge Studies: Assessment of Colorado pikeminnow nursery habitat in the Green River. Final report to Upper Colorado River Endangered Fish Recovery Program. Utah Division of Wildlife Resources, Salt Lake City, Utah.

Nursery habitat availability is considered a bottleneck to successful recruitment of Colorado pikeminnow (Ptychocheilus lucius). Detailed geomorphic studies were conducted in a $1.5-\mathrm{km}$ reach to examine channel response to flows and the geomorphic setting of nursery habitats during a 2-year period. Videography was used to extend relationships in the $1.5-\mathrm{km}$ reach to a longer $10-\mathrm{km}$ reach.

Nursery habitat availability varied yearly with little persistence in location or geomorphic setting of individual habitats for the 2 years of this study. A small number of habitats provided most of the area of high-quality (i.e., deep) habitat, and most of the total area of habitat was formed by three geomorphic classes. Although the 1993 flood reduced the area of available habitat, area of deep habitat increased. The 1994 low-peak flood increased the area of habitat, but most habitats were shallow.

The 1993 and 1994 multi-peaked habitat availability curves for the 1.5-km-reach bankattached bar were the result of the superposition of curves from habitats in each geomorphic classification, and showed that the discharge that maximized habitat availability changed yearly. A complexity index was evaluated for the $10-\mathrm{km}$ reach as a surrogate for habitat availability. Total base-flow habitat availability was significantly correlated to the complexity index, but deep habitat availability was not.

Measured channel topography was used as input to a flow and sediment transport model. Simulated hydrograph runs produced greater bank-attached bar aggradation and thalweg scour than steady flows, although some unrealistic patterns of scour occurred.

New flow recommendations must include occasional high flows sufficient to rebuild channel topography. Flaming Gorge Dam releases should be used to augment the Yampa River flood peak, but not increase low flood-peak duration. The conceptual model for habitat availability developed here may be used to target the formation and availability of habitats. Base 
flow recommendations designed to maximize habitat availability should be evaluated annually. Winter flows should be reevaluated for their negative effects on habitat.

Schmidt, J.C. and J. Brim Box. 2004. Application of a dynamic model to assess controls on age-0 Colorado pikeminnow distribution in the middle Green River, Colorado and Utah. Annals of the Association of American Geographers, Vol. 94 (3):458-476.

Analysis of field data and development and application of a dynamic model indicate that the processes that control the number and distribution of age- 0 Colorado pikeminnow in the middle Green River are poorly understood. Colorado pikeminnow are a federally endangered species endemic to the Colorado River basin that utilize backwaters during their larval stage. The present agency-mandated field sampling program for backwater habitats may be inadequate because it takes place at a time when the model predicts that most larval fish have drifted beyond the study area. The model predicts that water releases from Flaming Gorge Dam have a large potential effect on larval drift, because high releases at the time of drift greatly increase the proportion of the population transported beyond the study area to unfavorable river environments. Development of the model shows that the role of the geomorphic and hydraulic attributes that control larval drift and transport into backwaters, and that were parameterized in the model, are not well known. Resolution of these uncertainties by field study and experimentation would lead to refining this river management tool.

\section{Schmidt, J.C., K.L. Orchard and S.P. Holman. 1996. Spatial and temporal patterns of habitat availability in Desolation and Gray Canyons. 1995 Annual report and 1996 field progress report, Department of Geography and Earth Resources, Utah State University. Logan.}

Available shoreline habitat along the Green River in Desolation and Gray Canyons is strongly influenced by geology and discharge although the relationship between the three has not been readily apparent. To better associate the two, we established four geomorphic study reaches within the canyons. Within each reach, a series of cross sections was measured at different discharges. Surficial geology of the river corridor was mapped, and historic oblique photos were matched to establish the geomorphic organization of the canyon and assess changes that have occurred over the past century. Maps were also made of the distribution of eddies, low-velocity zones, and the distribution of shoreline habitat. These maps were repeated at several discharges including base flow and bank full discharge.

Preliminary results show that low-velocity zones occur predominantly in the lee of obstructions caused by debris fans. Debris fans in Desolation Canyon are predominantly expansive and of low gradient. Only the small portion of the fan that is active delivers sediment that restricts flow and causes rapids and eddies, while the main fan is so large that it acts more as a meander bend as the river flows around the fan. As discharge increases the total area of eddies increases, however, at bankfull discharge many of the relatively small active portions of the fans are overtopped, and eddy frequency decreases. Although very large debris fans dominate the river corridor, fine-grained alluvium is the most abundant bank material at low discharge, and vegetated fine-grained alluvium dominates at higher flows. 
Schultz. A.A., O.E. Maughan, S.A. Bonar and W.J. Matter. 2003. Effects of flooding on abundance of native and nonnative fishes downstream from a small impoundment. North American Journal of Fisheries Management 23:503-511.

Flooding can benefit native fishes in southwestern streams by disproportionately displacing nonnative fishes. We examined how the presence of an upstream impoundment affected this relationship in lower Sonoita Creek, Arizona. Nonnative species not found in the reservoir decreased in abundance in lower Sonoita Creek after flooding. The catch and relative abundance of some nonnative species found in both the reservoir and the creek increased in lower Sonoita Creek after flooding. Movement of nonnative fishes out of the reservoir via the spillway during periods of high water probably contributes to the persistence and abundance of these species downstream. Both preventing nonnative fishes from escaping reservoirs and the release of flushing flows would aid conservation of native southwestern fishes downstream.

\section{Shaffer, M.L. 1981. Minimum population sizes for species conservation. Bioscience 31:131-134.}

In this paper, the author proposes tentative criteria for successful preservation at the population level, discusses the various methods available for determining the population sizes and their area requirements to meet these criteria, and relates both to overall conservation strategy.

Trammell, M. A. and T. E. Chart. 1999. Colorado pikeminnow young-of-year habitat use, Green River, Utah, 1992-1996. Report C in Flaming Gorge Studies: Assessment of Colorado pikeminnow nursery habitat in the Green River. Utah Division of Wildlife Resources, Final report to Upper Colorado River Endangered Fish Recovery Program, Lakewood, Colorado.

This nursery habitat study was conducted from 1992 to 1996 under the auspices of the Recovery Implementation Program, to further define Colorado pikeminnow use of habitat. The relationships between peak and sampling flows, habitat availability, temperature, Colorado pikeminnow catch and growth rates, and density of sympatric non-native cyprinids were examined. The objectives of this study included: 1) determine the relationship between availability, formation, and maintenance of Colorado pikeminnow nursery habitat and test release flows from Flaming Gorge Dam; 2) describe the relationship between nursery habitat types available to and selected by Colorado pikeminnow; 3) describe the relationship between degree-day accumulation in main channel and nursery habitat areas, 4) determine the relationship between degree-day accumulation in all potential nursery habitat areas and those utilized by young Colorado pikeminnow; 5) determine the relationship between the quantity of nursery habitats available in the summer period to the number of young Colorado pikeminnow present in nursery habitats during the autumn period; 6) determine the usefulness of video imagery as a predictor of year class strength of Colorado pikeminnow; 7) refine the interpretation of video so that "quality" nursery habitats can be distinguished; and 8) compare intensive sampling data and the concept of habitat utilization to standardized monitoring data to assess a) ways of refining standardized monitoring procedures and $b$ ) ways of making greater use of the data currently being collected. 
Colorado pikeminnow prefer backwater habitats that are formed behind large sandbars from scour channels, and are larger, deeper and more persistent than other habitats. Non-native cyprinids also preferred this habitat. All types of habitat including quality habitat increased in quantity during low water years, and decreased in high water years. There were slight decreases associated with higher sampling flows. Non-native cyprinids were positively associated with increased habitat availability, while Colorado pikeminnow were negatively associated. Total degree day accumulation was higher in low water years, which in turn was positively correlated with high growth rates for pikeminnow, and with high overwinter survival rates. The density of non-native cyprinids was negatively correlated with Colorado pikeminnow catch rates. Colorado pikeminnow are limited more by the presence of non-native cyprinids than by habitat availability in the lower Green River. We recommend managing the river system for a variety of flow scenarios to emulate the natural hydrograph. The standardized monitoring program sampling protocol is sufficiently representative of Colorado pikeminnow annual trends. We recommend no changes.

\section{Tyus, H.M. 1991. Movements and habitat use of young Colorado squawfish in the Green River, Utah. Journal of Freshwater Ecology 6:43-51.}

Habitat use and movements of young Colorado squawfish Ptychocheilus lucius were determined by seining 1,194 of the fish in shoreline areas. A total of 922 of these was fin-clipped in selected habitats and 230 (25\%) were subsequently recaptured. Most young Colorado squawfish were captured in shallow shoreline embayments (backwaters; $85 \%$ of captures), where they were most abundant in spring (April; 68\%). Some individuals used more than one habitat and moved between backwaters, shoreline eddies, and main-channel runs. A diel pattern of backwater use was associated with warmer water temperatures, especially in spring (April) when backwater temperature exceeded river temperatures.

\section{Tyus, H.M. and G.B. Haines. 1991. Distribution, habitat use and growth of age-0 Colorado squawfish in the Green River basin, Colorado and Utah. Transactions of the American Fisheries Society 120:79-89.}

Age-0 Colorado squawfish Ptychocheilus lucius $(\mathrm{N}=11,379)$ were captured as larvae and post-larvae in drift nets and seines in the Green and Yampa rivers from 1979 to 1988. Larvae were captured in drift nets $(\mathrm{N}=601)$ for 2-6 weeks in June and July. Small post-larvae $(\mathrm{N}=3,079)$ were captured by seining shoreline habitats in July and August. In September and October, postlarvae were most abundant $(\mathrm{N}=6,459)$ in low-gradient reaches of the Green River. Catch data indicated that the post-larvae moved from the Yampa and Green river spawning areas and were concentrated about $150 \mathrm{~km}$ downstream by autumn of each year. Spring sampling indicated that young fish $(\mathrm{N}=1,240)$ overwintered in areas occupied the previous autumn. Post-larvae captured in the Green River ( $\mathrm{N}=5,043)$ most frequently occupied shoreline embayments (backwaters) that were relatively warm (mean, $17.0^{\circ} \mathrm{C}$ ), deep (mean, $38 \mathrm{~cm}$ ), large (mean, $826 \mathrm{~m}^{2}$ ), and turbid. Abundance and size of young Colorado squawfish in the Green River were inversely correlated with high summer and autumn flows, which inundated nursery habitats. Seine catches of young squawfish in 4 years of sampling the upper and lower Green River in autumn and the following spring were not reliable in assessing overwintering mortality of age- 0 Colorado squawfish, 
presumably due to differences in capture vulnerability between seasons. Survival of small fish in spring indicated their tolerance of prevailing winter conditions.

Tyus, H.M. and C.W. McAda. 1984. Migration, movements and habitat preferences of Colorado squawfish, Ptychocheilus lucius, in the Green, White and Yampa Rivers, Colorado and Utah. Southwestern Naturalist 29:289-299.

A total of 31 Colorado squawfish, Ptychocheilus lucius, endemic were collected from the Green River in 1980 and the Green, White, and Yampa rivers in 1981. the fish were surgically implanted with radiotransmitter modules and their movement monitored for up to five months each year. Two movement patterns were linked to fish maturity: mature fish were highly mobile; immature fish were sedentary. A spawning migration of up to $205 \mathrm{~km}$ one-way was documented in 1981. Fish migrated upstream and downstream to reach a common spawning ground in the lower Yampa River canyon. Diel studies indicated no diel rhythm in movement existed until after spawning, when the fish were more active from 0800-1200 h. Colorado squawfish were monitored primarily in shoreline habitat over sand substrates. There were significant differences recorded for water depths and velocities selected by Colorado squawfish between Green, White, and Yampa rivers, but no difference occurred between 1980 and 1981 values in the Green River.

Walters, C. and J. Korman. 1999. Linking recruitment to trophic factors: revisiting the Beverton-Holt recruitment model from a life history and multispecies perspective. Reviews in Fish Biology and Fisheries 9(2):187-202.

The Beverton-Holt recruitment model can be derived from arguments about evolution of life history traits related to foraging and predation risk, along with spatially localized and temporarily competitive relationships in the habitats where juvenile fish forage and face predation risk while foraging. This derivation explicitly represents two key biotic factors, food supply $(I)$ and predator abundance $(R)$, which appear as a risk ratio $(R / I)$ that facilitates modeling of changes in trophic circumstances and analysis of historical data. The same general recruitment relationship is expected whether the juvenile life history is simple or involves a complex sequence of stanzas; in the complex case, the Beverton-Holt parameters represent weighted averages or integrals of risk ratios over the stanzas. The relationship should also apply in settings where there is complex, mesoscale variation in habitat and predation risk, provided that animals sense this variation and move about so as to achieve similar survival at all mesoscale rearing sites. The model predicts that changes in food and predation risk can be amplified violently in settings where juvenile survival rate is low, producing large changes in recruitment rates over time.

\section{Ward, D.L. and S.A. Bonar. 2003. Effects of cold water on susceptibility of age-0 flannelmouth sucker predation by rainbow trout. Southwestern Naturalist 48:43-46.}

We conducted laboratory tests to evaluate the effects of an abrupt $10^{\circ} \mathrm{C}$ decrease in water temperature on ability of age-0 flannelmouth suckers (Catostomus latipinnis) to escape predation by rainbow trout (Oncorhynchus mykiss). Juvenile flannelmouth suckers (58 $\mathrm{mm}$ mean total length) were maintained at $20^{\circ} \mathrm{C}$ and introduced individually, without acclimation, into tanks containing a single adult rainbow trout ( $246 \mathrm{~mm}$ mean total length) at 10 or $20^{\circ} \mathrm{C}$. Rainbow trout 
attacked suckers more often at $20^{\circ} \mathrm{C}$, but were more likely to capture them at $10^{\circ} \mathrm{C}$. Age- 0 flannelmouth suckers experience an abrupt temperature decrease when they exit warm tributaries and enter cold hypolimnetic water released from Glen Canyon Dam on the Colorado River. This temperature change might increase susceptibility of young flannelmouth suckers to predation by rainbow trout, which are abundant in the Colorado River in Glen, Marble, and Grand canyons.

Williams, J.E., D.B. Bowman, J.E. Brooks, A.A. Echelle, R.J. Edwards, D.A. Hendrickson and J.J. Landye. 1985. Endangered aquatic ecosystems in North American deserts, with a list of vanishing fishes of the region. Journal of the Arizona-Nevada Academy of Sciences.

Habitat degradation and the introduction of exotic species are endangering an increasing number of fishes and other aquatic organisms in the desert areas of North America. We identify 164 fishes from North American deserts as endangered, vulnerable, rare, or of intermediate status. Forty-six of these are herein considered endangered. Additionally, 18 recently extinct fishes are recorded from the region. Fifteen ecosystems are identified as providing habitat for 83 of these vanishing fishes. These highly significant aquatic ecosystems, with locations given parenthetically, are: Cuatro Cienegas (Coahuila), Gila River (New Mexico, Arizona, and Sonora), Rio Grande (New Mexico, Texas, Chihuahua, Coahuila, Nuevo Leon, and Tamaulipas), Pecos River (New Mexico and Texas), Railroad Valley (Nevada), Colorado River (Colorado, Utah, New Mexico, Arizona, Nevada, California, Baja California del Norte, and Sonora) Green River (Wyoming, Colorado, and Utah), Paharanagat Valley (Nevada), Parras Valley (Coahuila) La Media Luna (San Luis Potosi), Ash Meadows (Nevada), Upper White River (Nevada), Moapa River (Nevada), Rio Yaqui (Arizona, Chihuahua, and Sonora), and Upper Klamath Basin (Oregon and California). A discussion of these ecosystems and their vanishing fishes, amphibians, reptiles, and invertebrates are provided. Protection of remaining natural habitats and communities within these areas provide the best opportunity for long-term survival of the constituent rare organism.

\section{Wolz, E.R. and D.K. Shiozawa. 1995. Soft sediment benthic macroinvertebrate communities of the Green River at the Ouray National Wildlife Refuge, Uintah County, Utah. Great Basin Naturalist 55:213-224.}

Benthic macroinvertebrates from four habitat types (river channel, ephemeral side channel, river backwater, and seasonally inundated wetland) were examined from the Green River at the Ouray National Wildlife Refuge, Uintah County, UT, June-August 1991. Four major taxa (Nematoda, Oligochaeta, Diptera, Ceratopogonidae, and Chironomidae) were quantified. Cluster analysis of densities showed that habitat types with comparable flow conditions were the most similar. Highest to lowest overall benthic invertebrate densities of the four habitats were as follows: ephemeral side channel, river backwater, seasonally inundated wetland, and river channel. Nematodes were the most abundant taxon in all habitat types and sample dates except the August sample of the river channel and river backwater and the July sample of the seasonally inundated wetland. 


\section{IMPACTS OF DAM OPERATIONS}

\subsection{EFFECTS ON FLOW}

\section{Chart, T.E. and L.D. Lentsch. 1999. Flow effects on humpback chub (Gila cypha) in Westwater Canyon. Final report of Utah Division of Wildlife Resources to Upper Colorado River Endangered Fish Recovery Program, Lakewood, Colorado.}

This five-year study to determine the effect of Colorado River flows on humpback chub (Gila cypha) reproduction and recruitment is a component of the Recovery Implementation Program (RIP) Aspinall Studies. The goal of this project was to develop relationships between observed flows and humpback chub life history responses, concentrating on the earlier life stages. To meet this goal, the following study objectives were identified: determine spawning and nursery requirements, describe the relationship between geomorphic processes of sediment transport and nursery habitat formation, identify and describe reproductive isolating mechanisms, and assess recruitment. Similar research is being conducted on the Green River in Desolation Canyon as part of the Flaming Gorge Studies. Three components of the Westwater Canyon fish community were studied: the YOY, juveniles (AGE1+ and 2+) and late juvenile/adults. Both humpback chub (Gila cypha) and roundtail chub (G. robusta) are common in Westwater Canyon. Unlike some Upper Basin chub populations, the adults of these two Gila spp. are morphologically distinct in Westwater Canyon. However, young chubs are difficult to identify to species wherever more than one of these species is found. YOY sampling was therefore broken into sub-reaches: above Westwater Canyon (where only roundtail chubs are common), within Westwater Canyon (roundtail and humpback are equally represented in the adult fish community) and below the canyon (where roundtail chubs are present in low numbers and humpback chub are absent). YOY were sampled with seines. Juvenile chubs were monitored with shoreline electrofishing in the canyon, and late juvenile and adults were sampled with hoop and trammel nets as well as with electrofishing. The design of the study focused on YOY densities (fish $/ \mathrm{m} 2$ of seined habitat) and habitat use to establish relationships with observed flows. Juvenile chubs (still not readily identified to species) were monitored in the canyon to take the flow/reproduction relationship to the next step. Only three of the five cohorts produced during this study (1992, 1993, and 1994) could be tracked past their first summer (age 0); the 1995 cohort was virtually non-existent and further monitoring of the 1996 cohort was beyond the scope of this study. Late juvenile and adult chubs were monitored to determine population trend and stability in light of the recent recruitment. Pre-project data were incorporated into these analyses. Hatching time and growth of young Gila spp. were correlated with flow parameters (peak flow at State Line gage and pre-peak flow in excess of $6000 \mathrm{cfs}$ (a cumulative flow metric similar to degree days)) and water temperature (degree days $>10^{\circ} \mathrm{C}$ prior to June 15 ). In general, YOY chubs hatched earlier above the canyon indicating roundtails likely spawned earlier than humpbacks. Catch rates of YOY Gila spp. were greatest in the above-canyon sub-reach with a project high density, 0.679, recorded there during July and August of 1993. The greatest density of YOY chubs within Westwater Canyon was nearly as high, 0.673, recorded during the summer of 1996. The catch rates of chubs were significantly higher in the above-canyon and canyon subreaches than in the sub-reach below the canyon. Reproductive success as measured by densities of YOY chubs was positively correlated with the previous year's peak flow, and negatively 
correlated with the amount the June monthly mean flow deviated from the historic monthly mean. The greatest canyon catch rates occurred when the river peaked near 30,000 cfs. A multinomial analysis indicated YOY chubs used backwater habitats as they were available, but did not select for them. Similar use was recorded in embayments and shoreline habitats within Westwater Canyon. Habitat availability within Westwater Canyon was not dependent on the spring peak as much as instantaneous flow. Nursery habitats were basically any low velocity area, whether that be a typical secondary channel backwater or merely a sculpted area in the shoreline bedrock (referred to as embayments). A chi-square analysis of presence/absence YOY chub in Westwater Canyon by habitat depth indicated no selection, supporting the finding of opportunistic habitat use. Habitat depth was positively correlated with peak flows and more strongly correlated with flows at the time of sampling. Shallow habitats were defined as those having a maximum depth $<0.7 \mathrm{~m}$. Much of the available habitat within Westwater Canyon was not formed by sediment deposition as the classic Colorado pikeminnow nursery areas are. Nonnative species were found in lower densities in Westwater Canyon than above or below the canyon, again a function of canyon habitat availability. Non-native densities were negatively correlated with the peak flow at the State Line gage. The analysis of chub recruitment was based on a comparison of cohort (as determined by length frequency analysis) densities (electrofishing CPE) relative from year to year. From this analysis, it appeared the 1994 cohort recruited the best; the 1993 cohort the worst. YOY produced in 1994, although not particularly abundant, had grown larger (45 mm TL by mid-August) than either the 1992 or 1993 cohorts. In addition, overwinter flows for the 1994 YOY cohort were lower and more stable than experienced by the other two cohorts. Survival of all juvenile chubs ( $>100 \mathrm{~mm}$ TL) appeared to be high, although not quantified. The humpback chub population in Westwater Canyon was monitored at three sites established for the Interagency Standardized Monitoring Program (ISMP): Miner's Cabin (RK 199.9-198.6), Cougar Bar (RK 194.4-193.6), and Hades bar (RK 192.2-191.8). Densities of adult humpback chub, as referenced by trammel net CPE (fish/23 m net hour), fluctuated greatly from trip to trip but overall remained fairly stable, with the trend in CPE slightly up at Miner's Cabin and slightly down at the other two. The same data for roundtail chub indicated a relatively strong downward trend at all sites. Lincoln-Peterson population estimates, although compromised by large $95 \%$ confidence intervals, showed a similar trend in population size for the two species.

\section{Goeking, S.A., J.C. Schmidt and M.K. Webb. 2003. Spatial and temporal trends in the size and number of backwaters between 1935 and 2000, Marble and Grand Canyons, Arizona. Department of Aquatic, Watershed and Earth Resources. Utah State University. report prepared for U.S. Geological Survey, Grand Canyon Monitoring and Research Center, Flagstaff, Arizona.}

The decline in native fish populations in the Colorado River in Marble and Grand Canyons over the past few decades has led biologists and river managers to investigate possible causes of that decline. One potential cause is declining habitat availability, including changes in the conditions of the backwater habitats used by nursery fish. Backwaters of the post-dam Colorado River in Grand Canyon occur in inundated return current channels in the lee of eddy bars. We evaluated spatial and temporal trends in backwater size and number based on: 1) analyses of detailed ground survey data from five eddy bars, and 2) interpretation of historical aerial photographs of five reaches totaling $21 \mathrm{~km}$. From the survey data, we developed 
topographic maps of each eddy bar and evaluated the potential backwater area and volume at each survey site as a function of discharge. The results of this analysis indicated that the relationship between discharge and backwater condition changes from year to year at each site, and it also varies among sites in a given year. Variations in backwater volume were larger than variations in backwater area, demonstrating that volume is the more sensitive indicator of backwater condition because it accounts for differences in size between deep backwaters and shallow ones. Analyses of aerial photographs involved delineation of all backwaters in five study reaches between 1984 and 2000, and we delineated all backwaters between 1935 and 2000 within two study reaches. In all reaches, backwater size was greater in October 1984 than at any other time during the period of record; the number of backwaters was largest in 1984 and 1990. Time series of backwater conditions within each reach showed qualitatively that floods tended to increase backwater area and the absence of floods tends to decrease backwater area, while there was no apparent relationship between floods and backwater numbers. Although the area and number of backwaters in each reach showed large temporal variation, this variation appeared to be within the range of variability observed during the period of record. We found no evidence for a progressive increase or decrease in the availability of backwater habitats.

\section{Harpman, D.A. and A.J. Douglas. 2005. Status and trends of hydropower at Glen Canyon Dam. Pages 165-176 in Gloss, S.P., J.E. Lovich and T.S. Melis, eds., The state of the Colorado River ecosystem in Grand Canyon. A report of the Grand Canyon Monitoring and Research Center 1991-2004. USGS Circular 1282. U.S. Geological Survey, Flagstaff, Arizona.}

Approximately $7 \%$ of the electricity in the United States is generated by hydroelectric powerplants. These plants are an invaluable component of the Nation's interconnected electric power system in which generation resources consist of thermal, nuclear, solar, wind, and other sources. Hydroelectric powerplants are characterized by exceptionally low costs of operation, are highly reliable, and produce electricity without burning fossil fuels and producing air pollution. In addition, they provide voltage control, system regulation, and other ancillary services which help ensure the reliability and electrical integrity of the system. Although they play an important role in the electric power system, hydroelectric powerplants, such as the one at Glen Canyon Dam, have some widely recognized environmental effects. Large hydro facilities have blocked the spawning of anadromous and migratory aquatic species, eliminated the downstream transport of sediment, fundamentally altered the seasonal hydrograph, affected water chemistry, and changed the downstream temperature regime. Furthermore, the operation of these plants, particularly those used to produce peaking, or variable, power, causes hourly variations in stream flow and elevation, thereby adversely affecting downstream aquatic and riparian communities and recreation. The unveiling of plans to construct Glen Canyon Dam spurred a nationwide protest. Construction of the dam started a public environmental discourse which continues to this day. 
Hickman, T.J. 1983. Effect of habitat alterations by energy resource developments in the Upper Colorado River basin on endangered fishes. Aquatic Resources Management of the Colorado River Ecosystem: Proceedings of the 1981 Symposium on the Aquatic Resources Management of the Colorado River Ecosystem November 16-18, 1981, Las Vegas, NV. Ann Arbor Science, Ann Arbor, MI. pp 1537-550.

The upper Colorado River system is the habitat of several endangered fish: Kendall Warm Springs dace, Colorado squawfish, humpback chub, and bonytail chub. The single most important factor contributing to the decline of these species has been the construction and operation of dams and reservoirs, which have effected flow, temperature, chemistry, biota, and migration routes. Water depletion amounting to about $25 \%$ of the total has also had similar effects, particularly by eliminating the backwater nursery areas. A predicted decrease in agricultural use and increase in energy development use would decrease the amount of used irrigation water percolating back into the groundwater and streams. In addition, water allocated for irrigation is not always used, whereas energy use would be more uniform. In order to preserve the endangered fish, cooperation between diverse groups is needed. This may require that some dam projects may be abandoned and that others may be changed or delayed. Reducing demands on the river's water supply can also aid in protecting the fish. This could take the form of energy alternatives (solar), water conservation, technological improvements, use of groundwater where feasible, and weather modification. Other habitat preservation activities are purchase of water rights, habitat manipulation and construction, fish passageways, and artificial propagation.

Hoffnagle, T.L. 1996. Changes in water quality parameters and fish usage of backwaters during fluctuating vs. short-term steady flows in the Colorado River, Grand Canyon. Arizona Game and Fish Dept. Prepared for Glen Canyon Environmental Studies, U.S. Bureau of Reclamation.

The changes in water quality of backwaters and their use by fishes during fluctuating vs. short-term steady flows were examined in the Colorado River, Grand Canyon, 25-31 May 1994. Temperature gauges were deployed in four backwaters in the vicinity of the confluence of the Colorado and Little Colorado Rivers. Thirteen backwaters were sampled for fish use.

Temperature, dissolved oxygen, and $\mathrm{pH}$ fluctuated daily under both fluctuating and steady flow regimes. Mean mainchannel temperatures was warmer under steady flows. Mean, minimum, maximum, and diel range of backwater temperatures were higher under steady flows. Mean and minimum dissolved oxygen were lower under steady flows. Specific conductance and $\mathrm{pH}$ did not vary between flow regimes. Catch-per-unit effort in backwaters did not differ under either flow regime. These results indicated that steady flows will cause warming of the mainchannel Colorado River and its backwaters and changes in other water quality parameters. These changes may both positively and negatively affect fish populations directly and indirectly through their influence on primary and secondary productivity and the potential for an increase in parasite and disease prevalence. These factors should be more closely examined before implementation of a steady flow regime or other changes that might increase water temperatures in the river. 
Johnson, R.R. and S.W. Carothers. 2005. External threats: the dilemma of resource management on the Colorado River in Grand Canyon National park, USA. Environmental Management 11(1):99-107.

The United States Congress established Grand Canyon National Park in 1919 to preserve for posterity the outstanding natural attributes of the canyon cut by the Colorado River. In some cases National Park Service attempts to maintain Grand Canyon's natural environment have been thwarted by activities outside the park. One of the most obvious external threats is Glen Canyon Dam, only $26 \mathrm{~km}$ upstream from the park boundary. Constructed in 1963, this gigantic dam has greatly altered the physicochemical and biological characteristics of $446 \mathrm{~km}$ of the Colorado River in Grand Canyon National Park. The river's aquatic ecosystem has been greatly modified through the loss of indigenous species and the addition of numerous exotics. We consider this an exotic ecosystem. The riparian ecosystem has been less modified, with addition of a few exotics and no loss of natives - this we consider a naturalized ecosystem.

The great dilemma now faced by park managers is that, after 20 years of managing resources along a river controlled by Glen Canyon Dam, the Bureau of Reclamation has proposed major changes in operational procedures for the dam. Scientists and managers from the National Park Service, Bureau of Reclamation, and cooperating federal and state resource management agencies are using a systems analysis approach to examine the impacts of various Colorado River flow regimes on aquatic, riparian, and recreational parameters in the park. This approach will help in the development of management alternatives designed to permit the most efficient use of that river's natural resources without their destruction.

\section{Korman, J. and S.E. Campana. 2009. Effects of hydropeaking on nearshore habitat use and growth of age-0 rainbow trout in a large regulated river. Transactions of the American Fisheries Society 138(1):76-87.}

We evaluated the effects of hourly variation in flow caused by power load following at Glen Canyon Dam ("hydropeaking") on the nearshore habitat use and growth of age-0 rainbow trout Oncorhynchus mykiss downstream from the dam in the Colorado River, Arizona. Reduction in the extent of hydropeaking is a common element of restoration efforts in regulated rivers, but empirical support for such a practice is limited. Our assessment was based on a comparison of abundance in shoreline areas determined by electrofishing at different flows as well as analysis of otolith microstructure. The catch rates of age- 0 rainbow trout in nearshore areas were at least two- to fourfold higher at the daily minimum flow than at the daily maximum, indicating that most age- 0 rainbow trout do not maintain their position within immediate shoreline areas when flows are high. A striping pattern, identified by the presence of atypical daily increments formed every $7 \mathrm{~d}$, was evident in over $50 \%$ of the 259 otoliths examined in 2003 but in only $6 \%$ of the 334 examined in 2004. The weekly pattern corresponded to a reduction in the extent of hourly flow fluctuations on Sundays during the growing season, which occurred in 2003 but not in 2004. The atypical increments were $25 \%$ wider than the adjacent increments and were indicative of significant $(\mathrm{F} \mathrm{sub}(15,235)=19.2, \mathrm{P}<0.0001)$ short-term increases in otolith growth. The somatic growth rate among fish with otoliths where striping was present $(11.2 \mathrm{~mm} / \mathrm{month})$ was slightly greater than that among fish with otoliths without striping $(10.8 \mathrm{~mm} / \mathrm{month})$, but the difference was not significant. We provide evidence suggesting that otolith growth improved on 
Sundays in 2003 because it was the only day of the week when most age- 0 fish were found in immediate shoreline areas, where higher water temperatures and lower velocities provided better growing conditions.

\section{Korman, J., M. Kaplinski, J.E. Hazel III and T.S. Melis. 2005. Effects of the experimental fluctuating flows from Glen Canyon Dam in 2003 and 2004 on the early life history stages of rainbow trout in the Colorado River. Final report to Grand Canyon Monitoring and Research Center, Flagstaff, Arizona.}

An experimental alteration of the hydrograph from Glen Canyon Dam (GCD), targeted at reducing the survival rate of young rainbow trout through increased daily fluctuations in flow, was implemented from January through March in 2003 and 2004. This report describes the impact of the experimental flow regime on the early life stages of rainbow trout below Glen Canyon Dam. The study consisted of five components. We measured the timing of redd excavation and the distribution of redds across elevations (i.e., redd hypsometry) in Glen Canyon to estimate the potential egg and alevin mortality caused by the experimental flow regime. We quantified the relationships between spawning habitat preference and depth, velocity, and substrate in Glen Canyon to evaluate the feasibility of controlling spawning elevations through changes in discharge. We obtained monthly samples of YOY from Glen Canyon to compare length-frequencies over time and among habitat types to make qualitative inferences regarding the seasonal timing of hatch, and YOY survival, growth, and movement among habitat types. We analyzed the microstructure of otoliths from a subsample of fish to establish length-age relationships and evaluate the effects of dam operations on YOY growth. These data were used in a stock synthesis model to estimate seasonal trends in the number of rainbow trout emerging from the gravel, and their subsequent survival rates and movement among habitat types. Finally, we conducted rainbow trout spawning habitat, redd, and fry surveys from Lees Ferry to the confluence of the Little Colorado River (LCR) to evaluate the extent of natural reproduction in this reach.

There was minimal spawning prior to mid-January in both 2003 and 2004 and peak counts of approximately 1,000 redds were obtained by late-March/early-April. We estimated that 4,000 and 2,100 redds were excavated in 2003 and 2004, respectively. The average percentage of redds above 12,8 , and $5 \mathrm{kcfs}$ at high elevation spawning sites was $27 \%, 54 \%$, and $82 \%$, respectively. The system-wide redd survey documented a total of 27 spawning locations in the Glen Canyon with the majority of redds located at elevations below $8 \mathrm{kcfs}$. Intergravel water temperatures at Four Mile and Powerline Bars increased with elevation and exceeded the lethal egg incubation limit of $16^{\circ} \mathrm{C}$ by mid-March at higher elevations. Estimates of the percentage of redds that did not produce viable young for Glen Canyon were 23\% and 33\% in 2003 and 2004, respectively. Mortality in 2004 was higher because of the implementation of a daytime Sunday steady flow of $8 \mathrm{kcfs}$ between January and March. Under normal Record of Decision (ROD) operations from January to March with a similar total volume released from Glen Canyon Dam (GCD) to the volumes in 2003 and 2004, the model predicted a redd loss of 19\% in January and $33 \%$ from February to March when the majority of spawning occurs. Thus, there was likely very little additional incubation mortality associated with the higher experimental fluctuations in January to March of 2003 and 2004. We estimated that between 1988 and 1991, when daytime low flows during the spawning and incubation period averaged 1-3 kcfs, total redd loss likely 
exceeded $75 \%$. We predicted that redd loss rates could be increased to over $50 \%$ if a daytime Sunday steady flow of $5 \mathrm{kcfs}$ was implemented.

The spawning habitat preference models we developed for rainbow trout in Glen Canyon were useful for evaluating the extent to which increased discharge during the January to March experimental flow period altered the elevations where spawning occurred. Depths of $0.5-1.5 \mathrm{~m}$, velocities of $0.3-1 \mathrm{~m} / \mathrm{sec}$, and D85 values of $15-45 \mathrm{~mm}$ were preferred. Weighted useable area computations showed that higher discharges increased total spawning habitat availability at sites that had spawning habitat located at higher stages such as Four Mile and Powerline Bars, and reduced spawning habitat availability at deep-water redd sites such as Ferry Swale. The model also showed that the stages of preferred suitable spawning habitat at Four Mile and Powerline Bars were increased under higher discharges. Such changes in spawning habitat availability would increase the proportion of redds that would be desiccated and increase the duration of exposure. The redd hypsometry study showed that there was a significant proportion of redds excavated in deep-water that would not be dewatered at flows as low as $5 \mathrm{kcfs}$. The large decline in spawning habitat availability at Ferry Swale under high discharge suggests that spawning at deep-water sites could be suppressed through maintenance of high flows through the entire spawning period; however this conclusion needs to be validated by direct field observations. This uncertainty is important as $40-50 \%$ of the redds in Glen Canyon were located below $5 \mathrm{kcfs}$.

Seasonal changes in length frequencies of YOY in Glen Canyon showed effects of hatch timing, growth, survival variation, and movement from low to steep angle shorelines. Substantial decreases in density following the early-September reduction in the minimum daily flow from 10 to $5 \mathrm{kcfs}$ were observed in both 2003 and 2004, and a very big drop in density in steep angle habitats following the November $200442.5 \mathrm{kcfs}$ beach habitat building flow was also seen. Catch rates obtained at the minimum daily flow were 3- to 5-fold higher compared to those during the daily maximum and these differences were statistically significant. A weekly striping pattern was evident in at least $51 \%$ of the 255 otoliths examined in 2003 but in only $5 \%$ of the 334 otoliths in 2004 . The atypical weekly increment was $25 \%$ wider compared to the other increments and indicated enhanced growth during Sunday steady flow periods. There was little weekly striping in 2004 because daytime flows were not steady on Sundays during the summer of 2004. Age determinations based on analysis of otolith microstructure were made from 237 and 318 fish in 2003 and 2004, respectively. Variation in length-at-age was very low with logistic growth models predicting $86-87 \%$ of the variation in forklength as a function of the number of days from hatch. YOY in steeper habitats were significantly larger at age than those in low angle habitats for fish that were at least 3 months old. Hatch date distributions for the total YOY catch in $2003(\mathrm{~N}=966)$ and $2004(\mathrm{~N}=4,647)$ were computed by length back-calculation. The correspondence between the back-calculated hatch date distributions and those inferred from redd counts was very strong, indicating that there was limited variation in mortality rates over the incubation period. The observation that YOY generally remain at the daily minimum flow elevation, and the post-September density reductions documented in Glen Canyon, coupled with the substantial literature on stranding impacts, support the need to evaluate a 'stranding' flow operation from GCD targeted at reducing YOY recruitment.

Estimates of YOY weekly survival rate from the stock synthesis model in both low and steep angle habitats were approximately 0.85 and were not dependent on the form of the hatch 
timing distribution. The constant and variable survival rate models provided good fits to the length frequency data and the improved fit of the latter models was useful in untangling were significantly lower than in the previous (0.91 and 0.95$)$ and following intervals $(0.87$ and 0.90$)$. This change may have been caused by the reduction in the daily minimum flow from 10 to $5 \mathrm{kcfs}$ in early-September. However, it is also possible that the decrease in survival we estimated was a natural occurrence, possibly driven by a normal ontogenetic habitat shift and/or densitydependent mortality. In steep habitats, weekly survival rates dropped from 0.90 for the period spanning early-September to early-November, to 0.59 for the period between November and December. This change was likely related to the $42.5 \mathrm{kcfs}$ Beach Habitat-Building Flow (BHBF), although it could also have been caused by a natural or flow-induced habitat shift rather. Uncertainty in survival rate estimates was generally larger in low angle habitats because of lower sample size. Hatch timing-patterns estimated from the model were highly uncertain when survival rates were allowed to vary among sample periods. The juvenile stock synthesis modeling approach we have developed represents a potential advance in monitoring the response of salmonid populations to habitat alterations. However, we caution that it does not replace the need to track trends in the adult population. Without this supporting data, it will be uncertain whether a measured change in the mortality at an early juvenile stage will be compensated by a subsequent change in density-dependent mortality.

Exposed gravels and cobbles above $8 \mathrm{kcfs}$ were generally much too coarse and poorly sorted to support spawning between Lees Ferry and the confluence with the Little Colorado River. We observed a handful of very small areas $\left(10-400 \mathrm{~m}^{2}\right)$ that contained appropriate grain sizes for spawning, however no redds were observed at any of these locations. Due to high turbidity we were unable to survey for spawning habitat or redds in Marble Canyon below the daily minimum flow elevation of $8 \mathrm{kcfs}$ on the April 2004 trip. In June 2004 water clarity was adequate and suitable spawning substrate below $8 \mathrm{kcfs}$ was found at a number of locations in Marble Canyon, with the majority of larger sites located between the confluence of Nankoweap Creek and Kwagunt rapid (river miles 52 and 56, respectively). The vast majority of these sites were located at the downstream end of riffles or small rapids at depths of 3-10 $\mathrm{m}$ at a discharge of ca. 9 kcfs. Nankoweap Creek was accessible to fish in the Mainstem Colorado River in 2004 and could support at least a few thousand spawners between January and early-February when water temperatures are suitable. We did not catch recruitment and survival effects in the length frequency data. Survival rates for the period between the August and September samples for low and steep angle habitats of 0.84-0.85 any YOY rainbow trout in Nankoweap Creek during the April 2004 survey and saw only limited spawning activity.

Relative to Glen Canyon, we found very few YOY rainbow trout between Lees Ferry and the LCR confluence during the June and August 2004 surveys. Across gear types, densities of YoY rainbow trout in Glen Canyon were 12-fold higher than in Marble Canyon in June and 15fold higher in August. Densities of YoY in Marble Canyon were highest in the 15-mile reach immediately below Lees Ferry and increased between June and August in the first 30 miles downstream of Lees Ferry. Length-at-age and hatch date distributions for YOY trout caught in Glen and Marble Canyons were very similar. These data suggest that the limited number of YOY caught in Marble Canyon in 2004 likely originated from Glen Canyon. The reach between river mile 45 and 60 had the lowest densities of YoY fish of all the reaches in Marble Canyon with only 14 and 4 YOY caught in June and August, respectively. Although this reach had the greatest 
amount of spawning habitat in the mainstem and a tributary that could support a substantial amount of spawning (Nankoweap Creek), these habitats clearly did not produce a significant number of viable young in 2004.

If our surveys in Marble Canyon are representative of reproductive conditions for rainbow trout in future years, it is unlikely that flows from GCD can be used to reduce the survival rate of young trout in this reach. There was virtually no spawning habitat above $8 \mathrm{kcfs}$ that could potentially be dewatered. The limited area of spawning habitat that was observed was well below $5 \mathrm{kcfs}$. The very low densities of YOY observed in 2004 indicate that recruitment to the Marble Canyon population is already quite low, thus the incremental effect of destabilizing shoreline habitats would be very small. Our results cannot be used to definitively determine the origin of the current population of rainbow trout in Marble Canyon. It is possible that these fish originated in Marble Canyon and that the limited reproduction we observed in 2004 was a unique occurrence. Continued documentation of YOY absence in Marble Canyon over the next few years, combined with observations of a constant or increasing adult population above the mechanical removal reach, would provide strong evidence that this population is supported by downstream dispersal from Glen Canyon. Alternatively, if downstream dispersal is not a significant process, and if the lack of local reproduction in Marble Canyon continues, the rainbow trout population in this reach should decline substantially over the next few years.

\section{Korman, J., S.M. Wiele and M. Torizzo. 2004. Modelling effects of discharge on habitat quality and dispersal of juvenile humpback chub (Gila cypha) in the Colorado River, Grand Canyon. Regulated Rivers 20:379-400.}

A two-dimensional hydrodynamic model was applied to seven study reaches in the Colorado River within Grand Canyon to examine how operation of Glen Canyon Dam has affected availability of suitable shoreline habitat and dispersal of juvenile humpback chub (Gila cypha). Suitable shoreline habitat typically declined with increasing discharges above 226$425 \mathrm{~m}^{3} / \mathrm{s}$, although the response varied among modeled reaches and was strongly dependent on local morphology. The area of suitable shoreline habitat over cover types that are preferred by juvenile humpback chub, however, stayed constant, and in some reaches, actually increased with discharge. In general, changes in discharge caused by impoundment tended to decrease availability of suitable shoreline habitat from September to February, but increased habitat availability in spring (May-June). Hourly variation in discharge from Glen Canyon Dam substantially reduced the amount of persistent shoreline habitat at all reaches. Changes in suitable shoreline habitat with discharge were shown to potentially bias historical catch per unit effort indices of native fish abundance up to fourfold. Physical retention of randomly placed particles simulating the movement of juvenile humpback chub in the study reaches tended to decline with increasing discharge, but the pattern varied considerably due to differences in the local morphology among reaches and the type of swimming behavior modeled. Implications of these results to current hypotheses about the effects of Glen Canyon Dam on juvenile humpback chub survival in the mainstem Colorado River are discussed. 
McGuinn-Robbins, D.K. 1995. Comparisons in the number and area of backwaters associated with the Colorado River in Glen, Marble and Grand Canyons, Arizona. Draft report to Glen Canyon Environmental Studies, U.S. Bureau of Reclamation. Arizona Game and Fish Department, Phoenix, Arizona.

Backwaters provide important rearing habitat for larval and juvenile native fishes in Marble and Grand Canyons. Geomorphology, sediment supply, and antecedent flow conditions dictate backwater location, number, and size. Size and number of backwaters have important implications for native fish populations.

This study compared the number and size of backwaters greater than $100 \mathrm{~m}^{2}$ recorded by aerial videography in Glen, Marble, and Grand Canyons of the Colorado River at $227 \mathrm{~m} / \mathrm{s}$ constant flows of 1990, 1992, 1993, and 1994. Number of backwaters among years was significantly different (G-test, $P<0.025$ ). Number of backwaters decreased from 146 in 1990 to 70 in 1992. Following winter flooding of the Little Colorado River in January and February 1993, and a concurrent input of sediment, number of backwaters increased to 113 in 1993.

Number of backwaters decreased to 89 in 1994. More backwaters occurred in wide reaches than in narrow reaches (G-test, $P<0.025)$. Crucial reaches for native fishes are found above and below the Little Colorado River confluence and below the Havasu Creek confluence Mean area of backwaters during constant $227 \mathrm{~m}^{3} / \mathrm{s}$ flows in $1990\left(733 \mathrm{~m}^{2}\right), 1992\left(450 \mathrm{~m}^{2}\right), 1993\left(649 \mathrm{~m}^{2}\right)$ and $1994\left(798 \mathrm{~m}^{2}\right)$ was not significantly different (Kruskal-Wallis test, $P=0.099, N=55$ for each year).

Number of backwaters at 142 and $227 \mathrm{~m}^{3} / \mathrm{s}$ flows during 1990 for river kilometers 89.3 to 122.3 were also compared. Significantly more backwaters appeared at the $142 \mathrm{~m}^{3} / \mathrm{s} \mathrm{discharge}$ level (42) than at the $227 \mathrm{~m}^{3} / \mathrm{s}$ level (21) (G-test, $P<0.05$ ). Mean backwaters in 1990 at $227 \mathrm{~m}^{3} / \mathrm{s}$ $\left(741 \mathrm{~m}^{2}\right)$ was greater than those at $142\left(493 \mathrm{~m}^{2}\right)$, but was not significantly different (MannWhitney test, $P=0.307$ ).

McKinney, T. and W.R. Persons. 1999. Rainbow trout and lower trophic levels in the Lee's Ferry tailwater below Glen Canyon Dam, Arizona: a review. Arizona Game and Fish Department report to U.S. Geological Survey, Grand Canyon Monitoring and Research Center, Flagstaff, Arizona. Abstract excerpted from study conclusions.

Alterations in flow regimes in regulated rivers profoundly influence fish populations. Our review similarly indicates that operations of Glen Canyon Dam influence Lee Ferry's rainbow trout population. Widely fluctuating discharges and particularly extended periods of flow reductions to between $28 \mathrm{~m}^{3} / \mathrm{s}$ and $142 \mathrm{~m}^{3} / \mathrm{s}$ are detrimental to trout health, condition, growth, reproduction, recruitment, and population size and structure. Negative impacts of dam operations result from the following influences:

(1) Disrupted or seasonally restricted spawning;

(2) Desiccation of redds;

(3) Stranding mortality of larvae, fry, and older fish; 
(4) Reduced suitable habitat, influencing survival of fry, environmental stress, and lowered health and condition of fish;

(5) Reduced available food base due to losses and slow recolonization of periphyton, submerged macrophytes, and benthic macroinvertebrates in the varial zone;

(6) Increased metabolic demands associated with local displacements and greater densityrelated stress (competition for food and space); and

(7) Reduced recruitment to sexual maturity associated with lower growth rates.

Conversely, more stable daily and seasonal flow regimes such as provided by interim flow (IF) and modified low fluctuating flows (MLFFs) operating alternatives for Glen Canyon Dam (GCD) benefit the rainbow trout fishery through the following influences:

(1) Increased suitable habitat for fry and older fish;

(2) Extended spawning;

(3) Reduced desiccation of redds;

(4) Prevention of stranding mortality due to restricted ramping rates and the magnitude of daily flow fluctuations;

(5) Improved health and condition;

(6) Increased aquatic food base due to the greater permanently wetter perimeter of the river channel;

(7) Reduced local displacement, density-related stress, and metabolic demands; and

(8) Greater recruitment due to increased growth rates.

In summary, the IF and MLFF operating alternatives benefited the Lee's Ferry recreational fishery by development of a self-sustaining rainbow trout population and increased fish densities and recreational use by anglers. Present resource quality likely will be sustained within the foreseeable future under current policies of dam operations (MLFF) and fisheries management. However, importance of density- and food-related factors and changing nutrient concentrations since 1993-1994 in affecting the fishery remain to be evaluated. Continued monitoring, research, and management efforts are essential to increase the knowledge base from which to manage the fishery in relation to operations of GCD. Greater consideration of habitat suitability, the aquatic food base, and energetic conditions for rainbow trout than in the past should enhance management capabilities. 
McKinney, T., R.S. Rogers and W.R. Persons. 1999. Effects of flow reductions on aquatic biota of the Colorado River below Glen Canyon Dam, Arizona. North American Journal of Fisheries Management 19(4):984-991.

We examined influences of $3 \mathrm{~d}$ of reduced flows on biotic assemblages in the Colorado River below Glen Canyon Dam, Arizona. Exposure in the varial zone reduced standing crops of periphyton, pondweed Potamogeton pectinatus, and benthic macroinvertebrates, and losses following the drawdown were not explained by expected seasonal trends. Losses in macroinvertebrate densities and mass and in periphyton mass and chlorophyll a suggest that effects of a sudden reduction in dam discharge of moderate duration and magnitude are comparable with losses associated with the varial zone of fluctuating daily flows. Compared with expected seasonal changes, abundance of rainbow trout Oncorhynchus mykiss increased during and following reduced flows. Proportional composition of fish less than $152 \mathrm{~mm}$ TL was greater after the drawdown, whereas the percentage of trout 406-558 mm declined. Relative condition factor before, during, and after the drawdown did not differ significantly for all fish combined, following a long-term pattern. However, among length-classes, condition of fish 305-405 mm TL declined following reduced flows. Feeding and composition of dietary items generally followed expected patterns of seasonal change and failed to correspond with changes in periphyton, macrophyte, and macroinvertebrate benthic densities after the drawdown. However, fewer rainbow trout ate Cladophora glomerata, and they ate less of this alga. In comparison, fish ate more gastropods following the drawdown than accounted for by long-term patterns, but frequency of occurrence was unchanged. Sudden reduction in flows of moderate duration and magnitude, although significantly reducing benthic assemblages, had little apparent negative short-term consequence for rainbow trout.

\section{Rogers, R.S., W.R. Persons and T. McKinney. 2003. Effects of a 31,000-cfs spike flow and low steady flow on benthic biomass and drift composition in the Lees Ferry tailwater. Cooperative Agreement 1425-98-FC-40-22690 (mod3). Arizona Game and Fish Department, Flagstaff, Arizona. Abstract excerpted from study discussion.}

McKinney et al. (1999a) reported that a controlled flood of brief duration and moderate magnitude $\left(1,278 \mathrm{~m}^{3} / \mathrm{s}\right.$ [45,000 cfs]) in March 1996 influenced phytobenthic dynamics in the Lee's Ferry tailwater by producing short-term reduction in macrophyte densities and distribution and reducing chlorophyll $a$ concentrations in periphyton. We observed no short-term reduction in relative macrophyte distribution or effects on macrophyte densities or periphyton chlorophyll $a$ after the $878 \mathrm{~m}^{3} / \mathrm{s}$ spike flow in early May 2000. However, we were unable to sample periphyton in the permanently inundated zone until two months after the spike flow.

It is likely that any short-term reduction in chlorophyll $a$ had recovered within two months of the spike flow. An acceleration or pulse of regrowth following release of persistent individuals or new immigrants from competitive constraint is common in many post-disturbance recovery sequences in lotic algal communities (Peterson and Stevenson 1992). Shannon et al. (2001) observed recovery of phytobenthos on hard substrata on some sites within one month after the 1996 test flood. 
Lack of change in macrophyte density and distribution in the present study is probably because the 2000 spike flow was of lower magnitude than the 1996 flood. Changes in the macrophye community of the Lee's Ferry tailwater between 1996 and 2000 may also have influenced its vulnerability during spike flows in 2000. The macrophyte community in 1996 was dominated by Chara spp. (McKinney et al. 1999a) and is presently dominated by Potamogeton spp. and Egeria densa (Benenati and Shannon 2000). Chara spp., a predominantly fall and winter species in the Lee's Ferry tailwater, was largely senescent at the onset of the 1996 spike flow. Potamogeton spp. and Egeria densa are both predominant spring and summer species (Barrat-Segretain and Amoros 1995) and were in the early stages of development during the 2000 spike flow.

Although periphyton ash-free dry mass (AFDM) was similar in both seasonal trend and magnitude to that observed from 1991 to 1997, macrophyte AFDM peaked in the summer during 2000 but peaked in the fall each year from 1994 to 1997 . This change in seasonal pattern is best explained by the change in species composition from one dominated by Chara spp. in 1994 and 1995 to that currently dominated by Potamogeton spp. and Egeria densa. Macrophyte AFDM was much higher and distribution more extensive in 2000 than in 1994-1997. It is likely that the stable flows increased the amount of suitable shoreline for macrophytes in 2000.

Our results were consistent with Shannon et al. (1996) and showed that organic drift was reduced by steady flows. Although benthic densities of macroinvertebrates, periphyton, and macrophytes were not diminished by the spike flow in early May, total drift AFDM, which was dominated by filamentous algae, was significantly reduced and did not recover until mid-July.

Schmidt, J.C., S.J. Topping, D.M. Rubin, J.E. Hazel and M. Kaplinski. 2007. Streamflow and sediment data collected to determine the effects of low summer steady flows and habitat maintenance flows in 2000 on the Colorado River between Lees Ferry and Bright Angel Creek, Arizona. U.S. Geological Survey, Reston, Virginia.

The low summer steady flows (LSSFs) experiment of 2000 further demonstrated that spike flows released from Glen Canyon Dam redistribute sand from the channel bed and lower elevation parts of eddy sandbars to channel-margin deposits and the higher elevation parts of eddy sandbars. Unfortunately, summer 2000 was a period of unusually low tributary influx of sediment and there was little fine sediment (i.e., sand and finer material) available for redistribution. Nevertheless, the low steady flows, which held releases from the dam steady at $230 \mathrm{~m}^{3} / \mathrm{s}\left(8,100 \mathrm{ft}^{3} / \mathrm{s}\right)$, during the summer of 2000 effectively retained on the channel bed the little sediment that was supplied by tributaries, and a subsequent 4 -day, $870 \mathrm{~m}^{3} / \mathrm{s}\left(30,700 \mathrm{ft}^{3} / \mathrm{s}\right)$ spike flow caused modest increases in the area of the mid-elevation zone of eddy sandbars.

Speas, D W. 2004. Effects of low steady summer flows on rainbow trout in the Lee's Ferry tailwater, 2000. Report to U.S. Geological Survey, Grand Canyon Monitoring and Research Center, Flagstaff, Arizona.

To improve survival and growth of native fishes, an experimental combination of flows simulating seasonal floods and low steady summer flows were conducted during marchSeptember of 2000 in the Colorado River below the Glen Canyon Dam, Arizona. Diel flow fluctuations were essentially zero and mean daily discharge was 8,000 cfs from occasions during 
2000 to assess impacts of the steady flow experiment on CPUE, size structure, and condition factor of rainbow trout. Mean catch-per-unit-effort, condition, growth rates, and proportional stock density values for 2000 show no significant departure from those observed in recent years (1997-1999), but seasonal peaks in condition and appearance of YOY in the catch occurred several months earlier during 2000 than during previous year (1991-1999). Previous studies and stock assessment models predicted enhanced survival of wild spawned age $\leq 1$ fish under low daily flow fluctuations, but CPUE of age $\leq$ fish during 2000 did not deviate significantly from those observed during the preceding 3 to 5 years. This lack of change may be attributed to both positive (stabilized flows) and negative (low flows) hydrologic forces acting simultaneously on early life history of trout, or it simply may be an artifact of low sample statistical power. We recommend that long-term monitoring sample sizes be increased in part to enhance statistical power for short-term experiments, and that future flow experiments consist of fewer hydrological treatments than those applied during 2000.

\section{Speas, D.W., W.R. Persons, R.S. Rogers, D.L. Ward, A.S. Makinster and J.E. Slaughter, IV. 2004. 2001 Fish Investigations in the Lee's Ferry Tailwater. Report to U.S. Geological Survey, Grand Canyon Monitoring and Research Center, Flagstaff, Arizona.}

We present results of rainbow trout monitoring activities in the Lee's Ferry tailwater (Colorado River below Glen Canyon Dam, AZ) during 2001. We also describe modifications made to monitoring strategies and techniques which were implemented to improve long-term monitoring programs. Objectives and subsequent findings are as follows:

Objective 1: Monitor the trout fishery in the Lee's Ferry reach to determine status and trends in abundance (population size and CPUE), population structure (size composition and proportional stock density, PSD), growth rate and relative condition $\left(\mathrm{K}_{n}\right)$.

Data collected during 2001 indicate the Lee's Ferry fishery is in a state of decline. High relative abundance of juvenile fish $(<305 \mathrm{~mm})$ since 1997 coincide with declines in fish growth rates and proportional stock density [PSD; (\# fish $\geq 406 \mathrm{~mm}$ TL/\# fish $\geq 305 \mathrm{~mm}$ TL)*100]. Relative condition reached low levels unobserved since 1991. Over-recruitment, resource limitation (food, space) and density dependent growth have become problematic aspects of the fishery, particularly in relation to declining dam discharge since 1997. Flexibility in management objectives is needed to allow for maintenance of fish densities that will permit objectives for relative condition, growth and PSD to be attained over a range of flow regimes. Modifying flow regimes to limit rainbow trout recruitment should be evaluated as a means of making progress toward size structure, growth and condition objectives.

Objective 2: Determine the relationship between Coffelt and Achilles electrofishing (EF) boats, measuring CPUE, Kn, PSD and catch size distribution so that linkages between the historic data (Coffelt) and data collected with the new gear type (Achilles) can be established.

Despite conflicting results among three paired gear comparison trials, we can infer that catchability of the Achilles electrofishing boat is higher than that of the Coffelt boat. Regression analysis indicates that CPUE values obtained with the Coffelt boat are $72-83 \%$ of those collected by the Achilles, although there is much unexplained variation in this relationship. Uncertainties 
surrounding catchability of the two boats remain, particularly in relation to performance under various environmental conditions (flow regimen, weather, moon phase, food base elevation, etc.) and new EF output regulators. Alternative sampling strategies may need to be implemented to ensure continuity of the old (Coffelt-based) data series. For example, a single trip could be conducted annually with the Coffelt boat at the nine fixed sites to allow continuity of the old (pre-2002) data series. The remaining two or three trips per year could consist of sampling ( $N=9$ fixed and $N=27$ random sample sites per trip) sampling trips conducted with the Achilles electrofishing boats.

Objective 3: Divide existing sample sites into smaller units that are representative of the larger sites for permanent inclusion in an augmented, serially alternating sampling design. Evaluate sample power gained by increasing sample size and predictive capability of habitat classifications.

Most sub-sites were representative of their parent sample sites in that sub-site mean CPUE values were of similar magnitude as grand means and $95 \%$ confidence intervals always overlapped substantially with those of grand means. We recommend moving forward during 2002 with selection of 27 random transects to augment the nine fixed sub-sites.

Sample power increased two to three-fold with increasing sample size from nine to 33 transects per trip during 2001. The present design appears capable of detecting moderate changes in $\mathrm{CPE}$ over the course of a single year.

Hydrologic unit, substrate type, shoreline type, and surface velocity were often correlated. Shoreline type (talus, cobble bars, cliff faces, sand bars) is the most useful variable, because it can be used to stratify catch rates for random site selection and is a surrogate variable for substrate type and hydrologic units. Extensive geographic coverage of shoreline type is also available in electronic format (GCMRC GIS database).

Objective 4: Develop and refine a repeatable, efficient and precise snorkel survey protocol for quantifying fish observations along the longitudinal axis of the shoreline for use in monitoring of trout relative density. Develop a method to measure fish distribution along the cross-sectional axis of the river.

Compared with previous surveys (1998-2000), protocols developed during 2001 provide a balance between repeatability, precision, efficiency, standardization of area surveyed, and agreement with electrofishing. However, the utility of snorkeling as a monitoring tool for fish abundance depends on its ability to reflect changes in the fish population over time with the same level of confidence demonstrated by electrofishing and AGFD creel surveys. It is apparent that we should expect some seasonal discrepancy between electrofishing and snorkeling trends. We recommend that snorkel surveys (longitudinal surveys of EF transects, cross-section surveys, and visibility tests) be continued during 2002, with emphasis placed on variables that affect catchability of snorkeling (diel and seasonal variance in visibility, turbidity, light availability, fish behavior). 
CPE data from 2001 shows signs of saturation at or above $4.2 \mathrm{fish} / \mathrm{min}$. At these densities more fish can be counted visually than can be captured by netting. Mechanisms that cause this saturation appear to vary by habitat type. On cobble bars, fish are stunned effectively but there are often too many to bring into the boat during a sample; on sand bars, fish are not stunned effectively, but can be counted easily by snorkeling.

While snorkel/EF data comparisons during 2001 were not entirely conclusive, it is evident that catchabilities of both techniques vary among habitat type. For electrofishing, literature suggests that large particle substrate types generally favor electrofishing, whereas visibility tests in the present study suggests that fish are less visible in such areas, particularly over talus. Both hypotheses suggest that apparent trends in fish abundance among habitat types may be in part be caused by variable catchability coefficients. The extent to which these biases affect population estimates is unknown, and quantifying them would require additional electrofishing depletion experiments and more visibility tests. Surveys of fish distribution across the river channel take little time to complete and are essential for accurate population estimates.

Objective 5: Estimate size of rainbow trout population in the Lee's Ferry tailwater using electrofishing CPE and snorkel count data; compare magnitude and variability of the two estimates.

Using habitat-stratified population models, there are an estimated 91,000 RBT $>$ $152 \mathrm{~mm}(95 \% \mathrm{CI}=55,000-149,000)$ in the Lees Ferry fishery based on near-shore estimates from electrofishing CPE. Use of abundance estimates from snorkel surveys in a similar model returns an estimate of 78,000 fish $(95 \% \mathrm{CI}=54,000-114,000)$. Confidence intervals of the latter (snorkel-based) estimate are narrower than those from electrofishing, perhaps reflecting the ability to control sample error during individual transect snorkel surveys. Fish density modeled in relation to river mileage returns an estimate of 77,000 fish $(95 \% \mathrm{CI}=44,000-110,000)$ based on electrofishing data, and 60,000 fish $(95 \% \mathrm{CI}=31,000-93,000)$ based on snorkel data.

Similarity of population estimates based on EF and snorkeling is likely coincidental, and further emphasizes the need to understand variance components (of a seasonal nature, in this case) of snorkel surveys. Had the population estimates been calculated from the October data, for example, estimates from electrofishing would have undoubtedly been greater than estimates from snorkeling because the latter data series suggested a $70 \%$ decline in trout abundance, whereas EF data showed no change.

The accuracy of tailwater-scale population estimates depends heavily on accurate estimates of what proportion of fish along the cross-channel axis of the river is represented by densities in areas surveyed (either by snorkel or EF). Direct extrapolation-which makes the assumption that fish densities are uniform across the river channel-results in three to eight-fold overestimate of fish per river mile. The 1991 population estimate (which lacked cross-sectional fish density information) was used to formulate management recommendations, which state that a population consisting of 100,000 age $2+$ rainbow trout should be maintained in the tailwater. Evidence from the present study indicates that this objective should be approximating 20,000 fish. The population of RBT in the tailwater today exceeds this objective by a factor of 3 to 4.5 . 
Declining growth, size structure and condition indices coincide with increased trout abundance over the past decade and supports the conclusion that the system is overpopulated.

Existing objectives for growth, PSD and condition need to be reassessed for their attainability in relation to a given target population size. To ensure flexibility in management of the Lee's Ferry fishery, we should establish objectives for population size that are specific to a range of discharge regimes and favorable for attaining population size structure (i.e., PSD) and Kn objectives.

\section{Trammell, M., R. Valdez, S. Carothers and R. Ryel. 2002. Effects of a low steady summer flow experiment on native fishes of the Colorado River in Grand Canyon, Arizona. SWCA Environmental Consultants. Final report to U.S. Geological Survey, Grand Canyon Monitoring and Research Center, Flagstaff, Arizona.}

Canyon Dam down the Colorado River through Marble Canyon and Grand Canyon. The purpose of the LSSF was to determine if low steady flows in summer would stabilize habitat and allow the Colorado River to warm sufficiently for increased growth and survival of the endangered humpback chub (Gila cypha) and other native fishes. The LSSF consisted of a high steady release of 17,000 cfs from April through May, with a 4-day spike of 30,000 cfs in early May, followed by steady releases of 8,000 cfs from June through September, with a 4-day spike of 30,000 cfs in early September. Data on species composition, relative abundance and distribution of fishes were gathered to provide a baseline for long-term monitoring and an evaluation of short-term response to the experimental flows. Systematic shoreline electrofishing and extensive mark-recapture efforts were used to gather data for stock-recruitment models to understand population dynamics as part of long-term monitoring. Concurrent periodic sampling with seines, hoop nets, and trammel nets was used to monitor short-term fish responses undetected by sampling schemes designed for long-term monitoring. The following is a summary of findings:

- Distribution and relative abundance of native and nonnative fish species in eight longitudinal reaches of the Colorado River through Grand Canyon were described using a variety of gear types. Rainbow trout (Oncorhynchus mykiss) were the most abundant species in the upper reaches and dominated the catch by electrofishing and netting. Fathead minnow (Pimephales promelas) and speckled dace (Rhinichthys osculus) were the most abundant species in the lower reaches and dominated the catch by seining. Adult humpback chub, bluehead sucker (Catostomus discobolus), flannelmouth sucker (Catostomus latipinnis), and brown trout (Salmo trutta) were locally abundant at aggregations. YOY native sucker were distributed throughout the study area.

- Efforts to calibrate trammel net catch rates of native fishes by comparing these to simultaneous removal estimators failed. Removal of native fishes from given habitats (e.g., large eddies) was ineffective because of our inability to block and sample the entire habitat. Fish moved to deep swift water, which could not be sampled. Mark-recapture estimates on a small scale were also ineffective because movement of fish to and from the sample area violated the assumptions of sample population closure. Calibration of trammel net catches of native fishes, using short-term abundance estimators, does not 
appear possible. However, it may be possible to calibrate catch rates with long-term mark-recapture estimates.

- The humpback chub aggregation near 30-Mile was not found during the LSSF of 2000. In 1993, 26 adults were captured and this aggregation was estimated at 52 adults $(95 \%$ $\mathrm{CI}=28-136)$, which was the 4th largest aggregation identified in the Colorado River through Grand Canyon. Also, 14 YOY (18-31 mm TL) humpback chub were collected and preserved from a school of approximately 100 at a warm shoreline spring at RM 30.8 on July 14, 1994, indicating successful reproduction by this aggregation. Failure to locate this aggregation is cause for concern over loss of a unique stock of mainstem fish.

Sampling should continue in this area to determine if the aggregation has been lost or has relocated to other suitable habitat, possibly in one of the other nearby warm springs associated with Fence Fault and Eminence Grabens.

- Mark-recapture population estimates of humpback chub in Middle Granite Gorge (MGG) in 2000 derived an estimated $107.7 \mathrm{fish} / \mathrm{mile}$, compared to a density of $31.1 \mathrm{fish} / \mathrm{mile}$ in 1993. These estimates indicate a three-fold increase in numbers of humpback chub at the MGG aggregation in the past 8 years. Average length and range in length were similar for the two sample periods, and estimated maximum age of these fish was 7-9 years, indicating ongoing recruitment to this aggregation. The source of this recruitment is not known, but could be from local mainstem reproduction or downstream drift from the LCR. There are no known warm mainstem springs near or immediately upstream of MGG, and the possibility of these fish originating from thermal springs is discounted.

- Size of humpback chub at the time of transition from the LCR to the mainstem was determined from temperature checks and first annuli on scales. Average size at transition was $83 \mathrm{~mm}$ TL, with a minimum of $69 \mathrm{~mm}$ TL (compared to mean of $74 \mathrm{~mm}$ TL and minimum of $52 \mathrm{~mm}$ TL reported in 1995). Current data suggest that fish smaller than about $69 \mathrm{~mm}$ TL do not survive the transition from the warm LCR to the cold mainstem. Similar growth checks in fish captured from the LCR suggest stress-related growth checks resulting from summer flooding. Similar lengths at first annuli and circuli disruptions suggest that fish successfully recruiting in the mainstem likely remained in the LCR until age 1.

- Growth patterns of YOY flannelmouth sucker and bluehead sucker were inconclusive during the LSSF because protracted spawning infused newly-hatched larvae into samples and kept average YOY lengths depressed.

- Mean mainstem temperatures were $1.4-3.0^{\circ} \mathrm{C}$ warmer than under previous dam operations (MLFF), and mean backwater temperatures were $0.3-5.3^{\circ} \mathrm{C}$ warmer; hence, a marked warming effect was observed. Longitudinal downstream warming greater than that during MLFF was observed.

- Catch-Per-Effort (CPE) of bluehead sucker, and flannelmouth sucker was significantly higher in August 2000 than in July/August from 1991-1997. Fathead minnow CPE was much higher than previous levels but the differences were not significant due to greater 
variation in CPE. The increase in abundance was likely a result of the warmer, more suitable temperatures, which may have affected reproduction and survival. Following the September flow spike, CPE of all species declined. However, fathead minnow CPE was nearly identical with previous years while CPE of native fishes remained significantly higher, suggesting the flow spike was disproportionately detrimental to fathead minnow.

- No population estimate or depletion of channel catfish (Ictalurus punctatus) in the LCR confluence area could be made. Few channel catfish and several humpback chub were caught. This effort should be repeated and timed to correspond with catfish spawning times, which probably occurred after the sample period of May 31 to June 5.

\section{Valdez, R.A. 1994. Effects of interim flows from Glen Canyon Dam on the aquatic resources of the lower Colorado River from Diamond Creek to Lake Mead: Phase I. Bio/West, Inc., Final report to Glen Canyon Environmental Studies.}

An investigation of the aquatic resources of the Colorado River from Diamond Creek (RM 226) to below Pearce Ferry (RM 286) in Lake Mead, was initiated in May of 1992 by the Hualapai Wildlife Management Department, with technical assistance from BIO/WEST, Inc. The purpose of this investigation was to determine the effects of interim flow releases from Glen Canyon Dam, located about 240 miles upstream of the upper end of the study reach. Seven research trips were conducted from June 1992 to December 1993 to sample fishes, macroinvertebrates, water quality, and to monitor variability in river stage associated with flow changes.

River stage changes recorded each sampling trip showed maximum daily changes of about $60 \mathrm{~cm}$, and $90 \mathrm{~cm}$ over a 3-day period. Most daily changes in narrow canyon reaches were 40 to $60 \mathrm{~cm}$. and $20-30 \mathrm{~cm}$ in more alluvial downstream reaches where stage changes was ameliorated by Lake Mead. River fluctuations in the study area were regular and cyclic, with lows of 8,000-10,000 cfs between 2:00 am and 4:00 am, and highs of 13,000-15,000 cfs between 11:00 am and 1:00 pm. As measured at the Diamond Creek gage.

Conductivity, water temperature, $\mathrm{pH}$, and dissolved oxygen concentrations were measured in the mainstem and in some tributaries with a constant recording Hydrolab Surveyor II or Datasonde with datalogger. Turbidity was measured in the mainstem with a secchi disk. Maximum mainstem water temperature change through the study area in 1992 was $3^{\circ} \mathrm{C}$, from $17^{\circ} \mathrm{C}$ at Travertine Canyon (RM 229.0) on June 24 to $20^{\circ} \mathrm{C}$ at Grand Wash Cliffs (RM 276.0) on July 1. Surface temperature at Pearce Ferry was 24.5 to $26.0^{\circ} \mathrm{C}$ on July 1. Water temperature ranged from $15.0^{\circ} \mathrm{C}$ at Bridge Canyon (RM 235.0) on September 27, to $23.0^{\circ} \mathrm{C}$ at Pearce Ferry (RM 280.0) on October 7. December water temperatures ranged from $8.6^{\circ} \mathrm{C}$ at Bridge Canyon on December 1 , to $10.2^{\circ} \mathrm{C}$ at Scorpion Island (RM 277.5) on December 11. 1992. Mainstem temperature in 1993 was similar and varied from about $8.5^{\circ} \mathrm{C}$ in December to about $20^{\circ} \mathrm{C}$ in September. Temperature of Spencer Creek varied from about $14^{\circ} \mathrm{C}$ in December to about $29^{\circ} \mathrm{C}$ in June.

Benthic and drifting macroinvertebrates sampled in the Colorado River and tributaries showed relatively low drift densities in the mainstem, and high benthic and drift densities in 
Spencer Creek. Densities of drifting macroinvertebrates in Spencer Creek were 40 to 200 times those of the mainstem. Terrestrial and other aquatic forms of macroinvertebrates were dominant, and when compared to more upstream samples show that drift changes longitudinally downstream. Chironomids, simulids, and Gammarus lacustris were less common than in upstream reaches.

Fish sampling was conducted in the Colorado River as well as the following tributaries: Diamond Creek, Travertine Falls, Spencer Creek, Surprise Canyon, Lost Creek, and Quartermaster Canyon. Fish were collected with seven primary gear types including electrofishing, gill nets, trammel nests, hoop nets, minnow traps, seines, and angling. Nineteen species of fish were captured representing 10 families. Only four of these species, humpback chub (Gila cypha), speckled dace (Rhinichthys osculus) flannelmouth sucker (Catostomus latipinnis), and bluehead sucker (Catostomus discobolus), are native to the Colorado River Basin. Carp and channel catfish were the most common species in the Colorado River, moving into the study area in large numbers in spring. Red shiners, fathead minnows, and mosquitofish were consistently most common in tributaries, and plains killifish were found in local aggregations. Striped bass, largemouth bass, green sunfish, black crappie, bluegill, threadfin shad, and walleye were lake species that were found in small numbers in tributaries or Separation Canyon in spring. The endangered species, razorback sucker (Xyrauchen texanus), Colorado squawfish (Ptychocheilus lucius), and bonytail (Gila elegans), were not seen or captured, and only one humpback chub was captured at RM 253.2.

Few studies have been conducted on the aquatic resources of this lower reach of the Colorado River in Grand Canyon. Fish species composition showed that the reach below Bridge Canyon was dominated by nonnative species, with a large influence from the Lake Mead ichthyofauna. Densities of fish upstream of Bridge Canyon were relatively low. Young flannelmouth suckers and bluehead suckers in tributaries indicate that these may be the only suitable locations for successful reproduction by native species in the area. Mainstem habitats may be too altered by sediment deposits or temperature modifications to provide suitable conditions, and the large number of nonnative species limits the chances for survival of young native fishes.

Sampling in Spencer Creek indicated that a series of waterfalls about 2 miles upstream of the outflow was a barrier to upstream movement, and the only species found above these falls was the native speckled dace. Perennial flow, good water quality, and good stream habitat make this tributary a suitable candidate as an introduction site for young razorback suckers, particularly above this fish barrier, since the area downstream is dominated by predaceous nonnatives and invaded in spring by channel catfish and carp. Young fish released above the water falls and allowed to grow past the size of predator susceptibility could use the Lake Mead inflow as adult habitat. The chances for successful reproduction and recruitment by these stocks cannot be assessed at this time but would be greatly reduced below fish barriers by large numbers of nonnative fishes in the region.

This investigation revealed that interim flows continue to be manifested as fluctuating river stages of as much as $90 \mathrm{~cm}$ just above the Lake Mead inflow, about 250 miles of Glen Canyon Dam. While these changes may destabilized shoreline habitats and periodically affect 
fish access to tributaries, no direct relationships have been identified to current fish population distributions and levels. Although this region of the Colorado River is far enough downstream from the dam to allow for longitudinal warming of river temperatures, effects of cold releases on primary and secondary production extend into this region, limiting food resources for fish. The preliminary determination from this investigation is that interim flows alone do not appear to detrimentally impact aquatic resources of the area. Instead, the synergistic effect of fluctuating flows, low temperatures, absence of spring runoff, and particularly nonnative fishes, has affected the riverine ecosystem throughout Grand Canyon. Effects of interim flows to the lower 45 miles of the study area, downstream of Bridge Canyon, are overwhelmed by fluctuating levels of Lake Mead, massive sediment deposits that have altered channel geomorphology, and the abundance nonnative fishes residing in the reservoir.

\section{Valdez, R.A. and S.W. Carothers. 1998. The aquatic ecosystem of the Colorado River in Grand Canyon. Final report of SWCA, Inc., Flagstaff, Arizona, to U.S. Bureau of Reclamation, Upper Colorado Region, Salt Lake City, Utah.}

Introduction- The U.S. Fish and Wildlife Service's 1995 Biological Opinion on the operation of Glen Canyon Dam found that current and proposed dam operations continue to jeopardize two endangered species within Grand Canyon: razorback sucker and humpback chub. Existing data on the population status of these two species indicate that the razorback sucker is virtually extinct in Grand Canyon and the humpback chub- although reproducing in the Little Colorado River- has been declining in number over a 35 year period of record.

In their Biological Opinion, the U.S. Fish and Wildlife Service identified a "Reasonable and Prudent Alternative" to the preferred alternative of the Environmental Impact Statement on the operation of Glen Canyon Dam. The preferred alternative was a regime of modified low fluctuating flows (MLFF). The Reasonable and Prudent Alternative recommends a seasonally adjusted steady flow experiment within the context of the MLFF and undertaken through the Adaptive Management Program.

The steady flow experiment would consist of sustained high releases during the period of April-May, followed by low steady releases during June-October. The high releases would be designed to pond tributary inflows and provide warm nursery habitats for young native fish descending from tributaries. The low releases would be designed to enhance habitat conditions for native fishes by stabilizing and warming mainstem and nearshore habitats, including backwaters (i.e., eddy return-current channels). Experimental steady flows would be released only during low-release years (i.e., $\leq 8.23$ million acre feet) over "a sufficient period of time to allow for experimental design, biological processes to function and for variability inherent in riverine ecosystems to be expressed. The number of years is, therefore, indeterminate." As a preliminary step toward the design of such an experiment, SWCA, Inc. Environmental Consultants was retained by the Bureau of Reclamation to summarize and evaluate known information about native and non-native fishes in Glen and Grand Canyons with the following objectives:

- Summarize known information that would help predict responses by endangered and other native fishes to steady flows; 
- Identify information that is still needed to understand the relationship of fish and dam release patterns (data gaps); and

- Frame testable hypotheses for research designed to acquire the needed information.

To this end, we reviewed the existing knowledge on aquatic ecosystems in Glen and Grand Canyons and synthesized that information so the following questions could be addressed:

- Do sufficient baseline data exist to evaluate the influence of the steady flow experiment described in RPA?

- Do existing data indicate that the steady flow experiment will likely have an overall positive influence on endangered and other native fishes in Grand Canyon?

Results- The best available scientific information indicates that primary and secondary production have been highest under short-term steady or low fluctuating flows, and lowest under high fluctuating releases. However, drift of algae and macroinvertebrates, a major food source of fishes, has generally been higher during fluctuating flows than during short-term steady flows, but the effect of long-term steady flows on drift, water clarity, and temperature, such as proposed in the experiment, have not been evaluated or modeled. Available data also indicate that, although cold mainstem temperatures and fluctuating flows have limited reproduction and perhaps survival of endangered and other native fishes, these flow variables have also limited invasion and proliferation of warm-water nonnative competing and predaceous fishes. Cold mainstem water temperatures have also limited the spread of recently introduced parasites, particularly the potentially lethal Asian tapeworm (Bothriocephalus acheilognathi), which has become prevalent in cyprinid fishes of the LCR.

Except for temperature and possibly turbidity, water quality parameters currently found in the Colorado River in Grand Canyon are not limiting to native fishes. Availability of suitable food for each life stage of fish has been considered a potentially important limiting factor; however, clear evidence of food limitations in Grand Canyon is lacking. Most studies of fish diet report few empty stomachs, and potential food supplies appear to be fairly abundant from drift and benthic macroinvertebrate studies. Nonetheless, a few observations have been made of possible food shortages for specific life stages of some species. Because of cold mainstem temperatures, the only known spawning habitats of native fishes in Grand Canyon are tributaries or warm springs. We believe that most larval flannelmouth suckers, bluehead suckers, and humpback chub descending from warm natal tributaries into the cold mainstem die of thermal shock or from predation elicited by erratic swimming behavior. For those fish old enough to survive the transition, swimming ability may be reduced by as much as $98 \%$ by cold mainstem temperatures. This reduced swimming ability, combined with reduced turbidity for cover, greatly advantage cold-water sight predators, such as rainbow trout and brown trout. Juvenile native along sheltered shoreline habitats are often forced to move to alternative locations by changing river stage, increasing exposure to predators and needless energy expenditure. 
The degree to which nonnative fish species have negatively affected native fish population in Grand Canyon through predation and competition has been clearly demonstrated. Nonnative fishes do prey on native fishes in Grand Canyon. Brown trout, channel catfish, rainbow trout, and black bullheads are the principle predators of native fish. The extent of this predation is not known, but predator-prey models suggest it is substantial. Competition between native fishes and nonnative fishes is implied by extensive overlap in diet and sympatry in many habitats for all life stages; however, data on abundances, distribution, and habitat use by nonnative species in Grand Canyon is patchy because life history studies of these fishes have not been conducted in the canyon.

Without knowing more about native/nonnative interactions under existing flow conditions (i.e., low fluctuating flows), it is difficult to predict which, if either group of fishes would benefit more from steady flows. We cannot predict the outcome for endangered and other native fishes if, indeed, nonnative predators and competitors increase in abundance, but all available evidence suggests a detrimental effect on native species unless these species receive substantially disproportionate benefits from the flows. By their nature, nonnative fishes have a more variable range of life history requirements that tends to make them more tolerant and resilient to disturbances that the native fishes in Grand Canyon. Hence, flow modifications, even if they resemble historic regimes, may directly benefit native fishes, but may also benefit nonnative forms. This could result in overall, long-term negative effects on the native species.

\section{Valdez, R.A., B.R. Cowdell and E. Pratts. 1995. Effects of interim flows from Glen Canyon Dam on the aquatic resources of the lower Colorado River from Diamond Creek to Lake Mead: Phase II, Bio/West, Inc., Final report to Glen Canyon Environmental Studies.}

An investigation of the aquatic resources of the Colorado River from Diamond Creek (RM 226) to below Pearce Ferry (RM 286) in Lake Mead, was initiated in May of 1992 by the Hualapai Wildlife Management Department, with technical assistance from BIO/WEST, Inc. The purpose of this investigation was to determine the effects of interim flow releases from Glen Canyon Dam on aquatic resources of the region of the Colorado River bordered by the Hualapai Indian Reservation. Eleven research trips were conducted from June 1992 through January 1995 to sample fishes, macroinvertebrates, water quality, and to monitor variability in river stage associated with flow changes. The first nine trips were conducted from Diamond Creek to Pearce Ferry, and the last two trips extended sampling upstream to National Canyon. The Colorado River forms 109 miles of the northern boundary of the Hualapai Indian Reservation from near National Canyon (RM 164.5) to near Emery Falls Canyon (RM 273.5). A Phase I Report (Valdez 1994) presented findings for the first seven trips. This Phase II Report presents the integration of data from all 11 trips.

River stage recorded each sampling trip showed a maximum vertical change of about 60 $\mathrm{cm}$ for 24 hours, and a net change of about $90 \mathrm{~cm}$ over a 3-day period. Most daily changes were 40 to $60 \mathrm{~cm}$ in narrow canyon reaches, and 20-30 cm in more alluvial downstream reaches where stage changes was ameliorated by Lake Mead. River fluctuations in the study area were regular and cyclic, with lows of 8,000 to $10,000 \mathrm{cfs}$ between 2:00 am and 4:00 am, and highs of 13,000 to $15,000 \mathrm{cfs}$ between 11:00 am and 1:00 pm, as measured at the Diamond Creek gage. 
Conductivity, water temperature, $\mathrm{pH}$, and dissolved oxygen concentrations were measured in the mainstem and in some tributaries with a constant recording Hydrolab Surveyor II or Datasonde with datalogger. Turbidity was measured in the mainstem with a secchi disk. Maximum mainstem water temperature change in summer was about $3^{\circ} \mathrm{C}$, from $17^{\circ} \mathrm{C}$ at Travertine Canyon (RM 229.0) on June 24, 1992 to $20^{\circ} \mathrm{C}$ at Grand Wash Cliffs (RM 276.0) on July 1. Maximum surface temperature at Pearce Ferry was 24.5 to $26.0^{\circ} \mathrm{C}$ on July 1 . Water temperature in fall (September-October) was typically isothermal at about $13.0^{\circ} \mathrm{C}$ to $16^{\circ} \mathrm{C}$ from the river to Pearce Ferry, while December temperature was usually warmer, from $8^{\circ} \mathrm{C}$ to $10^{\circ} \mathrm{C}$, and January temperature was usually colder near Pearce Ferry, from $10^{\circ} \mathrm{C}$ to $8^{\circ} \mathrm{C}$. Temperature of Spencer Creek varied from about $14^{\circ} \mathrm{C}$ in December to about $29^{\circ} \mathrm{C}$ in June.

Benthic and drifting macroinvertebrates sampled in the Colorado River and tributaries showed relatively low drift densities in the mainstem, and high benthic and drift densities in Spencer Creek. Densities of drifting macroinvertebrates in Spencer Creek were 40 to 200 times those of the mainstem. Terrestrial and other aquatic forms of macroinvertebrates were dominant, and when compared to more upstream samples show that drift changes longitudinally downstream. Chironomids, simuliids, and Gammarus lacustris were less common than in upstream reaches.

Fish sampling was conducted in the Colorado River as well as the following tributaries: Diamond Creek, Travertine Falls, Spencer Creek, Surprise Canyon, Lost Creek, and Quartermaster Canyon. Fish were collected with seven primary gear types including electrofishing, gill nets, trammel nests, hoop nets, minnow traps, seines, and angling. Nineteen species of fish were captured representing 10 families. Only four of these species, humpback chub (Gila cypha), speckled dace (Rhinichthys osculus) flannelmouth sucker (Catostomus latipinnis), and bluehead sucker (Catostomus discobolus), are native to the Colorado River Basin. Carp and channel catfish were the most common species in the Colorado River, moving into the study area in large numbers in spring. Red shiners, fathead minnows, and mosquitofish were consistently most common in tributaries, and plains killifish were found in local aggregations. Striped bass, largemouth bass, green sunfish, black crappie, bluegill, threadfin shad, and walleye were lake species that were found in small numbers in tributaries or Separation Canyon in spring. The endangered species, razorback sucker (Xyrauchen texanus), Colorado squawfish (Ptychocheilus lucius), and bonytail (Gila elegans), were not seen or captured, and only one humpback chub was captured at RM 253.2; the fish probably dispersed downstream from a central population at the Little Colorado River inflow about 19.1.9 miles upstream.

Few studies have been conducted on the aquatic resources of this lower reach of the Colorado River in Grand Canyon. Fish species composition showed that the reach below Bridge Canyon was dominated by nonnative species, with a large influence from the Lake Mead ichthyofauna. Densities of fish upstream of Bridge Canyon were relatively low. Young flannelmouth suckers and bluehead suckers in tributaries indicate that these may be the only suitable locations for successful reproduction by native species in the area. Mainstem habitats may be too altered by sediment deposits or temperature modifications to provide suitable conditions, and the large number of nonnative species limits the chances for survival of young native fishes. 
Sampling in Spencer Creek indicated that a series of waterfalls about 2 miles upstream of the outflow was a barrier to upstream movement, and the only species found above these falls was the native speckled dace. Perennial flow, good water quality, and good stream habitat make this tributary a suitable candidate as an introduction site for young razorback suckers, particularly above this fish barrier, since the area downstream is dominated by predaceous nonnatives and invaded in spring by channel catfish and carp. Young razorback suckers released above the water falls and allowed to grow past the size of predator susceptibility could use the Lake Mead inflow as adult habitat. The chances for successful reproduction and recruitment by these stocks cannot be assessed at this time but would be greatly reduced below fish barriers by large numbers of nonnative fishes in the region.

This investigation revealed that interim flows continue to be manifested as fluctuating river stages of as much as $90 \mathrm{~cm}$ just above the Lake Mead inflow, about 250 miles of Glen Canyon Dam. While these changes may destabilized shoreline habitats and periodically affect fish access to tributaries, no direct relationships have been identified to current fish population distributions and levels. Although this region of the Colorado River is far enough downstream from the dam to allow for longitudinal warming of river temperatures, effects of cold releases on primary and secondary production extend into this region, limiting food resources for fish. The preliminary determination from this investigation is that interim flows alone do not appear to detrimentally impact aquatic resources of the area. Instead, the synergistic effect of fluctuating flows, low temperatures, absence of spring runoff, and particularly nonnative fishes, has affected the riverine ecosystem throughout Grand Canyon. Effects of interim flows to the lower 45 miles of the study area, downstream of Bridge Canyon, are overwhelmed by fluctuating levels of Lake Mead, massive sediment deposits that have altered channel geomorphology, and the abundance nonnative fishes residing in the reservoir. Commercial motorized boat traffic (i.e., large jet boats) that transport rafters across flatwater areas (Bridge Canyon to Pearce Ferry) generate sudden and fast-moving waves that may erode banks and destabilize shorelines to a greater degree than dam operations.

\section{Valdez, R.A., T.L. Hoffnagle, C.D. McIvor, T. McKinney and W.C. Liebfried. 2001. Effects of a test flood on fishes of the Colorado River in Grand Canyon, Arizona. Ecological Applications 11:686-700.}

A beach/habitat-building flow (i.e., test flood) of $1,274 \mathrm{~m}^{3} / \mathrm{s}$, released from Glen Canyon Dam down the Colorado River through Grand Canyon, had little effect on distribution, abundance, or movement of native fishes, and only short-term effects on densities of some nonnative species. Shoreline and backwater catch rates of native fishes, including juvenile humpback chub (Gila cypha), flannelmouth suckers (Catostomus latipinnis), and bluehead suckers (C. discobolus), and all ages of speckled dace (Rhinichthys osculus), were not significantly different before and after the flood. Annual spring spawning migrations of flannelmouth suckers into the Paria River and endangered humpback chub into the LCR took place during and after the flood, indicating no impediment to fish migrations. Pre-spawning adults staged in large slack water pools formed at the mouths of these tributaries during the flood. Net movement and habitat used by nine radio-tagged adult humpback chub during the flood were not significantly different from prior observations. Diet composition of adult humpback chub varied, but total biomass did not differ significantly before, during, and after the 
flood, indicating opportunistic feeding for a larger array of available food items displaced by the flood. Numbers of nonnative rainbow trout (Oncorhynchus mykiss) ,152 mm total length decreased by $8 \%$ in electrofishing samples from the dam tailwaters $(0-25 \mathrm{~km}$ downstream of the dam) during the flood. Increased catch rates in the vicinity of the LCR (125 km downstream of the dam) and Hell's Hollow (314 km downstream of the dam) suggest that these young trout were displaced downstream by the flood, although displacement distance was unknown since some fish could have originated from local populations associated with intervening tributaries. Abundance, catch rate, body condition, and diet of adult rainbow trout in the dam tailwaters were not significantly affected by the flood, and the flood did not detrimentally affect spawning success; catch of YOY increased by $20 \%$ in summer following the flood. Post-flood catch rates of nonnative fathead minnows (Pimephales promelas) in shorelines and backwaters, and plains killifish (Fundulus zebrinus) in backwaters decreased in the vicinity of the LCR, and fathead minnows increased near Hell's Hollow, suggesting that the flood displaced this nonnative species. Densities of rainbow trout and fathead minnows recovered to pre-flood levels eight months after the flood by reinvasion from tributaries and reproduction in backwaters. We concluded that the flood was of insufficient magnitude to substantially reduce populations of nonnative fishes, but that similar managed floods can disadvantage alien predators and competitors and enhance survival of native fishes.

\section{Weiss, J. 1992. The relationship between flow and backwater fish habitat of the Colorado River in Grand Canyon. Draft report. Glen Canyon Environmental Studies, Bureau of Reclamation, Flagstaff. pp 13. Abstract excerpted from study introduction and results.}

The purpose of this study was to assess the size and number of backwaters at different flow levels in order that a recommendation might be made on a flow level that would optimize conditions for native fishes.

Colorado River backwaters are an important nursery and resting area for both native and introduced fishes. Since the construction of Glen Canyon Dam, backwaters are the only portion of the mainstem offering warm water for successful rearing, higher productivity, lower current, refugia from predatory fishes, and other characteristics needed for optimum growth.

In 1991, backwater numbers decreased from 36 at 5,000 cfs to 9 at $15,000 \mathrm{cfs}$. The total area of backwaters at $5,000 \mathrm{cfs}$ was $32,301 \mathrm{~m}^{2}$, and decreased to $5,708 \mathrm{~m}^{2}$ at $15,000 \mathrm{cfs},(18 \%$ of the backwaters at $5000 \mathrm{cfs}$ ). The total number of backwaters decreases with an increase in discharge. At 15,000 cfs, there were 8 connected backwaters and 1 isolated backwater. There were 32 return channels at 5,000 cfs, and at 15,000 cfs there were 8 return channels.

There was a four-fold increase in the number of backwaters at 4,800 cfs (130) as compared with the backwaters present at $28,000 \mathrm{cfs}(20)$ in 1985 . When availability of backwaters was examined at 28,000 cfs, RM 61.5-77 contained only 4 connected backwaters ( $2.1 \%$ of all backwaters). At $4,800 \mathrm{cfs}$, there were 78 connected backwaters $(15.7 \%)$, a twentyfold increase.

A comparison of backwaters with the 11 geomorphic reaches as defined by Schmidt and Graf (1988) was performed. The reaches are based on the types of bedrock exposed at river 
level. Because channel characteristics of the Colorado River vary with the types of bedrock that are exposed, these reaches may reflect backwater size and abundance. The analysis showed that the most numerous numbers of backwaters occurred in the widest reaches, which are reaches 4.5 and 10. This occurred in the $19854,800 \mathrm{cfs}$ flow and the $19915,000 \mathrm{cfs}$ flow. The 1991 data at $15,000 \mathrm{cfs}$ flow and the $19928000 \mathrm{cfs}$ flow showed the highest number of backwaters remaining in reaches: 4 and 10, respectively.

\subsection{EFFECTS ON SEDIMENT AND DEBRIS DEPOSITION}

\section{Benenati, E.P., J.P. Shannon, J.S. Hagan and D.W. Blinn. 2001. Drifting fine particulate organic matter below Glen Canyon Dam in the Colorado River, Arizona. Journal of Freshwater Ecology 16(2):235-248.}

The concentration and composition of drifting fine particulate organic matter (FPOM) in regulated rivers may be influenced by dam operations and site of collection within the river channel. The authors examined FPOM composition and biomass in the Colorado River, Arizona below Glen Canyon Dam along a $350 \mathrm{~km}$ reach during 15 collection trips over four years. Lotic zooplankton and detritus components were positively correlated with distance downriver from the dam, increased discharge, and near-shore habitats versus mid-channel locations. Lentic zooplankton also increased at higher discharges and in near-shore habitats but was negatively correlated with distance downriver. There is evidence that the near-shore habitat provides a more stable environment than the mainstem for invertebrates which may enhance rearing and development of lentic zooplankton.

\section{Dexter, L.R. and B.L. Cluer. 1999. Cyclic erosional instability of sandbars along the Colorado River, Grand Canyon, Arizona. Annals of the Association of American Geographers 89(2):238-266.}

The study and management of regulated rivers have become important issues. A prime example is Glen Canyon Dam and its operational impacts on the downstream environment in Grand Canyon National Park, Arizona. We present an overview of the Glen Canyon Dam environmental issue, a novel methodology for monitoring dam impacts on alluvial sediments, and three years of study relating to the stability of alluvial deposits along the Colorado River. This research uses oblique photographs taken daily, automatically, from twenty-one fixedposition programmable cameras. Digital image-processing techniques created planimetric models of sandbar area from the photos for the period of March 1993 through May 1995. The technique allowed daily tracking of sandbar areas for detection of rapid erosional events. We demonstrated that rapid erosional events occur commonly on Grand Canyon sandbars. Sandbars are unstable over the study period, especially the first two years. Most of the rapid erosional events are associated with weekend or seasonal reduction in flow. Sandbar area frequency is bimodal with negative kurtosis, indicating that measurements taken at long time-steps are not likely to document mean area but rather minima or maxima. Time-series analysis suggests that periods of relative stability occur between rapid area-reducing events. Sandbars appear to adjust in two modes, a short-term adjustment mode occurring over hours and a long-term adjustment mode over days to weeks. The understanding and minimization of rapid-failure events should be 
increased, and the phenomenon needs to be addressed in any comprehensive sediment management plan.

Grams, P.E., J.C. Schmidt and D.J. Topping. 2007. The rate and pattern of bed incision and bank adjustment on the Colorado River in Glen Canyon downstream from Glen Canyon Dam, 1956-2000. Bulletin of the Geological Society of America 119(5):556-575.

Closure of Glen Canyon Dam in 1963 transformed the Colorado River by reducing the magnitude and duration of spring floods, increasing the magnitude of base flows, and trapping fine sediment delivered from the upper watershed. These changes caused the channel downstream in Glen Canyon to incise, armor, and narrow. This study synthesizes over 45 yr of channel-change measurements and demonstrates that the rate and style of channel adjustment are directly related to both natural processes associated with sediment deficit and human decisions about dam operations. Although bed lowering in lower Glen Canyon began when the first cofferdam was installed in 1959, most incision occurred in 1965 in conjunction with 14 pulsed high flows that scoured an average of $2.6 \mathrm{~m}$ of sediment from the center of the channel. The average grain size of bed material has increased from $0.25 \mathrm{~mm}$ in 1956 to over $20 \mathrm{~mm}$ in 1999 . The magnitude of incision at riffles decreases with distance downstream from the dam, while the magnitude of sediment evacuation from pools is spatially variable and extends farther downstream. Analysis of bed-material mobility indicates that the increase in bed-material grain size and reduction in reach-average gradient are consistent with the transformation of an adjustable-bed alluvial river to a channel with a stable bed that is rarely mobilized. Decreased magnitude of peak discharges in the post-dam regime coupled with channel incision and the associated downward shifts of stage-discharge relations have caused sandbar and terrace erosion and the transformation of previously active sand-bars and gravel bars to abandoned deposits that are no longer inundated. Erosion has been concentrated in a few pre-dam terraces that eroded rapidly for brief periods and have since stabilized. The abundance of abandoned deposits decreases downstream in conjunction with decreasing magnitude of shift in the stage-discharge relations. In the downstream part of the study area where riffles controlling channel elevation have not incised, channel narrowing has resulted from decreased magnitude of peak discharges and minor post-dam deposition. These physical changes to the aquatic and riparian systems have supported the establishment and success of an artifact ecosystem dominated by non-native species. Models for the channel response downstream from large dams typically consider factors such as the degree of sediment deficit, the pre-dam surface and subsurface grain size, and the magnitude of post-dam average flows. These results suggest that it is also necessary to consider (1) the possibility of variable responses among different channel elements and (2) the potential importance of exceptional flows resulting from management decisions.

\section{Howard, A. and R. Dolan. 1981. Geomorphology of the Colorado River in the Grand Canyon. Journal of Geology 89:269-298.}

Sediment supplied to the Colorado River within the Grand Canyon has been sorted into distinct deposits of three grain size ranges. The major rapids are formed by boulder deposits from side-canyon tributaries. As a result of a fourfold reduction in peak discharge when Glen Canyon Dam was closed in 1963, new fan debris may increase the gradient through some of the rapids by a factor of 1.8. Cobbles and gravel, transported only during flood stages, are 
preferentially deposited in the wider sections of the river as bars and riffles and are, for the most part, inactive during post-dam discharges. Fine-grain (largely sandy) terraces occur throughout the canyon, especially along the banks of the large reverse eddies above and below the rapids. The lower terraces are being reworked into beach-like shores by diurnally-varying, post-dam discharges. A slight net lateral erosion of the terraces has resulted. Prior to construction of the dam, sandy bed deposits underwent scour averaging about $1 \mathrm{~m}$ during spring floods, balanced by deposition from tributary sources during the summer. Downstream from rapids, decreased turbulence due to lower discharges has resulted in deposition averaging $2.2 \mathrm{~m}$ on the bed within the upper portions of the canyon. Difference in rock types along the river determine overall channel morphology. Rocks of low resistance result in a wide valley, a meandering channel, and abundant cobble bars and sand terraces. Narrow channels with rapids and deep pools are most frequent within the sections of the canyon where Precambrian crystalline rocks dominate.

LaGory, K.E., J.W. Hayse, and D. Tomasko. 2003. Recommended priorities for geomorphology research in endangered fish habitats of the Upper Colorado River Basin. Final report of Argonne National Laboratory to Upper Colorado River Endangered Fish Recovery Program, Lakewood, Colorado.

Activities of the Upper Colorado River Endangered Fish Recovery Program (Recovery Program) include habitat improvement and management (e.g., restoration of flooded bottomlands, provision of fish passage) and flow management to provide suitable habitat conditions for the four species of endangered fishes in the Upper Colorado River Basin Colorado pikeminnow (Ptychocheilus lucius), humpback chub (Gila cypha), bonytail (Gila elegans), and razorback sucker (Xyrauchen texanus). In this report, we identify and apply an approach for prioritizing river reaches and habitats for geomorphic research in the Upper Colorado River Basin.

The goal of this project was to identify priorities for geomorphology research in endangered fish habitats of the Upper Colorado River Basin. These recommended priorities provide input to the Recovery Program as it develops a comprehensive research and monitoring program for endangered fish habitats. Project objectives included:

- Review and consolidate geomorphic, habitat, and flow information;

- Identify relationships among flow regimes, habitats, fish needs, and recovery goals; and

- Identify data gaps and rank their importance to recovery.

The report focuses on the reaches and habitats used by life stages (larvae, juveniles, subadults, adults, and spawning) of three of the four species - the Colorado pikeminnow, humpback chub, and razorback sucker. Insufficient information was available on the bonytail to permit a meaningful evaluation. The evaluation includes the Green River between Flaming Gorge Dam and its confluence with the Colorado River and the upper Colorado River upstream of the headwaters of Lake Powell. Major tributaries of these two rivers, up to the point of occupation by endangered fishes, also were included. 
We developed a linked-matrix approach to systematically and objectively identify overall priorities for research. Spreadsheets were developed that contained scores $(0,1,2$, or 3$)$ to represent relative importance of (1) existing reach use for species and life stages, (2) habitat use for species and life stages, (3) habitat occurrence within planform types, and (4) dependencies between habitat characteristics and hydrologic and geomorphic parameters. Scores also were assigned to life stages and species on the basis of sensitivity to environmental variability and population status, respectively. These scores enabled weighting of life stages and species when scores were combined to determine overall priorities. Weights were applied in a phased manner that enabled consideration of priorities at various levels, including (1) species-life stage, (2) species, and (3) all species combined. Scores were developed during two workshops attended by researchers from various agencies, consulting firms, and universities.

The Upper Colorado River Basin was subdivided into the Green River subbasin and the upper Colorado River subbasin. Each major river was divided into reaches based on the dominant geomorphic planform (restricted meander, fixed meander, and canyon). These planforms describe various levels of confinement of the river channel within the surrounding geology, which in turn affects habitat characteristics relevant to endangered fishes. Restricted meanders occur in broad alluvial terraces that are bounded by relatively more resistant geology. Fixed meanders are confined by resistant geology on both outside and inside bends of the main channel. Canyons consist of relatively straight sections of river with resistant geology on both sides of the river. Habitat types considered included pools, runs, riffles/rapids, connected backwaters, side channels, eddies, flooded tributary mouths, and flooded bottomlands.

Consideration also was given to potential use of reaches, assuming improvements in conditions in response to implementation of flow recommendations, planned removal of existing barriers to passage, and successful establishment of populations through augmentation. Consideration of potential reach use was considered especially important for the razorback sucker in the upper Colorado River subbasin, because existing levels of use are so low and so few larvae and juveniles exist in the system.

Once we computed reach-habitat scores and scored the dependence of habitat characteristics on hydrology and geomorphology, we searched the available literature for studies that addressed important parameters in the highest scoring reaches and habitats. Remaining information needs were those important relationships in priority reaches and habitats that had not been addressed by previous studies.

In the Green River subbasin, the highest overall reach-habitat scores for species and life stages combined are in the Split Mountain Canyon to Desolation Canyon reach. Habitats with high scores in this restricted-meander reach include connected backwaters, side channels, flooded tributary mouths, and flooded bottomlands. All are low-velocity habitats that serve as critical nursery areas for Colorado pikeminnow and razorback suckers.

The extremely dynamic nature of backwater and side-channel habitats demands a greater understanding of the geomorphic processes that form and maintain those habitats. Additional research is needed to verify the existing conceptual model of backwater formation and more fully understand underlying geomorphic processes, including the effects of antecedent conditions. 
Studies are also needed to address the effects of base-flow variability (inter-annual, intra-annual, and within day) on backwater and side-channel habitat availability and conditions.

Scores were high for spawning bar complexes in the Desolation and Gray Canyons reach and in the Yampa Canyon reach because several species spawn in each. Studies are needed of spawning bars in the Split Mountain Canyon to Desolation Canyon reach and in Desolation and Gray Canyons to determine the effects of peak flow, base flow, and sediment characteristics on the formation and maintenance of suitable spawning habitats. Although several studies have examined geomorphic properties of the razorback spawning bar in the Split Mountain Canyon to Desolation Canyon reach, additional study is needed to verify the existing conceptual model for this bar and better understand the effects of peak-flow magnitude, peak-flow duration, peak-flow frequency, peak-flow timing, and sediment on habitat conditions during the spawning period.

Several studies have examined the underlying geomorphic processes that affect the formation and characteristics of backwaters and side channels in the upper Colorado River upstream of Westwater Canyon, and focused on the effects of a few high-water years in the 1990s. It is important to study flow-habitat relationships in more years and to determine the role of peak-flow magnitude, duration, frequency, and variability on habitat maintenance. In addition, geomorphic processes affecting backwaters in the Moab Bridge to Green River reach have not been studied, and the processes identified for the gravel-bedded upper river would not apply to this sand-bedded reach. As for the Green River, additional studies of backwater availability need to be conducted because of the dynamic nature of this habitat.

No studies have been conducted of spawning habitat in any reach in the upper Colorado River subbasin because spawning apparently is not concentrated in a few areas as it is in the Green River subbasin. However, studies of spawning habitat and the underlying geomorphic processes that affect availability and characteristics during the spawning season are critically needed. Studies should focus on identifying suitable spawning habitats and determining the effects of peak flow, base flow, and sediment characteristics on spawning habitat.

We suggest that reach-habitat priorities based on existing levels of reach use be used wherever possible to avoid the uncertainties associated with potential use. However, the population status of razorback suckers in the upper Colorado River subbasin and barriers to fish passage in the upper river reduces the value of using existing use patterns in developing priorities for geomorphic research. Consequently, we recommend basing prioritization on potential reach use for the upper Colorado River subbasin. As the status of populations change in response to management actions, including stocking, habitat improvements, and reconnection to historic habitat, priorities for the upper Colorado River subbasin should be reconsidered.

We recommend a phased, integrated approach to implementation of the research priorities identified in this report. Primary information needs for overall reach-habitat priorities should be considered the highest priorities for research because research on these topics and reaches has the potential to have the largest benefit to recovery of the endangered fishes. Consideration should also be given to those primary species-specific information needs. Primary information needs for overall reach-habitat priorities in the Green River and upper Colorado River subbasins include: 


\section{Green River Subbasin (based on existing conditions in the subbasin)}

1. Connected backwaters and side channels (Split Mountain Canyon to Desolation Canyon and Labyrinth and Stillwater Canyons)

- Role of peak flow (magnitude, duration, and frequency) and sediment on formation and maintenance of habitats.

- Effects of antecedent conditions (flow and sediment) and base-flow magnitude on habitat availability.

- Effects of base-flow variability on inter-annual availability, intra-annual stability, and within-day stability.

2. Flooded bottomlands (Split Mountain Canyon to Desolation Canyon)

- Effects of peak flow (magnitude, duration, and frequency), sediment, and configuration of connection to main channel on maintenance of connection and sediment deposition effects.

3. Spawning bar complexes (Desolation and Gray Canyons)

- Effects of peak flow (magnitude, duration, frequency, and timing), base flow (magnitude and duration), and sediment on habitat conditions during the spawning period.

\section{Upper Colorado River Subbasin (based on potential conditions in the subbasin)}

1. Connected backwaters and side channels (Moab Bridge to Green River)

- Same as those identified for Split Mountain Canyon to Desolation Canyon reach of the Green River.

2. Flooded bottomlands (Palisade to Gunnison River and Gunnison River to Loma)

- The relationship of habitat availability to peak-flow and base-flow magnitude.

- Effects of peak flow (magnitude, duration, and frequency), sediment, and configuration of connection to main channel on maintenance of connection and sediment deposition effects.

3. Flooded bottomlands (Gunnison River-Hartland Dam to Roubideau Creek)

- Effects of peak flow (magnitude, duration, and frequency), sediment, and configuration of connection to main channel on maintenance of connection and sediment deposition effects.

4. Spawning bar complexes in the Colorado River (Palisade to Gunnison River, Gunnison River to Loma, and Loma to Westwater) and Gunnison River (Hartland Dam to Roubideau Creek, Roubideau Creek to Colorado River)

- Location and characteristics of spawning habitats. 
- Effects of peak flow (magnitude, duration, frequency, and timing), base flow (magnitude and duration), and sediment on habitat conditions during the spawning period.

Primary information needs to address species-specific reach-habitat priorities include:

\section{Green River Subbasin (based on existing conditions in the subbasin)}

1. Colorado Pikeminnow

a. Connected backwaters and side channels (Split Mountain Canyon to Desolation Canyon, Gray Canyon to Labyrinth Canyon, Labyrinth and Stillwater Canyons)

- Same as those identified for Split Mountain Canyon to Desolation Canyon reach under overall reach-habitat priorities above.

b. Spawning bar complexes (Desolation and Gray Canyons)

- Same as those identified for Desolation and Gray Canyons reach under overall reach-habitat priorities above.

2. Humpback Chub

a. Spawning bar complexes (Desolation and Gray Canyons)

- Same as those identified for Desolation and Gray Canyons reach under overall reach-habitat priorities above.

3. Razorback Sucker

a. Spawning bar complexes (Split Mountain Canyon to Desolation Canyon)

- Same as those identified for Desolation and Gray Canyons under overall reach-habitat priorities above.

- Location of additional potential spawning areas in reach.

b. Flooded bottomlands (Split Mountain Canyon to Desolation Canyon)

- Same as those identified for Split Mountain Canyon to Desolation Canyon reach under overall reach-habitat priorities above.

\section{Upper Colorado River Subbasin (based on potential conditions in the subbasin)}

1. Colorado Pikeminnow

a. Connected backwaters and side channels (Cottonwood Wash to Dewey Bridge, Jackass Canyon to Moab Bridge, Moab Bridge to Green River)

- Same as those identified for connected backwaters in Split Mountain Canyon to Desolation Canyon reach of the Green River under overall reach-habitat priorities above.

b. Spawning bar complexes in the Colorado River (Palisade to Gunnison River, Gunnison River to Loma, Loma to Westwater, Cottonwood Wash to Dewey Bridge) and Gunnison River (Hartland Dam to Roubideau Creek, Roubideau Creek to Colorado River) 
- Same as those identified for spawning bar complexes in upper Colorado River subbasin under overall reach-habitat priorities.

2. Humpback Chub

a. Spawning bar complexes (Loma to Westwater Canyon-Black Rocks portion, Westwater Canyon)

- Same as those identified for spawning bar complexes in upper Colorado River subbasin under overall reach-habitat priorities.

3. Razorback Sucker

a. Flooded bottomlands (Palisade to Gunnison River, Gunnison River to Loma, Gunnison River-Hartland Dam to Roubideau Creek)

- Same as those identified for flooded bottomlands in upper Colorado River subbasin under overall reach-habitat priorities above.

b. Spawning bar complexes in the Colorado River (Palisade to Gunnison River, Gunnison River to Loma, Moab Bridge to Green River) and Gunnison River (Hartland Dam to Roubideau Creek).

- Same as those identified for spawning bar complexes in upper Colorado River subbasin under overall reach-habitat priorities.

c. Connected backwaters and side channels (Moab Bridge to Green River)

- Same as those identified for connected backwaters in Split Mountain Canyon to Desolation Canyon reach of the Green River under overall reach-habitat priorities above.

One aspect of a phased, integrated approach is selection among the identified information needs. For instance, rather than attempting to determine the geomorphic basis of spawning habitats in all nine of the identified high-priority reaches of the upper Colorado River subbasin simultaneously, research should focus on a limited subset of representative spawning areas in one or a few of these reaches. Reaches should be selected for further study on the basis of the results of initial studies to identify and characterize spawning habitats in the subbasin. As relationships among flow, geomorphology, and habitat characteristics are determined in representative study reaches, results can be verified in other high priority reaches.

All research of geomorphic processes and habitats should be based on hypothesis testing. We recommend that, whenever possible, studies incorporate experimental manipulations and the testing of predicted responses. We also recommend standardization of research protocols and data collection techniques. It is important to recognize that these recommendations are based on current understanding of habitat requirements and geomorphic processes. It is likely that adjustments to research priorities will be necessary as the research proceeds, and, indeed, the success of the effort will require such adaptation as new information is obtained and inferences are drawn. The research priorities identified in the report are recommendations based on data needs and their importance to recovery. Ultimately, the Recovery Program will determine the direction of future research, and multiple factors (including, but not limited to those considered in this report) will be considered in those determinations. 
Powell, K. 2002. Open the floodgates!--A second attempt to restore the altered environment of the Grand Canyon, by letting the Colorado River run free. Nature 420(6914):356-358.

On 27 March 1996, the Colorado River ran three meters higher than the previous day. The flood continued for seven days, as 1,290 cubic meters of water per second flowed through the bypass tubes of the Glen Canyon Dam, more than 160 kilometers upstream. The goal was to rebuild sandbars and beaches that had been eroded since the dam was completed in 1963 . The flood should have liberated years of accumulated sand, silt and clay from the river channel and deposit it onto the eroded beaches. A chronic lack of sediment in the river downstream of the dam doomed the flood to fail in its goal of restoring the Grand Canyon's beaches to a more natural state. Hydrologists are now planning to flood the canyon once more, timing the deluge to coincide with an abundance of fresh sediment.

Rubin, D.M., D.J. Topping, J.C. Schmidt, J. Hazel, M. Kaplinski and T.S. Melis. 2002. Recent sediment studies refute Glen Canyon Dam hypothesis. Transactions American Geophysical Union 83(25):273.

Recent studies of sedimentology, hydrology, and geomorphology indicate that releases from Glen Canyon Dam are continuing to erode sandbars and beaches in the Colorado River in Grand Canyon National Park, despite attempts to restore these resources. The current strategy for dam operations is based on the hypothesis that sand supplied by tributaries of the Colorado River downstream from the dam will accumulate in the channel during normal dam operations and remain available for restoration floods. Recent work has shown that this hypothesis is false, and that tributary sand inputs are exported downstream rapidly, typically within weeks or months under the current flow regime.

Rubin, D.M., J.M. Nelson and D.J. Topping. 1998. Relation of inversely graded deposits to suspended-sediment grain-size evolution during the 1996 flood experiment in Grand Canyon. Geology 2692):99-102.

Before Glen Canyon Dam was completed upstream from Grand Canyon, floods scoured sand from the channel bed and deposited sand on bars within recirculating eddies. After completion of Glen Canyon Dam in 1963, peak discharge of the mean annual floods dropped from about 2600 to $900 \mathrm{~m}^{3} / \mathrm{s}$, and $85 \%$ of the sediment supply was eliminated. Under the postdam flow regime, sand bars in eddies have degraded. In an experiment to study, in part, the effects of floods in rebuilding these bars, a controlled flood was released from Glen Canyon Dam in late March and early April 1996. Although fluvial sequences characteristically fine upward, the deposits of the experimental flood systematically coarsen upward. Measurements of suspended-sediment concentration and grain size and of bed-material grain size suggest that the upward coarsening results from the channel becoming relatively depleted of fine-grained sediment during the seven days of the high-flow experiment. Pre-dam flood beds of the Colorado River also coarsen upward, indicating that supply-limitation and grain-size evolution are natural processes that do not require the presence of a dam. 
Schmidt, J.C. 1994. Compilation of historic hydrologic and geomorphic data for the upper Colorado River basin. Annual report of Utah State University Department of Geography and Earth Resources to Upper Colorado River Endangered Fish Recovery Program, Lakewood, Colorado. Abstract excerpted from results and conclusions.

Preliminary results of ongoing investigations of the geomorphology and hydrology records of the Green River Basin are: (1) The magnitude of the annual peak discharge of the Green River upstream from the Yampa River has decreased about 60\% from the 1923-1962 period to the period following closure of Flaming Gorge Dam. At Jensen and Green River, Utah, the changes have been about $25 \%$, depending on the recurrence of the flood being evaluated. Floods on the Yampa River were unchanged during the same periods. (2) The highest floods of this century occurred in the early part of the century. Instantaneous peak discharge at Green River, Utah, exceeded $60,000 \mathrm{ft}^{3} / \mathrm{s}\left(1,698 \mathrm{~m}^{3} / \mathrm{s}\right)$ in $1897,1909,1917$, and 1921 . Peak flows at Greendale are estimated to have exceeded $20,000 \mathrm{ft}^{3} / \mathrm{s}\left(566 \mathrm{~m}^{3} / \mathrm{s}\right)$ in 1899,1918 , and 1921 . These floods are unprecedented; the fact that floods of this magnitude do not occur at present may be related to climatic change and be unrelated to the existence of dams. The effects of these floods on habitat availability have not been evaluated. (3) The bed at the Greendale gage aggraded 0.3 $\mathrm{ft}$ between 1961 and 1987. (4) The bed at the Jensen gage has not changed in elevation since 1948. Speculation about channel degradation in the Razorback Bar and Escalante Bottoms area is not supported by these findings. (5) Degradation of about $0.3 \mathrm{ft}$ of the channel bed at Ouray occurred between 1951 and 1966. It is unlikely that these changes are related to the Flaming Gorge Dam. (6) Prior to closure of the Flaming Gorge Dam, the Green River near Greendale, Utah, was covered by ice between 3 and 5 months per year. The last year that ice cover was reported at this gage was 1958. (7) Between the winters of 1946-47 and 1960-67, the average duration of ice cover was 3.6 months near Jensen. Since that time, the duration has decreased to 0.8 months. At Ouray, the average duration of ice cover was 3 months between 1951 and 1965 . (8) A new floodplain, in apparent equilibrium with reduced floods, has developed in the Uinta Basin, especially in the Ouray National Wildlife Refuge. This floodplain is regularly inundated, but the areal extent of these surfaces is an order of magnitude less than the pre-dam floodplain. It appears that significant inundation of the alluvial valley of the Green River may not have regularly occurred since the 1920s. (9) Significant channel narrowing in Lodore Canyon has occurred since closure of Flaming Gorge Dam. Numerous eddy bars have been vegetated, and backwater habitats may have been lost.

Schmidt, J.C. and D.M. Rubin. 1995. Regulated streamflow, fine-grained deposits, and effective discharge in canyons with abundant debris fans. Pages 177-195 in J. E. Costa, A. J. Miller, K. W. Potter and P. R. Wilcock, editors. Natural and anthropogenic influences in fluvial geomorphology. AGU Geophysical Monograph 89. Abstract excerpted from results and conclusions.

The debris fan-eddy complex is the fundamental geomorphic channel unit in canyons with abundant debris fans. This assemblage includes, in a downstream direction, a river segment of ponded flow that has a low downstream velocity and that is controlled by a downstream channel constriction, a constricting debris fan, eddies and eddy bars, and a gravel bar. This assemblage occurs at nearly every tributary mouth where debris fans constrict the river. Such tributaries exist along many, but not all, of the narrow canyons of the Green and Colorado 
Rivers. Reaches affected by debris fans are steeper, have higher stream power per unit bed area, and have coarser beds than other narrow canyons of the same river system. The extent of each channel element varies from site to site.

Schmidt, J.C., D.J. Topping, P.E. Grams and J.E. Hazel. 2004. System wide changes in the distribution of fine sediment in the Colorado River corridor between Glen Canyon Dam and Bright Angel Creek, Arizona. Final report of the Fluvial Geomorphology Laboratory, Utah State University, Logan, Utah. 99 p.

The riverine ecosystem of the Colorado River between Glen Canyon Dam and Bright Angel Creek had less fine sediment on its bed, in eddies, and as channel-margin deposits in 2001 than it did prior to completion of the dam. Changes in dam operations in the 1990s did not arrest this trend.

The decrease in fine sediment storage is documented by comparison of historical oblique photographs, analysis of historical aerial photographs, and field surveys since 1990. The magnitude of the decrease is uncertain. The loss of sand is probably about $25 \%$ of the area typically exposed at base flow in pre-dam photographs, but estimates range between 0 and $-55 \%$, depending on study reach and method of analysis. There is no indication that the magnitude of decrease is less in the downstream part of the study area. The cumulative loss of eddy sand is about $1 \mathrm{~m}$ in thickness but also varies greatly.

Eddies are now the primary storage site of fine sediment. Eddies have always been a very large storage site for fine sediment, but the bed once played a more important role than it does today. The bed has been significantly lowered in Glen Canyon, but the bed has only degraded in pools and ponded backwaters in Marble and Upper Grand Canyons. There is no evidence that fine sediment aggrades on the main channel bed or in the deep parts of eddies for longer than a few weeks to a few months, and these parts of the river respond quickly to changes in flow and sediment transport. These areas evacuate fine sediment during flows typical of the 1990s. Postdam flood deposits have a longer response time and adjust over a period of years to decades to changes in dam operations. These deposits are only constructed by dam releases that exceed power plant capacity. They are subject to large erosion rates during the first months following flood recession, but erosion rates thereafter decrease. The area of these deposits caused by the 1996 Controlled Flood lasted about 5 years, although some individual deposits remain large today.

Topping, D.J., D.M. Rubin and L.E. Vierra, Jr. 2000. Colorado River sediment transport 1. Natural sediment supply limitation and the influence of Glen Canyon Dam. Water Resources Research 36:515-542.

Analyses of flow, sediment-transport, bed-topographic, and sedimentologic data suggest that before the closure of Glen Canyon Dam in 1963, the Colorado River in Marble and Grand Canyons was annually supply-limited with respect to fine sediment (i.e., sand and finer material). Furthermore, these analyses suggest that the predam river in Glen Canyon was not supplylimited to the same degree and that the degree of annual supply limitation increased near the head of Marble Canyon. The pre-dam Colorado River in Grand Canyon displays evidence of 
four effects of supply limitation: (1) seasonal hysteresis in sediment concentration, (2) seasonal hysteresis in sediment grain size coupled to the seasonal hysteresis in sediment concentration, (3) production of inversely graded flood deposits, and (4) development or modification of a lag between the time of a flood peak and the time of either maximum or minimum (depending on reach geometry) bed elevation. Analyses of sediment budgets provide additional support for the interpretation that the pre-dam river was annually supply-limited with respect to fine sediment, but it was not supply-limited with respect to fine sediment during all seasons. In the average predam year, sand would accumulate and be stored in Marble Canyon and upper Grand Canyon for 9 months of the year (from July through March) when flows were dominantly below 200$300 \mathrm{~m}^{3} / \mathrm{s}$; this stored sand was then eroded during April through June when flows were typically higher. After closure of Glen Canyon Dam, because of the large magnitudes of the uncertainties in the sediment budget, no season of substantial sand accumulation is evident. Because most flows in the post-dam river exceed $200-300 \mathrm{~m}^{3} / \mathrm{s}$, substantial sand accumulation in the post-dam river is unlikely.

\section{Topping, D.J., D.M. Rubin and T.S. Melis. 2007. Coupled changes in sand grain size and sand transport driven by changes in the upstream supply of sand in the Colorado River: relative importance of changes in bed-sand grain size and bed-sand area. Sedimentary Geology 202(3):538-561.}

Sand transport in the Colorado River in Marble and Grand canyons was naturally limited by the upstream supply of sand. Prior to the 1963 closure of Glen Canyon Dam, the river exhibited the following four effects of sand supply limitation: (1) hysteresis in sediment concentration, (2) hysteresis in sediment grain size coupled to the hysteresis in sediment concentration, (3) production of inversely graded flood deposits, and (4) development or modification of a lag between the time of a flood peak and the time of either maximum or minimum (depending on reach geometry) bed elevation. Construction and operation of the dam has enhanced the degree to which the first two of these four effects are evident, and has not affected the degree to which the last two effects of sand supply limitation are evident in the Colorado River in Marble and Grand canyons. The first three of the effects involve coupled changes in suspended-sand concentration and grain size that are controlled by changes in the upstream supply of sand. During tributary floods, sand on the bed of the Colorado River fines; this causes the suspended sand to fine and the suspended-sand concentration to increase, even when the discharge of water remains constant. Subsequently, the bed is winnowed of finer sand, the suspended sand coarsens, and the suspended-sand concentration decreases independently of discharge. Also associated with these changes in sand supply are changes in the fraction of the bed that is covered by sand. Thus, suspended-sand concentration in the Colorado River is likely regulated by both changes in the bed-sand grain size and changes in the bed-sand area. A physically based flow and suspended-sediment transport model is developed, tested, and applied to data from the Colorado River to evaluate the relative importance of changes in the bed-sand grain size and changes in the bed-sand area in regulating suspended-sand concentration. Although the model was developed using approximations for steady, uniform flow, and other simplifications that are not met in the Colorado River, the results nevertheless support the idea that changes in bed-sand grain size are much more important than changes in bed-sand area in regulating the concentration of suspended sand. 
Webb, R.H., D.L. Wegner, E.D. Andrews, R.A. Valdez and D.T. Patten. 1999. Downstream effects of Glen Canyon dam on the Colorado River in Grand Canyon: a review. Geophysical Monograph 110:1-21.

Glen Canyon Dam, completed in 1963, has altered geomorphic and ecological processes and resources of the Colorado River in Grand Canyon. Before the dam was completed, the river transported large quantities of sediment during spring floods as large as $8500 \mathrm{~m}^{3} / \mathrm{s}$. After 1963 , dam releases typically were less than $900 \mathrm{~m}^{3} / \mathrm{s}$ with large diurnal fluctuations and little sediment. The 2-yr peak discharge decreased by a factor of 2.5 , resulting in aggraded rapids and a large increase in riparian vegetation. The clearwater releases from the dam eroded sand deposited on the bed and banks. Although pre-dam water temperatures varied seasonally, darn releases typically are about $8^{\circ} \mathrm{C}$ year round. Because of the clear, cold water and reduced flooding, postdam aquatic productivity is considerably higher in the tailwater. Rainbow trout and other nonnative fishes are now common, 3 native species have been extirpated, and the remaining species, including the endangered humpback chub, cannot successfully reproduce in the river.

\section{Webb, R.H., P.G. Griffiths, C.S. Magirl and T.C. Hanks. 2005. Debris flows in Grand Canyon and the rapids of the Colorado River. Pages 139-152 in Gloss, S.P., J.E. Lovich and T.S. Melis, eds., The state of the Colorado River ecosystem in Grand Canyon. A report of the Grand Canyon Monitoring and Research Center 1991-2004. USGS Circular 1282. U.S. Geological Survey, Flagstaff, Arizona.}

Debris flows transport poorly sorted sediment onto debris fans in the Colorado River at a frequency that varies through Grand Canyon. Historically, an average of 5.0 debris flows per year has occurred in Grand Canyon. The occurrence of these debris flows does not appear to be related to seasonal precipitation amounts. Modeling debris-flow frequency in Grand Canyon based on the interpretation of 1,365 photographs of the river corridor yielded frequency information in 167 of 740 tributaries (23\%). Of the 167 tributaries, 98 (59\%) had debris flows during the last $100 \mathrm{yr}$.

Frequency estimates indicate that $57 \%$ of the tributaries had at least one debris flow per century, while about $10 \%$ of the tributaries had a frequency of more than two debris flows per century. Estimates of sediment yield to the Colorado River in Grand Canyon by debris flow are as high as 3.3 million tons (3.0 million $\mathrm{Mg}$ ) of sediment per decade, of which 452,000 tons $(410,000 \mathrm{Mg})$ are boulders larger than 10 inches $(>256 \mathrm{~mm})$ in diameter. Distributed evenly throughout the river corridor, these boulders would raise the bed in Grand Canyon by $2.3 \mathrm{ft}$ per thousand years $(0.72 \mathrm{~m}$ per thousand years). If deposition is limited to existing debris fans at tributary mouths, these boulders would raise the bed by an average of $8.66 \mathrm{ft}(2.64 \mathrm{~m})$ per thousand years at each confluence.

By combining the frequency model with relations for debris-flow volume and particlesize distribution, debris-flow sediment yields were calculated for several time periods. On average, debris flows deliver between 0.15 .106 and 0.33 .106 tons/yr $(0.14 .106$ and $0.30 .106 \mathrm{Mg} /$ $\mathrm{yr}$ ) of sediment to the main channel. Although debris flows deliver only 23,142 to 48,488 tons/yr (21,000 to $44,000 \mathrm{Mg} / \mathrm{yr}$ ) of boulders to the river, these boulders control the longitudinal profile and geomorphic framework of the river, defining debris fans, rapids, and related sandbars, and 
are unlikely to be removed by regulated flows. Moreover, the effects of debris flows are shown to affect the river on several length and temporal scales.

Comparison of the two water-surface profiles (one surveyed in 1923 and one in 2000) showed a change in 80 rapids. The average elevation of pools at the heads of rapids was $0.85 \mathrm{ft}$ $(0.26 \mathrm{~m})$ higher between 1923 and 2000, indicating net aggradation of the coarse-grained sediment forming the rapids throughout Grand Canyon. Furthermore, comparison of the two water-surface profiles showed enhanced pool-and-rapid structure; while 50\% of the total drop of the river occurred in just $9 \%$ of the river distance in 1923, that figure increased to $66 \%$ by 2000 . Reconstruction of water-surface profiles showed that debris-flow deposition can also have large upstream effects, particularly in the cases of reducing gradients between rapids and reducing the fall in the upstream rapid.

Analysis of the entire longitudinal profile through Grand Canyon reveals convexities that reflect sustained debris-flow deposition. Specifically, there are two long wavelength (about 62 mi (about $100 \mathrm{~km})$ ), large-amplitude (49 to $98 \mathrm{ft}(15$ to $30 \mathrm{~m})$ ) river-profile convexities: the eastern canyon convexity between RM 30 and RM 80 and the western canyon convexity between RM 160 and RM 250. These large amplitude convexities have strong spatial correlations with high probabilities of debris-flow occurrence, high densities of debris fans, and the largest debris fans along the river. These convexities appear to be maintained by debris-flow activity in Grand Canyon, presumably for all of the Holocene. In this period, the Colorado River has been expending its energy transporting sediment within Grand Canyon and integrating shortwavelength convexities into long-wavelength convexities, with little or no bedrock incision.

Coarse-sediment fill in the channel of the Colorado River at any wavelength has its origins in the rapids, which result from the tributary debris flows and fans that feed them. In contrast, the amount of fill in the rapids, either individually or collectively, is a small volume compared to the fill that creates the longer wavelength convexities. Periodic channel maintenance floods are not likely to perform the transport necessary to create the longwavelength convexities, although reworking of locally aggraded debris fans is clearly feasible. The river reworking processes by which point-source contributions of debris-flow sediment are aggregated into longer wavelength convexities are as yet unknown and certainly involve a more detailed understanding of the flood dynamics of the pre-dam river. Nevertheless, the close spatial associations of the longer wavelength convexities with the locations and sizes of debris fans and with the frequency of debris flows lead to the conclusion that unusual accumulations of debris fill in the channel are their principal cause, just as they are for the rapids.

In terms of adaptive management and operations of Glen Canyon Dam, reworking of aggraded debris fans has been shown to be feasible. Reworking has been documented during modified low fluctuating flow releases, maximum powerplant releases, and flood releases up to $47,500 \mathrm{cfs}$. Both reworking and transport capacity increase with increasing discharge, which suggests that flood releases larger than powerplant capacity of about 33,500 cfs are more efficient than smaller events. Because reworking mostly occurred in the rising limb of flood hydrographs, large-magnitude floods designed for debris-fan reworking do not have to have significant duration. As shown in figure 13, a flood designed to rework debris fans could have a peak discharge of 100,000 cfs for only $1 \mathrm{~min}$ at Diamond Creek then drop rapidly to a beach- 
building discharge for several days. This type of management prescription may be only used every 5 to $10 \mathrm{yr}$, with smaller intervening releases.

Webb, R.H., P.G. Griffiths, T.S. Melis and D.R. Hartley. 2000. Sediment delivery by ungaged tributaries of the Colorado River in Grand Canyon, Arizona. Water Resources Investigations Report, U.S. Geological Survey no. 4055, pp 78.

The purpose of this report is to estimate the total sediment yield and sand delivery from ungaged tributaries in each of six reaches between Glen Canyon Dam and upper Lake Mead reservoir at the Grand Wash Cliffs. This includes the entire drainage area between Glen Canyon Dam and upper Lake Mead reservoir except for the four largest tributaries. These estimates are based on an evaluation of both the debris-flow and streamflow components of sediment yield by multiple techniques. As a secondary objective, the authors evaluate the potential influence of climatic variability on sediment input in the light of historical climatic fluctuations. This study was funded in cooperation with the Bureau of Reclamation, as part of the Glen Canyon Environmental Studies Program, and the Grand Canyon Monitoring and Research Center.

Wiele, S.M., J.B. Graf and J.D. Smith. 1996. Sand deposition in the Colorado River in the Grand Canyon from flooding of the Little Colorado River. Water Resources Research 32:3579-96.

A model of flow, sand transport, and bed evolution is used to examine processes during the 1996 controlled flood and to examine the effect of low and high sand concentrations on depositional rate, magnitude, and location. During a flood on the Little Colorado River in January 1993, water discharge in the main stem was increased to about $950 \mathrm{~m}^{3} / \mathrm{s}$ and a sand volume sufficient to increase sand concentrations to about twice the sand concentration measured on the first day of the controlled flood was delivered to the main stem and redistributed downstream. This influx of sand led to large deposits in depressions in main channel pools and deposition in recirculation zones that the model predicts originated as separation deposits and spread downstream and into the recirculation zone. In contrast, during the controlled flood at a discharge of $1270 \mathrm{~m}^{3} / \mathrm{s}$ sand was eroded from the main channel and the delivery of suspended sand from the main channel to the recirculation zones was focused at the reattachment point. Similar depositional patterns were predicted by the model using sand inputs at the upper and lower bounds of measured sand transport at the controlled flood water discharge. Rates of deposition and deposit volume were proportional to the sand input to the reach.

Wright, S.A., T.S. Melis, D.J. Topping and D.M. Rubin. 2005. Influence of Glen Canyon Dam operations on downstream sand resources of the Colorado River in Grand Canyon. Pages 17-31 in Gloss, S.P., J.E. Lovich and T.S. Melis, eds., The state of the Colorado River ecosystem in Grand Canyon. A report of the Grand Canyon Monitoring and Research Center 1991-2004. USGS Circular 1282. U.S. Geological Survey, Flagstaff, Arizona.

Extensive research and monitoring of fine-sediment transport and sandbars since the completion of the EIS have resulted in a better understanding of the geomorphology of the Colorado River in Marble and Grand Canyons and of the effects of the operations of Glen Canyon Dam on the river's downstream resources. Probably the single most important finding of 
this research and monitoring is that post-dam mainstem sand transport exceeds the post-dam supply of sand from tributaries on a seasonal to annual basis, such that the post-dam river is in an annual fine-sediment deficit (i.e., export exceeds input). This sediment deficit has resulted in a consistent downstream pattern of erosion of channel and sandbar deposits from Marble and Grand Canyons despite restrictions on daily power plant fluctuations required by the implementation of the MLFF alternative.

The finding of an annual sediment deficit directly contradicts the critical EIS assumption that sand will accumulate on the bed of the Colorado River over multiple years under the MLFF operating alternative (and minimum annual volume releases) and has important implications for the potential success of managing tributary sediment inputs. It is also worth noting that the EIS conclusion resulted fundamentally from a lack of long-term records for tributary sand supply and mainstem sand-transport rates, illustrating the importance of long-term data sets in river management. A continuous sediment budget for the Colorado River in Grand Canyon since construction of Glen Canyon Dam, based on high-frequency measurements, likely would have resulted in a different EIS conclusion about fine sediment dynamics below the dam, one that may have prevented the continued erosion of sandbars between 1991 and 2004.

A second important finding of recent research and monitoring efforts is that during the 1996 BHBF the primary source of sand for building high-elevation sandbars was the lowelevation portion of the sandbars instead of the channel bed as hypothesized in the EIS. This scenario of building high-elevation sandbars at the expense of the low-elevation portions was repeated during the powerplant capacity flow in September 2000. This process of sandbar building is supported by the finding of an absence of multiyear accumulation on the channel bed: sand cannot be transported from the bed to high-elevation sandbars because there is typically little sand available on the channel bed.

Neither of these two findings supports the EIS hypotheses, but they have led scientists and managers to reassess the management strategy for sand resources within Grand Canyon. An emerging paradigm is the need to strategically time high-flow releases in order to take advantage of sporadic tributary sediment inputs, a scenario that requires greater flexibility in the annual operating plan for the dam with respect to both hydroelectric power generation and economic cost. Only immediately after these inputs are significant sand available on the channel bed for transfer to high-elevation sandbars through high-flow releases. Alternatively, dam releases may be constrained following inputs for a period of time until a high flow can be released from the dam; however, during extended periods of above-average upper Colorado River Basin hydrology and high storage in Lake Powell, constraining daily operations may not be possible. In the absence of high-flow releases strategically timed to redistribute tributary inputs to high-elevation sandbars, the inputs are exported from Grand Canyon in a period of weeks or months under normal dam operations, leading to continued long-term erosion of sandbars.

In November 2004, this paradigm of strategically timed, high-flow releases was tested for the first time on the Colorado River. Scientists are in the process of evaluating the results of this experiment. The findings will be critical for the long-term management of fine sediment resources and sandbars in Grand Canyon. If a management approach of strategically timed, highflow releases, triggered by tributary inputs, is to be followed, then further research will be 
required to define the appropriate triggering criteria and to develop high-flow hydrographs (peaks and durations) that may optimize deposition of tributary sand inputs within eddies while minimizing export during controlled flood peaks.

If strategically timed, high-flow releases are deemed inadequate for meeting the management objectives for Grand Canyon sandbars, then alternative approaches must be considered, such as further restraints on daily powerplant operations, changes in monthly volume release patterns, or sediment augmentation.

\subsection{EFFECTS ON TEMPERATURE}

Clarkson, R.W. and M.R. Childs. 2000. Temperature effects of hypolimnial-release dams on early life stages of Colorado River Basin big-river fishes. Copeia 402-412.

Declines of native big-river fishes of the Colorado River Basin, southwestern United States, have been attributed in part to emplacement of hypolimnial-release dams. Lowered spring-summer tailwater temperatures inhibit spawning and embryonic development, depress swimming performance and growth, and reduce survival of early life stages. We examined effects of three temperatures $\left(10^{\circ} \mathrm{C}, 14^{\circ} \mathrm{C}, 20^{\circ} \mathrm{C}\right)$ on aspects of growth, development, and physiology of larval and early juvenile life stages of Xyrauchen texanus (Razorback Sucker), Catostomus latipinnis (Flannelmouth Sucker), Gila cypha (Humpback Chub), and Ptychocheilus lucius (Colorado Squawfish) in the laboratory. Lengths, weights, and specific growth rates of all species were significantly lower at $10^{\circ} \mathrm{C}$ and $14^{\circ} \mathrm{C}$ than at $20^{\circ} \mathrm{C}$, and time to transformation from larval to juvenile life stage was delayed at colder temperatures. Transfer of fishes from $20^{\circ} \mathrm{C}$ to $10^{\circ} \mathrm{C}$ (simulating transport from warm tributaries to cold tailwaters) caused loss of equilibrium in youngest life stages. All these effects increase exposure of larvae to existing sources of mortality. Conservation of the big-river species in hypolimnial-release tailwaters will require thermal modification of dam discharges to lessen detrimental effects of cold water temperatures. Because such action may also benefit nonindigenous biota, recovery of the native fauna may ultimately depend upon implementation of comprehensive (and likely expensive) control measures against nonnative species.

Paukert, C.P. and J.H. Petersen. 2007. Comparative growth and consumption potential of rainbow trout and humpback chub in the Colorado River, Grand Canyon, Arizona, under different temperature scenarios. The Southwestern Naturalist 52(2):234-242.

We used bioenergetics models for humpback chub, Gila cypha, and rainbow trout, Oncorhynchus mykiss, to examine how warmer water temperatures in the Colorado River, Grand Canyon, Arizona, through a proposed selective withdrawal system (SWS) at Glen Canyon Dam, would affect growth, consumption, and predation rates. Consumption by the rainbow trout population was at least 10 times higher than by the smaller humpback chub population. Water temperature increases of $6^{\circ} \mathrm{C}$ during autumn increased growth of humpback chub and likely increased their survival by reducing the time vulnerable to predation. Water temperature increases caused by drought in 2005 did not alter humpback chub growth as much as the SWS. Increased temperatures might cause changes to the invertebrate community and the distribution 
and abundance of other warmwater nonnative fishes. The implications on the entire aquatic community need to be considered before any management action that includes increasing water temperatures is implemented.

Vernieu, W.S., S.J. Hueffle and S.P. Gloss. 2005. Water quality in the Lake Powell and the Colorado River. Pages 1991-2004 in Gloss, S.P., J.E. Lovich and T.S. Melis, eds., The state of the Colorado River ecosystem in Grand Canyon. A report of the Grand Canyon Monitoring and Research Center 1991-2004. USGS Circular 1282. U.S. Geological Survey, Flagstaff, Arizona.

Water temperature, nutrient concentrations, turbidity, and other water-quality parameters are of interest to managers and scientists because these parameters influence a range of ecosystem components, from support of aquatic microorganisms and invertebrates to the behavior of native and nonnative fishes. For example, declines of Colorado River Basin native fishes and changes in their condition have been attributed, in part, to low water temperatures downstream from dams, such as Glen Canyon Dam, that release water from deeper portions of the reservoir. Similarly, water quality is an important determinant of food-web structure in aquatic habitats and abundance of consumers like fish in those food webs.

\subsection{EFFECTS ON FOOD AVAILABILITY}

Benenati, E.P., J.P. Shannon, D.W. Blinn, K.P. Wilson, and S.J. Hueftle. 2000. Reservoirriver linkages: Lake Powell and the Colordao River, Arizona. Journal of the North American Benthological Society 19(4):742-755.

The effect of lotic-lentic interactions on the phytobenthic community was studied in the Colorado River below Glen Canyon Dam (GCD), Arizona. Major compositional changes in river phytobenthos occurred following high snowmelt inflows that filled the Lake Powell reservoir and resulted in high, steady discharges from GCD. Cladophora glomerata, the previously dominant alga, was partly displaced by a mixed mucilaginous phytobenthic assemblage consisting of miscellaneous algae, macrophytes, and bryophytes (MAMB). Relationships between abiotic parameters (discharge, conductivity, nutrient concentration, and season) and biotic responses (composition and biomass of filamentous and epiphytic algae, and invertebrate biomass) were analyzed from 1995 to 1998. In addition, the response of the phytobenthos to an experimental flood (1275 m super (3)/s) was examined in the tailwaters below GCD. Significant compositional changes occurred within 3 mo of lake filling and the onset of elevated discharges in June 1995. Relative phytobenthic composition by biomass prior to June 1995 was: Cladophora glomerata $=91.5 \%, \mathrm{MAMB}=3.5 \%$, and cyanobacteria $=5.0 \%$, compared to 49.6, 47.9, and 2.5\%, respectively, after the initiation of high discharges. Cladophora and MAMB had an inverse relationship that fluctuated seasonally. Cladophora was positively associated with increased nutrient concentrations and lower discharge during summer-autumn, whereas MAMB was positively correlated with decreased nutrients and higher discharge during winter-spring. Cladophora was positively associated with invertebrate biomass and also had greater epiphyton biomass and density than MAMB. The 1996 experimental flood resulted in a significant loss of MAMB biomass, in contrast to a minimal decrease in Cladophora and invertebrates. Interactions 
between inflow patterns, reservoir chemistry, and discharge regime have an important effect on benthic community structure below dams. Resource managers need to consider these relationships and regard water resources above and below impoundments as a connected system when making management decisions.

Blinn, D.W. and G.A. Cole. 1991. Algal and invertebrate biota in the Colorado River: Comparison of pre-and post-dam conditions. Pages 102-123 in Colorado River Ecology and Dam Management, Proceedings of a symposium, May 24-25, 1990. National Academy Press, Washington, DC.

Few reports exist on the physicochemical conditions of the pre-impounded Colorado River that relate to the growth and development of algal and aquatic invertebrate communities. Post-impoundment studies indicate that Cladophora glomerata is the dominant attached filamentous green algal species. Two hundred-thirty-five diatom taxa from the Colorado River and tributaries and from springs in the Glen and Grand Canyon systems have been reported. Ephemeropterans, snails, leeches, species from at least 10 insect families, and crayfish were intentionally introduced into the Colorado River after the Glen Canyon dam was closed. Zooplankters show a richness of faunas in backwaters along the borders of the river channel and at the mouths of tributaries. The macroinvertebrates occurring in the Colorado River consist of only a few species. The amphipod Gammarus lacustris constitutes an important food for most of the fishes of the Colorado River. Exotic and unusual species such as Craspedacusta sowerbyi, Branchiura sowerbyi, and the parasite Lernaea cyprinacea have also been reported in the Colorado River. Damming of the river has caused stranding of some plant and animal communities during periods of low flow. Some species have shown adaptations to fluctuating flow regimens caused by dams. Regulated flow can increase the standing crops of both attached algae and aquatic macrophytes, as well as aquatic mosses. Creation of reservoirs may cause enrichment of some nutrients that affect algal growth. The most common effect of impounded rivers on the macroinvertebrate community is reduced species diversity accompanied by high density and biomass. Modifications in thermal conditions also contribute to the compositional changes in macroinvertebrates below reservoirs. Research priorities recommended are: seasonal studies of Cladophora glomerata, studies on optimal flow rates for Cladophora glomerata population growth, food web studies in tailwaters of Glen Canyon Dam, phenological studies of invertebrates in the Colorado River ecosystem, and model development to study the effects of physicochemical parameters on plant and animal communities in regulated rivers.

\section{Blinn, W., J.P. Shannon, L.E. Stevens and J.P. Carder. 1995. Consequences of fluctuating discharge for lotic communities. Journal of the North American Benthological Society 14(2):233-248.}

We used five in situ experiments to test the influence of fluctuations in river discharge on the structure and function of the tailwaters benthos associated with cobble substrate in the Colorado River downstream from Glen Canyon Dam, Arizona, U.S.A. Periods of daily desiccation and freezing during river fluctuation significantly limited community biomass and energy. The permanently submerged channel supported 4-fold higher macroinvertebrate mass than the varial zone. Daily harvest of benthos showed a 50\% reduction in mass of Cladophora glomerata after $2 \mathrm{~d}$ of repeated 12-h summer exposure. Five days of repeated exposure resulted 
in $>70 \%$ reduction in macroinvertebrate mass after only one 12 -h summer exposure. One night time exposure to subzero winter air temperatures resulted in $\geq 50 \%$ loss of chlorophyll $a$ and mass of $C$. glomerata and $\geq 90 \%$ loss in macroinvertebrate mass. Gastropod densities on resubmerged cobbles that were subjected to long-term desiccation $(\sim 6 \mathrm{mo})$ equaled submerged control cobbles within $1 \mathrm{wk}$, whereas recolonization by C. glomerata, Gammarus lacustris, and chironomid larvae was significantly slower; i.e. $\leq 30 \%$ of controls after 4 mo. Hence, our data showed that two 12-h exposure periods may require $>4$ mo for recovery to achieve the mass of permanently submerged benthos. Incremental increases in benthic energy (joules $/ \mathrm{m}^{2}$ ) over increased base discharge from 142 to $793 \mathrm{~m}^{3} / \mathrm{s}$ may result in an increase in trout mass of approximately $42.5 \mathrm{~kg} / \mathrm{ha}$ in the tailwaters of Lees Ferry.

\section{Dresser, Jr., T.J. 1996. Diet of adult humpback chub. Pages 59-65. In The effects of an experimental flood on the aquatic biota and their habitats in the Colorado River, Grand Canyon, Arizona. Arizona Game and Fish Department, Phoenix. Abstract excerpted from study discussion.}

The null hypothesis being tested is that there is no difference in the stomach contents of adult humpback chub before, during, or after the high river discharge. We anticipate that scouring caused by the flood will alter food availability, which will alter the diet of these opportunistic feeders.

Humpback chub in the Colorado River, Grand Canyon, consumed a variety of aquatic and terrestrial invertebrates during the study period. Simuliids were the most common aquatic invertebrates ingested by humpback chub during all phases of the experiment. Chironomids and Gammarus lacustris were next in occurrence. The bulk of the terrestrial invertebrates found in the stomach contents of humpback chub were primarily Coleoptera. During the pre-flood phase, simuliids and chironomids comprised the bulk of the diet by ash-free dry weight. The observed increases in Gammarus in the stomach contents of humpback chub during the flood and postflood phases may be attributed to increased stream flow. High flows that scoured the backwaters and margins of the Colorado River transported Gammarus downstream making them more accessible to the chub.

Based on ash-free dry weights, simuliids and chironomids in the stomach contents of humpback chub decreased significantly during the flood. This decrease in simuliid and chironomid biomass may be attributed to increased turbidity, which may have made these organisms less visible to the chub. Decreases in simuliid and chironomid biomass may also be related to changes in benthic community structure because of high discharges.

Increases in the occurrence and percent (AFDM) of terrestrial invertebrates in the stomach contents of humpback chub were observed during this study. Increases in terrestrial invertebrates can be attributed to increased flows washing them into the river.

Based on the findings of this study, we conclude that humpback chub are very opportunistic in their feeding habits and can use food sources as they become available. Our findings indicate no significant changes in mean total biomass or mean number of invertebrates 
in the stomach contents of chub. Therefore, we conclude that the effects of the 1996 Experimental Flood on the feeding behavior of the adult humpback chub were minimal.

Haden, G.A., D.W. Blinn, J.P. Shannon and K.P. Wilson. 1999. Driftwood: an alternative habitat for macroinvertebrates in a large desert river. Hydrobiologia 397:179-186.

Driftwood was an important substratum for macroinvertebrates in the Colorado River, a desert river in southwestern U.S.A. with high suspended sediments and limited cobble substrate. Higher light availability and reduced abrasion on driftwood substrata resulted in a significantly higher ash-free dry mass (AFDM) of biofilm when compared to cobbles. Overall mean mass of biofilm on driftwood was $3.76 \mathrm{~g} \mathrm{~m}^{-2}$ AFDM ( $\mathrm{SE} \pm 0.19$ ) compared to $2.45 \mathrm{~g} \mathrm{~m}^{-2}$ AFDM (SE $\pm 0.15)$ on cobbles. Total macroinvertebrates AFDM was not significantly different between cobble and driftwood substrate. However, there were differences in the Ephemeroptera assemblage on the two substrata which were attributed to the type of food resources available in each habitat. Driftwood was dominated by the scraper/collector Heptagenia elegantula (Eaton), while the filter/collector, Traverella albertana (McDunnough) dominated cobbles. Twenty taxa were found on driftwood substrata. This habitat expands the type of niches available to macroinvertebrates in lotic systems with high suspended sediments. We calculated that $4.4 \mathrm{~m}^{2}$ of driftwood substratum passed our sample station each minute during a 12-h sampling period on the rising limb of the hydrograph. River impoundments limit the supply and transport of driftwood, which may have negative implication on macroinvertebrate communities in desert rivers with high suspended sediment. Studies in turbid desert rivers that do not sample driftwood may underestimate both the total standing mass/energy of the system and taxon richness.

Kennedy, T.A. and S.P. Gloss. 2005. Aquatic ecology: the role of organic matter and invertebrates. Pages 87-102 in Gloss, S.P., J.E. Lovich and T.S. Melis, eds., The state of the Colorado River ecosystem in Grand Canyon. A report of the Grand Canyon Monitoring and Research Center 1991-2004. USGS Circular 1282. U.S. Geological Survey, Flagstaff, Arizona.

Closure of Glen Canyon Dam and the beginning of flow regulation of the Colorado River through Grand Canyon in 1963 changed the river through the canyon considerably. The river changed from having highly variable discharge rates and temperatures and high suspendedsediment loads to having a relatively constant flow regime, cold and constant water temperatures, and suspended-sediment loads that are dramatically reduced relative to pre-dam levels. These changes in the physical environment, coupled with changes in the quantity and types of organic matter present in the Colorado River and intentional introductions of aquatic invertebrates that occurred shortly after Glen Canyon Dam was closed, have led to substantial changes in the kinds of aquatic invertebrates present in the Grand Canyon ecosystem. Since the closure of the dam, considerable effort has been directed toward understanding the aquatic ecology of this altered ecosystem. This chapter describes the results of the research and monitoring activities that have investigated the kinds of organic matter and invertebrate communities in the Colorado River below Glen Canyon Dam. Collectively, organic matter and the aquatic invertebrates that consume it largely constitute the food base for fish in the Colorado River ecosystem. This chapter focuses on patterns, trends, and important controls on the amount and sources of organic matter and invertebrates that are primary food resources for humpback 
chub (Gila cypha) and rainbow trout (Oncorhynchus mykiss) in an effort to understand the role that food plays in determining the distribution, population density, and growth of these fish in this ecosystem. Furthermore, most of the research and monitoring that have been conducted on organic matter and invertebrates in this ecosystem have centered on the food items that are important for these two species. This chapter also addresses how organic matter and invertebrates are affected by the timing and magnitude of water releases from Glen Canyon Dam, including the modified low fluctuating flow (MLFF) alternative, which was implemented in 1996 and continues as the operating regime for Glen Canyon Dam today. Finally, this chapter concludes with a brief discussion of recommended research directions and management actions.

\section{Shannon, J.P., D.W. Blinn, T. McKinney, E.P. Benenati, K.P. Wilson and C. O'Brien. 2001. Aquatic food base response to the 1996 test flood below Glen Canyon Dam, Colorado River, Arizona. Ecological Applications 11(3): 672-685.}

We examined the impact of the 1996 test flood released from Glen Canyon Dam (GCD) on the aquatic food base in the Colorado River through Grand Canyon National Park, Arizona, USA. Benthic scour and entrainment of both primary and secondary producers occurred at all study sites along the $385-\mathrm{km}$ river corridor. The majority of the organic drift occurred within the first $48 \mathrm{~h}$ of the test flood with the arrival of the hydrostatic wave. Recent macrophyte colonizers (Chara, Potamogeton, and Elodea) of fine sediment in the tailwaters were scoured from the channel bottom, with recovery to pre-flood estimates within 1-7 months depending on taxa. Macroinvertebrates and filamentous algae recovered within three months depending on taxa. The test flood removed suspended particles from the water column and increased water clarity, which enhanced benthic recovery. The test-flood hydrograph was designed primarily as an experiment in sand transport and occurred during a period of sustained high releases from GCD starting in June 1995 due to above-average inflow into Lake Powell. We discuss the implications of the hydrograph shape, pre- and post-riverine conditions, and the slow response time of biological resources for design of aquatic ecosystem experiments.

\section{Shannon, J.P., D.W. Blinn, P.L. Benenati and K.P. Wilson. 1996. Organic drift in a regulated desert river. Canadian Journal of Fisheries and Aquatic Sciences 53(6):1360- 1369.}

Coarse particulate organic mass varied seasonally and changed from autochthonous to allochthonous organic matter along a 386-km section of the Colorado River below Glen Canyon Dam, Arizona. Dam operations influenced drift components selectively throughout the hydrograph; however, ramping rate had no effect on drift mass. Eddies and pools collected approximately $50 \%$ of the mainstem drift with only detritus retained long enough to settle in pools. Coarse particulate organic drift mass was negatively correlated with stream gradient in the Colorado River. Cladophora drift packets were pulverized by rapids, which subsequently increased fine particulate organic matter at downriver sites. Tributary type (spring stream or large desert watershed river) significantly altered the mass and composition of tributary drift; however, tributaries contributed $<0.1 \%$ of the total organic matter to main-stem drift. Terrestrial insects represented $<0.001 \%$ of the total invertebrate mass in main-stem drift. As a result of hydraulics and suspended sediment, organic drift mass throughout the river corridor is reach specific. Longitudinal change in drift composition corresponds with a shift in fish species. 
Shaver, M.L., J.P. Shannon, K.P. Wilson, P.L. Benenati and D.W. Blinn. 1997. Effects of suspended sediment and desiccation on the benthic tailwater community in the Colorado River, USA. Hydrobiologia 357(1-3):63-72.

We demonstrated that differences in habitat requirements by C. glomerata and Oscillatoria have a profound bottom-up influence on the foodweb in the tailwaters below Glen Canyon Dam in the Colorado River through Grand Canyon National Park, USA. We examined the effects of suspended sediment and desiccation on the colonization sequence of Cladophora glomerata and Oscillatoria spp. and the consequent effects on macroinvertebrates in each algal community in a series of reciprocal transplants in the regulated Colorado River, AZ. Our experiments showed that C. glomerata grows best in continuously submerged, clear-water, stable habitats, whereas Oscillatoria forms dense mat-like matrices of trichomes and sand in varial zones and habitats with high suspended sediments typical of many southwestern USA streams. Varial zone conditions have a stronger influence on community structure than habitats with high suspended sediments. Recruitment by chironomid larvae was less dependent on C. glomerata and less affected by suspended sediment and periodic desiccation than Gammarus lacustris. We estimated the energy from macroinvertebrate biomass associated with tufts of C. glomerata to be an order of magnitude higher than that in Oscillatoria matrices. Therefore, loss of C. glomerata and replacement of habitat more suitable for Oscillatoria as a result of regulated flows indirectly reduces potential energy flow in the Colorado River foodweb.

\subsection{SUPPORTING ARTICLES}

\section{Bestgen, K. and L.W. Crist. 2000. Response of the Green River fish community to construction and re-regulation of Flaming Gorge Dam, 1962-1996. Final report of Colorado State University Larval Fish Laboratory to Upper Colorado River Endangered Fish Recovery Program, Lakewood, Colorado.}

We evaluated aspects of the protocol offered by Stanford et al. (1996) for restoration of biota in regulated rivers. The chronology of river regulation events and associated biotic evaluations that occurred in the regulated reach of the Green River upstream of the Yampa River from 1962 to 1996 offered an opportunity to determine the effectiveness of thermal enhancement and discharge re-regulation to restore native fishes. Prior to closure of Flaming Gorge Dam, the Green River supported an intact native fish assemblage and few non-native fishes occurred there. Closure and operation of Flaming Gorge Dam eliminated most native fishes in the regulated reach of the Green River from 1967 to 1978 because low water temperatures inhibited reproduction. The hydrograph was flat with no spring peak, high summer base flow, and sediment load was reduced. Thermal enhancement of the regulated reach in 1978, via dam penstock modification, had an immediate effect because reproduction by most resident native fishes was restored. The regulated reach supported nine native fishes, and only rare Colorado pikeminnow and razorback sucker did not reproduce. Discharge re-regulation begun in 1992 partially restored spring peaks and lowered early summer base flows. Sampling conducted during the period 1994 to 1996 demonstrated that native fishes were numerically dominant in electrofishing samples collected in Lodore Canyon. Native fishes were dominant in seine 
samples collected in upstream Lodore Canyon low-velocity habitats. Roundtail chub was very rare in the reach and may be declining in abundance. Non-native fishes dominated in backwaters in lower Lodore and in Island -Rainbow Park. Populations of other native fishes were stable and abundance of Colorado pikeminnow increased since 1980, perhaps in response to flow reregulation and subsequent changes in the thermal environment. Abundance of cold water fishes has declined since 1980, and abundance of cool or warm-water fishes increased. Diversity and abundance of non-native fishes increased since 1980, especially in lower Lodore Canyon. Especially problematic may be piscivorous channel catfish, smallmouth bass, and northern pike. A strong water temperature gradient played a large role in controlling distribution and abundance of fishes in the regulated reach during the period 1994-1996. Relatively cool upstream temperatures may have limited the distribution and abundance of several warm-water fishes to reaches of the Green River downstream of lower Lodore Canyon. Limited backwater habitat in the upper reaches of Lodore Canyon may have restricted occurrence of obligate backwater species such as red and sand shiner, fathead minnow, and redside shiner. Abundance of several combinations of hybrid suckers was high and much increased since 1980. Particularly common were hybrids that had white sucker as one parental type. Occurrence of cool water white suckers and hybrids declined in a downstream direction in Lodore Canyon, presumably in response to warmer water temperatures. Drift net sampling captured few fish of any kind, and reproduction by Colorado pikeminnow was not detected. A moderate-sized population of Colorado pikeminnow inhabited Lodore Canyon and were captured there in spring, summer, and fall. Length changes of recaptured fish and length-mass relationships indicated that resident fish had high growth rates. Minimally, Lodore Canyon provided important habitat for adult feeding. Water temperature of the Green River downstream of Flaming Gorge Dam was reliably predicted by ambient air temperature and discharge level. Water temperatures suitable for reproduction by Colorado pikeminnow were present early in the summer in some years. However, mid- and late-summer warming associated with reproduction by Colorado pikeminnow in the unregulated Yampa River was negated in the regulated reach of the Green River by increased discharge from Flaming Gorge Dam. Increased discharge was mandated by the 1992 Biological Opinion on operation of Flaming Gorge Dam. Further restoration of the fish community and habitat in the regulated reach of the Green River requires re-establishment of more natural discharge and temperature regimes, similar in pattern to those which occur in the unregulated Yampa River and the historical Green River. More natural flow and temperature patterns may also benefit native fishes in Green River reaches downstream of the Yampa River. Distribution and abundance of non-native fish populations will also likely expand if summer water temperatures of the regulated reach of the Green River are enhanced.

\section{Bowen, Z.K., M.C. Freeman and K.D. Bovee. 1998. Evaluation of generalized habitat criteria for assessing impacts of altered flow regimes on warmwater fishes. Transactions of the American Fisheries Society 127:455-468.}

Our study investigated relationships between availability and temporal persistence of key habitats and fish assemblage structure at regulated and unregulated sites in the Tallapoosa River system. Fish assemblage characteristics at seven sites were quantified based on 1,400 electrofishing samples collected during 1994 and 1995. Physical Habitat Simulation (PHABSIM) programs were used to model availability and persistence of key habitats at regulated and unregulated sites. Associations between fish assemblages and availability or persistence of key 
habitats were identified via regression and analysis of variance. We found that hydropeaking dam operation reduced the average length of time that shallow-water habitats persisted and also reduced year-to-year variation in the persistence of shallow-water habitats compared with unregulated sites. Across sites and years, proportional representation of catostomids was positively correlated with persistence of shallow and slow-water habitats during spring. Proportion of individuals as cyprinids was positively correlated with median availability of deep-fast habitat whereas proportion of percids was inversely related to median availability of deep-fast habitat. Mean fish density was positively correlated with the persistence of shallow and slow-water habitats. Comparisons of key-habitat measures and fish abundances between 1994 and 1995 at each site indicated that higher abundances of percids, catostomids, and cyprinids were associated with increased availability and persistence of shallow and slow-water habitats in 1995. These findings demonstrate that the temporal and spatial availability of key habitats could serve as useful measures of the potential effects of flow alteration on lotic fish assemblages and suggest that both short-term persistence of key habitats as well as annual variation in key-habitat availability are important for maintaining diverse fish assemblages.

\section{Casagrandi, R. and M. Gatto. 1999. A mesoscale approach to extinction risk in fragmented habitats. Nature 400: 560-562.}

Assessing the fate of species endangered by habitat fragmentation $1 \pm 3$ using spatially explicit and individual-based models $4 \pm 7$ can be cumbersome and requires detailed ecological information that is often unavailable. Conversely, Levins-like8 macroscale models neglect data on the distribution of local numbers, which are frequently collected by field ecologists $11 \pm 13$. Here we present an alternative, mesoscale approach for metapopulations that are subject to demographic stochasticity, environmental catastrophes and habitat loss. Starting from a model that accounts for discrete individuals in each patch and assumes a birth-death stochastic process with global dispersal14,15, we use a negative binomial approximation 16 to derive equations for the probability of patch occupancy and the mean and variance of abundance in each occupied patch17. A simple bifurcation analysis 18 can be run to assess extinction risk. Comparison with both the original model and a spatially explicit model with local dispersal proves that our approximation is very satisfactory. We determine the sensitivity of metapopulation persistence to patch size, catastrophe frequency and habitat loss, and show that good dispersers are affected more by habitat destruction than by environmental disasters.

\section{Johnson, J.E. and R.T. Hines. 1999. Effect of suspended sediment on vulnerability of young razorback suckers to predation. Transactions of the American Fisheries Society 128:648-655.}

The decline of native fishes in North America is principally a result of altered habitats, and the impact of mainstream dams has accounted for many of the habitat changes. Diminished turbidity, and introduced nonnative predators were investigated as possible reasons for the decline of endangered razorback suckers Xyrauchen texanus in the Colorado River. In laboratory tests, young razorback suckers selected clear water over two water samples with higher concentrations of suspended sediment. In clear water, however, young razorback suckers were extremely susceptible to predation; native Colorado squawfish Ptychocheilus lucius consumed $90 \%$ of test razorback suckers, and nonnative green sunfish Lepomis cyanellus consumed 99.6\%. 
As turbidity increased, razorback sucker predator avoidance improved and differences in predator success disappeared. Winter-spring spawning by razorback suckers in Lake Mohave, along with the extreme susceptibility of larvae to predation in clear water, may account for total recruitment failure in that lake. However, in upper basin rivers, suspended sediments remain high enough to limit predation by fishes tested, suggesting that other impacts, including contaminants and lack of floodplain habitat, may be thwarting recruitment in those rivers.

Junk, W.J., P.B. Bailey and R.E. Sparks. 1989. The flood pulse concept in river-floodplain systems. Canadian Special Publication of Fisheries and Aquatic Sciences 106:110-127.

The principal driving force responsible for the existence, productivity, and interactions of the major biota in river-floodplain systems is the flood pulse. A spectrum of geomorphological and hydrological conditions produces flood pulses, which range from unpredictable to predictable and from short to long duration. The flood pulse is a "batch" process and is distinct from concepts that emphasize the continuous processes in flowing water environments, such as the river continuum concept. Floodplains are distinct because they do not depend on upstream processing inefficiencies of organic matter, although their nutrient pool is influenced by periodic lateral exchange of water and sediments with the main channel.

Papoulias, D. and W.L. Minckley. 1990. Food limited survival of larval razorback sucker, Xyrauchen texanus, in the laboratory. Environmental Biology of Fishes 29:73-78.

Razorback suckers in Lake Mohave, Arizona-Nevada, are suffering recruitment failure. Concomitantly, lake zooplankton levels are low and variable. We test, under laboratory conditions, the possibility that starvation is a cause of low recruitment. Razorback sucker larvae that were starved, received food too late, or were provided with insufficient food died between 20 and $30 \mathrm{~d}$ after hatching. Yolk absorption was at $\approx 8 \mathrm{~d}$ after hatching, the critical period during which larvae must feed or most will die lies between $\sim 8$ and 19d, and the point of irreversible starvation for individuals is between 19 and $23 \mathrm{~d}$ after hatching. Results support food-related mortality as a contributor to year-class failure of razorback sucker in Lake Mohave.

\section{Stevens, L.E., J.C. Schmidt, J.C. Ayers, T.J. Brown and T. Bryan. 1995. Flow regulation, geomorphology, and Colorado River marsh development in the Grand Canyon, Arizona.}

New, productive fluvial marshes may develop along regulated canyon rivers through reduction in flood frequency, thereby increasing diversity, production, and wildlife habitat availability. Few fluvial marshes occurred along the eddy-dominated Colorado River in the Grand Canyon prior to construction of Glen Canyon Dam in 1963. Reduction of flooding after 1963 permitted widespread marsh development. Fluvial marshes exhibited low stability but high resilience, quickly redeveloping after scouring by high flows between 1983 and 1986. In 1991, 253 fluvial wet marshes (cattail/reed and horseweed/Bermuda grass) and 850 dry marshes (horsetail/willow) occupied 25.0 ha (1\%) of the $363 \mathrm{~km}$ mainstream riparian corridor between Lees Ferry and Diamond Creek, Arizona. Fluvial marsh development and composition varied in relation to local and reach-based geomorphology, and microsite gradients in inundation frequency and soil texture. Colorado River marsh density (number $/ \mathrm{km}^{2}$ ) increased with distance downstream, and marshes were larger and more abundant in wide reaches. Wet marsh 
cattail/reed stands developed on silty loam soils in low velocity depositional environments that were inundated 54\% of the days from 1986 to 1991, whereas dry horsetail/willow marshes occupied less frequently inundated sites with sandy soils. Mean marsh standing mass (641 g $\mathrm{C} / \mathrm{m}^{2}$ ) was comparable with values from regulated alluvial river marshes, but litter retention appeared limited by flow variability in both regulated and unregulated fluvial marshes. We discuss implications of flow management on the four marsh assemblages, and the need for consensus on priorities for management of regulated fluvial wetlands.

\section{Ward, D.L. and S.A. Bonar. 2003. Effects of cold water on susceptibility of age-0 flannelmouth sucker predation by rainbow trout. Southwestern Naturalist 48:43-46.}

We conducted laboratory tests to evaluate the effects of an abrupt $10^{\circ} \mathrm{C}$ decrease in water temperature on ability of age-0 flannelmouth suckers (Catostomus latipinnis) to escape predation by rainbow trout (Oncorhynchus mykiss). Juvenile flannelmouth suckers (58 $\mathrm{mm}$ mean total length) were maintained at $20^{\circ} \mathrm{C}$ and introduced individually, without acclimation, into tanks containing a single adult rainbow trout $\left(246 \mathrm{~mm}\right.$ mean total length) at 10 or $20^{\circ} \mathrm{C}$. Rainbow trout attacked suckers more often at $20^{\circ} \mathrm{C}$, but were more likely to capture them at $10^{\circ} \mathrm{C}$. Age- 0 flannelmouth suckers experience an abrupt temperature decrease when they exit warm tributaries and enter cold hypolimnetic water released from Glen Canyon Dam on the Colorado River. This temperature change might increase susceptibility of young flannelmouth suckers to predation by rainbow trout, which are abundant in the Colorado River in Glen, Marble, and Grand canyons.

\section{Ward, J.V. and J.A. Stanford. 1995. Ecological connectivity in alluvial river ecosystems and its disruption by flow regulation. Regulated Rivers: Research \& Management 11(1):105-119.}

The ecological integrity of dynamic floodplain river systems was maintained by ecological connectivity operating across a range of time scales through dynamic interactions between hydrological, geomorphological and successional processes. During seasonal inundation of the floodplain the flood pulse formed a 'moving littoral' that traversed the aquatic/terrestrial transition zone increasing productivity and enhancing connectivity. Spatiotemporal heterogeneity of floodplain river systems structured biotic communities and natural levels of disturbance maintained the floodplain ecological integrity. Flow regulation decreased the frequency and extent of floodplain inundation, reduced channel migration and altered the temporal pattern of flooding, while truncation of sediment transport resulted in channel degradation and channel deepening affected riparian vegetation dynamics. Connectivity between the river channel and floodplain was decreased and habitat heterogeneity declined. Regulation tended to accelerate the successional trend towards terrestrialization and reduce the formation of floodplain water bodies but the ecological integrity of river-floodplain ecosystems could be restored by re-establishing dynamic connectivity between the channel and floodplain water bodies. 
Ward, D.L., O.E. Maughan, S.A. Bonar and W.J. Matter. 2002. Effects of temperature, fish length and exercise on swimming performance of age-0 flannelmouth sucker. Transaction of the American Fisheries Society 131:492-497.

The flannelmouth sucker Catostomus latipinnis is one of the few native fish that persists in the lower Colorado River basin. Little is known about the effects of hypolimnetic releases of cold, swift water from Colorado River dams on flannelmouth sucker populations. We conducted fatigue velocity tests on age-0 flannelmouth suckers in the laboratory to evaluate the effects of water temperature and fish size on swimming ability. Fish of 25-114 mm total length (TL) were subjected to incremental increases in water velocity until the upper limit of their swimming ability was reached. Swimming tests were conducted at 10,14 , and $20^{\circ} \mathrm{C}$. Swimming ability increased with fish length and was directly related to water temperature at all fish sizes. A decrease in water temperature from $20^{\circ} \mathrm{C}$ to $10^{\circ} \mathrm{C}$ resulted in an average decrease in swimming ability of $40 \%$. Mean swimming ability of wild-caught flannelmouth suckers was $7 \mathrm{~cm} / \mathrm{s}$ higher than that of captive-reared flannelmouth suckers of similar size at $20^{\circ} \mathrm{C}$ and $14^{\circ} \mathrm{C}$. Flannelmouth suckers subjected to an abrupt $10^{\circ} \mathrm{C}$ temperature drop did not have significantly different swimming ability than flannelmouth suckers acclimated to $10^{\circ} \mathrm{C}$ over $4 \mathrm{~d}$.

\section{OTHER IMPACTS}

\subsection{NONNATIVE SPECIES}

Douglas, M.E. and P.C. Marsh. 1996. Endangered humpback chub (Gila cypha) as prey of introduced fishes in the Little Colorado River, Arizona. Section 2 in M.E. Douglas and P.C. Marsh, eds. Ecology and Conservation Biology of Humpback Chub (Gila cypha) in the Little Colorado River. Bureau of Reclamation, Salt Lake City, Utah.

Endangered humpback chub and other native fishes were a significant dietary component (13.5\% of 408 stomachs) of five predatory, non-native fishes from the Little Colorado River, Arizona. Stomach contents varied among species, were low in diversity, and predominated by detritus, algae (primarily Cladophora), and aquatic insects. Twenty-one introduced species occur $\mathrm{n}$ Grand Canyon, and more than 25.8 million fish have been stocked there and in reservoirs immediately up- and downstream. Interaction between non-native and native fishes predation, resource competition, displacement) may constitute a significant impact on the latte.

Kennedy, T.A. 2007. A Dreissena risk assessment for the Colorado River ecosystem. U.S. Geological Survey open file report 2007-1085.

Nonnative zebra and quagga mussels (Dreissena polymorpha and Dreissena bugensis, respectively; fig. 1) were accidentally introduced to the Great Lakes in the 1980s and subsequently spread to watersheds of the Eastern United States (Strayer and others, 1999). The introduction of Dreissena mussels has been economically costly and has had large and farreaching ecological impacts on these systems. Quagga mussels were found in Lakes Mead and Havasu in January 2007. Given the likelihood that quagga mussels and, eventually, zebra 
mussels will be introduced to Lake Powell and the Colorado River at Lees Ferry, it is important to assess the risks that introduction of Dreissena mussels pose to the Colorado River ecosystem (here defined as the segment of river from just below Glen Canyon Dam to Diamond Creek; hereafter CRE). In this report, I assess three different types of risks associated with Dreissena and the CRE: (1) the risk that Dreissena will establish at high densities in the CRE, (2) the risk of ecological impacts should Dreissena establish at high densities in the CRE or in Lake Powell, and (3) the risk that Dreissena will be introduced to tributaries of the CRE.

The risk of Dreissena establishing within the CRE is low, except for the Lees Ferry tailwater reach where the risk appears high. Dreissena are unlikely to establish at high densities within the CRE or its tributaries because of high suspended sediment, high ratios of suspended inorganic:organic material, and high water velocities, all of which interfere with the ability of Dreissena to effectively filter feed. The rapids of Grand Canyon may represent a large source of mortality to larval Dreissena, which would limit their ability to disperse and colonize downstream reaches of the CRE. In contrast, conditions within the Lees Ferry tailwater generally appear suitable for Dreissena establishment, with the exception of high average water velocity.

If Dreissena establish within the CRE, the risks of negative ecological impacts appear low. If Dreissena are able to attain moderate densities in Lees Ferry, estimates of filtration capacity indicate they are unlikely to substantially alter the composition (e.g., nutrient concentrations, suspended organic matter concentrations) of water exported from Lees Ferry. Further, a moderate density of Dreissena within Lees Ferry may actually increase food available to fishes by increasing habitat complexity and stimulating benthic production. If Dreissena attain moderate densities in the CRE mainstem, which seems unlikely, ecological impacts will probably be comparable to Lees Ferry - an increase in benthic production. Dreissena may have ecological impacts on the CRE, if they become established in Lake Powell and substantially alter the composition of water released from Glen Canyon Dam; however, it is unclear whether changes in the composition of water released from Glen Canyon Dam will have a net positive or negative impact on food availability in the CRE mainstem.

The risk of Dreissena introduction to tributaries appears low. None of the tributaries have upstream lakes or reservoirs that could actually serve as a source population for Dreissena; reservoirs on the Little Colorado River may eventually support Dreissena, but they are far up in the watershed and the segment of river connecting them with the mainstem CRE is intermittent. If the CRE mainstem is colonized by Dreissena, there are no significant vectors for transporting them upstream into the tributaries. In addition, lethally high summer water temperatures make it unlikely that Dreissena will establish in many tributaries.

Lake Powell is a logical focus for management and research efforts, given that maintenance of Dreissena populations within the CRE will require an upriver source population and the uncertainty associated with the downstream impact of changes in Lake Powell water quality. 
Marsh, P.C. 2005. Immiscibility of native and nonnative species. Pages 59-63 in Proceedings of two symposia: restoring native fish to the lower Colorado River: interaction of native and non-native fishes. July 13-14, 1999. Las Vegas, Nevada. U.S. Fish and Wildlife Service, Southwest Region, Albuquerque, New Mexico.

Native and non-native fishes in the lower Colorado River overlap broadly in their physical habitat and resource uses, and no attribute of either use-category favors one group of fishes over another. The presence of nonnative fishes alone precludes life-cycle completion by the natives. In the absence of non-natives, however, the natives thrive even in severely altered habitats. Compelling evidence supports a recommendation of segregated management of native and non-native fishes. Unabated declines of the imperiled native fish fauna demands expedient action by responsible parties to plan and implement appropriate strategies.

Marsh, P.C. and M.E. Douglas. 1995. Humpback chub as food of non-native fishes in the Little Colorado River. Proceedings of the Desert Fishes Council, Flagstaff, Arizona.

We examined foods of non-native rainbow and brown trout, channel catfish, and yellow and black bullhead in monthly samples from the Little Colorado River, Arizona, from June 1991 to July 1994. Food items varied among species, were low in diversity, and dominated by detritus, algae, and aquatic insects. Endangered humpback chub and other native fishes appeared minor components (5\% frequency of occurrence in 315 guts). However, non-native fish are abundant, and even modest predation rates could result in consumption of substantial numbers of native fish. For example, if 5\% of predators each eat 2 fish a week (the average number per stomach), then as few as 1,000 predators would consume 5,200 fish a year. Consumed chubs that we were able to measure $(N=11)$ averaged $121 \mathrm{~mm}$ TL and were mostly yearlings. We have not quantified age/size specific mortality, but recaptures of PIT-tagged individuals $>150 \mathrm{~mm}$ TL suggest rates are low. Thus, annual loss to non-native predators of several thousand young chub could significantly impact the native population, even to the point of limiting or reducing population size by curtailing recruitment.

\section{Marsh, P.C. and M.E. Douglas. 1997. Predation by introduced fishes on endangered humpback chub and other native species in the Little Colorado River, Arizona. Transactions of the American Fisheries Society (Bethesda) 126(2):343-346.}

Fishes in the Little Colorado River in the Grand Canyon, Arizona, were sampled monthly from July 1991 to June 1995 as part of a study of the ecology of endangered humpback chub Gila cypha. Diets of five introduced predatory fish species were examined. Stomach contents varied among species and were low in diversity and dominated by algae (primarily Cladophora), aquatic insects, and fishes. Humpback chub plus other native species were a significant component of the diet (13.7\% frequency of occurrence among 219 of 408 stomachs that contained food). Predation mortality from introduced fishes may significantly affect the native species by depleting numbers and reducing recruitment. 
Marsh, P.C., C.A. Pacey and W.L. Minckley. 1999. Resource use attributes of Colorado River fishes and implication for management of native and non-native species. Proceedings of the Desert Fishes Council 30:24.

The Colorado River is physically altered and hydrologically regulated. New habitats created by dams include impoundments and thermally depressed tailwaters, which differ dramatically from the stream before dams. Nonetheless, evidence from case studies argues that these altered places should be occupied by self-sustaining native fish communities. Instead, an introduced ichthyofauna overwhelmingly dominates the lower river, and native fishes are reduced to a few imperiled species in isolated reaches. The array of non-native fishes has feeding, behavioral, and reproductive attributes that allow it to displace, replace, or exclude the natives independent of physical habitat features. We therefore recommend segregated management of native and non- native fishes as the only means of attaining the maintenance of self-perpetuating populations of indigenous species.

\section{Mueller, G.A. 2005. Predatory fish removal and native fish recovery in the Colorado River mainstem: what have we learned? Fisheries 30(9):10-19.}

Mechanical predator removal programs have gained popularity in the United States and have benefited the recovery of several native trout and spring fish. These successes have been limited to headwater streams and small, isolated ponds or springs. Nevertheless, these same approaches are being applied to large river systems on the belief that any degree of predator removal will somehow benefit natives. This attitude is prevalent in the Colorado River mainstem where recovery and conservation programs are struggling to reverse the decline of four endangered fish species. Predator removal and prevention are major thrusts of that work but unfortunately, after 10 years and the removal of $>1.5$ million predators, we have yet to see a positive response from the native fish community. This leads to the obvious question: is mechanical removal or control in large ( $>100$ cfs base flow) western streams technically or politically feasible? If not, recovery for some mainstem fishes may not be practical in the conventional sense, but require innovative management strategies to prevent their extirpation or possible extinction. This article examines (1) what has been attempted, (2) what has worked, and (3) what has not worked in the Colorado River mainstem and provides recommendations for future efforts in this critical management area.

\section{Ruppert, J.B., R.T. Muth, and T.P. Nesler. 1993. Predation on fish larvae by adult red shiner, Yampa and Green Rivers, Colorado. Southwestern Naturalist 38:397-399. Abstract excerpted from results and conclusions.}

The objective of this study was to document predation on fish larvae, particularly larvae of native fishes, by nonnative adult cyprinids or juvenile centrarchids or ictalurids collected from ephemeral shoreline embayments near the confluence of the Green and Yampa Rivers, Colorado, in early summer. Collections with fine-mesh seines (1.6-mm-square mesh) were made on June 30 and July 2, 14, 19, and 25, 1991. Sampling on June 30 was at 1600-1800 hours, and on other dates at 0000-0200, 0400-0600, 1200-1400, 1600-1800, and 2000-2200 hours. Nonnative fishes collected and analyzed were yearling channel catfish Ictalurus punctatus $(N=17 ; 51-$ $144 \mathrm{~mm} \mathrm{TL})$ and adult red shiners Cyprinella lutrensis ( $N=184 ; 36-79 \mathrm{~mm} \mathrm{TL})$, sand shiners 
Notropis stramineus ( $N=47 ; 30-65 \mathrm{~mm}$ TL), fathead minnows Pimephales promelas $(N=42 ; 32-$ $60 \mathrm{~mm}$ TL), and redside shiners Richardsonius balteatus ( $N=176 ; 36-77 \mathrm{~mm}$ TL). Fish larvae $(N=58 ; 1-9$ per digestive tract) were found in $15 \%$ of the red shiners collected during daylight or dusk on June 30 and July 2 and 14; no larvae were detected in digestive tracts of the other species. Most of the fish larvae found were too digested for species identification or accurate length measurements, but all were cypriniforms (mostly catostomids) and probably less than $16 \mathrm{~mm}$ TL. Seven fish larvae, 11-13 mm TL, were identified as native bluehead sucker Catostomus discobolus. The high incidence of fish larvae ingested by red shiners suggests that this widespread and abundant species may be an important predator on native fishes in the Colorado River system. The degree of predation may be influenced by the abundance of alternative invertebrate prey and may be especially severe during spring and early summer in ephemeral nursery habitats with fluctuating water levels.

Stone, D.M. and O.T. Gorman. 2005. Ontogenesis of endangered humpback chub (Gila cypha) in the Little Colorado River, Arizona. The American Midland Naturalist 155:123135.

The largest population of endangered humpback chub Gila cypha inhabits the Colorado River below Glen Canyon Dam and the lower $14 \mathrm{~km}$ of the Little Colorado River (LCR), Arizona. Currently, adults from both rivers spawn and their progenies grow and recruit to adulthood primarily within the LCR, where we studied G. cypha's life history using hoop net capture data. Humpback chub undergo an ontogenesis from diurnally active, vulnerable, nearshore-reliant YOY (30-90 mm total length) into nocturnally active, large-bodied adults ( $\geq 180 \mathrm{~mm}$ TL). During the day, adults primarily resided in deep midchannel pools; however, at night they dispersed inshore amongst the higher densities of YOY conspecifics. Many YOY $G$. cypha shifted to nocturnal habitats that provided greater cover, possibly, to avoid inshore invading adults. These findings mirror predator-prey scenarios described in other freshwater assemblages, but do not refute other plausible hypotheses. Gila cypha piscivorous activity may escalate in hoop nets, which can confine fish of disparate sizes together; adults were significantly associated with YOY conspecifics and small dead fish in hoop nets at night and eight G. cypha (156-372 $\mathrm{mm}$ TL) regurgitated and/or defecated other fish body parts during handling following capture. Gila cypha can definitely be piscivorous given the opportunity, but the magnitude of their piscivorous activity in the wild is debatable.

\section{Stone, D.M., D.R. Van Haverbeke, D.L. Ward and T.A. Hunt. 2007. Dispersal of nonnative fishes and parasites in the intermittent Little Colorado River, Arizona. Southwestern Naturalist 52(1):130-137.}

We sampled nonnative fishes stranded in isolated pools near Grand Falls in the Little Colorado River (LCR), Arizona, after the river ceased flowing (21 June and 12 July 2005) to evaluate whether nonnative fishes can invade the perennial, lower $21 \mathrm{~km}$ of the LCR from upriver sources. The encroachment of nonnative fishes could jeopardize resident populations of endangered humpback chub, Gila cypha, and other native fishes in the lower LCR. We captured red shiner, Cyprinella lutrensis; common carp, Cyprinus carpio; fathead minnow, Pimephales promelas; black bullhead, Ameiurus melas; and plains killifish, Fundulus zebrinus, all of which have been captured $0.132 \mathrm{~km}$ downriver in the lower LCR and $0.127 \mathrm{~km}$ upriver in the closest 
perennial sources. Moreover, we detected Asian tapeworm, Bothriocephalus acheilognathi, in 9 of 30 common carp examined. Our findings suggest that nonnative fishes, including those hosting parasites, can invade the lower LCR from upriver sources $0.250 \mathrm{~km}$ away during freshets and provide a mechanism for the dispersal of invasive aquatic species in intermittent river systems.

Tyus, H.M. and J.F. Saunders. 1996. Nonnative fishes in the Upper Colorado River Basin and a strategic plan for their control. Final report of University of Colorado Center for Limnology to Upper Colorado River Endangered Fish Recovery Program, Lakewood, Colorado.

Native freshwater fish populations are declining in North America and more than 100 fishes are federally listed as threatened or endangered. The Colorado River system in the southwestern United States has been especially affected. Most of its native fish populations are in decline, including four "big river" fishes, Colorado pikeminnow (Ptychocheilus lucius), humpback chub (Gila cypha), bonytail (G. elegans), and razorback sucker (Xyrauchen texanus), whose populations have declined so precipitously that they are endangered. Physical habitat alteration caused native fish declines, but nonnative fishes pose a more serious threat to native fishes than previously thought. Nonnative fish control measures needed in the upper Colorado River system, identified in part by a workshop of experts, include: (1) preventing movements of game fishes out of impoundments and curtailing future stockings, (2) reducing numbers of small, nonnative cyprinids in shoreline habitat used as rearing areas by young native fishes, and (3) increasing the harvest of channel catfish (Ictalurus punctatus) and common carp (Cyprinus carpio) in the mainstream. Large-scale implementation of these nonnative fish control measures has proven difficult. Recovery efforts have identified the need for developing nonnative fish control strategies and testing methodologies, but no solutions have emerged. A holistic approach, including ecosystem recovery plans, should be used in systems where more than one species share common problems, such as interactions with nonnative fishes. Nonnative fish interactions should be suspected as a potential cause of declining native fish populations.

\subsection{PARASITISM}

Brouder, M.J. and T.L. Hoffnagle. 1997. Distribution and prevalence of the Asian fish tapeworm, Bothriocephalus acheilognathi, in the Colorado River and tributaries, Grand Canyon, Arizona, including two new host records. Journal of the Helminthological Society of Washington 64(2):219-226.

The Asian tapeworm, Bothriocephalus acheilognathi, was introduced into the United States via imported grass carp in the early 1970's. It has since become well established in the southeast and mid-south and has been recently found in the southwest. The definitive host in the life cycle of B. acheilognathi is cyprinid fishes and therefore, is a potential threat to the federally endangered humpback chub, Gila cypha, in the Colorado River, Grand Canyon. In past studies, Arizona Game and Fish Department has found that humpback chub in the LCR were infested with the Asian tapeworm. However, the cold water of the mainstem Colorado River may be limiting their expansion beyond the LCR. This study was conducted to determine the prevalence 
of B. acheilognathi in two cyprinid fishes, fathead minnows, Pimephales promelas, and speckled dace, Rhinichthys osculus, and determine if it has expanded its distribution to sites outside of the LCR. Preliminary data from 1994 show that $54 \%$ of the humpback chub, 27\% of the speckled dace, and $6 \%$ of the fathead minnows that were caught were infested with the Asian tapeworm. All infested humpback chub were caught in a 15-mile stretch of the Colorado River just downstream from the mouth of the LCR, the likely source of their infestation.

\section{Choudhoury, A., T.L. Hoffnagle and R.A. Cole. 2001. Parasites of native and nonnative fishes of the Little Colorado River, Grand Canyon, Arizona. Journal of Parasitology 90: 1042-1053.}

A 2-yr, seasonal, parasitological study of 1,435 fish, belonging to 4 species of native fishes and 7 species of nonnative fishes from the lower Little Colorado River (LCR) and tributary creeks, Grand Canyon, Arizona, yielded 17 species of parasites. These comprised 1 myxozoan (Henneguya exilis), 2 copepods (Ergasilus arthrosis and Lernaea cyprinacea), 1 acarine (Oribatida gen. sp.), 1 piscicolid leech (Myzobdella lugubris), 4 monogeneans (Gyrodactylus hoffmani, Gyrodactylus sp., Dactylogyrus extensus, and Ligictaluridus floridanus), 4 nematodes (Contracaecum sp., Eustrongylides sp., Rhabdochona sp., and Truttaedacnitis truttae), 3 cestodes (Bothriocephalus acheilognathi, Corallobothrium fimbriatum, and Megathylacoides giganteum), and 2 trematodes (Ornithodiplostomum sp. and Posthodiplostomum sp.). Rhabdochona sp. was the only adult parasite native to the LCR. Infection intensities of Ornithodiplostomum sp. and B. acheilognathi were positively correlated with length of the humpback chub Gila cypha. Adult helminths showed a high degree of host specificity, except $B$. acheilognathi, which was recovered from all fish species examined but was most abundant in cyprinids. Abundance of B. acheilognathi in the humpback chub was highest in the fall and lowest in the summer in both reaches of the LCR. There was no major taxonomic difference in parasite assemblages between the 2 different reaches of the river (LC1 and LC2). Parasite community diversity was very similar in humpback chub, regardless of sampling site or time. The parasite fauna of the LCR is numerically dominated by B. acheilognathi and metacercariae of Ornithodiplostomum sp. The richest and most diverse component community occurred in a nonnative species, the channel catfish Ictalurus punctatus, but infra-community species richness was highest in a native host, humpback chub.

Clarkson, R.W., A.T. Robinson and T.L. Hoffnagle. 1997. Asian tapeworm, Bothriocephalus acheilognathi, in native fishes from the Little Colorado River, Grand Canyon, Arizona. Great Basin Naturalist 57: 66-69.

Examination of gastrointestinal tracts of native cyprinids from the Little Colorado River (LCR) in Grand Canyon, Arizona, 1990-1994, revealed varying rates of prevalence and infrapopulation levels of Asian tapeworm (Bothriocephalus acheilognathi). Mean prevalence was $28 \%$ (range $0-78 \%$ ) in humpback chub (Gila cypha) and $8 \%$ (range $0-46 \%$ ) in speckled dace (Rhinichthys osculus), with infrapopulation as high as 46 and 28 respectively. We also note Asian tapeworm infection of the nonnative carp (Cyprinus carpio), fathead minnow (Pimephales promelas), and plains killifish (Fundulus zebrinus) from the LCR. Reported pathogenic and chronic effects of this cestode to its definitive hosts add concern for the status of the Grand Canyon population of the federally endangered humpback chub. The rapidity with which Asian 
tapeworm has spread to different drainages of the Colorado River Basin likely portends an eventual cosmopolitan basin distribution in lower elevations suitable to the parasite's thermophilic life history. Such biotic changes must be considered among the most serious threats to conservation and recovery of native fish populations.

\section{Cole, R. 2005. Exotic tapeworm found in endangered desert fishes. U.S. Geological Survey, Fisheries and Aquatics Bulletin 4(1):2-3. Abstract excerpted from article contents.}

The Asian fish tapeworm (Bothriocephalus acheilognathi) was introduced into the US in the 1970s with the importation of grass carp (Ctenopharyngodon idella) and has become established in the endangered humpback chub (Gila cypha) population from the Colorado and Little Colorado Rivers in Grand Canyon, AZ. This parasite is known to cause disease and death primarily in hatchery raised carp, however, pathogenic effects have also been observed in other fish species. At the USGS National Wildlife Health Center in Madison, WI, a series of experimental trials were carried out using the closely related bonytail chub (Gila elegans), another endangered fish of the southwest US, to study the potential impacts of Asian fish tapeworm infections on survival, growth, and physiological condition of humpback chub. While older juvenile fish (10 months old and $83 \mathrm{~mm}$ long) revealed no negative effects associated with infections, subsequent experiments with younger and smaller fish ( 2.5 months and $22 \mathrm{~mm}$ long) demonstrated infected fish length was reduced as much as $9 \%$ on average compared to control fish by the end of the 24-week study. Infected fish were found to have significantly lower hematocrit levels and a reduced amount of visceral fat when compared with control fish.

An experiment was also conducted to examine whether tapeworm infections exacerbate the effects of thermal shock that small chub undergo when being swept from the warm waters of the Little Colorado River $\left(23.5^{\circ} \mathrm{C}\right)$ into the cold waters of the Colorado River $\left(9.5^{\circ} \mathrm{C}\right)$ during monsoon flooding. Results from this experiment revealed no synergistic effects of cold shock and tapeworm infection, with control and infected fish exhibiting similar stress responses to the thermal extremes.

Hansen, S.P., A. Choudhury, D.M. Heisey, J.A. Ahumada, T.L. Hoffnagle and R.A. Cole. 2006. Experimental infection of the endangered bonytail chub (Gila elegans) with the Asian fish tapeworm (Bothriocephalus acheilognathi): impacts on survival, growth, and condition. Canadian Journal of Zoology 84(10):1383-1394.

Bothriocephalus acheilognathi Yamaguti, 1934, a tapeworm known to be pathogenic to some fish species, has become established in the endangered humpback chub (Gila cypha Miller, 1964) in Grand Canyon, USA, following the tapeworm's introduction into the Colorado River system. The potential impact of this tapeworm on humpback chub was studied by exposing the closely related bonytail chub (Gila elegans Baird and Girard, 1853) to the parasite under a range of conditions that included potential stressors of humpback chub in their natal waters, such as abrupt temperature change and a limited food base. Survival of infected fish under low food rations was considerably lower than that of control fish, and mortality of infected fish began 20 days earlier. Growth of infected fish was significantly reduced, and negative changes in health condition indices were found. No significant negative impacts were revealed from the synergistic effects between temperature shock and infection. Bothriocephalus acheilognathi does present a potential threat to humpback chub in Grand Canyon and should be considered, along with 
conventional concerns involving altered flow regimes and predation, when management decisions are made concerning conservation of this endangered species.

\section{Hoffnagle, T.L., A. Choudhury and R.A. Cole. 2006. Parasitism and body condition in humpback chub from the Colorado and Little Colorado rivers, Grand Canyon, Arizona. Journal of Aquatic Animal Health 18: 184-193.}

Glen Canyon Dam has greatly altered the Colorado River in Grand Canyon. The Little Colorado River (LCR) provides a small refuge of seasonally warm and turbid water that is thought to be more suitable than the Colorado River for endangered humpback chub Gila cypha. However, the LCR has low productivity and contains nonnative fishes and parasites, which pose a threat to humpback chub. The Colorado River hosts a different suite of nonnative fishes and is cold and clear but more productive. We compared condition factor $(\mathrm{K})$, abdominal fat index (AFI), and presence and number of two introduced pathogenic parasites (Lernaea cyprinacea and Bothriocephalus acheilognathi) between juvenile ( $<150 \mathrm{~mm}$ total length) humpback chub from the LCR and those from the Colorado River during 1996-1999. Both K and AFI were lower and L. cyprinacea prevalence and B. acheilognathi prevalence were higher in LCR fish than in Colorado River fish for all years. Mean K and AFI were 0.622 and 0.48, respectively, in the LCR and 0.735 and 2.02, respectively, in the Colorado River, indicating that fish in the Colorado River were more robust. Mean prevalence of $L$. cyprinacea was $23.9 \%$ and mean intensity was $1.73 \mathrm{~L}$. cyprinacea/infected fish in the LCR, whereas prevalence was $3.2 \%$ and intensity was $1.0 \mathrm{~L}$. cyprinacea/infected fish in the Colorado River. Mean prevalence of $B$. acheilognathi was $51.0 \%$ and mean intensity was 25.0 B. acheilognathi/infected fish in the LCR, whereas prevalence was $15.8 \%$ and intensity was $12.0 \mathrm{~B}$. acheilognathi/infected fish in the Colorado River. Increased parasitism and poorer body condition in humpback chub from the LCR challenge the paradigm that warmer LCR waters are more suitable for humpback chub than the colder Colorado River and indicate the need to consider the importance and benefits of all available habitats, as well as biotic and abiotic factors, when managing endangered species and their environment.

\section{Ward, D.L. 2007. Removal and quantification of Asian tapeworm from bonytail chub using praziquantel. North American Journal of Aquaculture 69(3):207-210.}

The spread of the Asian tapeworm Bothriocephalus acheilognathi has been identified as a potential threat to endangered cyprinid fishes, such as bonytail Gila elegans and humpback chub G. cypha. Praziquantel is often used to remove Asian tapeworms from these species, but little information is available on the effectiveness or side effects of these treatments. I performed laboratory experiments using bonytails (110-457 $\mathrm{mm}$ total length) to evaluate the dosage and time needed to effectively remove $100 \%$ of Asian tapeworms using praziquantel. A low dose of $0.7 \mathrm{mg} / \mathrm{L}$ for $24 \mathrm{~h}$ was not effective at removing all Asian tapeworms, whereas a 24-h exposure at $1.5 \mathrm{mg} / \mathrm{L}$ and higher was $100 \%$ effective. A bath treatment of 12-h duration only appears effective at the highest dose of $36 \mathrm{mg} / \mathrm{L}$, but not all Asian tapeworms are cleared from the host within this time frame. No short-term mortality or side effects of praziquantel treatment were observed. Praziquantel bath treatments can effectively and safely remove $100 \%$ of Asian tapeworms from bonytail if dosage and treatment duration are adequate. In some cases, repeated 
treatments may be necessary to ensure that Asian tapeworms are not spread into new environments.

\subsection{CLIMATE CHANGE}

Christensen, N.S., A.W. Wood, N. Voisin, D.P. Lettenmaier and R.N. Palmer. 2004. The effects of climate change on the hydrology and water resources of the Colorado River Basin. Climatic Change 62: 337-363.

The potential effects of climate change on the hydrology and water resources of the Colorado River basin are assessed by comparing simulated hydrologic and water resources scenarios derived from downscaled climate simulations of the U.S. Department of Energy/National Center for Atmospheric Research Parallel Climate Model (PCM) to scenarios driven by observed historical (1950-1999) climate. PCM climate scenarios include an ensemble of three 105-year future climate simulations based on projected 'business-as-usual' (BAU) greenhouse gas emissions and a control climate simulation based on static 1995 greenhouse gas concentrations. Downscaled transient temperature and precipitation sequences were extracted from PCM simulations, and were used to drive the Variable Infiltration Capacity (VIC) macroscale hydrology model to produce corresponding stream flow sequences. Results for the BAU scenarios were summarized into Periods 1, 2, and 3 (2010-2039, 2040-2069, and 20702098). Average annual temperature changes for the Colorado River basin were $0.5^{\circ} \mathrm{C}$ warmer for control climate, and $1.0,1.7$, and $2.4^{\circ} \mathrm{C}$ warmer for Periods $1-3$, respectively, relative to the historical climate. Basin-average annual precipitation for the control climate was slightly (1\%) less than for observed historical climate, and 3, 6, and 3\% less for future Periods 1-3, respectively. Annual runoff in the control run was about $10 \%$ lower than for simulated historical conditions, and 14, 18, and 17\% less for Periods 1-3, respectively. Analysis of water management operations using a water management model driven by simulated stream flows showed that stream flows associated with control and future BAU climates would significantly degrade the performance of the water resources system relative to historical conditions, with average total basin storage reduced by $7 \%$ for the control climate and 36,32 and $40 \%$ for Periods 1-3, respectively. Releases from Glen Canyon Dam to the Lower Basin (mandated by the Colorado River Compact) were met in $80 \%$ of years for the control climate simulation (versus $92 \%$ in the historical climate simulation), and only in $59-75 \%$ of years for the future climate runs. Annual hydropower output was also significantly reduced for the control and future climate simulations. The high sensitivity of reservoir system performance for future climate is a reflection of the fragile equilibrium that now exists in operation of the system, with system demands only slightly less than long-term mean annual inflow.

Christensen, N.S. and D.P. Lettenmaier. 2006. A multi-model ensemble approach to assessment of climate change impacts on the hydrology and water resources of the Colorado River basin. Hydrology and Earth System Sciences Discussions 3: 3727-3770.

Implications of 21 st century climate change on the hydrology and water resources of the Colorado River basin were assessed using a multi-model ensemble approach in which downscaled and bias corrected output from 11 General Circulation Models (GCMs) was used to drive macroscale hydrology and water resources models. Downscaled climate 
scenarios (ensembles) were used as forcings to the Variable Infiltration Capacity (VIC) macroscale hydrology model, which in turn forced the Colorado River Reservoir Model (CRMM). Ensembles of downscaled precipitation and temperature, and derived streamflows and reservoir system performance were assessed through comparison with current climate simulations for the 1950-1999 historical period. For each of the 11 GCMs, two emissions scenarios (IPCC SRES A2 and B1, corresponding to relatively unconstrained growth in emissions, and elimination of global emissions increases by 2100) were represented. Results for the A2 and B1 climate scenarios were divided into period 1 (2010-2039), period 2 (2040-2069), and period 3 (2070-2099). The mean temperature change averaged over the 11 ensembles for the Colorado basin for the A2 emission scenario ranged from 1.2 to $4.4^{\circ} \mathrm{C}$ for periods $1-3$, and for the $\mathrm{B} 1$ scenario from 1.3 to $2.7^{\circ} \mathrm{C}$. Precipitation changes were modest, with ensemble mean changes ranging from -1 to -2 percent for the $\mathrm{A} 2$ scenario, and from +1 to -1 percent for the $\mathrm{B} 1$ scenario. An analysis of seasonal precipitation patterns showed that most GCMs had modest reductions in summer precipitation and increases in winter precipitation. Derived 1 April snow water equivalent declined for all ensemble members and time periods, with maximum (ensemble mean) reductions of 38 percent for the A2 scenario in period 3. Runoff changes were mostly the result of a dominance of increased evapotranspiration over the seasonal precipitation shifts, with ensemble mean runoff reductions of $-1,-6$, and -11 percent for the A2 ensembles, and $0,-7$, and -8 percent for the $\mathrm{B} 1$ ensembles. These hydrological changes were reflected in reservoir system performance. Average total basin reservoir storage generally declined, however there was a large range across the ensembles. Releases from Glen Canyon Dam to the Lower Basin (mandated by the Colorado River Compact) were reduced for all periods and both emissions scenarios in the ensemble mean. The fraction of years in which shortages occurred increased by approximately $20 \%$ by period 3 in for both emissions scenarios, and the average shortage increased to a maximum of $3.7 \mathrm{BCM} / \mathrm{yr}$ for 5 the period $3 \mathrm{~A} 2$ ensemble average. Hydropower output was reduced in the ensemble mean for all time periods and both emissions scenarios.

\section{Hoerling, M. and J. Eischeid. 2006. Past peak water in the Southwest. Southwest Hydrology 6(1).}

Nobody relishes being "past peak" anything. Whether it's the prime of our human existence or the prime of Nature's abundance, the notion of having less rather than more is often vehemently denied. But demand growth in the face of production and storage decline has severe consequences, especially when existing uses already consume the available supply. The lifeblood of the Southwest is the Colorado River, which is increasingly impacted by climate forces not previously experienced. The recent drought prompts concern among water users and water stewards alike, and requires the scientific community to probe whether a sustained threat is rising to our already perilous moisture balance. The consensus of the Intergovernmental Panel on Climate Change (IPCC, 2001) affirms that Earth's atmosphere is accumulating unprecedented quantities of carbon dioxide that are now causing detectable increases in surface air temperature.

Seager, R., M. Ting, I. Held, Y. Kushnir, J. Lu, G. Vecchi, H. Huang, N. Harnik, A. Leetmaa, N. Lau, C. Li, J. Velez and N. Naik. 2007. Model projections of an imminent transition to a more Arid Climate in Southwestern North America. Science.10:1126. 
How anthropogenic climate change will affect hydroclimate in the arid regions of southwestern North America has implications for the allocation of water resources and the course of regional development. Here we show that there is a broad consensus among climate models that this region will dry in the 21 st century and that the transition to a more arid climate should already be under way. If these models are correct, the levels of aridity of the recent multiyear drought or the Dust Bowl and the 1950s droughts will become the new climatology of the American Southwest within a time frame of years to decades.

\subsection{SUPPORTING ARTICLES}

\section{Bulow, F.J., J.R. Winningham and R.C. Hooper. 1979. Occurrence of copepod parasite Lernaea cyprinacea in a stream fish population. Transactions of the American Fisheries Society 108: 100-102.}

Although Lernaea cyprinacaea is often an epizootic in lakes, ponds, and hatcheries, its occurrence and intensity of infection in a central Tennessee stream system were quite low. Ten of the 13 species of fish collected in the Blackburn Fork watershed (Tennessee) were infected and intensity of infection was highest during the warmest of the seasons. There was also a tendency for the rate of infection to be higher in fish from smaller streams. Adult female $L$. cyprinacaea showed a definite affinity for attachment to the host fish body near the base of a fin.

Granath, W.O., Jr. and G.W. Esch. 1983. Seasonal dynamics of Bothriocephalus acheilognathi in ambient and thermally altered areas of a North Carolina cooling reservoir. Proceedings of the Helminthological Society Washington 50: 205-218.

The seasonal dynamics of Bothriocephalus acheilognathi were studied in three arbitrarily established size classes of mosquitofish, Gambusia affinis, from thermally altered and ambienttemperature locations in predator-free areas of Belews Lake, a North Carolina cooling reservoir. At both stations, lowest prevalence and densities of the cestode were observed during summer months. Densities rose sharply in the fall and peaked by early winter, after which they began to decline. Recruitment of the parasite at each site was also seasonal, beginning in late spring and continuing into October of both years of the study. However, recruitment at the thermally altered site began about 2 wk sooner, lasted about 2 wk longer, and was interrupted for several weeks in late summer when water temperatures exceeded $35^{\circ} \mathrm{C}$.

\section{Hamilton, S. J. and B. Waddell. 1994. Selenium in eggs and milt of razorback sucker (Xyrauchen texanus) in the middle Green River, Utah. Archives of Environmental Contamination and Toxicology 27:195-201.}

Eggs from three females and milt from five male endangered razorback suckers (Xyrauchen texanus) were collected from the Razorback Bar (about $20 \mathrm{~km}$ upstream of Ashley Creek) in the Green River of northeastern Utah. Eggs, but not milt, had concentrations of selenium that were above the range of selenium concentrations in control fish from laboratory studies or reference fish from field studies. The concentrations, however, were below those reported in selenium-exposed fish that had reproductive problems in laboratory studies or field 
investigations. Tests with three streamside spawned pairs of razorback suckers, which were sampled for eggs and milt in this study, resulted in no hatching of fertilized eggs. Concentrations of selenium in eggs and milt were significantly correlated with selenium concentrations in muscle plugs taken from the same fish, but egg and milt concentrations were not significantly different from muscle plugs. Selenium concentrations in eggs of razorback suckers in the Green River may be sufficiently elevated to cause reproductive problems that are contributing to the decline of this species in the upper Colorado River basin.

\section{Hamilton, S.J., R.T. Muth, B. Waddell and T.W. May. 1998. Selenium and other trace elements in wild larval razorback suckers from the Green River, Utah. Final report of U.S. Geological Survey Environmental and Contaminants Research Center to U.S. Bureau of Reclamation Irrigation Drainage Program, Denver, Colorado.}

Contaminant investigations of the middle Green River, Utah, have documented selenium contamination at sites receiving irrigation drainage. The middle Green River provides critical habitat for four endangered fishes including the largest extant riverine population of razorback sucker (Xyrauchen texanus). Although 2,175 larval razorback suckers were collected from the river between 1992 and 1996, very few juveniles have been captured within recent decades. Selenium concentrations were measured in larval razorback suckers collected from five sites in the middle Green River to assess the potential for adverse effects on recruitment of larvae to the juvenile stage and the adult population. Larvae from all sites contained selenium concentrations at or above the proposed toxic threshold of $4 \mu \mathrm{g} / \mathrm{g}$ for adverse biological effects in fish, derived from several laboratory and field studies with a wide range of fish species. At two sites, Cliff Creek and Stewart Lake Drain, selenium concentrations in larvae increased over time as fish grew, whereas selenium concentrations decreased as fish grew at Sportsman's Drain. Evaluation of a 279-larvae composite analyzed for 61 elements demonstrated that selenium, and to lesser extent vanadium, were elevated to concentrations reported to be toxic to a wide range of fish species. Elevated selenium concentrations in larval razorback suckers from the five sites suggests that selenium contamination may be widespread in the middle Green River, and that survival and recruitment of larvae to the juvenile stage may be limited due to adverse biological effects. Selenium contamination may be adversely affecting the reproductive success of endangered razorback sucker.

Hinck, J.E., V.S. Blazer, N.D. Denslow, K.R. Echols, T.S. Gross, T.W. May, PJ. Anderson, L.J. Coyle and D.E. Tillit. 2007. Chemical contaminants, health indicators and reproductive biomarker responses in fish from the Colorado River and its tributaries. Science of the Total Environment 378: 376-402.

Common carp (Cyprinus carpio), black bass (Micropterus spp.), and channel catfish (Ictalurus punctatus) were collected from 14 sites in the Colorado River Basin (CRB) to document spatial trends in accumulative contaminants, health indicators, and reproductive biomarkers. Organochlorine residues, 2,3,7,8-tetrachlorodibenzo- $p$-dioxin-like activity (TCDDEQ), and elemental contaminants were measured in composite samples of whole fish, grouped by species and gender, from each site. Selenium (Se) and mercury $(\mathrm{Hg})$ concentrations in fish were elevated throughout the $\mathrm{CRB}$, and pesticide concentrations were greatest in fish from agricultural areas in the Lower Colorado River and Gila River. Selenium concentrations 
exceeded toxicity thresholds for fish $(>1.0 \mu \mathrm{g} / \mathrm{g} \mathrm{ww})$ at all CRB sites except the Gila River at Hayden, Arizona. Mercury concentrations were elevated ( $>0.1 \mu \mathrm{g} / \mathrm{g} \mathrm{ww})$ in fish from the Yampa River at Lay, Colorado; the Green River at Ouray National Wildlife Refuge (NWR), Utah and San Rafael, Utah; the San Juan River at Hogback Diversion, New Mexico; and the Colorado River at Gold Bar Canyon, Utah, Needles, California, and Imperial Dam, Arizona. Concentrations of $p, p^{\prime}$-DDE were relatively high in fish from the Gila River at Arlington, Arizona ( $>1.0 \mu \mathrm{g} / \mathrm{g} \mathrm{ww})$ and Phoenix, Arizona ( $>0.5 \mu \mathrm{g} / \mathrm{g} \mathrm{ww})$. Concentrations of other formerly used pesticides including toxaphene, total chlordanes, and dieldrin were also greatest at these two sites but did not exceed toxicity thresholds. Currently used pesticides such as Dacthal, endosulfan, $\gamma-\mathrm{HCH}$, and methoxychlor were also greatest in fish from the Gila River downstream of Phoenix. Total polychlorinated biphenyls (PCBs; $>0.11 \mu \mathrm{g} / \mathrm{g} \mathrm{ww}$ ) and TCDDEQs ( $>5 \mathrm{pg} / \mathrm{g} \mathrm{ww})$ exceeded wildlife guidelines in fish from the Gila River at Phoenix. Hepatic ethoxyresorufin $O$-deethylase (EROD) activity was also relatively high in carp from the Gila River at Phoenix and in bass from the Green River at Ouray NWR. Fish from some sites showed evidence of contaminant exposure as indicated by fish health indicators and reproductive biomarker results. Multiple health indicators including altered body and organ weights and high health assessment index scores may be associated with elevated Se concentrations in fish from the Colorado River at Loma, Colorado and Needles. Although grossly visible external or internal lesions were found on most fish from some sites, histopathological analysis determined many of these to be inflammatory responses associated with parasites. Edema, exophthalmos, and cataracts were noted in fish from sites with elevated Se concentrations. Inter-sex fish were found at seven of 14 sites and included smallmouth bass (M. dolomieu), largemouth bass ( $M$. salmoides), catfish, and carp and may indicate exposure to endocrine disrupting compounds. A high proportion of smallmouth bass from the Yampa River at Lay (70\%) was intersex but the cause of this condition is unknown. Male carp, bass, and catfish with low concentrations of vitellogenin were common in the CRB. Comparatively high vitellogenin concentrations $(>0.2 \mathrm{mg} / \mathrm{mL})$ were measured in male bass from the Green River at Ouray NWR and the Colorado River at Imperial Dam and indicate exposure to estrogenic or anti-androgenic chemicals. Anomalous reproductive biomarkers including low GSI and gonadal abnormalities (calcifications, edema, and parasites) observed in fish downstream of Phoenix are likely related to the poor water-quality of the Gila River in this area.

\section{Hunt, T.A. 2008. The effects of capture by trammel nets on native Arizona fishes. Master's Thesis. Northern Arizona University, Flagstaff, Arizona.}

Trammel nets are commonly used to sample fish; however, little is known about postcapture effects of this gear type on the fish captured. We conducted experiments to evaluate the effects of trammel net sampling on survival and cortisol levels of razorback sucker, Xyrauchen texanus, bonytail, Gila elegans, and roundtail chub, Gila robusta, at $15^{\circ} \mathrm{C}, 20^{\circ} \mathrm{C}$, and $25^{\circ} \mathrm{C}$. Fish between $139 \mathrm{~mm}$ to $388 \mathrm{~mm}$ in total length (TL) were obtained from both captive hatchery stock and wild populations, quarantined for two weeks, and acclimated in two 18,000 L tanks for 13 days. Treatment fish were entangled in a trammel net for two hours and control fish were captured with a seine net. After capture, all fish were weighed, measured, PIT tagged. We extracted $\sim 0.37 \mathrm{~mL}$ (between $0.1 \mathrm{~mL}$ and $0.5 \mathrm{~mL}$ ) of blood from the caudal vasculature of 30$80 \%$ of fish in both the treatment and control groups. All fish were placed in a 36,000 L holding tank, where they were monitored for delayed mortality for 14 days. 
Fish captured in the trammel net experienced up to $94 \%$ mortality within the first two weeks after capture, whereas seined fish experienced less than $24 \%$ mortality. There was little immediate net mortality for both control and treatment fish, which is consistent with field observations; however, up to two weeks after capture trammel netted fish were still dying. In warmer water temperatures, both bonytail and razorback suckers experienced significantly increased mortality rates ( $\mathrm{p}<0.05$, Fisher's Exact Test); however, roundtail chub did not show this trend. Even higher levels of mortality may occur in nature, as any increased stress and/or physical injury that fish incur during capture and handling may lead to a competitive disadvantage and impair foraging ability. Post-capture mortality of wild fish may have gone undocumented thus far because of the time delay between capture and death. Our results suggest management agencies should re-examine the appropriateness of trammel net sampling for imperiled fish populations, especially when water temperatures are above $20^{\circ} \mathrm{C}$.

Although the magnitude of the cortisol response varied among species, cortisol levels were higher for fish captured by the trammel net than for fish captured by the seine net ( $\mathrm{p}<$ $0.05)$. Fish captured at the highest temperature $\left(25^{\circ} \mathrm{C}\right)$ were more likely to have elevated cortisol levels than fish captured in the same way at lower temperatures $(p<0.05)$. Significantly more fish died after capture by trammel net $(\mathrm{p}<0.05)$, and more fish died at the highest experimental temperatures: $20^{\circ} \mathrm{C}$ and $25^{\circ} \mathrm{C}(\mathrm{p}<0.05)$. For bonytail and razorback suckers, elevated cortisol levels were an effective predictor of mortality $(\mathrm{p}<0.05)$; however, roundtail chub did not demonstrate a significant association between cortisol levels and subsequent mortality. These results suggest that cortisol could be used as a potential index of stress and post-capture mortality, at least for some species.

Mueller, G.A., J. Carpenter and D. Thornbrugh. 2006. Bullfrog tadpole (Rana catesbeina) and red swamp crayfish (Procambarus clarkii) predation on early life stages of endangered razorback sucker (Xyrauchen texanus). The Southwestern Naturalist 51(2):258-261.

Bullfrog tadpoles (Rana catesbeiana) and red swamp crayfish (Procambarus clarkii) are widespread introduced taxa that are problematic throughout the western United States. Their impact on native amphibians and crustaceans is well documented, but less is known regarding their influence on native fishes. Predator-prey tank tests showed both species consumed eggs and larvae of the endangered razorback sucker (Xyrauchen texanus) in a laboratory setting. Tadpoles consumed 2.2 razorback sucker eggs/d and 1.4 razorback sucker larvae/d, while crayfish ate 6.0 eggs/d and 3.5 larvae/d. Relatively high densities of bullfrog tadpoles and crayfish in razorback sucker spawning areas suggest that these nonnative taxa might pose a threat to the recruitment success of this and other imperiled native fish.

Webb, R.H., R. Hereford and G.J. McCabe. 2005. Climatic fluctuations, drought and flow in the Colorado River. Pages 57-68 in S.P. Gloss, Lovich, J.E. and Melis, T.S. (eds.). The state of the Colorado River ecosystem in the Grand Canyon: U.S. Geological Survey Circular 1282.

From 2000 through 2004, the early 21st century drought caused abnormally low flows in the Colorado River and its tributaries upstream from Lake Powell. By using either actual annual 
flow data or annual flow records adjusted for consumptive uses in the upper basin, it was found that runoff from 2000 through 2004 was the lowest in the period of record (99-110 yr). This low flow has caused considerable concern about the ability of the reservoirs on the Colorado River to deliver water from upper basin States to lower basin States. Water managers increasingly want to know the predictability of climate and its effects on water resources over annual, decadal, and longer term spans.

Climate, drought, and streamflow in the Colorado River are linked in poorly understood ways. Initial understanding of flows in the system was based on a relatively short historical record that is now believed to be a period of above-average precipitation. Examination of longterm records based on tree-ring analyses suggests that drought magnitude and persistence patterns are associated with much broader hemispheric climate patterns; however, these correlations are imperfect and do not provide a clear understanding of long-term precipitation patterns.

Currently, there is no reliable way to predict how long the early 21 st century drought will last in the Colorado River Basin. Components of the climate system, such as sea-surface temperature of the Atlantic and Pacific Oceans, provide some context for understanding past variations in precipitation and streamflow, but they are insufficient for predicting the fate of the ongoing drought. Time series of the relevant climate indices indicate a large amount of year-toyear variability and relatively rapid changes from one regime to another. Above-average precipitation for winter 2004-05 and forecasts for above average runoff may signal the end of the drought, or the drought conditions may resume after the present El Niño ends. Both outcomes underscore the unpredictability of climatic shifts affecting the Colorado River Basin.

\section{CONSERVATION AND MANAGEMENT}

\subsection{HABTIAT AND SPECIES MANAGAMENT}

\section{Arizona Game and Fish Department. 1996. Ecology of Grand Canyon backwaters. Final report to U.S. Bureau of Reclamation, Upper Colorado Region. Arizona Game and Fish Department, Phoenix. Abstract excerpted from report introduction.}

The closure of Glen Canyon Dam in 1963 turned a river that was characteristically warm and muddy into a cold clear one, and greatly affected the biota of the river corridor, particularly the native fishes. The controlled daily fluctuations in the relatively clear Colorado River of today differ greatly from pre-dam conditions. Prior to impoundment by Glen Canyon Dam, the Colorado River, laden with sediment, underwent large, seasonally predictable floods, peaking in May and June. These floods probably created and maintained a system of backwaters similar to those created by high discharge in the system today. Pre-dam mean annual maximum flow was $86,617 \mathrm{cfs}$ and reached $300,000 \mathrm{cfs}$. Post-dam mean annual maximum flow is $27,898 \mathrm{cfs}$, ranging from 1,000-31,500 cfs. Post-dam flows fluctuate on a daily basis, instead of a seasonal basis, with a peak flow and low flow within every 24 -hour period. Since closure of the dam, in 1963 through July 1991, daily discharge release patterns fluctuated widely with no restrictions on 
ramping rates. On 1 August 1991, interim operations were implemented, restricting daily flow fluctuations to range of 5,000-20,000 cfs.

Tributaries also contribute to the discharge of the Colorado River in Grand Canyon and provide spawning areas for native fishes. Most notable is the LCR, which joins the mainstem Colorado River at RM 61.5. Since closure of the dam, the LCR and Paria River (RM 0.9) are the major sources of sediment input into the system. Floods in these tributaries can cause high discharges of sediment-laden water into the Colorado River and result in the formation of numerous sand deposits and associated backwaters. However, these backwaters are generally temporary and are usually formed in the mainstem just downstream of the source tributary.

Backwaters are pockets of quiet water connected to the main channel with little or no flow, and are usually formed in eddies where scouring occurs during high flows. Backwaters and other slow water habitats add to the diversity of the riverine environment. Due to changes in mainstem habitat caused by dams, particularly decreased water temperature, backwaters have become increasingly important as rearing areas for larval and juvenile native fishes in the Colorado River system because they provide sheltered habitats with warmer water that contains greater densities of food than the mainchannel. However, fluctuations in dam releases can inundate or dewater backwaters, reducing their ability to support juvenile fish. These fluctuating flow regimes force small fish into the mainchannel where they are stressed by cold temperatures and high velocities and are more susceptible to predation.

The studies addressed herein use a number of sampling protocols and gear types. Six general objectives were addressed in an attempt to understand the effects of Glen Canyon Dam on the ecology of the fish communities and their habitats in the Colorado River, Grand Canyon:

- Continue the AGFD monitoring and research program for native fishes of the Colorado River and its tributaries in the Grand Canyon.

- Identify the temporal and spatial distribution patterns and movements of early life stages of fishes in the LCR and other tributaries.

- Determination of the changes in environmental conditions in mainstream and tributary confluence zone native fish rearing habitats under different flow regimes.

- Determine invertebrate standing crops and their relative contributions to diets of young native fishes in tributary, backwater and mainchannel habitats under different flow regimes.

- Determine the behavioral responses of larval to juvenile native fishes to changing environmental conditions in rearing habitats.

- Determine the extent to which limnological factors, with emphasis on water chemistry and aquatic productivity, potentially limit the distribution and abundance of native fishes in the Little Colorado River and other tributaries which might serve as streams for augmentation of humpback chub in Grand Canyon. 
This report summarizes data collected by the AGFD during 25 research trips conducted on the Colorado River from 1991-94. It provides information concerning how changes in habitat may affect the distribution and relative abundance of native fishes and their food in the Colorado River, Grand Canyon, Arizona. The information in this report, along with data collected by AGFD during GCES Phase I studies, will provide baseline data for evaluating the long-term effects of Interim or Modified Low Fluctuating Flows, proposed habitat building and habitat maintenance flows, and the effects of thermal modification should those studies materialize in the future.

\section{Arizona Game and Fish Department. 1996. Effects of an experimental flood on the aquatic biota and their habitats in the Colorado River, Grand Canyon, Arizona. Final report. Arizona Game and Fish Department, Phoenix. Abstract excerpted from study conclusions.}

The immediate impacts of the experimental flood on the morphology, number, sediments, and the benthic macroinvertebrate community of backwaters, and the zooplankton and fish communities in the Colorado River, Grand Canyon, have been shown. The number and surface area of backwaters immediately after the flood increased from that of the year prior. However, the effect of flooding on long-term backwater number and size remains uncertain. It is apparent that changes in flow patterns from flood discharge to operating flows and the subsequent fluctuating flows of normal dam operations were detrimental to the longevity of backwaters created by the flood. Floods of lower magnitude and/or a much slower downramp may alleviate some of these problems, making the new backwaters more permanent. The loss of backwaters observed after the resumption of operating flows may detrimentally affect survival and growth of larval and juvenile native fishes.

The availability of nursery/rearing habitats to larval and juvenile native fishes in the reach below the LCR is important because all native species spawn in the LCR, particularly humpback chub. Larval fish migrating out of the LCR are faced with colder water temperatures $\left(>8^{\circ} \mathrm{C}\right.$ mean temperature change), which decreases swimming ability and probably causes larvae to have difficulty reaching backwaters. Although large numbers of larvae are transported out of the LCR into the mainstem Colorado River each year, few are believed to survive. An increase in the number of backwaters immediately below the LCR will likely help increase the survival of larval native fishes spawned in the LCR.

How closely the environmental conditions within a backwater conform to those preferred by larval and juvenile native fishes (i.e., water temperature, depth, area, amount of cover, invertebrate density, etc.) is also of importance. It has been reported that YOY humpback chub preferred backwaters with no current, a firm silt bottom, $0.6 \mathrm{~m}$ maximum depth, and of temperature between $21.0-24.4^{\circ} \mathrm{C}$. Backwater temperature and conductivity immediately following the Experimental Flood were mostly sub-optimal for larval and juvenile native fishes. The new backwaters created by the flood had larger surface area and greater zooplankton densities, but had no vegetation, sediments made up primarily clean sand, and decreased benthic invertebrate densities. Many benthic invertebrate species are important prey items for juvenile native fishes and their loss may detrimentally affect growth of these fishes. However, over time 
fine sediments and detritus will accumulate in backwaters, and benthic invertebrate will recolonize.

Native fishes appear to have been unaffected by the flood. The timing of the flood largely prevented newly hatched fish from being affected. YOY humpback chub were able to maintain themselves in their sheltered, preferred habitats during the flood and showed no evidence of being displaced downstream. Diet of adult humpback chub varied, but they demonstrated their omnivory and adaptability to this type of perturbation.

Finney, S. 2006. Adult and juvenile humpback chub monitoring for the Yampa River population, 2003-2004. Final report of U.S. Fish and Wildlife Service to Upper Colorado River Endangered Fish Recovery Program, Lakewood, Colorado.

The humpback chub (Gila cypha) is an endangered species native to the Colorado River Basin listed under the Endangered Species Act in 1967 (32 FR 4001). The "Yampa" population of humpback chub includes individuals that may be found in Yampa, Lodore, Whirlpool, and Split Mountain canyons and is one of the smallest existing populations of humpback chub. The objectives of this study are to define the distribution, length frequency and abundance of the adult Yampa humpback chub population and numbers of juveniles in the Yampa humpback chub population.

A two-year study began in 2003 that sampled adult humpback chub using trammel nets, boat electrofishing and angling. Juvenile fish were collected using backpack electrofishing and seining. All adult humpback chub were measured for TL, weighed, scanned for the presence of PIT tags, tagged with PIT tags if none were found and immediately released. All juvenile samples were preserved for laboratory identification.

During the two-year study, 13 adult humpback chub were captured (10 in Yampa Canyon and 3 in Whirlpool Canyon) and three hundred and forty nine juvenile Gila spp. were collected of which 30 were questionably identified as G. cypha. Abundance estimates were not possible due to the low number of captures. Distribution was similar to historical ranges. Catch per effort of adult humpback chub dramatically decreased from other recently collected data.

Gloss, S.P., Lovich, J.E. and Melis, T.S., eds. 2005. The state of the Colorado River ecosystem in Grand Canyon: U.S. Geological Survey Circular 1282, Reston, Virginia.

Research and monitoring conducted by U.S. Geological Survey scientists and their cooperators have conclusively demonstrated a net loss of sediment from the system and have documented the decline of the federally endangered humpback chub during the last decade. At this first milestone, both findings are critical pieces of information to assess conditions and adjust management actions in the spirit of adaptive management.

It is important to note that water-delivery requirements continued to be met throughout the decade after the EIS, despite increased costs associated with environmental and experimental regulation of flows. 
Although incomplete, a substantial body of knowledge now exists for the Colorado River ecosystem in Grand Canyon. The overarching question is, "What will society do with the knowledge now available to move into the next active phase of the Glen Canyon Dam Adaptive Management Program?" The complexity of the natural system presents enormous challenges for determining how resources and population numbers vary in time and space and underscores the importance of long-term studies to describe patterns and processes. The next critical phase of adaptive management requires strategic action on the part of both managers and scientists.

Along with future action come the continuing challenge and need for greater integration of monitoring and research studies. As the complexity of issues in the Glen Canyon Dam Adaptive Management Program becomes more obvious, so does the need for interdisciplinary, not just multidisciplinary, science. Good examples of recent interdisciplinary science include (1) the interface between fine-sediment studies and cultural resources as the result of research efforts to understand the deposition of wind-carried sediment, (2) water-quality studies related to temperature and fish biology, and (3) the developing link between aquatic ecology studies and fish diets. Continued efforts will be required to integrate knowledge across disciplines and scales and to develop a more robust conceptual model for the Grand Canyon ecosystem.

A continued adaptive management approach below Glen Canyon Dam, one focused on systematic experimentation, is recommended as a more efficient strategy for learning than the approach initially undertaken of monitoring the MLFF operation without comparing it to other flow and non-flow (e.g., mechanical removal of nonnative fish) alternatives. Future experimental treatments (flow or otherwise) must be evaluated within a strategic framework of periodic milestones and with rigorous scientific review so as to effectively identify viable management options for achieving the desired mix of resource responses. Success in this approach relies first and foremost on managers and stakeholders identifying what is desired, as well as determining whether identified objectives are measurable by science and attainable through dam operations.

In the context of an adaptive ecosystem management process, the information identified at this milestone should lead to a dialog between managers and scientists about what other flow or non-flow alternatives might be considered to achieve the desired environmental outcomes.

Because of the uncertainty about the cause and effect of MLFF operations on Grand Canyon resources and the even greater uncertainty about other conservation options, such as mechanical removal or thermal modification, the next steps in the process seem best approached as ongoing management policy experiments in the spirit of adaptive management, punctuated with frequent milestones at which the state of knowledge gained is assessed by all interested parties.

\section{Gorman, O.T. and L. Coggins. 2000. Status and trends of native and non-native fishes of the Colorado River in Grand Canyon 1990-2000. Final report. U.S. Fish and Wildlife Service, Flagstaff, Arizona.}

Status, trends, and seasonal patterns of relative abundance of humpback chub, rainbow trout, brown trout, and flannelmouth sucker in Grand Canyon were analyzed for the period 19902000 at the following mainstem reaches: LCR inflow, Bright Angel, Shinumo, Middle Granite 
Gorge, Kanab, and Havasu. These 7 reaches were selected because they were the only ones for which sufficient data exist for long-term analysis of relative abundance. Humpback chub (HBC) were divided into small ( $<200 \mathrm{~mm}$ TL) and adult $(>200 \mathrm{~mm}$ TL) size groups for analysis. In addition, we characterized the long-term and seasonal patterns in condition factor for $\mathrm{HBC}>200$ $\mathrm{mm}$ total length. For the native species, HBC and flannelmouth sucker, no long-term trends in abundance were evident nor was a long-term trend condition factor for $\mathrm{HBC}>200 \mathrm{~mm}$ total length evident. Abundance of large and small HBC was greatest in the LCR Inflow (RM 60.068.2). Flannelmouth sucker showed increasing abundance downstream of the LCR inflow. Rainbow trout was the most abundant of the four species considered in the analysis. Although abundance was highest in the Fence Fault reach, rainbow trout was abundant throughout the Grand Canyon. Brown trout were most abundant in the Bright Angel reach and were rare upstream of this area. Throughout the Canyon, rainbow trout abundance declined after 1990 but increased back to 1990 levels after 1996. Brown trout abundance downstream of the LCR Inflow increased after 1997. Changes in trout abundance, particularly rainbow trout, appeared to be correlated with changes in dam operations and resulting flow regimes over the period of the study. Widely fluctuating daily flows prevailed before 1990, greatly reduced fluctuating flows were instituted during 1990-1995, and moderately fluctuating flows were practiced after 1997. Of the two sampling methods considered, electrofishing was judged effective in sampling all species except adult HBC. Trammel netting was effective in capturing adult HBC, but this sampling method was focused on known concentrations of fish and showed great variability in estimates of abundance. Because extensive amounts of shoreline habitat were sampled by electrofishing, this method provided a more representative sample of the mainstem Colorado River fish community. Trammel netting may be more successful in capturing rare and highly clustered adult HBC but implementation of this method for long-term assessment of abundance is fraught with sampling difficulties.

\section{Hendrickson, D. A. 1997. A preliminary study of utility of data obtainable from otoliths to management of humpback chub in the Grand Canyon. Final report to Arizona Game and Fish Department KR92-00310-LNR G20019-A. Abstract excerpted from report.}

This study was initiated with the objective of studying various aspects of the physical and chemical structure of otoliths of humpback chub from the Grand Canyon of Arizona, and primarily from the LCR. These studies were to shed light on the utility of otolith studies for improving knowledge of the life history of this endangered species, and to evaluate the potential applications of these techniques to questions posed by resource managers. Specifically, the study was to obtain age estimates (years of age) from otoliths of 50 selected skeletonized adult specimens of Gila cypha collected from the Grand Canyon by AGFD in 1989 and 1990. It was also to obtain age estimates (days of age) for 100 selected YOY G. cypha collected during the same subsequent years. Age estimates for YOY were predicated on the assumption that increments counted in the otoliths were deposited daily, and that increment counts could thus be translated to days of life since the date of first increment formation (generally within the first few days following spawning). Since that hypothesis had not been specifically tested in this species, the study also was to test the hypothesis that increments form on a daily basis, both in the field and in hatchery experiments. Since at least some humpback chub appear to move across a typically strong thermal gradient at the interface of mainstem Colorado River (MCR) waters and the discharge of the LCR, which is generally much warmer than MCR, it was hypothesized that 
this transition might lead to the formation of marks, both physical and chemical, in otoliths and that these marks might be used to reconstruct individual life histories with respect to timing of this inter-river movement. It had been hypothesized that if swept out of the LCR into the mainstem Colorado, the transition might be lethal or have other deleterious impacts on YOY survival and growth. A mark in otoliths that unambiguously conveyed information about extent and timing of movements across this inter-river interface, could thus be valuable in further understanding of population dynamics and movements. It was thus proposed to search for such marks in otoliths and to conduct experiments to study the effects of temperature changes on otolith structure. The original study design also called for an analysis of the feasibility of determining annual growth period duration from otoliths of post YOY individuals of G. cypha for all growth periods throughout the life of specimens.

\section{Leibfried, W.C., H. Johnstone, S. Rhodes and M. Lauretta. 2005. Feasibility study to determine the efficacy of using a weir in Bright Angel Creek to capture brown trout. Final report to Grand Canyon Monitoring and Research Center from SWCA Environmental Consultants, Flagstaff, Arizona.}

The highest concentration of brown trout in the Colorado River occurs near the confluence of Bright Angel Creek. It is likely that Bright Angel Creek is the main spawning tributary for brown trout in the Grand Canyon. Over 400 brown trout were caught moving into Bright Angel Creek between November 18, 2002 and January 16, 2003, the majority of which were in peak spawning condition. The movement of spawning brown trout into the creek may have begun prior to the sampling period, as indicated by the steady number of ripe brown trout captured at the start of the period. One brown trout caught in Bright Angel Creek had traveled over 32 miles upstream from the place in the Colorado River where it was tagged in late February 2002. These data support the hypothesis that Bright Angel Creek is the major spawning area for brown trout in the Colorado River in Grand Canyon.

More trout were captured overnight than during the day for each of the days sampled. These data imply that trout preferentially move into Bright Angel Creek throughout the night. This may be due to greater activity of trout in the Colorado River at night and better protection from predators such as bald eagles and osprey, which were observed during the study period along Bright Angel Creek. Similar nocturnal movements were observed in Nankoweap Creek for rainbow trout.

Our stomach content analysis revealed little evidence of fish remains in brown trout stomachs. However, most stomachs were empty, a typical condition of spawning fish. Mainstem studies by the Grand Canyon Monitoring and Research Center and BIO/WEST have shown evidence of fish remains in brown trout stomachs. Stomach analyses from 2000 documented piscivory in $8 \%$ of brown trout sampled from the Colorado River in Grand Canyon and in 21\% of brown trout from the Little Colorado River reach of the mainstem. There is little doubt that brown trout are predatory on native fishes and are a contributing factor in the decline of native fishes of the Colorado River.

The weir proved to be an effective method for capturing adult brown trout that were migrating into Bright Angel Creek to spawn. Because the weir was not installed until November 
18 , it is likely that some brown trout had already moved upstream to spawn. Earlier installation is recommended to capture and remove a greater number of brown trout from Bright Angel Creek and thereby increase the effectiveness of the weir. Additional data collection will be necessary to determine if removal of brown trout in Bright Angel Creek will benefit native fishes. A baseline inventory of both native and non-native fish should be undertaken as soon as possible to determine current populations within Bright Angel Creek and enable an evaluation of the effects of brown trout removal on the native fish community. Studies conducted by Otis (1994) are more than 10 years old and are outdated. The effect of Bright Angel Creek trout removal may also be detected by the mainstem monitoring and removal programs coordinated by GCMRC.

Although it is unlikely that every brown trout would be removed from the system, a reduction in numbers is possible, as shown by the intensive salmonid removal effort concentrated at the confluence of the Colorado River and the Little Colorado River. Based on this first year's weir-removal experiment, it appears that the Bright Angel Creek weir could be a very efficient and cost effective way of removing non-native salmonids that are migrating into Bright Angel Creek to spawn. The removal of migrating fish, coupled with removal of resident brown trout in Bright Angel Creek, could provide an opportunity for the recovery the native fish community in the creek and aid mainstem recovery efforts for by reducing predation pressure.

Recommendations- Based on the results of this study, SWCA recommends the following actions for future activities in Bright Angel Creek:

1) Earlier installation of the weir to coincide with spawning period of brown trout will allow for a higher number of captures.

2) Fish community monitoring in Bright Angel Creek will provide a baseline to determine the effectiveness of future trout reductions efforts.

3) Population estimates of salmonids and native fish in Bright Angel Creek will provide baseline population levels to determine the effect of trout removal.

4) Coordination with main channel fish monitoring programs (GCMRC and AGFD) will provide for data exchange and cooperation in a collaborative effort for trout reduction.

5) Captured trout can be used for additional data collection, such as the use of otolith chemical analyses for determining fish movements and age and growth studies (GCMRC).

Lupher, M.L. and R.W. Clarkson. 1994. Temperature tolerance of humpback chub (Gila cypha) and Colorado squawfish (Ptychocheilus lucius). Proceedings of the Desert Fishes Council 25:38.

The closure of Glen Canyon Dam on the Colorado River above Grand Canyon, Arizona, in 1963 resulted in a depression of spring-summer downstream water temperatures. Post-dam temperatures likely have precluded successful mainstem reproduction of most native species due to mortality during incubation. In addition, movements of early life stage fishes from the Little 
Colorado River, a major undammed tributary used for spawning and rearing, to the Colorado River mainstem across a large thermal gradient have been surmised to negatively affect survival and growth. We exposed early life stages of endangered humpback chub (Gila cypha) and Colorado squawfish (Ptychocheilus lucius) to several temperatures to examine effects on survival and growth in the laboratory. All eggs were incubated at $18.6^{\circ} \mathrm{C}$ and moved to $20^{\circ} \mathrm{C}$ at swimup for a minimum of $24 \mathrm{~h}$. When transferred from $20^{\circ} \mathrm{C}$ to $10^{\circ} \mathrm{C}$ for $4 \mathrm{~h}, 5-7 \mathrm{~d}$ old humpback chub larvae lost equilibrium and mobility for $90 \mathrm{~min}$, but recovered. Same age humpback chub larvae became lethargic but did not lose equilibrium when transferred from $20^{\circ} \mathrm{C}$ to $12^{\circ} \mathrm{C}$, and no behavioral effects were observed when moved to $14^{\circ} \mathrm{C}$. Similar cold shock experiments with 11-13 d chub larvae affected only the $10^{\circ} \mathrm{C}$ group, which lost equilibrium for $15 \mathrm{~min}$ before recovering. No mortality was observed under any treatment during the $4 \mathrm{~h}$ observation period. Growth patterns of 6-8 d humpback chub larvae reared at $10^{\circ} \mathrm{C}, 14^{\circ} \mathrm{C}$, and $20^{\circ} \mathrm{C}$ averaged $10 \%, 37 \%$, and $83 \%$ length gain, respectively, and $28 \%, 195 \%$, and $951 \%$ weight gain, over $30 \mathrm{~d}$. Overall patterns of growth of 13-15 d humpback chub and Colorado squawfish larvae and 39-41 d chub post-larvae reared at these temperatures were similar. Results suggest that detrimental effects of reduced growth on individuals and populations of native fishes in Grand Canyon can be ameliorated by reducing levels of daily discharge fluctuations from Glen Canyon Dam, which will provide greater stability and potential for warming of mainstem rearing habitats. We also recommend consideration of thermal modification of discharges from Glen Canyon Dam.

\section{Masslich, W.J., B.R. Cowdell and R.A. Valdez. 1993. Radiotelemetry studies of humpback chub Gila cypha in the Colorado River, Grand Canyon, Arizona. Proceedings of the Desert Fishes Council 24:68-69.}

Four native fishes of the Colorado River system are listed as endangered under the Endangered Species Act: the Colorado squawfish Ptychocheilus lucius, the humpback chub Gila cypha, the bonytail chub Gila elegans, and the razorback sucker Xyrauchen texanus. The Recovery Implementation Program for Endangered Fish Species in the Upper Colorado River Basin (Recovery Program) is a partnership among Federal and State agencies, environmental organizations, and private water development interests whose mission is to recover the endangered fishes in the upper Colorado River basin while allowing for water development to continue. In its first 6 years of existence, major Recovery Program accomplishments include: (1) the operation of several Federal reservoirs has been modified to help meet the instream flow requirements of the fish, (2) water and water rights have been acquired provide instream flows in several critical river reaches; (3) genetic refugia have been established for several of the most endangered fish stocks; (4) interim guidelines have been developed for stocking of non-native fishes in the upper basin, and (5) a broad based information and education effort has been implemented. Over 150 favorable biological opinions have been issued on water depletion projects since the inception of the Program in 1988. Recovery Program activities are currently focused on acquisition and legal protection of instream flows, expanding refugia for the endangered fish, restoration of flooded bottomland habitats, providing fish passage at several historic diversion structures, control of non-native fish population in selected river reaches, and implementation of an experimental stocking program for the razorback sucker. 


\section{Minckley, C.O. 1980. Recovery of the humpback chub Gila cypha and observations on that species 1977-1978. Proceedings of the Desert Fishes Council 12:130.}

During 1978, twenty adult humpback chubs were placed at Willow Beach National Fish Hatchery, for propagation purposed. The fish were collected from the Little Colorado River, in the vicinity of its mouth, flown to the south rim of the Grand Canyon, and transported to Willow Beach. All fish arrived in good condition and were in the hatchery raceways within five hours of lift-off from the Little Colorado River.

During 1978, 555 humpback chubs were collected. Of these fish, 21.5\% (196) were juveniles, and 78.5\% (359) were adults. Distribution of this species within the mainstream Colorado River was extended to river mile 194, based on a report from a commercial river runner. General distribution within the system reflects the size of fish, with larger adults preferring water over two meters in depth. Juvenile fish occurred in water less than two meters in depth. Both size groups were usually found in moderate to slow current over silt-sand bottom in the Little Colorado River.

Schooling was observed both in adult and juvenile humpback chubs, as was feeding behavior. Schooling fish were observed feeding both on the bottom substrate and the surface film. Adult chubs were observed to take Cladophora as well as food from commercial river parties. The stomachs of three YOY humpback chubs were found by direct examination to contain dipteran families of Chironomidae, Ceratopogonidae, and Dolichopodidae.

Reproduction appeared to have occurred in early June based on the small size of the fish collected by seining (mean $\mathrm{TL}=19 \mathrm{~mm}$ ). It is suspected that spawning commences in early spring (March) and continues through early summer, as observed.

Estimated numbers of humpback chubs, based on seining collections, ranged from $122 \mathrm{fish} / \mathrm{ha}$ in May up to $1527 \mathrm{fish} /$ hectare in June. Tagging operations were also implemented in July of 1978 using 3/8 in. $\times 1 / 8$ in. fingerling tags. To date, 120 humpback chubs have been tagged and none have been recaptures.

Major problems faced by this population of humpback chubs are human impact, water fluctuations, and a newly discovered infestation of the anchorworm parasite Learnea. During October, $54 \%$ of the chubs were infested.

Minckley, W.L., P.C. Marsh, J.E. Deacon, T.E. Dowling, P.W. Hedrick, W.J. Mathews and G. Mueller. 2003. A conservation plan for native fishes of the Lower Colorado River. Bioscience 53(3):219-234. Abstract excerpted from report.

Among the native fishes of the Colorado River are four "big-river" species: humpback chub (Gila cypha), bonytail (Gila elegans), Colorado squawfish (Ptychocheilus lucius), and razorback sucker (Xyrauchen texanus). Once generally widespread and abundant, these species are now critically imperiled. Water development - damming rivers, creating impoundments and cold tailwaters, degrading habitats, and desiccating long reaches - and the introduction and establishment of a suite of nonnative species have adversely affected the native fishes. Severely 
reduced in abundance and range and under continuing threats, the four big-river species are now federally listed as endangered.

Thirteen fishes, including 10 freshwater species, constituted the original fish fauna of the lower Colorado River mainstem. Over the past century, the original fish fauna of the lower Colorado River has largely been replaced by nonnative species, especially downstream from Hoover (formerly Boulder) Dam.

This article presents our recommendations for a science-based recovery strategy that could aid the recovery of the big-river fishes in the lower Colorado River. The recommendations are not new. They are based on our collective knowledge, published papers, and unpublished plans. We believe they offer important new perspectives that should be incorporated into criteria used by the RIP to determine when a listed big-river species has "recovered."

Our proposal deals with the concepts of, rationale for, and uncertainties about the numbers of individuals necessary to satisfy the goal of species maintenance. The need to maintain large effective population sizes makes it necessary to use space in the main stem, offchannel floodplain, and distributaries (effective size is a term that relates a population in nature to an idealized population with certain genetic characteristics). The proposed solution involves translocation of native species between predator-free, off-channel habitats and the main channel, backwaters, and reservoirs (hereafter, channel plus connectives). Reproduction and recruitment take place off-channel, and large, wide-ranging, and panmictic populations of adults maintain both population size and genetic variation there and in the channel plus connectives. The plan briefly addresses habitats that are needed to accomplish such goals and anticipated problems in developing such habitats; it also suggests ways that the native fishes can be managed successfully over the long term.

Rationale for Population Goals. No quantitative data, historic or otherwise, exist on original numbers of any native fish in any habitat of the Colorado Basin. It is thus impossible to specify numbers required for downlisting or delisting that are based on restoration of historical population sizes. Estimates might be made using methods such as population viability analysis, but demographic data are too sparse for accuracy or reliability. We therefore used three approaches to estimate the numbers of reproducing adults that are sufficient to sustain the four species: (1) qualitative observations, (2) genetic information, and (3) empirical data on survivorship, standing crops, growth, and other population statistics.

Off-channel Habitats for Conservation. Part of our proposal's rationale is to avoid competition with sport fishermen. Traditional off-channel angling areas such as backwaters and ponds behind levees cannot realistically be expropriated, so new habitats - exclusively for native species - must be provided. Costs are also a concern, so these habitats should be secure, simple, and low maintenance, and they should exclude nonnative predators while providing adequate physicochemical and other conditions for life history requirements of natives. We envision a series of excavated habitats resembling the pristine lower Colorado River floodplain-isolated oxbow lakes and backwaters - as primary components of dedicated off-channel complexes. A successful prototype has been developed on the USFWS Havasu National Wildlife Refuge at Beal Lake, Arizona. 
Population Goals. We are convinced that large populations and high genetic diversity are the only sound biological options for all four species, and these are feasible and sustainable through dedicated management. Even a modest effort using off-channel habitats will yield populations far exceeding the meager 700 to 5,800 individuals proposed by USFWS. We advocate and describe means of producing and rearing recruits in isolated habitats for introduction en masse into the channel plus connectives to establish and maintain a large, genetically diverse, panmictic population that closes the circle by supplying brood fish for ongoing production in isolation.

National Park Service. 2009, August 12. Humpback chub translocation experiment in Shinumo Creek [Press release]. Available at http://www.nps.gov/grca/naturescience/ cynsk-v12.htm.

In June 2009, the National Park Service translocated 300 juvenile humpback chub from the Little Colorado River to Shinumo Creek in Grand Canyon National Park. The goal of this experiment is to obtain information about how this endangered species will respond to translocation in another tributary.

An intensive three-year monitoring program will follow the translocation of humpback chub into Shinumo Creek. Biologists will evaluate the success of the humpback chub translocation using established fish surveying techniques such as snorkeling, hoop-netting, seining, and electrofishing. Data will be collected on the size, condition and health of humpback chub and their distribution in the translocation reach. The habitat characteristics of Shinumo Creek, including water flow, water quality and temperature, and other variables, will also be monitored. A PIT tag antenna placed near the falls will record any fish that are washed out of the stream by monsoonal floods. Specific questions to be evaluated include whether the young humpback chub survive the translocation and if they will remain in Shinumo Creek.

This project will enable biologists to assess the feasibility of using translocation to establish an offsite refuge and potentially an additional aggregation of humpback chub in Grand Canyon. Regardless of the experiment's success, it will increase the understanding of conservation efforts that must be undertaken in order to ensure that this native fish continues to survive in Grand Canyon.

\section{Patten, D.T., D.A. Harpman, M.I. Voita and T.J. Randle. 2001. A managed flood on the Colorado River: background, objectives, design, and implementation. Ecological Applications 11(3):635-643.}

The Colorado River ecosystem in lower Glen Canyon and throughout Marble and Grand Canyons was greatly altered following closure of Glen Canyon Dam in 1963, as flood control and daily fluctuating releases from the dam caused large ecological changes. Ecosystem research was conducted from 1983 through 1990, and intensively from 1990 through 1995 when dam releases were modified both for scientific purposes and protection of the river ecosystem. High flows (e.g., beach/habitat building flows) were included in the Glen Canyon Dam Environmental Impact Statement (EIS), which identified a preferred strategy for dam operations and protection 
of the downstream ecosystem. Use of high flows partially fulfills recommendations of many river and riparian scientists for return of more natural flows, as part of initial efforts in river restoration. In 1996, a seven-day experimental controlled flood was conducted at Glen Canyon Dam to closely study the effects of a high flow event equivalent to those proposed for future dam management. It is an example of modification of operations of a large dam to balance economic gains with ecological protection. Limited to $1274 \mathrm{~m}^{3} / \mathrm{s}$, the test flood was lower than pre-dam spring floods. The experiment was conducted to (1) test the hypothesis that controlled floods can improve sediment deposition patterns and alter important ecological attributes of the river ecosystem without negatively affecting other canyon resources and (2) learn more about river processes, both biotic and abiotic, during a flood event. Along with an explanation of the planning and background of this flood experiment, this paper summarizes expected and realized changes in canyon resources studied during the flood. Responses of specific resources to the flood are synthesized in the following compendium papers.

\section{Paukert, C.P. 2004. Comparison of electrofishing and trammel netting variability for sampling native fishes. Journal of Fish Biology 65(6):1643-1652.}

The variability in size structure and relative abundance (CPUE; number of fish $\geq 200 \mathrm{~mm}$ total length, LT, collected per hour of electrofishing or trammel netting) of three native Colorado River fishes, the endangered humpback chub Gila cypha, flannelmouth sucker Catostomus latipinnis and bluehead sucker Catostomus discobolus, collected from electrofishing and trammel nets was assessed to determine which gear was most appropriate to detect trends in relative abundance of adult fishes. Coefficient of variation (CV) of CPUE ranged from 210 to 566 for electrofishing and 128 to 575 for trammel netting, depending on season, diel period and species. Mean $\mathrm{CV}$ was lowest for trammel nets for humpback chub $(P=0.004)$ and tended to be lower for flannelmouth sucker $(P=0.12)$, regardless of season or diel period. Only one bluehead sucker $>200 \mathrm{~mm}$ was collected with electrofishing. Electrofishing and trammel netting CPUE were not related for humpback chub $(\mathrm{r}=-0.32, P=0.43)$ or flannelmouth sucker $(\mathrm{r}=-0.27$, $P=0.46)$ in samples from the same date, location and hour set. Electrofishing collected a higher proportion of smaller $(<200 \mathrm{~mm} \mathrm{LT})$ humpback chub $(P<0.001)$, flannelmouth suckers $(P<0.001)$ and bluehead suckers $(P<0.001)$ than trammel netting, suggesting that conclusions derived from one gear may not be the same as from the other gear. This is probably because these gears fished different habitats, which are occupied by different fish life stages. To detect a $25 \%$ change in CPUE at a power of 0.9 , at least 473 trammel net sets or 1918 electrofishing samples would be needed in this $8 \mathrm{~km}$ reach. This unattainable amount of samples for both trammel netting and electrofishing indicates that detecting annual changes in CPUE may not be practical and analysis of long-term data or stock assessment models using mark-recapture methods may be needed to assess trends in abundance of Colorado River native fishes, and probably other rare fishes as well. 


\section{Rogers, R.S., D.L. Speas and A.S. Makinster. 2003. Grand Canyon Long-term Nonnative Fish Monitoring, 2003 Annual report to Grand Canyon Monitoring and Research Center Cooperative Agreement 02WRAG0030, October 2003. Abstract excerpted from study introduction and discussion.}

Robust long-term monitoring of aquatic populations is important to adaptive management programs because it characterizes a baseline or antecedent context in which response of biota to changing management policies or experiments can be interpreted. In the Colorado River below Glen Canyon Dam (GCD), Arizona, long-term monitoring of fishery resources is an essential component of the Glen Canyon Dam Adaptive Management Program in ensuring that GCD is operated in a manner consistent with the pertinent sections of Grand Canyon Protection Act of 1992. In particular, the non-native salmonids rainbow (Oncorhynchus mykiss, RBT) and brown trout (Salmo trutta, BNT) have displayed increased abundance, likely because changes in operation of GCD since the early 1990s in the Colorado River in Glen and Grand Canyons (GCMRC 2001a; McKinney et al. 1999, 2001).

Working under cooperative agreement with Grand Canyon Monitoring and Research Center (GCMRC), Arizona Game and Fish Department (AGFD) conducted studies of salmonid catchability using electrofishing and population size as well as relative abundance, distribution, and sampling requirements for long-term monitoring of RBT, BNT, and common carp (Cyprinus carpio, CRP) in the Grand Canyon during 2000-2001. In this paper, we report results from nonnative fish monitoring activities in the mainstem Colorado River in Grand Canyon during 2002.

Specific objectives during 2002 were to:

(1) Estimate salmonid and carp relative density and distribution, and estimate salmonid abundance and evaluate trends in abundance during 2000-2002.

(2) Reevaluate required annual sample sizes and sample allocation for long-term monitoring of salmonids and carp in the Grand Canyon.

(3) Assist with collections of salmonid genetic materials in the main channel Colorado River and select tributaries.

Bootstrapping indicated that changes in salmonid relative abundance (CPUE) of 20-30\% and $30-40 \%$ for RBT and BNT, respectively, are detectable between consecutive years with the current stratified random sample design, provided we complete between 800 and 900 samples per year. Long-term (5-year) analysis of the same data yields a much more sensitive monitoring tool for 5-year linear changes in CPUE. Confidence intervals of the regression line used to model population size are much wider than those obtained for CPUE, which likely precludes detection of similar changes in absolute abundance. However, no changes in CPUE or absolute abundance of RBT, BNT, and CRP are detectible with the most recent three years of data (2000 2002). 
We did not expect or observe much movement of BNT over the past three years. Most movement of BNT occurs in fish less than 15 months old and with adults during the spawning season (Solomon and Templeton 1976). Almost all fish that we mark are older than 15 months, and our long term monitoring does not occur during the spawning season (Nov - Jan). The experimental weir placed in Bright Angel Creek in 2002 by the Park Service has captured at least two BNT that have traveled over $50 \mathrm{RM}$. It is our recommendation that tagging of BNT continue only as long as the use of a weir at Bright Angel Creek is maintained.

The analyses of lengths by trip for BNT and RBT suggest that the low summer steady flows of 2000 resulted in relatively strong recruitment of both RBT and BNT. The modes observed in the RBT data match length-at-age calculated for age- 0 and age- 1 RBT from Lees Ferry. We have attempted to compute length-at-age for BNT by utilizing mark-recapture data from this monitoring program. Attempts to date have been unsuccessful because BNT tagging began in 2000 and few fish have grown between mark and recapture events. Future monitoring may provide data necessary for estimated growth rates. Future analysis of BNT otoliths may also provide length-at-age estimates.

There is an apparent difference in the CPUE between electrofishing boats. Variation in catch between boats may be caused by the individual boat driver or the physical electronic equipment on the boat. Regardless of the source of this variation, there are apparent differences between boats that account for a large portion (15\%) of the variability within the dataset. Small differences in catchability can have large effects on population estimates derived using CPUE. When CPUE data are used to evaluate population trends, the assumption is made that catchability remains constant over time. This assumption may not be met because of variations in discharge, turbidity, boat driver, or netters between and among trips. All of these factors have the potential to affect catchability. Attempts to minimize changes in these factors are made by sampling during the same months each year and attempting to keep crews consistent. All of our sampling has used the same two boat drivers, but future changes in boat driver may increase variance in the dataset, potentially confounding CPUE trends. We strongly recommend that any new boat drivers receive training prior to monitoring trips. We also recommend that information on the specific electronic units (CPS units) used on each boat along with the name of the boat driver must be recorded so that differences in catch can be evaluated further.

\section{Schmidt, J.C., R.H. Webb, R.A. Valdez, G.R. Marzolf and L.E. Stevens. 1998. Science and values in river restoration in the Grand Canyon. BioScience 48: 735-747. Abstract excerpted from article.}

Restoration of riverine ecosystems is often stated as a management objective for regulated rivers, and floods are one of the most effective tools for accomplishing restoration. In the case of some large rivers, restoration may be impossible; a more feasible goal may be rehabilitation of some ecosystem components and processes in parts of the river. We examine the appropriate role of science in determining whether or not to restore or rehabilitate the Colorado River in the Grand Canyon by summarizing studies carried out by numerous agencies, universities, and consulting firms since 1983. The segment of the Colorado River flowing through the Grand Canyon is federally designated as critical habitat for two endemic endangered fish: the razorback sucker (Xyrauchen texanus) and the humpback chub (Gila cypha). In 
addition, the river provides essential water for humans as well. Because the discharge of Colorado River is relatively small for the basin's size, large reservoirs have been constructed to assure water availability where the potential for flood control and sediment reduction is nearly complete. As such, restoration or rehabilitation of the river can only be achieved by changing the dams or their operations.

The Colorado River ecosystem in the Grand Canyon is sustained by the flow of water and nutrients released by Glen Canyon Dam, but other controlling factors are unrelated to the dam, such as regional geology and geomorphology, climate, tributary inflows of water and sediment, and human activities. Changes in these factors have caused adjustments in channel geomorphology, alterations in riparian vegetation and fish assemblages, decreases in habitat availability for endangered fish, and changes in water temperature and quality.

The construction and operation of Glen Canyon Dam reduced the frequency, magnitude, and duration of floods through the Grand Canyon as well as the amount of sediment transport. Debris fans have also increased in volume, and thus narrowed adjacent rapids. Unvegetated sandbars have been replaced by a near-river riparian zone consisting of marsh vegetation.

Fish assemblages native to the Colorado River evolved in an environment of highly variable discharge, large annual temperature fluctuation, high turbidity, large input of organic material, and the opportunity for basin-wide fish migration. These conditions have all changed. River temperatures no longer vary seasonally. What's more, releases of cold, clear water and reduced transport of organic material have dramatically changed the conditions for the aquatic macroinvertebrates downstream from the dam. Thus, the food supply available for native fish in the Grand Canyon has changed greatly.

The fish assemblages of the Colorado River through the Grand Canyon have altered dramatically during the past century due to dam-related impacts as well as the introduction of nonnative fish species. Cold water releases impede reproduction of native fish. These effects are compounded by the increased competition and predation by nonnative fish.

From a continuum of possibilities, we identify five management approaches: traditional river management; managing the river as a naturalized ecosystem; rehabilitating it as a simulated natural ecosystem; rehabilitating it as a substantially restored ecosystem; and reestablishing a fully restored ecosystem.

\section{Sharber, N.G. and S.W. Carothers. 1987. Submerged, electrically shielded live tank for electrofishing boats. North American Journal of Fisheries Management 7:450-453.}

Fish caught by electrofishing are usually held in live tanks before appropriate data are recorded; however, if the tank water is not circulated, changes in water temperature and oxygen concentration may harm the fish. Also, if the water is circulated by pumps or other mechanical means, the power required may reduce the effectiveness of the electrofishing gear. We designed and successfully used a live tank which is submerged through the hull of a catamaran-type whitewater raft. The live tank is placed in the water being electrofished so that power-free but continuous water circulation is maintained. Fish in the tank are protected from the electrofishing 
field by the design of the tank, which uses to advantage a phenomenon known as Faraday shielding. The tank is easy and inexpensive to construct and safe to use.

Stone, D.M. 2005. Effect of baiting on hoop net catch rates of endangered humpback chub. North American Journal of Fisheries Management 25(2):640-645.

The effects of unbaited, scented (odor emitted by inaccessible hatchery feed), and baited (accessible feed) single-throated hoop nets on the catch rates of the federally endangered humpback chub Gila cypha ( greater than or equal to $100 \mathrm{~mm}$ total length) were assessed in the Little Colorado River, Arizona, to determine how baiting affected the catch of these fish. Of a total of 1,297 unique humpback chub captured, 262 (20\%) were caught in 179 unbaited nets, 330 $(25 \%)$ in 179 scented nets, and $705(54 \%)$ in 178 baited nets. Humpback chub retention in unbaited nets did not differ from a 50:50 chance event $(P=0.075)$ but probably peaked in baited nets where these fish were preoccupied with feeding (i.e., gorging themselves), which would explain the higher catch rates in baited than in scented or unbaited nets ( $\mathrm{P}$ less than or equal to 0.001). Moreover, humpback chub catch rates were not significantly higher in scented than in unbaited nets $(P=0.779)$, which suggests that elevating both "fish attraction" and "fish retention" are essential to substantially increase their captures in these nets. However, scenting may still be a viable option when used in conjunction with passive gears possessing higher fish retention capabilities or to target species less prone to escape. The findings of this study should provide valuable insight to anyone wishing to optimize catch rates by baiting or scenting passive entrapment gear.

Thompson, J.M., E.P. Bergersen, C.A. Carlson and L.R. Kaeding. 1991. Role of size, condition, and lipid content in the overwinter survival of age-0 Colorado squawfish. Transactions of the American Fisheries Society 120:346-353.

In a survey study conducted to obtain base-line data, eleven extensive float trips were made down the Colorado River in the period from September 1970 through mid-June 1976. Samples of fish, mammals, plants and herpetofauna were collected; species collected are listed. In addition, terrestrial surveys were made at various land sites in the region. Major results of this survey were the lack of success in obtaining a specimen of the humpback sucker, Xyrauchen texanus, and the discovery of the relative scarcity of chubs of the genus Gila. Both of these outcomes have been tied to the low water temperatures caused by releases from the Grand Canyon Dam, as well as to the barrier that the dam presents to upstream movement to suitable spawning areas.

Trammel, M. and R. Valdez. 2003. Native fish monitoring activities in the Colorado River within Grand Canyon during 2001. SWCA, Inc., Flagstaff, Arizona, to Grand Canyon Monitoring and Research Center, Flagstaff, Arizona.

The feasibility of and effort required to conduct a population estimate for humpback chub (Gila cypha) in the Colorado River in the Grand Canyon near the Little Colorado River (LCR) inflow were assessed in 2001. The largest aggregation of HBC in the Colorado River mainstem occurs in the LCR area from RM 56.3, above the LCR, to RM 68.3 below the LCR. The LCR enters the Colorado River near RM 61.5. Population size was estimated using a two-pass mark- 
recapture design. Two sampling trips were conducted; one in July/August and the other in August/September using trammel nets and hoop nets to capture HBC. Sampling effort included a total of 264 person days, 605 hoop net sets comprising 13,524.5 sampling hours, and 1,102 trammel net sets comprising 2,151.9 sampling hours and resulted in $425 \mathrm{HBC}$ captured. HBC greater than $100 \mathrm{~mm}$ TL were marked with PIT tags on the first trip and examined for marks on the second trip. We captured $104 \mathrm{HBC}>100 \mathrm{~mm}$ TL on the first trip and 160 on the second trip. During the second trip no fish less than $200 \mathrm{~mm}$ TL were recaptured from the first trip. Thus, the population estimate was stratified to include only fish greater than $200 \mathrm{~mm}$ TL, resulting in 83 marked on the first trip and 111 examined on the second trip, with 8 recaptured fish, for a population estimate of 1,044 fish $>200 \mathrm{~mm}$ TL (95\% confidence interval 559 to 2,137), with a coefficient of variation (CV) of 29\%. Despite the large effort, the number of captures and recaptures was lower than expected, and the precision of the estimate was less than desired. Increased effort is recommended for future population estimates. However, the 2001 estimate was significantly different from similar estimates made in 1991-1993 (Valdez and Ryel 1995) and suggests a significant decline in the abundance of $\mathrm{HBC}$ in the mainstem Colorado River near the LCR.

\section{Tyus, H.M. 1992. An instream flow philosophy for recovering endangered Colorado River fishes. Rivers 3:27-36.}

Remnant stocks of some endangered Colorado River fishes persist, including Colorado squawfish (Ptychocheilus lucius), humpback chub (Gila cypha), razorback sucker (Xyrauchen texanus), and bonytail (Gila elegans). Recovery of these species to a non-endangered status is problematic. Provision of flows to maintain habitats in which the fish are declining may do little to slow their decline or prevent their loss. It is argued that determination of instream flows for endangered fishes should be based on the premise that the fish are not occupying optimal, or perhaps even acceptable habitats, a philosophically different approach than that addressed by prevailing flow methodologies. A recovery rather than survival philosophy is recommended that includes developing instream flow needs through a combination of empirical studies, simulations, and assessments.

\section{Tyus, H.M. and J.F. Saunders, III. 2000. Non-native fish control and endangered fish recovery: lessons from the Colorado River. Fisheries 25(9):848-855.}

Native freshwater fish populations are declining in North America and more than 100 fishes are federally listed as threatened or endangered. The Colorado River system in the southwestern United States has been especially affected. Most of its native fish populations are in decline, including four "big river" fishes, Colorado pikeminnow (Ptychocheilus lucius), humpback chub (Gila cypha), bonytail (G. elegans), and razorback sucker (Xyrauchen texanus), whose populations have declined so precipitously that they are endangered. Physical habitat alteration caused native fish declines, but nonnative fishes pose a more serious threat to native fishes than previously thought. Nonnative fish control measures needed in the upper Colorado River system, identified in part by a workshop of experts, include: (1) preventing movements of game fishes out of impoundments and curtailing future stockings, (2) reducing numbers of small, nonnative cyprinids in shoreline habitat used as rearing areas by young native fishes, and (3) increasing the harvest of channel catfish (Ictalurus punctatus) and common carp (Cyprinus 
carpio) in the mainstream. Large-scale implementation of these nonnative fish control measures has proven difficult. Recovery efforts have identified the need for developing nonnative fish control strategies and testing methodologies, but no solutions have emerged. A holistic approach, including ecosystem recovery plans, should be used in systems where more than one species share common problems, such as interactions with nonnative fishes. Nonnative fish interactions should be suspected as a potential cause of declining native fish populations.

Tyus, H.M., J.L. Cooper and R.H. Hamre. 1991. Management of Colorado River fishes. USDA Forest Service, Washington, D.C.

Native warmwater fishes of the upper Colorado River basin have declined, and four bigriver fishes are in danger of extinction. Of these, Colorado squawfish Ptychocheilus lucius, humpback chub Gila cypha, and bonytail G. elegans are listed as federally-endangered, and razorback sucker Xyrauchen texanus, is proposed for listing Rare status, continuing habitat change, and lack of knowledge about their habitat needs have made management programs difficult to develop and implement. Recent efforts to recover the listed fishes have provided some information about all of the native fishes and prompted some management activities. The future of native Colorado River fishes is uncertain, but efforts of an interagency recovery implementation program offers some hope for them.

\section{U.S. Bureau of Reclamation. 1999. Glen Canyon Dam modification to control downstream temperatures. Plan and draft environmental assessment. U.S. Bureau of Reclamation, Upper Colorado Region, Salt Lake City, Utah.}

The U.S. Bureau of Reclamation is considering whether on not to modify Glen Canyon Dam to allow downstream temperatures to be managed. It is believed by the U.S. Fish and Wildlife Service and Reclamation that the cold summer temperatures created by the dam are a constraint to native and endangered warmwater fish, but there are other ecological interactions complicating the issue that cannot be conclusively resolved without physical testing. Reclamation has developed a relatively inexpensive way to modify the dam to allow temperatures to be controlled and tested. The plan includes a monitoring program to further our understanding of the ecosystem's response to temperature and an adaptive management program to apply this knowledge.

Before Glen Canyon Dam was constructed, the temperature of the Colorado River in the Grand Canyon would increase from near freezing in the winter to about $30^{\circ} \mathrm{C}\left(86^{\circ} \mathrm{F}\right)$ in the late summer. Though several native fish were present in the river system, Leibfried and Zimmerman (1994) reported that the fish community was dominated by warmwater non-native species. Channel catfish comprised $90 \%$ of the fish community in Glen Canyon. The dominant forms of non-native fish were channel catfish and carp, with red shiners, largemouth bass, green sunfish, and bullheads present but less abundant. Once the dam was constructed, release temperatures became relatively cold during the summer season. Water is now drawn year round from the deep intakes used for power production. Release temperatures vary little and are typically $8^{\circ} \mathrm{C}-10^{\circ} \mathrm{C}$ $\left(46^{\circ} \mathrm{F}-50^{\circ} \mathrm{F}\right)$. 
Cold mainstem temperatures and high water velocity are thought to have expatriated (or at least greatly limited) most non-native competitors in the mainstem. Of the non-native species, rainbow trout do well in the clear water near the dam. Carp and catfish are abundant further downstream, in and near warm tributaries like the Little Colorado River. Native, warmwater fish have also been greatly limited by cold-water releases. Some are no longer present below Glen Canyon Dam. The endangered humpback chub are essentially limited to the area in and near the Little Colorado River.

Cold-water releases from Glen Canyon Dam are below optimal for the existing trout fishery and far below those temperatures needed to allow native and endangered warmwater fish (such as the humpback chub) to thrive in the mainstem of the Colorado River. Thermal shock from cold mainstem temperatures has been recognized as a likely cause of mortality for young endangered fish leaving seasonally warmed tributaries. In their integration report on studies in Glen and Grand Canyons, Valdez and Carothers (1998) concluded that, "We believe that most larval flannelmouth suckers, bluehead suckers, and humpback chub descending from warm natal tributaries into the cold mainstem die of thermal shock or from predation elicited by erratic swimming behavior. For those fish old enough to survive the transition, swimming ability may be reduced by as much as 98 percent by cold mainstem temperatures."

In commenting on the proposed plan, Gorman (Arizona Game and Fish) suggested that temperature controls could be an effective tool to reduce this thermal shock problem during the relatively short period of time that the humpback chub are descending into the mainstem (mid to late summer) without greatly favoring their competitors. Furthermore, once recruited, these longlived native fish would potentially out-live their competitors by well over a decade.

According to the Fish and Wildlife Service's (FWS) biological opinion on the operation of Glen Canyon Dam, main channel spawning of endangered fish (critical habitat) is severely limited by cold-water releases from Glen Canyon Dam. In their biological opinion on the operation of the dam, the FWS's reasonable and prudent alternative recommended that Reclamation evaluate methods to control release temperatures and, if viable, implement controls. Reclamation agreed with this recommendation and included it in the U.S. Department of the Interior's (USDI) Final Environmental Impact Statement (USDI 1995) and Record of Decision on the Operation of Glen Canyon Dam.

This report integrates two purposes, planning and an environmental assessment of the alternatives. In Chapter II, the report summarizes Reclamation's study of various methods available to control temperature. Several designs were found to meet the temperature control needs of the project and are technically viable; however, costs varied significantly. The proposed alternative takes maximum advantage of the existing intake structures to reduce costs, yet meets the performance goals for temperature controls. This innovative approach would cost an estimated \$15 million (to modify all eight intakes) and would be within Reclamation's spending authority. More traditional designs like those used at Flaming Gorge Dam and Shasta Dam would cost up to $\$ 149$ million at Glen Canyon Dam, would have far exceeded Reclamation's spending authority, and would have required returning to Congress for legislation. The least costly method (the 4-intake modification at \$10 million) was rejected by Reclamation because it lacked the flexibility needed to meet the downstream temperature objectives. 
In Chapter III, the report compares the effects of the proposed warmer-water releases to those of the no action alternative (continued coldwater releases). It should be noted that although the proposed alternative is discussed as warmwater releases, in effect temperature controls would actually release water that is only about $5^{\circ} \mathrm{C}\left(10^{\circ} \mathrm{F}\right)$ warmer than the existing condition. To most rafters and recreationists, the water would still seem quite cold $\left(59^{\circ} \mathrm{F}\right.$ vs. $\left.46^{\circ} \mathrm{F}\right)$. The goal of the proposed alternative would be to modify Glen Canyon Dam to allow release temperatures to be controlled to improve conditions for endangered fish while at the same time protecting other important resources like the Lees Ferry trout fishery. The proposed plan would create a tiered (cold/warmwater) fishery. Release temperatures would be increased from the existing levels $\left(8^{\circ} \mathrm{C}-10^{\circ} \mathrm{C}\right)$ to about $15^{\circ} \mathrm{C}$ during the summer months. This would improve temperatures for rainbow trout in the reach immediately below the dam (first 16 miles to Lees Ferry). Then, as the water flows downstream and warms, it would quickly reach temperatures preferred by native and endangered (warmwater) fish. Warmwater releases may not be made in every year to help control competitors to the humpback chub. Release periods might be as short as a month to prevent thermal shock as the chub descend into the main channel, or as long as the May through September season to promote better growth rates.

Input received at scoping meetings identified several areas of particular interest to the public and scientific community. More detailed discussions are included in Chapter III of this assessment. In summary, this report finds:

Lake Powell Fishery - Temperatures in Lake Powell are already low enough to cause occasional winter-kill of threadfin shad, an important forage fish for the lake (game) fishery. It was recommended that Reclamation carefully evaluate the potential impact on this resource of releasing warm water from the reservoir. Computer modeling of the reservoir shows that temperatures in the surface layer of Lake Powell would be cooled by up to $1^{\circ} \mathrm{C}$ if warmwater releases were maintained through the entire "summer" season (140 days). Shorter duration releases would have even smaller effects on lake temperatures. Little or no impact is expected to threadfin shad or the lake fishery. However, the existing lake monitoring program would be continued to confirm or refute these predictions.

Primary Productivity - Field and laboratory experiments conducted for Reclamation by Northern Arizona University indicate that the existing macroinvertebrates in the downstream environment can tolerate warmwater releases of $20^{\circ} \mathrm{C}$ for at least 30 days (the duration of the study). Release temperatures for the proposed action would normally be limited to a maximum of $15^{\circ} \mathrm{C}$. Computer modeling of Lake Powell shows that surface withdrawals from the reservoir would increase nutrient and detritus release levels below the dam by up to 300 percent; thus, potentially improving the productivity of the river ecosystem. Studies of warmwater releases at Flaming Gorge Dam suggest that some minor changes (increases) may occur in diversity and abundance. The effects would be carefully monitored through the adaptive management process and the Grand Canyon Monitoring and Research Center.

Endangered Fish - Under present conditions (the no-action alternative), endangered fish do not reproduce in the river, young fish thermal shock while entering the main channel from warm tributaries, and those that survive are easy prey due to their reduced swimming efficiency. 
The proposed temperature control alternative would allow releases to be made to improve the reproductive success of humpback chub by reducing thermal shock with late-summer, warmwater releases. Additionally, summer-long warmwater releases may be used in an attempt to further improve conditions for endangered species; however, nonnative fish may also benefit from sustained releases. Of primary concern is competition between carp/catfish and humpback chub. Summer-long, warmwater releases would likely cause carp and catfish populations to increase in the mainstem (along with other non-native species).

However, this does not necessarily mean that humpback chub will be unable to find opportunities once the cold-water restraints are eliminated. For example, it is a well know fact that the humpback chub thrive in the warm water of the Little Colorado River and that they compete very successfully against carp, catfish, and other competitors in that warmwater system. Clear, summer-long, warmed releases (about $13.5^{\circ} \mathrm{C}$ ) from Flaming Gorge Dam have also improved conditions for native fish populations even though non-native fish are present in great numbers.

Predator Controls - Modeling studies underway by the Grand Canyon Monitoring and Research Center suggest that carp and channel catfish populations may need to be controlled by methods beyond the timing and duration of temperature controls. Physical controls (harvesting) may be needed to reduce predation on native fish in specific areas. Careful monitoring of these competitors would be an important part of the proposed alternative. If physical controls are needed, the Adaptive Management Work Group may recommend to the Secretary of the Interior actions that would be appropriate given the details of the monitoring results and the problems that are identified.

Rainbow Trout - Numerous experiences at other dams strongly suggest that the proposed warmwater release of up to $15^{\circ} \mathrm{C}$ would benefit the rainbow trout fishery below Glen Canyon Dam by removing temperature stresses. The current $8^{\circ} \mathrm{C}\left(46^{\circ} \mathrm{F}\right)$ releases are well below the $15^{\circ} \mathrm{C}$ $\left(59^{\circ} \mathrm{F}\right)$ optimum for rainbow trout. Reservoir modeling studies also suggest that nutrient and detritus releases from the dam would increase, potentially improving the food base for trout in the Lees Ferry reach of the river.

Adaptive management is an essential component of the proposed alternative. Because of the complexity of the ecological interactions in the Grand Canyon, no one (fixed) plan of operation could be expected to optimize the goals of the proposed temperature control alternative. Modeling and predictions are of limited usefulness when dealing with complex environmental systems. It is clear that temperature release patterns (operations) will need to be adjusted and evolve as our knowledge increases from each successive year of testing. Carefully monitored experiments are necessary to assure that these adaptations help (not harm) the resources. The testing and monitoring program would be developed by the Glen Canyon Technical Work Group and Grand Canyon Monitoring and Research Center within the existing adaptive management process. The Glen Canyon Adaptive Management Work Group would then review this work and make recommendations to the Secretary of the Interior for implementation. 
The temperature control alternative included in this assessment proposes to avoid or mitigate the potential adverse impacts that have been identified in this assessment. It also includes the Adaptive Management Program and Grand Canyon Monitoring and Research Center to monitor and evaluate management options to avoid unforeseen impacts that may occur in the future. And finally, if monitoring shows that warmwater releases do not to benefit endangered species, cold-water releases would be available anytime. With time, the proposed action would be reversible (except for the expense of the modifications).

If, after a public review, Reclamation finds that endangered fish are likely to benefit from warmwater releases and all significant adverse impacts can be avoided or mitigated or reversed, Reclamation would then consider proceeding with a Finding of No Significant Impact and would begin modifying the intakes in fiscal year 2000. On this schedule, temperature controls would potentially be available as early as the summer of 2002 .

\section{U.S. Bureau of Reclamation. 2002. Proposed experimental releases from Glen Canyon Dam and removal of non-native fish. U.S. Department of the Interior, Bureau of Reclamation, Upper Colorado Region, Salt Lake City, Utah.}

The Grand Canyon is one of the Nation's treasures. The Department of the Interior is proposing a series of experimental actions, some of which involve modifying the operations of Glen Canyon Dam, which is located upstream of the Grand Canyon, to improve the condition of the habitat within the Grand Canyon and the species that have their home in the canyon. This proposed action was deemed necessary by the GCDAMP because endangered species and sandbars in the Grand Canyon have not responded as well as predicted to past management actions regarding the operation of Glen Canyon Dam. The proposed actions, detailed in the accompanying report, are the product of years of scientific study and would implement the recommendation of an independent advisory committee that has been studying the natural and cultural resources of the Grand Canyon since 1997. The proposed actions presented in this report are multifaceted and complex, and have been designed to protect both the endangered species and the important beach habitat found in the Grand Canyon.

The 1996 Record of Decision (ROD) on the Operation of Glen Canyon Dam Final Environmental Impact Statement (FEIS) modified the operation of the dam in an effort to protect downstream resources. An adaptive management program was established by the ROD to monitor the effects of this change, perform research necessary to measure whether these resource protection objectives were met, and make recommendations to the Secretary of the Interior.

Since 1996, the non-native trout population in the Grand Canyon has tripled, the endangered humpback chub population has declined precipitously, and tributary sediment inputs are not being conserved as expected in the FEIS. These trends are contrary to the expectations of the FEIS and the goals of the adaptive management program. If no actions are taken and current operations continue, these trends are expected to continue.

An experiment consisting of a combination of Glen Canyon Dam releases and mechanical removal of non-native fish is proposed to determine if these proposed actions can reverse current trends. The proposed dam releases are intended to conserve sediment inputs from 
the Paria River and reduce spawning and recruitment success of non-native trout. Mechanical removal of non-native fish is proposed in order to remove trout who feed on young chubs near the confluence of the LCR, which is the only known stream in Grand Canyon where the endangered humpback chub reproduces and survives to adulthood.

To conserve Paria sediment inputs, proposed dam releases will either be reduced to store sediment in the main channel or raised to powerplant capacity to store the sediment in eddies following Paria River inputs. In addition, dam releases up to 45,000 cfs, similar to the 1996 test flow are proposed in an attempt to rebuild beaches.

Non-native trout are known to negatively impact native fish. Daily high fluctuating releases are proposed during January-March to interrupt spawning of adult trout and to displace small trout from their preferred habitats. Proposed mechanical removal of trout by electrofishing will test whether the juvenile and adult trout population can be reduced in a 10-mile reach of Colorado River that contains the largest known number of mainstream humpback chub. About 20,000 rainbow and brown trout are expected to be removed from this river reach in each of two years under the experiment.

The environmental consequences of the Proposed Action are expected to be positive for resources intended to be benefited by the action, though due to the experimental nature of the proposal, there is some uncertainty as to the outcome. The estimated financial cost of the proposed experiment to power customers is about $\$ 1.7$ million as compared with estimated 2003 power revenues of $\$ 130$ million under ROD operations. Objectives of this proposed action are in agreement with the 12 management goals of the Glen Canyon Dam Adaptive Management Program and applicable provisions of federal law.

The effects of the various components of the Proposed Action on endangered species have been fully described in Section 3.8, "Endangered Species". With respect to the Proposed Action in total, a condition of "may affect, not likely to adversely affect" is projected for the California condor, razorback sucker, and Southwestern willow flycatcher. A condition of "may affect, likely to adversely affect" is projected for the humpback chub, Kanab amber snail, and bald eagle. It is important to note that the Proposed Action is expected to produce an overall positive benefit to the ecosystem downstream of Glen Canyon Dam, including the endangered species, despite short-term minor impacts to some resources.

The proposed combination of experimental dam releases and non-native fish removal has been developed using knowledge gained in nearly 20 years of research and monitoring of resources in this reach of the Colorado River, first under the Glen Canyon Environmental Studies and now as part of the Adaptive Management Program. Accordingly, this EA provides analysis that builds upon the scientific information developed over this entire period. 


\section{U.S. Bureau of Reclamation. 2007. Biological assessment of the Colorado River interim guidelines for lower basin shortages and coordinated operations for Lake Powell and Lake Mead, final environmental impact statement. U.S. Bureau of Reclamation, Boulder Canyon Operations Office, Boulder City, Nevada. Abstract excerpted from report.}

The proposed action for this biological opinion consists of the Bureau of Reclamation's (Reclamation) implementation of the Colorado River interim guidelines for Lower Basin shortages and coordinated operations for Lake Powell and Lake Mead (Guidelines). The Guidelines have four operational elements that collectively are designed to address shortages and coordinated operations for Lake Powell and Lake Mead and will be used by the Secretary to:

(1) determine those circumstances under which the Secretary would reduce the annual amount of water available for consumptive use from Lake Mead to the Colorado River Lower Division states (Arizona, California, and Nevada) below 7.5 million acre-feet (maf) (a "Shortage") pursuant to Article II(B)(3) of the United States Supreme Court in the case of Arizona v. California, 547 U.S. (2006) (Consolidated Decree); (2) define the coordinated operation of Lake Powell and Lake Mead to provide improved operation of these two reservoirs, particularly under low reservoir conditions; (3) allow for the storage and delivery, pursuant to applicable Federal law, of conserved Colorado River system and non-system water in Lake Mead to increase the flexibility of meeting water-use needs from Lake Mead Intentionally Created Surplus (ICS), particularly under drought and low reservoir conditions; and (4) determine those conditions under which the Secretary may declare the availability of surplus water for use within the lower division states. The proposed Federal action would modify the substance of the existing Interim Surplus Guidelines (ISG), published in the Federal Register on January 25, 2001 (66 FR 7772), and the term of the ISG from 2016 to 2026.

Reclamation has included the following conservation measures for the listed species, including the humpback chub, in the action area as part of its proposed action.

Nonnative Fish Control. In coordination with other Department of the Interior (DOI) Adaptive Management Program (AMP) participants and through the AMP, Reclamation will continue efforts to control both cold- and warm-water nonnative fish species in the mainstem of Marble and Grand Canyons, including determining and implementing levels of nonnative fish control, as necessary. Control of these species using mechanical removal and other methods will help to reduce this threat.

Humpback Chub Refuge. Reclamation will assist USFWS in development and funding of a broodstock management plan and creation and maintenance of a humpback chub refuge population at a Federal hatchery or other appropriate facility by providing expedited advancement of $\$ 200,000$ in funding to the USFWS during CY 2008; this amount shall be funded from, and within, the amount identified in the Multispecies Conservation Plan Biological Opinion (MSCP BO) (USFWS 2005a; page 26). Creation of a humpback chub refuge will reduce or eliminate the potential for a catastrophic loss of the Grand Canyon population of humpback chub by providing a permanent source of genetically representative stock for repatriating the species. 
Genetic Biocontrol Symposium. Reclamation will transfer up to $\$ 20,000$ in fiscal year 2008 to USFWS to help fund an international symposium on the use and development of genetic biocontrol of nonnative invasive aquatic species, which is tentatively scheduled for October 2009. Although only in its infancy, genetic biocontrol of nonnative species is attracting worldwide attention as a potential method of controlling aquatic invasive species. Helping fund an effort to bring researchers together will further awareness of this potential method of control and help mobilize efforts for its research and development.

Sediment Research. In coordination with other DOI AMP participants and through the AMP, Reclamation will monitor the effect of sediment transport on humpback chub habitat and will work with the GCMRC to develop and implement a scientific monitoring plan acceptable to USFWS. Although the effects of dam operation-related changes in sediment transport on humpback chub habitat are not well understood, humpback chub are known to utilize backwaters and other habitat features that require fine sediment for their formation and maintenance. Additional research will help clarify this relationship.

Parasite Monitoring. In coordination with other DOI AMP participants and through the AMP, Reclamation will continue to support research on the effects of Asian tapeworm (Bothriocephalus acheilognathi) on humpback chub and potential methods to control this parasite. Continuing research will help better understand the degree of this threat and the potential for management actions to minimize it.

Our analysis of the effects of the proposed action relies in part on Reclamation's analysis from its EIS and biological assessment (Reclamation 2007a, 2007b, 2007c). Potential effects of the proposed action on listed species, including the humpback chub, could result from changes in Lake Powell reservoir storage and release operations from current conditions. The potential hydrologic effects could result in changes in the range and duration of the water elevations maintained in Lake Powell and river flow, river temperature, and sediment transport in the Colorado River that support habitat conditions for the listed species. Reclamation compared Lake Powell elevations; river flows; average monthly river temperatures at Lees Ferry, the LCR confluence, and below Diamond Creek; and river sediment transport under current conditions to corresponding values expected under the proposed action, to evaluate if differences in hydrologic conditions under the proposed action would affect listed species and designated critical habitats. Future Colorado River system characteristics under current and proposed action conditions were simulated using the Colorado River Simulation System (CRSS).

Reclamation's CE-QUAL-W2 model was used to simulate Lake Powell's seasonal transformation to analyze dam release temperatures for various reservoir starting elevations and inflows. The Generalized Environmental Modeling System for Surface Waters (GEMSS) model was used to route Glen Canyon Dam release temperatures through the Grand Canyon downstream to Lake Mead. To estimate the effects of modifying the annual release volumes from Glen Canyon Dam under the proposed action on sediment transport, the USGS prepared an analysis relating normalized sediment transport from the Grand Canyon to annual release volumes. The hydrologic model, CRSS, used as the primary basis of Reclamation's effects analysis does not project future inflows, but rather relies on the historic record to analyze a range of possible future inflows. 
The proposed action could alter critical habitat including the Primary Constituent Elements (PCEs) related to sediment transport, water temperature, and flow volumes in the Colorado River below Glen Canyon Dam relative to current conditions. These changes could result in adverse effects to humpback chub in three primary ways: (1) increased competition and predation from nonnative fish species; (2) increased parasitism from Asian tapeworm and anchorworm (Lernaea cyprinacea); and (3) reduced suitability of mainstem nearshore habitats due to changes in river flow and sediment transport.

In order to be exempt from the prohibitions of Section 9 of the Endangered Species Act, Reclamation must comply with the following terms and conditions, which implement the following reasonable and prudent measures as well as terms and conditions that are nondiscretionary: (1) monitor the effects of the proposed action on humpback chub and its habitat to document levels of incidental take and report the findings to the USFWS. Reclamation shall work in collaboration with the AMP participants, including GCMRC and other cooperators, to complete this monitoring; and (2) Reclamation, in collaboration with the AMP participants, including the GCMRC and other cooperators, shall submit a written report to the USFWS annually documenting activities of the proposed action for the year that resulted in documented take. The report will include a discussion of the progress of the implementation of Reclamation's conservation measures included in the proposed action.

\section{U.S. Bureau of Reclamation. 2007. Biological assessment on the operation of Glen Canyon Dam and proposed experimental flows for the Colorado River below Glen Canyon Dam during the years 2008-2012. U.S. Bureau of Reclamation, Upper Colorado River Region, Salt Lake City, Utah. Abstract excerpted from report and accompanying letter.}

Pursuant to Section 7(a)(2) of the Endangered Species Act, 16 USC 1531 et seq. and the implementing regulations at 50 CFR 402.16, the U.S. Bureau of Reclamation (Reclamation ) requested reinitiation of formal consultation with the U.S. Fish and Wildlife Service (Service) regarding operations of Glen Dam, Colorado River Storage Project, Coconino County, Arizona. The basis of this request is new information that may reveal effects of dam operations that may affect listed species including the humpback chub (Gila cypha) or designated critical habitat in a manner or to an extent not previously considered. This new information pertaining to the humpback chub includes:

- Recruitment failure through the mid-1990s resulted in a decline of the Little Colorado River (LCR) population of humpback chub to 2,400 to 4,400 adult fish.

- Increase in recruitment of humpback chub under MLFF began 4 to 9 years prior to implementation of non-native fish control, warmer dam release temperatures, the 2000 steady-flow experiment, and the 2004 high-flow test.

- Significantly greater numbers of young humpback chub have been found in the mainstem during 2002 to 2006, including upstream of the LCR. 
- Current adult population estimates for humpback chub have increased to an estimated 5,300 to 6,800 adult fish in 2006 .

- Humpback chub translocated above Chute Falls have experienced high survival and growth rates, and are a source of recruitment to the lower LCR and the mainstem.

- Douglas and Douglas (2007) recommended further study of the 30-mile aggregation of humpback chub to evaluate their potential distinctiveness.

- Mainstem parasite infestation rates in humpback chub are much lower than fish in the LCR and may be temperature-limited.

- Hoffnagle (2000) reported greater condition and abdominal fat of humpback chub in the mainstem than the LCR, possibly due to increased prevalence of parasites in the LCR fish.

The biological assessment incorporates results of onsite inspections, updates information on listed species and designated habitats based on views of recognized experts, reviews the literature, and reaches new findings about the status of listed species and critical habitat in the action area below the dam. The findings are that the proposed action: (1) is likely to adversely affect the humpback chub due to potential take of individuals from proposed high-flow test of 41,500 cubic feet per second in March 2008; and (2) is not likely to result in destruction or adverse modification of designated critical habitat for the endangered humpback chub.

\section{U.S. Fish and Wildlife Service. 1994. Determination of critical habitat for four endangered Colorado River fishes. Federal Register 59(54):13374-13400.}

This document amends and supplements the Humpback Chub Recovery Plan of 1990. The purpose of this document is to describe site-specific management actions/tasks; provide objective, measurable recovery criteria; and provide an estimate of the time to achieve recovery of the endangered humpback chub (Gila cypha), according to Section 4(f)(1) of the Endangered Species Act of 1973, as amended. Recovery or conservation programs that include the humpback chub will direct research, management, and monitoring activities and determine costs associated with recovery.

The humpback chub is listed as endangered under the Endangered Species Act of 1973, as amended. The species is endemic to the Colorado River Basin of the southwestern United States. Adults attain a maximum size of about $480 \mathrm{~mm}$ total length (TL) and $1.2 \mathrm{~kg}$ in weight. Six extant wild populations are known: (1) Black Rocks, Colorado River, Colorado; (2) Westwater Canyon, Colorado River, Utah; (3) Yampa Canyon, Yampa River, Colorado; (4) Desolation/Gray Canyons, Green River, Utah; (5) Cataract Canyon, Colorado River, Utah; and (6) the mainstem Colorado River in Marble and Grand Canyons and the Little Colorado River, Arizona. The first five populations are in the Upper Colorado River Basin (i.e., upstream of Glen Canyon Dam, Arizona), and the sixth population is in the Lower Colorado River Basin. 
Populations of humpback chub are restricted to deep, swift, canyon-bound regions of the mainstem and large tributaries of the Colorado River Basin. Adults require eddies and sheltered shoreline habitats maintained by high spring flows. These high spring flows maintain channel and habitat diversity, flush sediments from spawning areas, rejuvenate food production, and form gravel and cobble deposits used for spawning.

Spawning occurs on the descending limb of the spring hydrograph at water temperatures typically between 16 and $22^{\circ} \mathrm{C}$. Young require low-velocity shoreline habitats, including eddies and backwaters, that are more prevalent under base-flow conditions. Threats to the species include streamflow regulation, habitat modification, predation by nonnative fish species, parasitism, hybridization with other native Gila, and pesticides and pollutants.

Objective, measurable criteria for recovery of humpback chub in the Colorado River Basin are presented for each of two recovery units (i.e., the upper basin, including the Green River and upper Colorado River subbasins; and the lower basin, including the mainstem and its tributaries from Glen Canyon Dam downstream to Lake Mead National Recreation Area) because of different recovery or conservation programs and to address unique threats and sitespecific management actions/tasks necessary to minimize or remove those threats. Recovery of the species is considered necessary in both the upper and lower basins because of the present status of populations and existing information on humpback chub biology. The humpback chub was listed prior to the 1996 distinct population segment (DPS) policy, and the U.S. Fish and Wildlife Service (Service) may conduct an evaluation to designate DPSs in a future rule-making process. If DPSs are designated, criteria for recovery of humpback chub will need to be reevaluated. These recovery goals are based on the best available scientific information, and are structured to attain a balance between reasonably achievable criteria (which include an acceptable level of uncertainty) and ensuring the viability of the species beyond delisting. Additional data and improved understanding of humpback chub biology may prompt future revision of these recovery goals.

Downlisting can occur if, over a 5-year period: (1) the trend in adult (age 4+; $200 \mathrm{~mm}$ TL) point estimates for each of the six extant populations does not decline significantly; and (2) mean estimated recruitment of age-3 (150-199 mm TL) naturally produced fish equals or exceeds mean annual adult mortality for each of the six extant populations; and (3) two genetically and demographically viable, self-sustaining core populations are maintained, such that each point estimate for each core population exceeds 2,100 adults $(2,100$ is the estimated minimum viable population [MVP] needed to ensure long-term genetic and demographic viability); and (4) when certain site-specific management tasks to minimize or remove threats have been identified, developed, and implemented. Delisting can occur if, over a 3-year period beyond downlisting: (1) the trend in adult point estimates for each of the six extant populations does not decline significantly; and (2) mean estimated recruitment of age-3 naturally produced fish equals or exceeds mean annual adult mortality for each of the six extant populations; and (3) three genetically and demographically viable, self-sustaining core populations are maintained, such that each point estimate for each core population exceeds 2,100 adults; and (4) when certain site-specific management tasks to minimize or remove threats have been finalized and implemented, and necessary levels of protection are attained. 
Management actions needed include: 1) Provide and legally protect habitat (including flow regimes necessary to restore and maintain required environmental conditions) necessary to provide adequate habitat and sufficient range for all life stages to support recovered populations; 2) Investigate the role of the mainstem Colorado River in maintaining the Grand Canyon population; 3) Investigate the anticipated effects of and options for providing warmer water temperatures in the mainstem Colorado River through Grand Canyon; 4) Ensure adequate protection from overutilization; 5) Ensure adequate protection from diseases and parasites; 6 Regulate nonnative fish releases and escapement into the main river, floodplain, and tributaries; 7) Control problematic nonnative fishes as needed; 8) Minimize the risk of increased hybridization among Gila spp.; 9) Minimize the risk of hazardous-materials spills in critical habitat; and 10) Provide for the long-term management and protection of populations and their habitats beyond delisting (i.e., conservation plans).

\section{U.S. Fish and Wildlife Service. 1994. Final rule, determination of critical habitat for the Colorado River endangered fishes: razorback sucker, Colorado squawfish, humpback chub and bonytail chub. Federal Register 59:13374-13400. Abstract excerpted from summary and affected habitat.}

The U.S. Fish and Wildlife Service designates critical habitat for four species of endemic Colorado River Basin fishes: Razorback sucker (Xyrauchen texanus), Colorado squawfish (Ptychocheilus lucius), humpback chub (Gila cypha), and bonytail chub (Gila elegans). These species are listed as endangered under the Endangered Species Act 1973, as amended. The critical habitat designated is located primarily on Federal land and, to a lesser extent, on tribal, state, and private lands. The designation provides additional protection required under Section 7 of the Endangered Species Act with regard to activities that require Federal agency action. The Service designates $3,168 \mathrm{~km}(1,980 \mathrm{mi})$ of critical habitat for the four Colorado River endangered fishes in portions of Colorado, Utah, New Mexico, Arizona, Nevada, and California.

The historical abundance and distribution of the species are not well known. In the Lower Basin, the humpback chub occurs in the Little Colorado and Colorado Rivers in the Grand Canyon. This population is the largest remaining in the Basin. In the Upper Basin, humpback chub are found in the Black Rocks/Westwater Canyon and Cataract Canyon of the Colorado River, Desolation and Gray Canyons of the Green River, and Yampa and Whirlpool Canyons in the Green and Yampa Rivers of the Dinosaur National Monument.

Spawning occurs soon after the highest spring flows when water temperatures approach $20^{\circ} \mathrm{C}\left(68^{\circ} \mathrm{F}\right)$. Flow reductions and low water temperatures in the Grand Canyon have been implicated as factors curtailing successful spawning of the humpback chub and increasing competition from other species.

Populations of humpback chub are found in river canyons, where they use a variety of habitats, including pools, riffles, and eddies. This diversity in habitat use suggests that the adult fish are adapted to a variety of habitats, and studies of tagged fish indicated that they move between habitats, presumably in response to seasonal habitat changes and life history needs. Reduced spring peak flows, availability of shoreline eddy and deep canyon habitats, and competition and predation from nonnative fish were reported as potential limiting factors for 
humpback chub in the Yampa River. The impact of hybridization with other species is currently being evaluated.

\section{U.S. Fish and Wildlife Service. 2002. Recovery goals: amendment and supplement to the humpback chub recovery plan. Mountain-Prairie Region, Denver, Colorado.}

This document amends and supplements the Humpback Chub Recovery Plan of 1990. The purpose of this document is to describe site-specific management actions/tasks; provide objective, measurable recovery criteria; and provide an estimate of the time to achieve recovery of the endangered humpback chub (Gila cypha), according to Section 4(f)(1) of the Endangered Species Act of 1973, as amended. Recovery or conservation programs that include the humpback chub will direct research, management, and monitoring activities and determine costs associated with recovery.

Current Species Status: The humpback chub is listed as endangered under the Endangered Species Act of 1973, as amended. The species is endemic to the Colorado River Basin of the southwestern United States. Adults attain a maximum size of about $480 \mathrm{~mm}$ total length (TL) and $1.2 \mathrm{~kg}$ in weight. Six extant wild populations are known: (1) Black Rocks, Colorado River, Colorado; (2) Westwater Canyon, Colorado River, Utah; (3) Yampa Canyon, Yampa River, Colorado; (4) Desolation/Gray Canyons, Green River, Utah; (5) Cataract Canyon, Colorado River, Utah; and (6) the mainstem Colorado River in Marble and Grand Canyons and the Little Colorado River, Arizona. The first five populations are in the Upper Colorado River Basin (i.e., upstream of Glen Canyon Dam, Arizona), and the sixth population is in the Lower Colorado River Basin.

Habitat Requirements and Limiting Factors: Populations of humpback chub are restricted to deep, swift, canyon-bound regions of the mainstem and large tributaries of the Colorado River Basin. Adults require eddies and sheltered shoreline habitats maintained by high spring flows. These high spring flows maintain channel and habitat diversity, flush sediments from spawning areas, rejuvenate food production, and form gravel and cobble deposits used for spawning. Spawning occurs on the descending limb of the spring hydrograph at water temperatures typically between 16 and $22^{\circ} \mathrm{C}$. Young require low-velocity shoreline habitats, including eddies and backwaters, that are more prevalent under base-flow conditions. Threats to the species include streamflow regulation, habitat modification, predation by nonnative fish species, parasitism, hybridization with other native Gila, and pesticides and pollutants.

Recovery Objective: Downlisting and Delisting.

Recovery Criteria: Objective, measurable criteria for recovery of humpback chub in the Colorado River Basin are presented for each of two recovery units (i.e., the upper basin, including the Green River and upper Colorado River subbasins; and the lower basin, including the mainstem and its tributaries from Glen Canyon Dam downstream to Lake Mead National Recreation Area) because of different recovery or conservation programs and to address unique threats and site-specific management actions/tasks necessary to minimize or remove those threats. Recovery of the species is considered necessary in both the upper and lower basins because of the present status of populations and existing information on humpback chub biology. 
The humpback chub was listed prior to the 1996 distinct population segment (DPS) policy, and the U.S. Fish and Wildlife Service (Service) may conduct an evaluation to designate DPSs in a future rule-making process. If DPSs are designated, criteria for recovery of humpback chub will need to be reevaluated. These recovery goals are based on the best available scientific information, and are structured to attain a balance between reasonably achievable criteria (which include an acceptable level of uncertainty) and ensuring the viability of the species beyond delisting. Additional data and improved understanding of humpback chub biology may prompt future revision of these recovery goals. Downlisting can occur if, over a 5-year period: (1) the trend in adult (age 4+; $200 \mathrm{~mm}$ TL) point estimates for each of the six extant populations does not decline significantly; and (2) mean estimated recruitment of age-3 (150-199 mm TL) naturally produced fish equals or exceeds mean annual adult mortality for each of the six extant populations; and (3) two genetically and demographically viable, self-sustaining core populations are maintained, such that each point estimate for each core population exceeds 2,100 adults $(2,100$ is the estimated minimum viable population [MVP] needed to ensure long-term genetic and demographic viability); and (4) when certain site-specific management tasks to minimize or remove threats have been identified, developed, and implemented.

Delisting can occur if, over a 3-year period beyond downlisting: (1) the trend in adult point estimates for each of the six extant populations does not decline significantly; and (2) mean estimated recruitment of age-3 naturally produced fish equals or exceeds mean annual adult mortality for each of the six extant populations; and (3) three genetically and demographically viable, self-sustaining core populations are maintained, such that each point estimate for each core population exceeds 2,100 adults; and (4) when certain site-specific management tasks to minimize or remove threats have been finalized and implemented, and necessary levels of protection are attained.

Conservation plans will go into effect at delisting to provide for long-term management and protection of the species, and to provide reasonable assurances that recovered humpback chub populations will be maintained without the need for relisting. Elements of those plans could include (but are not limited to) provision of flows for maintenance of habitat conditions required for all life stages, regulation and/or control of nonnative fishes, minimization of the risk of hazardous-materials spills, and monitoring of populations and habitats. Signed agreements among State agencies, Federal agencies, American Indian tribes, and other interested parties must be in place to implement the conservation plans before delisting can occur.

Management Actions Needed:1) Provide and legally protect habitat (including flow regimes necessary to restore and maintain required environmental conditions) necessary to provide adequate habitat and sufficient range for all life stages to support recovered populations; 2) Investigate the role of the mainstem Colorado River in maintaining the Grand Canyon population; 3) Investigate the anticipated effects of and options for providing warmer water temperatures in the mainstem Colorado River through Grand Canyon; 4) Ensure adequate protection from over-utilization; 5) Ensure adequate protection from diseases and parasites; 6) Regulate nonnative fish releases and escapement into the main river, floodplain, and tributaries; 7) Control problematic nonnative fishes as needed; 8) Minimize the risk of increased hybridization among Gila spp.; 9) Minimize the risk of hazardous-materials spills in critical 
habitat; and 10) Provide for the long-term management and protection of populations and their habitats beyond delisting (i.e., conservation plans).

Estimated Time to Achieve Recovery: Reliable population estimates, based on a multiple mark-recapture model, are needed for all six extant populations over a 5-year monitoring period for downlisting and over a 3-year monitoring period beyond downlisting in order to achieve delisting. The accuracy and precision of each point estimate will be assessed by the Service in cooperation with the respective recovery or conservation programs, and in consultation with investigators conducting the point estimates and with qualified statisticians and population ecologists. First reliable point estimates are expected for all populations by 2002. If those estimates are acceptable to the Service and all recovery criteria are met, downlisting could be proposed in 2007 and delisting could be proposed in 2010. This estimated time frame is based on current understanding of the status and trends of populations and on the monitoring time required to meet the downlisting and delisting criteria.

\section{U.S. Fish and Wildlife Service. 2007. Final biological opinion for the proposed adoption of Colorado River interim guidelines for lower basin shortages and coordinated operations for Lake Powell and Lake Mead. Consultation number 22410-2006-F-0224. U.S. Fish and Wildlife Service, Phoenix, Arizona. Abstract excerpted from report.}

At issue are impacts that may result from the proposed adoption of the Colorado River interim guidelines for Lower Basin shortages and coordinated operations for Lake Powell and Lake Mead in Coconino and Mohave Counties, Arizona, and Clark County, Nevada. The proposed action may affect humpback chub (Gila cypha) and its critical habitat, Kanab ambersnail (Oxyloma haydeni kanabensis), and southwestern willow flycatcher (Empidonax traillii extimus) and its critical habitat.

The proposed action will take place on the Colorado River from Lake Powell to the international border with Mexico, and in general concerns how water will be delivered through this reach of the river (specifically via the Guidelines) for the period from December 2008 through September 2026. The Guidelines include a coordinated operation of Lake Powell and Lake Mead, designed to minimize shortages in the Lower Basin and avoid risk of curtailments of use in the Upper Basin. They also provide a mechanism, called Intentionally Created Surplus (ICS), for promoting water conservation in the Lower Basin.

Our analysis of the effects of the proposed action relies in part on Reclamation's analysis from its EIS and biological assessment. This section describes the methods and assumptions used by Reclamation to conduct the analysis of potential effects of the proposed action on species in the Lake Powell to Lake Mead portion of the action area. Potential effects of the proposed action on listed species could result from changes in Lake Powell reservoir storage and release operations from current conditions. The potential hydrologic effects could result in changes in the range and duration of the water elevations maintained in Lake Powell and river flow, river temperature, and sediment transport in the Colorado River that support habitat conditions for the listed species. 
Changes in allowable annual release volume under the proposed action will essentially create a more variable and potentially drier Colorado River in Grand Canyon annually. Whereas release volume in low runoff years has been restricted to 8.23 million acre-feet per year (mafy) under current conditions, the Guidelines will allow more flexibility, generally allowing from 7.0 to 9.0 mafy. Thus, the proposed action could alter critical habitat including the Primary Constituent Elements (PCEs) related to sediment transport, water temperature, and flow volumes in the Colorado River below Glen Canyon Dam relative to current conditions. These changes could result in adverse effects to humpback chub in three primary ways: (1) increased competition and predation from nonnative fish species; (2) increased parasitism from Asian tapeworm and anchorworm (Lernaea cyprinacea); and (3) a reduction in the suitability of mainstem nearshore habitats due to changes in river flow and sediment transport.

After reviewing the current status of the humpback chub and its critical habitat, the current status of the southwestern willow flycatcher and its critical habitat, the current status of the Kanab ambersnail, the environmental baseline for the action area, the effects of implementation of the proposed Guidelines, and the cumulative effects, it is our biological opinion that implementation of the Guidelines, as proposed, is not likely to jeopardize the continued existence of the humpback chub, the southwestern willow flycatcher, or the Kanab ambersnail, and is not likely to destroy or adversely modify designated critical habitat for the humpback chub or the southwestern willow flycatcher.

\section{U.S. Fish and Wildlife Service. 2008. Final biological opinion on the operation of Glen Canyon Dam. U.S. Fish and Wildlife Service, Phoenix, Arizona. Abstract excerpted from report.}

At issue are impacts that may result from the proposed adoption of the experimental dam operations of Glen Canyon Dam in Coconino County, Arizona. The proposed action may affect humpback chub (Gila cypha) and its critical habitat. We note that one of the purposes of the proposed action is to benefit the Grand Canyon population of humpback chub. Thus the proposed action takes a conservative approach to changes in dam releases in an attempt to capitalize on this trend in status without unduly risking these gains with more drastic changes in dam operations. However, there exists the possibility that the population could decline, despite the current trend and the potential for beneficial effects from Reclamation's proposed action.

The proposed action is to continue MLFF releases as described in the 1995 EIS (U.S. Bureau of Reclamation 1995, 1996). As part of this experimental action, Reclamation also proposes to incorporate experimental flows that have been designed to benefit endangered humpback chub and conservation of sediment resources in the Grand Canyon. The experimental proposed action is: (1) an experimental high-flow test of approximately 41,500 cfs for a maximum duration of 60 hours in March 2008 (only one high-flow test is proposed for the 5-year period), and (2) fall (September and October) steady flows over the next 5 years (2008-2012).

After reviewing the current status of the humpback chub and its critical habitat, the environmental baseline for the action area, the effects of implementation of the proposed action, and the cumulative effects, it is our biological opinion that implementation of the March 2008

high-flow test and the 5-year implementation of MLFF with steady releases in September and 
October, as proposed, are not likely to jeopardize the continued existence of the humpback chub and are not likely to destroy or adversely modify designated critical habitat for the humpback chub.

\section{U.S. Fish and Wildlife Service. 2009. A plan for the captive maintenance of humpback chub from the Yampa River population. Upper Colorado River Endangered Fish Recovery Program, Lakewood, Colorado.}

Population estimates for humpback chub (Gila cypha) in the Yampa River have never been successful because too few fish have been collected. It was recommended to remove individuals from the Yampa River into captivity to preserve their unique genetics. This plan recommends maintaining humpback chub collected from an initial effort in October 2007, as well as future collections, at the Ouray National Fish Hatchery and J.W. Mumma Aquatic Species Restoration Facility as a captive population and for potential future propagation. This plan recommends maintaining 500 adults in captivity, with active genetic monitoring and maintenance, which should provide an initial buffer for the accumulation of deleterious mutations, as well as maintaining genetic diversity available in the Yampa River population. This plan provides three objectives with associated management actions and tasks for maintaining captive humpback chub from the Yampa River population.

\section{U.S. Geological Survey. 2007. Science Plan for Potential 2008 Experimental High Flow at Glen Canyon Dam, Grand Canyon Monitoring and Research Center, Flagstaff, Arizona. 104 p.}

This science plan describes proposed monitoring and research activities to be conducted by the U.S. Geological Survey's Grand Canyon Monitoring and Research Center (GCMRC), should the Secretary of the Interior approve an experimental high flow at Glen Canyon Dam in spring 2008. A high-flow release from the dam has been proposed in 2008, not only to rebuild sandbars and aid the endangered humpback chub, but also to benefit various downstream resources, including rainbow trout (Oncorhynchus mykiss), the aquatic food base, riparian vegetation, and archaeological sites. Additionally, the system is currently enriched with sediment as a result of repeated tributary floods from the Paria River in late 2006 and fall 2007; the current level of sand enrichment is greater than it has been since at least 1998.

The international prominence of Grand Canyon National Park and public concern about the impacts of Glen Canyon Dam resulted in Federal efforts to protect downstream resources. In 1992, the Grand Canyon Protection Act (GCPA) was enacted "to protect, mitigate adverse impacts to and improve the values for which Grand Canyon National Park and Glen Canyon National Recreation Area were established." The 1996 Record of Decision on the Operation of Glen Canyon Dam Environmental Impact Statement established an adaptive management program, of which the GCMRC is a part, to ensure that the primary mandate of the GCPA is met.

Before the dam, the Colorado River swelled with spring snowmelt from the Rocky Mountains in most years, producing flood events and transporting large quantities of sediment that created and maintained sandbars in Grand Canyon. In Grand Canyon, sandbars provide camping beaches for river runners and hikers, serve as a source of sediment needed to protect 
archaeological resources from weathering and erosion, and create habitats used by native fish and other wildlife. Today, the river usually runs clear below Glen Canyon Dam, because Lake Powell traps all of the sediment upstream from the dam. As a result, Grand Canyon receives 6\%$16 \%$ of its pre-dam sand supply, which comes primarily from the Paria and Little Colorado Rivers when they enter the mainstem below the dam.

The native fish community found in Grand Canyon evolved in the large, turbid, and seasonally variable pre-dam Colorado River. Today, three of the eight native fish species have been eliminated from the Colorado River in the study area and two are federally listed as endangered, razorback sucker (Xyrauchen texanus) and humpback chub (Gila cypha), under the Endangered Species Act of 1973. The razorback sucker is widely thought to no longer be present in Grand Canyon. Only six populations of humpback chub are known to exist, five in the Colorado River Basin above Lees Ferry, Arizona, and the one in Grand Canyon, Arizona, which is the largest population remaining in the basin.

Importantly, the design of the proposed 2008 high flow and the accompanying experimental studies outlined in this plan build on learning that occurred as the result of highflow experiments conducted in 1996 and 2004. For example, from the 1996 high-flow, scientists learned that tributary-supplied sand does not accumulate on the riverbed over multiyear periods under typical dam operations. In fact, erosion of low-elevation sandbars caused by the 1996 high flow actually resulted in a net reduction in overall sandbar size. Approval of a supplemental environmental assessment allowed scientists to evaluate the efficacy of conducting a high flow following tributary floods in 2004 for the first time and generated the following conclusions:

- The 2004 experiment resulted in an increase of total sandbar area and volume in the upper half of Marble Canyon, but further downstream, where sand was less abundant, a net transfer of sand out of eddies occurred that was similar to that observed during the 1996 experiment.

- More sand will be required than was available during the 2004 high flow $(800,000$ to $1,000,000$ metric tons) to achieve increases in total sandbar area and volume throughout all of Marble and Grand Canyons in the future.

- Sandbars created by the 2004 high flow increased the windborne transport of sand toward some archaeological sites in Grand Canyon. This led to the hypothesis that increased sand carried by the wind from restored sandbars may reduce erosion and increase preservation potential at some archaeological sites.

The sediment-related data that researchers propose to collect for a possible 2008 high flow would facilitate comparison with data collected during the two previous experiments. Proposed experimental studies will also generate new data that can be compared to previous tests on the physical processes regulating sandbar erosion and deposition during high-flow experiments, sediment deposition at archaeological sites and camping areas, ecosystem flux measurements related to organic tributary inputs, effects of flood disturbance on vegetation, and formation of backwater habitats used by native and nonnative fishes. These comparisons are required to determine whether greater and more geographically extensive sandbar rebuilding is 
possible with a future high flow than occurred in 1996 and 2004. The data are also needed to determine if consecutive high flows in the future might cause sand to accumulate through time to reverse erosion documented after the closure of Glen Canyon Dam in 1963.

Sandbar rebuilding is thought to be important in creating backwater habitat that may lead to increased production of young fish by native species. Overall, recruitment of humpback chub has been increasing from 1994 to 2002, a period that includes the 1996 high flow, though the uncertainty in these estimates is large. These data suggest that high flows have not been detrimental to humpback chub. It is also possible that high flows offer advantages to humpback chub, including the temporary displacement of nonnative fishes and the maintenance and construction of backwater habitats, which may offer growth advantages to humpback chub and other native fishes.

The best timing to conduct a high flow to maximize resource benefits or to avoid undesirable impacts has yet to be determined. For 2007-08, the earliest practical time for a high flow would be early March 2008, given the logistical, administrative, and compliance requirements associated with conducting the research outlined in this plan.

The GCMRC proposes replication of the 2004 hydrograph in a potential 2008 high flow (41,500 cubic feet per second (cfs) for 60 hours). These conditions would allow scientists to determine whether the locally robust and consistent sandbar-building responses that occurred in upper Marble Canyon in 2004 can be repeated and possibly enhanced. However, a possible 2008 experiment would be different from the two high-flow experiments conducted previously in several important ways. In November 2007, for example, sand supplies in the main channel of the Colorado River were two to three times larger and distributed differently than in 2004. The system is currently enriched with sediment as a result of repeated tributary floods from the Paria River in October 2006 and August-September 2007 that delivered 2,500,000 metric tons ( $\pm 500,000$ metric tons) of sand into the Colorado River ecosystem below Glen Canyon Dam. Based on the entire period of record on the Paria River (1923-present), this annual magnitude of sand supply from the river occurs, on average, once in every 10 years. A second important difference is that a 2008 high flow would be followed by normal Record of Decision operations associated with annual release volumes, unlike previous experiments, which were followed by higher fluctuating flows than would have otherwise occurred.

Additionally, this science plan focuses on a wider range of research questions than previous high-flow experiments. For example, experimental study 1 (parts A-D) addresses questions related to sediment and seeks to determine not only if high-flow releases are an effective tool that will rebuild and maintain sandbars over time, but also if they have the ability to create additional backwater habitats for native fish and how new sand deposits affect archaeological sites. Experimental study 1 expands on work begun with the 2004 high flow to document the connection between high-flow releases and the transfer of sand to cultural sites by the wind and the formation and persistence of backwaters as the result of high flows. Additionally, data gathered as a result of a possible 2008 high-flow experiment would provide information to inform the continued development of a sediment model, which will help determine the optimum frequency, timing, duration, and magnitude of future high flows under varying sediment enrichment conditions. Experimental studies 2-5 address the impacts of high- 
flow experiments on riparian vegetation, the food base, rainbow trout, and Lake Powell water quality, respectively. Study 7 will provide a comprehensive synthesis of the results of all of the experimental studies conducted in association with a possible 2008 high-flow experiment. A well-calibrated, robust predictive sediment model will help minimize the impacts of high-flow tests on Glen Canyon Dam hydropower production.

The experimental studies outlined in this plan are designed to address strategic science questions identified in the Grand Canyon Monitoring and Research Center's monitoring and research plan; strategic science questions are designed to guide science activities over the next 5 years. Questions specific to the impacts of a high-flow flow are also identified for each study and would be addressed during the 2008 high-flow experiment, if it occurs.

Based on the two previous high-flow experiments conducted to date, scientists cannot say at this time whether such experiments are an effective strategy for stopping the ongoing erosion of sand and sandbars in the Colorado River ecosystem. A long-term research strategy involving further high-flow experimentation and model development will be necessary to assess whether high flows can effectively conserve sediment and help achieve other related resource benefits (increased humpback chub recruitment, enhanced camping beaches, protection of cultural resource, minimized hydropower impacts, etc). At this time, it is not anticipated that a single high-flow release can answer all such relevant questions: accordingly, it is very likely that additional high-flow experiments will be needed to address the major uncertainties associated with the use such dam operations as an effective long-term management tool.

\section{Upper Colorado River Endangered Fish Recovery Program. 2008. A plan for the captive maintenance of humpback chub from the Yampa River. Draft report, Upper Colorado River Endangered Fish Recovery Program, Lakewood, Colorado.}

Population estimates for humpback chub (Gila cypha) in the Yampa River have never been successful because too few fish have been collected. It was recommended to remove individuals from the Yampa River into captivity to preserve their unique genetics. This plan recommends maintaining humpback chub collected from an initial effort in October 2007, as well as future collections, at the Ouray National Fish Hatchery and J.W. Mumma Aquatic Species Restoration Facility as a captive population and for potential future propagation. This plan recommends maintaining 500 adults in captivity, with active genetic monitoring and maintenance, which should provide an initial buffer for the accumulation of deleterious mutations, as well as maintaining genetic diversity available in the Yampa River population. This plan provides three objectives with associated management actions and tasks for maintaining captive humpback chub from the Yampa River population.

\section{Valdez, R.A. and R.T. Muth. 2005. Ecology and conservation of native fish in the Upper Colorado River Basin. American Fisheries Society Symposium 45:157-204.}

The upper Colorado River basin supports a native ichthyofauna of 14 species or subspecies that have been impacted by poor land-use practices, altered flows, physical habitat fragmentation, competition and predation from nonnative fish species, and degraded water quality. Five taxa are federally endangered, including the large-river species, Colorado 
pikeminnow Ptychocheilus lucius, humpback chub Gila cypha, bonytail G. elegans, razorback sucker Xyrauchen texanus, and a warm-stream subspecies, Kendall Warm Springs dace Rhinichthys osculus thermalis. Two recovery programs, formed through cooperative agreements among federal, state, tribal, and private agencies and stakeholders, coordinate activities in the upper basin that have helped to resolve water resource issues, implement management actions to minimize or remove threats, and conserve endangered species. A cooperative biological management program among state and federal agencies works to protect the Kendall Warm Springs dace. Conservation agreements have also been established for the other native fish species. Continued public and institutional support for these programs is vital to species recovery and to the balance between long-term species conservation and human demands on the Colorado River system.

Valdez, R.A., S.W. Carothers, M.E. Douglas, M. Douglas, R.J. Ryel, K.R. Bestgen and D.L. Wegner. 2000. Research and implementation plan for establishing a second population of humpback chub in Grand Canyon, Final report to U.S. Department of the Interior, U.S. Geological Survey, Grand Canyon Monitoring and Research Center, Flagstaff, Arizona.

Introduction-The humpback chub (Gila cypha) is an endangered cyprinid fish species endemic to the Colorado River Basin in Colorado, Utah, and Arizona. Six populations remain, including five in the upper basin and one in the lower basin in Grand Canyon. The Grand Canyon population consists of nine mainstem Colorado River aggregations and one spawning aggregation in the Little Colorado River (LCR), a major tributary located about $123 \mathrm{~km}$ downstream of Glen Canyon Dam. Humpback chub that spawn in the LCR, which includes fish from the mainstem aggregation around the LCR inflow, are considered a single successfully reproducing population. Fish in the remaining eight mainstem aggregations are unable to spawn successfully, presumably because of cold water temperatures from Glen Canyon Dam releases. Establishing a second self-sustaining population in Grand Canyon will reduce the risks associated with a catastrophic loss of the LCR population, thereby aiding in conservation of the species, and helping to address the "jeopardy" determination of the Biological Opinion on the Operation of Glen Canyon Dam.

This plan for establishing a second population of humpback chub in Grand Canyon was developed jointly by a team of biologists, population ecologists, and geneticists. Only biological factors were taken into consideration; potential cultural and political constraints were disregarded. The plan identifies specific time-line action items with contingencies in case a particular action fails or is ineffective. A description of hatchery needs and availability is provided, along with estimated costs for each element of the plan.

Criteria for the Second Plan- The primary criteria for establishing a second population of humpback chub in Grand Canyon are (1) establishing successfully reproducing adults of sufficient number to maintain the maximum genetic viability of the species and (2) achieving long-term demographic stability in suitable habitat reasonably protected from threats and catastrophes. A genetic effective population size (Ne) was determined to be 1,667 adults and is presented in this document to serve as a guideline to help evaluate alternative approaches to establishing a second population. Demographic structure is presented as the estimated numbers of adults (age 4+) and juveniles (ages 3,2, 1, and 0) that are thought to constitute long-term 
demographic stability. Suitable habitat is ascertained from evaluation of various parameters, including water quantity, water quality, barriers to movement, presence of non-native fishes, and proximity to other populations of humpback chub.

Alternatives- The plan evaluates four alternatives: (1) Existing Mainstem Aggregation, (2) Metapopulation Approach, (3) Tributaries, and (4) Tributary and Mainstem. Preliminary habitat analyses show that genetic criteria (i.e., target population size and structure) are unlikely to be met in a tributary, but may be met in two contiguous aggregations (Stephen Aisle/Middle Granite Gorge) or in the mainstem taken as a whole (the metapopulation concept, which assumes sub-populations periodically exchange individuals and, hence, are linked genetically). The metapopulation concept is thought to present the greatest likelihood for success in establishing a new, genetically viable population of humpback chub in Grand Canyon.

Existing Mainstem Aggregation- The principal factor now limiting successful reproduction and recruitment of humpback chub in the Colorado River in Grand Canyon is thought to be cold water temperatures released from Glen Canyon Dam. Thus, implementation of the U.S. Bureau of Reclamation's proposal to modify the dam penstocks to warm downstream water temperatures is the key feature of this element. Providing warmer water temperatures of $16-22^{\circ} \mathrm{C}$ at aggregation sites from May through September is expected to promote successful reproduction and enhance survival and growth of young. Although the proposal to warm dam releases is likely to affect all eight non-spawning mainstem aggregations, we believe the greatest chance of success is with the two largest existing mainstem aggregations: Stephen Aisle and Middle Granite Gorge (210-235 km downstream from Glen Canyon Dam). Assuming that habitat for adults is determined by availability of eddy complexes, we estimate that the $25-\mathrm{km}$ reach occupied by these two aggregations could support enough fish to meet the criteria of genetic viability and long-term demographic stability. The Middle Granite Gorge aggregation by itself appears to have a sufficient number of adults to minimize the effect of inbreeding and this aggregation receives downstream migrants from the LCR. Transfer or stocking of fish is not a feature of this alternative. The aggregations would be monitored for 5-10 years to evaluate success, based on the criteria for success.

Metapopulation Approach- This alternative acknowledges possible responses to warming by fish from most of the mainstem aggregations. The criteria of a second population would be met as the sum of proximate aggregations which exhibit some exchange of individuals and, hence, genetic linkage. This alternative was selected as the most feasible for meeting the goals of a second population.

Tributaries- Establishing a resident population of humpback chub in one or more tributaries other than the LCR is the third alternative of the plan. Two seasonally warmed tributaries, Havasu Creek and Shinumo Creek, were selected as most likely to meet the life history needs of the species. Introductions would be made in both streams in reaches above falls that prevent passage of non-native fishes upstream from the Colorado River. Of the two tributaries, Havasu Creek is preferred because it is more similar in hydrology and habitat to the currently occupied reach of the LCR. Shinumo Creek is recommended as an additional site because it appears to have appropriate water quality, low densities of non-native fish predators, and little human disturbance. These recommendations are preliminary; detailed assessments of 
habitat suitability and current fish communities in these two streams would have to be conducted before a final determination is made.

Since these tributaries do not currently support humpback chub, fish would be transferred from the LCR to initiate and possibly augment a population. We do not advocate use of a hatchery as a primary tool for establishing a new population of humpback chub in Grand Canyon because hatchery programs may result in reduced genetic viability in the target species. Instead, fish would be transferred from the LCR in totals of 500 YOY (50-100 mm total length) and 100 juveniles (100-250 mm) to each tributary annually for 3 consecutive years. If the numbers of young fish from the LCR are inadequate and if genetic variability can be assured, hatcheryreared fish would be used. These initial transfers would be experimental to determine the best release methods for survival and residence of fish. Positive results of these field experiments could lead to additional transfers of fish to these tributaries over a 3-year period. As a contingency, if transfer of LCR fish fails, hatchery-reared humpback chub would be released in large numbers over a 2-year period. Releasing young hatchery-reared fish into small earthen ponds in the lower Paria River or lower Bright Angel Creek may also be considered a contingency.

Tributary and Mainstem- This alternative considers establishing a population of fish in a tributary with free access to the mainstem. The new population would be expected to move to and from the mainstem in the same manner as the existing LCR population. No tributary in Grand Canyon meets the criteria for this alterative since those with suitable habitat have natural fish barriers near their outflows (Havasu Creek, Shinumo Creek); cold water temperatures (Tapeats Creek); support large populations of non-native fish predators, such as brown trout or rainbow trout (Bright Angel Creek); or lack sufficient flow volume and suitable habitat (Paria River, Kanab Creek).

Hatcheries and Genetic Considerations- We recommend initiating a hatchery program at the outset of this plan (1) as a refuge for unique genetic stocks if they are found to exist, (2) to develop a brood stock of humpback chub, and (3) to produce fish for supplementation, if necessary. Fish and/or gametes from at least the 30-Mile aggregation should be taken into a hatchery refuge in the first year of the plan for genetic assessment and to protect unique genetic material if it is found. These fish are behaviorally distinct from the LCR population and may be relicts of mainstem stocks. Genetic profiles should be developed to determine if significant genetic differences exist among any of the nine aggregations in Grand Canyon, and if transfer of fish among aggregations or use of hatchery products is feasible. If various genetic markers show no significant differences, a brood stock will be developed from progeny of LCR fish. Approximately 200 YOY fish would be captured and transferred from the LCR for rearing at a hatchery facility. Assuming losses from handling and mortality over time, 100-150 would be expected to reach adulthood at 4+ years of age (assume 50:50 gender ratio). Fish for supplementation (F1 progeny of wild fish) would be produced from paired matings of this brood stock to maximize genetic diversity. The numbers of males and females needed would be determined by assessing the genetic diversity of the population. Once established, this brood stock would be capable of producing approximately 200,000 young annually for stocking. 
Contingencies and Costs- This plan contains several alternative actions and contingencies to provide the maximum likelihood of success. If efforts to establish a mainstem population fail, the concept of a second population and the efficacy of the temperature control device on Glen Canyon Dam will have to be re-evaluated. If all efforts to establish a new population fail, the feasibility of establishing a second population of humpback chub in Grand Canyon will have to be re-evaluated. Total estimated cost of establishing a second population of humpback chub in Grand Canyon is \$4.7-\$6.2 million. This cost assumes that existing hatchery facilities will be used and that a new hatchery will not need to be constructed. Estimated costs are divided into four elements: mainstem monitoring, tributary stocking and monitoring, hatchery program, and genetic profiles. At the full development scenario for the program, the most expensive elements would be the mainstem monitoring $(\$ 2.0-\$ 2.5$ million) and the hatchery program $(\$ 2.0-$ \$2.4 million). Monitoring for a second population of humpback chub would be merged with monitoring programs for the temperature control device and experimental steady flows, both of which require mainstem monitoring of fish assemblages. To the extent possible, requirements of all three efforts should be satisfied with one monitoring program.

\section{Van Haverbeke, D.R. and L.G. Coggins, Jr. 2002. Stock assessment and fisheries monitoring activities in the Little Colorado River within Grand Canyon during 2001. Document number USFWS-AZFRO-FL-02-002. U.S. Fish and Wildlife Service, Flagstaff, Arizona. 82 pages.}

The GCMRC determined that a rigorous stock assessment program for the LCR was a priority for 2001 (USFWS 2001). As a result, the USFWS was contracted by the GCMRC to conduct stock assessment and monitoring activities in the LCR. A total of four monitoring trips were conducted during 2001: (1) 30 April to 11 May, (2) 4 to 15 June, (3) 1 to 12 October, and (4) 5 to 16 November. The primary goal of these trips was to obtain information for stock assessment of the humpback chub (Gila cypha; hereafter HBC). In addition, a secondary goal of these trips was to provide information for characterizing attributes of the natural history of the LCR fish community (e.g., species composition, sexual condition, parasites, etc.).

The four trips were used to conduct two mark-recapture experiments to estimate the abundance of HBC in the lower 14.2 kilometers of the LCR. The results of the spring markrecapture effort indicate that there were 3,510 ( $\mathrm{SE}=282) \mathrm{HBC} \geq 100 \mathrm{~mm}$ TL residing in the lower LCR during the spring of 2001. Of these fish, it is estimated that there were $1,470(\mathrm{SE}=240)$ $\mathrm{HBC} \geq 200 \mathrm{~mm}$ (4+ year old adults). The results of the fall effort indicate that there were 2,424 $(\mathrm{SE}=129) \mathrm{HBC} \geq 100 \mathrm{~mm}$ total length residing in the lower LCR during the fall of 2001 . The fall 2001 estimate was not significantly different from the fall 2000 effort (Coggins and Van Haverbeke 2001). 
Van Haverbeke, D.R. and R.L. Simmonds, Jr. 2004. Feasibility of developing a program to augment the population of humpback chub (Gila Cypha) in Grand Canyon. USFWSAZFRO-FL-03-007. U.S. Fish and Wildlife, Arizona Fishery Resources Office, Flagstaff.

This report summarizes findings by the U.S. Fish and Wildlife Service on the feasibility of performing three management actions to promote the conservation of the humpback chub (Gila cypha) in Grand Canyon.

First, we address the feasibility of establishing a captive broodstock program for humpback chub. Broodstock development is considered within the context of captive propagation policy as defined by the U.S. Fish and Wildlife Service and the National Oceanic and Atmospheric Association, and within the context of the scientific literature. Part of this policy requires that captive broodstock activities are based on the specific recommendations of recovery strategies identified in recovery plans whenever practical; a feature for which the current Recovery Goals for the species make no provision.

Establishment of a captive broodstock may serve as a genetic refugium, and the activity by itself poses no risk to the wild population. However release of captive propagated individuals into the wild poses serious biological risks, and as such should not be considered as a management strategy unless all other conservation measures fail. Potential biological risks involved with release of captive propagated fish into the wild include introgression, inbreeding depression, domestication, and potential to decrease the genetic effective population size of the wild population.

A captive broodstock program will require being preceded by completion of genetics studies being performed on humpback chub, development of a formal captive broodstock management plan, identification of a an adequate site equipped with a quarantine facility and capable of holding several thousand fish, development of a formal reintroduction plan, and commitment of significant long term funding. This document discusses basic questions in relation to broodstock development, and lists hatchery attributes required to raise broodstock fish. The humpback chub currently held at Willow Beach National Fish Hatchery may serve as a starting point for such an activity.

Second, we address the feasibility of establishing a program for captive grow-out of wild caught age- 0 humpback chub for release into the wild. Modeling suggests that if $\sim 960$ to 1,400 age- 0 humpback chub were captured per year from the Little Colorado River (LCR), and grown out to $\sim 170 \mathrm{~mm}$ before release, this should arrest further population decline and maintain the abundance of age-4+ humpback chub at levels estimated in 2000. Alternatively, the model predicts that if $\sim 4,300$ to 6,350 age- 0 fish were captured per year from the LCR, and grown out to $\sim 170 \mathrm{~mm}$ before release, this may achieve a positive increase in the abundance of age-4+ fish to the level estimated in 1990. These predicted numbers may need to be inflated, depending upon the rate of post-release mortality (i.e., they may need to be doubled). These predicted effects should be fully realized by the year 2020 . The primary biological risks associated with this activity appear to be related to ethological issues, such as lack of anti-predator responses or lack of ability to feed efficiently. In addition, depending on where the fish are released, a potential exists to effect density-dependant dynamics in the wild population. It is recommended that if this action is performed, and is to succeed, a naturalistic rearing facility and methodologies are used. Although the action, if properly performed, appears to pose no serious biological risks to the wild population, the action would not promote a self sustaining population, a feature required in 
the recovery criteria for the species. In addition, this management action would likely require significant long term effort and funding (years to decades) to achieve a sustained positive population response.

Third, we address the feasibility of augmenting the Grand Canyon population of humpback chub via translocation. Considered are 1) translocation of fish within the LCR, and 2) translocation of fish into other tributaries (Bright Angel, Shinumo, and Havasu creeks) in Grand Canyon.

Translocation of humpback chub within the LCR appears to offer potential for minor gain in the wild census population, and may significantly expand the current spawning range of the species, but may pose some potential for genetic risk to the main population in Grand Canyon. These risks are related to inbreeding and depression of genetic effective population size. Corrective measures to avoid these problems (should they occur) appear to be available, provided monitoring and funding is emplaced to detect them.

Translocation of humpback chub to other tributaries in Grand Canyon may offer potential for augmenting mainstem aggregations, and some potential exists for creation or significant expansion of downstream aggregations. Translocation efforts to these tributaries may need to be accompanied by sizeable predator removal efforts to effect a change. Genetic risks to the main population of humpback chub in Grand Canyon appear to be minor.

It is recommended that if any of these actions are pursued, they be carried out with the priorities in mind of: 1) posing least potential for genetic harm to the wild population, and 2) having the best potential for promoting a self-sustaining wild population. This suggests that translocations might be a first priority, followed by supplemental stocking of wild caught age- 0 fish, and as a last resort the release of captive propagated fish. Maintaining fish in captivity for refugium purposes poses no genetic risks to the wild population, however, the release into the wild of captive reared individuals does pose numerous genetic risks that need to be seriously evaluated.

Van Haverbeke, D.R., R.S. Rogers, M.V. Lauretta and K. Christensen. 2007. 2005 Grand Canyon Long-Term Fish Monitoring Colorado River, Diamond Creek to Lake Mead. 2005 Annual report to Grand Canyon Monitoring and Research Center from U.S. Fish and Wildlife Service, Hualapai Tribe and SWCA Environmental Consultants, Flagstaff, Arizona. Abstract excerpted from study introduction and discussion.

The purpose of the 2005 Annual Report for Grand Canyon long-term fish monitoring from Diamond Creek to Pearce Ferry is to provide analysis and discussion of 2005 (Trip ID: GC20050531) and previous monitoring efforts downstream of Diamond Creek. In addition, the 2005 annual report addresses the objectives and sub-objectives of the Diamond Creek to Pearce Ferry fish monitoring program. The global objectives of the program are to detect changes in fish abundance, distribution, and length structure in the Colorado River between Diamond Creek and Pearce Ferry, and, more specifically, to provide information on the distribution, movement, and sources of warm water non-native species that inhabit this portion of the Colorado River 
ecosystem. This information will be used in combination with other long-term monitoring data to elucidate best management of native and non-native fishes in the Colorado River, Grand Canyon.

In addition to the global objective, the sub-objectives of 2005 sampling efforts below Diamond Creek are to:

- Evaluate the utility of different fish sampling gears for detection of long-term trends in fish abundance, distribution, and movement.

- Evaluate tributaries downstream of Diamond Creek as potential future refugia for native fishes.

- Document presence of native and non-native fishes in selected tributaries downstream of Diamond Creek.

Monitoring efforts upriver of Diamond Creek rely on CPUE as an index to detect changes in the relative abundance of fish. The ability to estimate changes in the relative abundance of species and therefore to make inferences regarding population trends is related to the variation of the catch rates. Sampling strategies have been designed to detect a $20 \%$ change in CPUE over a 5-year period for native and nonnative species. A CV of 0.1 is necessary for this level of detection; however, sampling efforts in 2005 were unable to achieve this target for any species or gear type.

The methods employed during the trip were evaluated by comparing the catch rates and variances for each species and gear type. The CV for each species was compared across gear types, and the gear type with the lowest $\mathrm{CV}$ was assumed to have the greatest ability to estimate species' relative abundance and to monitor trends in the population. Electrofishing was the most effective method of sampling for the majority of species captured, including carp, fathead minnow, flannelmouth sucker, red shiner, smallmouth bass, speckled dace, and striped bass. Angling proved to be the most effective gear type for monitoring channel catfish. Hoop netting and seining were the only sampling methods that detected the presence of humpback chub; trammel netting was the only method that captured threadfin shad; and backpack electrofishing was the only method that detected the presence of mosquitofish. Long lines captured channel catfish and striped bass; however, comparison of variances indicates that angling is a much more effective method of monitoring channel catfish, and long lines are the least effective method of monitoring striped bass.

Power analyses were completed for several of the most common species captured by electrofishing, trammel netting, and hoop netting to assess the change in variance associated with increased sample sizes. These analyses indicate that current monitoring efforts with electrofishing are the most effective in monitoring carp, red shiner, and striped bass; however, current monitoring efforts are not likely to be able to estimate yearly changes in relative abundance with enough precision to assess the impact of management actions on the fish community in this reach of the Grand Canyon. Similarly, analyses of hoop and trammel netting data suggest that current monitoring efforts will not achieve target variance levels for any species. No power analysis was completed for seining because the sample size is limited by the 
number of backwaters present. No power analysis was conducted for angling since the angling effort is limited by sampling opportunistically while traveling downstream, and increased effort would impact the ability to sample with other gear types at designated sites. Furthermore, the current angling effort produced a relatively low variance for channel catfish $(\mathrm{CV}=0.18)$, which indicates that this method may be suitable for monitoring this species at current effort levels. A power analysis was not completed for backpack electrofishing because sampling with this gear type occurs opportunistically during travel between study sites. An analysis of long lines was not completed since other methods are shown to be more effective in monitoring species captured with this gear type.

Sampling during 2005 established an initial baseline of the species composition, age structure, and distribution of native and non-native species. A comparison of the fish community present in 2005 with historical capture information gives some interesting insight into the changes of the fish community over the last decade. During sampling trips from 1992 to 1995, Valdez et al. (1995) noted a dramatic change in the ichthyofauna downstream of Bridge Canyon (RM 235). Numbers of species increased from 9 to 20 below Bridge Canyon, and densities of non-native species increased dramatically. Included in the species captured below Bridge Canyon were: black crappie, black bullhead, bluegill, green sunfish, largemouth bass, walleye, plains killifish, and golden shiner, with bluegill and largemouth bass captures being particularly high in fall 1992. None of these species were identified during 2004 or 2005. Furthermore, smallmouth bass, a species not observed during the 1990s, was captured during 2005 sampling. Additionally, captures of fathead minnow, red shiner, and threadfin shad were noticeably higher during most of the 1990s sampling, particularly in fall 1992. Finally, the presence of age-0 flannelmouth sucker inhabiting mainstem habitat appears to have increased compared with studies during the 1990s.

Habitat characteristics in the Diamond Creek to Pearce Ferry reach were assessed. Because the elevation of Lake Mead has dropped over the past decade, aquatic habitat conditions have undergone extensive changes. In previous years, low-gradient braided channels characterized the stretch of river from Quartermaster to Dry Canyons, with numerous offchannel habitats (e.g., overflow channels, backwaters, etc.). On both of the 2004 and 2005 sampling trips, it was observed that the mainstem has undergone extensive downcutting and channelization. This was evident from Separation Canyon downstream, but the effects were particularly dramatic below Quartermaster. Many stands of cottonwood and willow that had previously been close to water level are now stranded several meters above the riverbed, which has been dramatically downcut into alluvial deposits. Some vegetative stands have recolonized at lower levels, while other higher stands have perished, leaving large, dead stands of trees. The river is now characterized in many places by high, collapsing, alluvial cut-banks.

As a result of these hydrological changes, the system has undergone a change from being somewhat lentic to riverine. Rather than river currents' abating near Separation Canyon (RM 240), as they have in former years, strong currents now flow well below Pearce Ferry (RM 280) and continue (albeit in a somewhat abated form) into Iceberg Canyon. A river channel and small rapid are now present near Pearce Ferry, where formerly a wide bay provided access to a boat ramp (now land-locked). The Lake Mead inflow area has shifted from the Pearce Ferry area to below Iceberg Canyon. Currents are channelized and moderately fast to Pearce Ferry and 
continue until the lake interface at the bottom of Iceberg Canyon. Substrates are largely sandy, and limited off-channel habitat exists (only a few small backwaters are present).

Species captured in tributaries included channel catfish, carp, flannelmouth sucker, mosquitofish, red shiner, and speckled dace, with the majority of the catch being composed of speckled dace and red shiner. The presence of YOY native species in the tributaries indicated that these streams might be suitable for native fish rearing. Large-bodied non-native species were observed within Spencer Creek; however, no adult native species were captured or observed within the tributaries.

Wieringa, M.J. and A.G. Morton. 1996. Hydropower, adaptive management and biodiversity: Environmental Management 20(6):831-840.

Adaptive management is a policy framework within which an iterative process of decision making is followed based on the observed responses to and effectiveness of previous decisions. The use of adaptive management allows science-based research and monitoring of natural resource and ecological community responses, in conjunction with societal values and goals, to guide decisions concerning man's activities. The adaptive management process has been proposed for application to hydropower operations at Glen Canyon Dam on the Colorado River, a situation that requires complex balancing of natural resources requirements and competing human uses. This example is representative of the general increase in public interest in the operation of hydropower facilities and possible effects on downstream natural resources and of the growing conflicts between uses and users of river-based resources. This paper describes the adaptive management process, using the Glen Canyon Dam example, and discusses ways to make the process work effectively in managing downstream natural resources and biodiversity.

Wyodoski, R.S., and E.J. Wick. 1998. Ecological value of floodplain habitats to razorback suckers in the upper Colorado River basin. Final report of U.S. Fish and Wildlife Service and U.S. National Park Service to Upper Colorado River Endangered Fish Recovery Program, Lakewood, Colorado.

This report is intended as a reference document for persons working on habitat enhancement projects related to the Recovery Implementation Program for Endangered Fishes in the Upper Colorado River Basin (Recovery Program). It summarizes the published literature on the ecological value of floodplains to riverine fish communities and relates this literature to reports that have been developed through the Recovery Program and management endeavors in the Lower Colorado River Basin. The report emphasizes the need for concurrent integration of all Recovery Program elements, specially habitat development and maintenance, management of nonnative fishes and sport fishing, and captive propagation. 


\subsection{MONITORING TECHNIQUES}

\section{Bestgen, K. R., D. W. Beyers, J. A. Rice, and G. B. Haines. 2006. Factors affecting recruitment of young Colorado pikeminnow: Synthesis of predation experiments, field studies, and individual-based modelling. 2006. Transactions of the American Fisheries Society 135:1722-1742.}

Predation experiments, field studies, and individual-based-model (IBM) simulations revealed factors that affected the survival and recruitment of early life stages of endangered Colorado pikeminnow Ptychocheilus lucius in the Green River basin, Utah and Colorado. Smallbodied, nonnative red shiners Cyprinella lutrensis attacked Colorado pikeminnow larvae an average of once per minute, and predation success approached 30\% in laboratory aquaria. Attack rate was also high in mesocosm experiments; turbidity and alternative prey reduced predation success. Distributions of hatching dates derived from otolith daily increment analysis showed that large cohorts of Colorado pikeminnow larvae that hatched in the Green River in early summer had low survival to autumn and that the few survivors were fast growing. Larvae hatched in midsummer or later had higher survival. Autumn juveniles grew $12-73 \%$ faster than summer juveniles, which suggested differential mortality of slow-growing fish. The IBM simulations integrated size-dependent predator-prey relationships, Colorado pikeminnow life history information, temperature-dependent pikeminnow growth, Green River predator sizestructure dynamics, seasonally variable Green River water temperatures, and turbidity and alternative prey availability effects; the simulations showed that red shiner predation interacting with environmental variables may significantly reduce age- 0 pikeminnow recruitment in autumn. Recruitment and growth patterns from simulations and field observations were consistent and suggested that the IBM is useful in evaluating management scenarios. Experiments, field studies, and predictive modeling provided consistent evidence that interacting effects of predation and environmental variables, including flow fluctuations, may structure intra-annual growth and recruitment patterns of age-0 Colorado pikeminnow. Flow management to benefit growth and survival of young pikeminnow, particularly early hatching ones, and reduced nonnative predator abundance in Green River backwaters may enhance the Colorado pikeminnow populations.

\section{Elsdon, T. S., B. K. Wells, S. E. Campana, B. M. Gillanders, C. M. Jones, K. E. Limburg, D. H. Secor, S. R. Thorrold, and B. D. Walther. 2008. Otolith chemistry to describe movements and life-history parameters of fishes: hypotheses, assumptions, limitations, and inferences. Oceanography and Marine Biology: an Annual Review 46: 297-330.}

In ever-increasing numbers, researchers wish to extract information based on chemical analyses from otoliths to determine movements and life-history patterns of fish. Such analyses make assumptions about chemical incorporation and interpretation that are beyond those that are important for stock discrimination studies, another common application. The authors aim to clarify the methods of determining fish movement based on natural and artificial otolith chemical tags and review current trends in determining movement using otolith chemistry, otolith sampling methods, and what influences otolith chemistry. Both spatial and temporal variability in water and otolith chemistries, which underpin the assumptions of several methods, are discussed. Five methods for determining movement and migration of fish are outlined: (1) estimates of movement and life-history traits of a single fish group, (2) assessing connectivity 
among groups using natural chemical tags in otoliths, (3) transgenerational marks to determine parentage and natal origins, (4) profile analysis to define life-history variation within a population and (5) profile analysis to describe movements through different environments. Within each of these methods, background information, specific hypotheses being tested and assumptions and limitations of each technique are provided. Finally, research directions required to fill current knowledge gaps and enhance the usefulness of otolith chemistry to determine fish movement are identified.

\section{Minckley, W.L. 1995. Translocation as a tool for conserving imperiled fishes: Experiences in western United States. Biological Conservation 72(2):297-309.}

Conservation efforts for imperiled fishes in western United States have included numerous translocations, either among natural localities or from nature to propagation facilities then back into nature. The goal has been to increase population size and dispersion while maintaining genetic diversity, thus increasing probability of survival Environmental laws governing translocations of fishes for conservation purposes involve complexities often equally as difficult to cope with as the biological problems of species' endangerment. Translocations perceived not to impinge on resource use or proprietary rights may be readily approved, while those which interfere with actual or projected development may meet strong resistance. Major biological considerations include the suitability and security of transplant sites (assurances that each meets a taxon's life-history and other requirements) and appropriateness of transplanted individuals (genetic' and population structure, sufficient numbers of individuals, freedom from disease, etc.) for establishing new populations. Success of translocation is difficult to define and major inadequacies exist in information exchange -- the latter can be remedied by publication in the peer-reviewed literature. It is anticipated that fish translocations and the technology required to support them will expand along with future needs and desires to re-establish native biotic elements in depleted communities and ecosystems.

\section{Paukert, C.P., D.L. Ward, P.J. Sponholtz and K.D. Hilwig. 2005. Effects of repeated hoopnetting and handling of bonytail chub. Journal of Freshwater Ecology 20:649-653.}

We evaluated the effects of repeated hoop net sampling and subsequent handling on the endangered bony tail chub (Gila elegans) to determine if these sampling techniques cause increased mortality or reduce fish growth. A total of 327 bonytail chub was tagged with PIT tags and placed in a 0.04 ha pond on July 2003. These fish were sampled with hoop nets during four, three-day sampling events, two in fall (September-October 2003) and two in spring (June 2004). Fish were measured and weighed with the time required to complete all steps for processing an individual fish being recorded. Individual fish were handled from one to eight times during the study, with $>95 \%$ recaptured five or fewer times. Fish that were recaptured multiple times grew less in length $(P<0.001)$ and weight $(P<0.001)$ than fish that were not recaptured. Fish recaptured up to five times grew only $12.8 \%$ of their initial weight compared to fish not recaptured which grew $29.7 \%$ of their initial weight. 
Pine, W. E., III, K. H. Pollock, J. E. Hightower, T. J. Kwak, J. A. Rice. 2003. A review of tagging methods for estimating fish population size and components of mortality. Fisheries 28:10-23.

Techniques to improve estimation of animal population size and mortality from tagging studies have received substantial attention from terrestrial biologists and statisticians during the last 20 years. However, these techniques have received little notice from fisheries biologists, despite the widespread applicability to fisheries research, the wide variety of tag types used in fisheries research (from traditional fin clips to telemetry tags), and the development of new computer software to assist with analyses. We present a brief review of population models based on recaptures, returns, or telemetry relocations of tagged fish that can be used to estimate population size, total mortality, and components of mortality (i.e., fishing and natural) that are frequently of interest to fisheries biologists. Recommended strategies include (1) use closed population models (e.g., Lincoln-Peterson) to estimate population size for short term studies where closure assumption can be met, (2) use the robust design to estimate population size for studies of longer duration, (3) use high-reward tags in conjunction with other methods of estimating reporting rate in tag-return studies, (4) combine a subset of telemetry tagged fish with either a high-reward tagging program or a traditional capture-recapture study to improve mortality estimates and understanding of mortality components, and (5) use pilot studies and simulation analyses to assess precision of estimated parameters to evaluate study feasibility. Incorporation of these improved techniques could lead to greater accuracy and precision of parameter estimates from tagging studies and thus to improved understanding and management of fish populations.

\section{Pollock, K. H., H. Jiang, H. and J. E. Hightower. 2004. Combining radio-telemetry and fisheries tagging models to estimate fishing and natural mortality rates. Transactions of the American Fisheries Society, 133:639-648.}

The traditional multiple-year tag return method is a fundamental approach to estimating fishing and natural mortality rates in fisheries. It can provide reliable and precise estimation of the parameters when the tag reporting rate, 1 , is known. However, it is often difficult to estimate $\lambda$ accurately. An additional disadvantage is that this method has to estimate natural mortality indirectly because natural deaths are not observable. Recently, fisheries biologists have begun to implement telemetry methods to estimate fishing and natural mortality. The advantage of a telemetry method is that it contains direct information about natural mortality and survival. A shortcoming is that there is no direct information on fishing deaths. In this paper, we combine the two methods, using direct information about both fishing and natural mortality to obtain more precise and effectively unbiased parameter estimates, including reporting rate estimates for the regular tags. Using simulation when the telemetry tag relocation probability equals 1 , we found that the relative standard error (RSE) of natural mortality estimates in the combination method is much improved relative to those of the tag return and telemetry methods. Annual fishing mortality estimates can also be estimated precisely. As expected, as the relocation probability of telemetry tags decreases the RSE of natural mortality and the other parameter estimates increases, but only slightly. Studies clearly should have relocation probabilities that are as high as possible. The tag reporting rate estimates are typically precisely estimated in the combined 
model. This is very important, as the tag reporting rate is not easy to estimate with other methods.

Ruppert, J.B. and R.T. Muth. 1997. Effects of electrofishing fields on captive juveniles of two endangered cyprinids. North American Journal of Fisheries Management 17:314-320.

We conducted laboratory experiments to address concerns about potential harmful effects of electrofishing on juvenile humpback chubs Gila cypha. Four types of square-wave pulsed DC in homogeneous fields were tested: $30 \mathrm{~Hz}(12 \%$ duty cycle), $60 \mathrm{~Hz}$ (24\% duty cycle), $80 \mathrm{~Hz}$ (40\% duty cycle), and a complex pulse train of three $240-\mathrm{Hz}, 2.6-\mathrm{ms}$ pulses delivered at $15 \mathrm{~Hz}$ (12\% duty cycle). We first determined peak-voltage gradients for each current sufficient to induce the electroshock responses of taxis, narcosis, or tetany in captive-reared early juvenile humpback chubs (49-96 mm total length) and bonytails G. elegans (46-79 mm). Bonytails were intended as surrogates for humpback chubs in most subsequent tests. However, mean voltagegradient response thresholds were 8-43\% lower for humpback chubs than for bonytails. We then exposed 30 humpback chubs for $10 \mathrm{~s}$ to the complex pulse current at mean tetanizing field intensity and 60 bonytails for $10 \mathrm{~s}$ to one of the four currents at mean field intensities required for each of the three responses. All humpback chubs and half of the bonytails were euthanized, frozen, and later examined for internal injuries; remaining bonytails were reared for $98 \mathrm{~d}$ to assess effects on growth and survival. No mortalities, external injuries, or vertebral injuries were observed in either species. Moderately severe spinal hemorrhages were found in $20 \%$ of shocked humpback chubs and $13 \%$ of shocked bonytails. Shocked humpback chubs had a significantly higher $(\mathrm{P} \leq 0.05)$ incidence of injuries than unshocked control fish. The number of injured bonytails was significantly higher $(\mathrm{P} \leq 0.05)$ than controls in the $80-\mathrm{Hz}$ taxis treatment and the 30-, 60-, and 80-Hz tetany treatments. Differences in the number of shocked bonytails with injuries among currents at each response threshold and among response thresholds for each current were not significant. No significant differences in injury rates were detected between humpback chubs and bonytails exposed to the complex pulse current at tetanizing field intensities. Growth of bonytails was not affected by shocking. Results suggest that electrofishing could cause spinal hemorrhages in some early juvenile humpback chubs but does not affect short-term growth or survival. Studies are needed to evaluate the significance of electrofishing injuries in humpback chubs at the population level.

\section{Simpfendorfer, C. A., M. R. Heupel, and A. B Collins. 2008. Variation in the performance of acoustic receivers and its implication for positioning algorithms in a riverine setting. Canadian Journal of Fisheries and Aquatic Sciences 65:482-492.}

The performance of an array of data-logging single frequency acoustic receivers in the Caloosahatchee River (Florida, USA) was examined and the results incorporated into a positioning algorithm for animals tracked within the system. The mean code detection efficiency across all individual receivers and all download periods was 0.414 detections per synchronization code. On average, the code rejection coefficient was approximately $4 \%$, indicating that it was only a minor factor in reducing code detection efficiency. There were significant performance differences between stations and download periods, but no interaction between these two factors for all three metrics. Code detection efficiency, the rejection coefficient, and the noise quotient all showed significant variations with distance from the river 
mouth and time since deployment. Comparison of position estimates with and without efficiency produced small differences for bull sharks (Carcharhinus leucas) and cownose rays (Rhinoptera bonasus) monitored via this system. Root mean square errors were higher for cownose rays $(48 \mathrm{~m})$ than for bull sharks $(23 \mathrm{~m})$. Mean differences for individuals were always slightly downstream because of the increasing code detection efficiency of upriver receivers. The results of this comparison indicated that the inclusion of code detection efficiency did not significantly improve the results of the positioning algorithm.

\section{Stevenson, D.K. and Campana, S.E. (Editors). 1992. Otolith microstructure examination and analysis. Canadian Special Publication of Fisheries and Aquatic Sciences 117.}

The field of otolith microstructure research has experienced phenomenal growth since the early 1970's and now forms the basis for hundreds of studies of early life history, age, growth, recruitment, migration, mortality, and stock structure. While the field continues to grow and evolve, there is no question that otolith microstructure examination is now an important and accepted technology in fisheries biology.

This book represents the first effort to compile and summarize the many techniques and procedures associated with studies of otolith microstructure. The complete sequence of events, from sample collection to data analysis, is covered comprehensively, so as to be applicable to most species and situations. The various chapters include both published and unpublished procedures, making the book valuable to beginning and experienced investigators alike.

Valdez, R.A. 1993. Use of scales to determine emigration of juvenile humpback chub Gila cypha from the Little Colorado River in Grand Canyon, Arizona. Proceedings of the Desert Fishes Council 24:61.

Scales from age groups 0, I, and II humpback chub Gila cypha, examined microscopically, revealed marks or checks believed to represent emigration from spawning and nursery areas in the Little Colorado River to the mainstem Colorado River in Grand Canyon. The checks were identified by closely- spaced and incomplete circular rings believed to be formed when individual fish descended from LCR temperatures of about $20 \mathrm{C}$ to mainstem temperatures of $10 \mathrm{C}$. Aging was coordinated with length- frequency histograms. Determining timing and size of descent by young- and adult- humpback chub may reveal size- specific survival of emigrating chub.

\subsection{COMPUTER MODELING}

\section{Allen, E.J., J.M. Harris and L.J.S. Allen. 1992. Persistence-time models for use in viability analyses of vanishing species. Journal of Theoretical Biology 155: 33-53.}

Mathematical models can provide guidance as to the size and number of wildlife refuges required for long-term persistence of various species. Simple mathematical models for rough estimation of persistence time have been developed, but efficient algorithms for calculating persistence times using these models are unavailable. In addition, the mathematical relations 
required between critical parameters in the models have not been thoroughly studied. In this investigation, an efficient algorithm for implementing the models is developed and several different relations among the parameters in the models are tested against mammalian persistence data available for montane habitat of the south-western U.S.A. Furthermore, these models are compared with a new persistence-time model which is described in the present investigation.

Baedecker, M.J. and L.C. Friedman, eds. 2000. Modeling and experimental flooding in the Grand Canyon. Pages 10-11. In M.J. Baedecker and L.C. Friedman, eds. U.S. Geological Survey National Research Program in the Hydrologic Sciences. U.S. Geological Survey Circular 1195.

The USGS has a strong commitment to understand and predict flow and sediment transport in rivers, including the impacts of dams, the processes responsible for building and eroding sand bars, and the manner in which sediment is supplied to the river systems. The knowledge gained from these studies is being applied to a problem on the Colorado River in Grand Canyon National Park. In 1963, Glen Canyon Dam was constructed about 24 kilometers upstream from the Park boundary at Lees Ferry, which is the launch point for boating trips through the Grand Canyon. Prior to the dam, the river's floodwaters prevented growth of vegetation on the channel banks, deposited sand bars, and eroded boulder deposits in the main channel left by flash floods in tributaries. After the dam was completed and most large floods were controlled, a riparian zone developed along the river, marshes were formed, sand bars eroded, and boulders were left in the main channel. By the mid-1970s, river runners expressed concern about eroding sand bars that were used as campsites. In 1978, the USFWS concluded that Glen Canyon Dam and its operation were jeopardizing an endangered fish, the humpback chub (Gila cypha). These findings led the U.S. Bureau of Reclamation to establish the Glen Canyon Environmental Studies, which organized and supported research in Grand Canyon starting in 1983.

Beyers, D.W., J.A. Rice. and W.H. Clements. 1999. Evaluating biological significance of chemical exposure to fish using a bioenergetics-based stressor-response model. Canadian Journal of Fisheries and Aquatic Sciences 56:823-829.

We demonstrate how contaminant exposure-response relationships can be integrated with a bioenergetics model to estimate the biological significance of sublethal exposure under fluctuating environmental conditions. The integrated bioenergetics-based stressor-response model (SRM) was evaluated by comparing observed and predicted growth of largemouth bass (Micropterus salmoides) exposed to several dieldrin concentrations and by conducting sensitivity analyses. Predictions of the SRM suggest that energetic effects of exposure of largemouth bass to ambient concentrations of dieldrin in lakes at the Rocky Mountain Arsenal National Wildife Refuge are not biologically significant because the amount of energy lost by resident fish is small compared with variation in food consumption. Furthermore, influence of dieldrin exposure is small compared with the effects of a natural stressor like water temperature. The SRM provides a general framework for integrating laboratory-derived exposure-response relationships with ecological processes to determine the biological significance of multiple stressors in a natural environment. Comparisons of relative effects of anthropogenic and natural stressors can be used to assess potential costs and benefits of alternative ecosystem management strategies. 
Grand, T., C.S.F. Railsback, J.W. Hayse and K.E. LaGory. 2006. A physical habitat model for predicting the effects of flow fluctuations in nursery habitats of the endangered Colorado pikeminnow Ptychocheilus lucius. River Research and Applications 22:11251142.

Larval and juvenile Colorado pikeminnow (Ptychocheilus lucius) use shallow, lowvelocity, channel-margin areas (backwaters) as nursery habitats. It is hypothesized that withinday flow fluctuations caused by hydropower operations can directly affect the suitability of such habitats by altering water temperature and habitat geometry. Despite the importance of backwaters to juvenile fishes, there is a lack of established approaches for modeling how river management affects these habitats. Here, we describe a physical habitat model that predicts the effects of mainstem flow variation on backwater temperature, geometry and invertebrate availability. We specifically modeled these effects on habitat in a portion of the Green River in Utah below Flaming Gorge Dam.

The overall model combines a cell-based model of backwater geometry, a pond-based temperature model and a model of invertebrate production. Results from a series of simulations suggest that the most important biological effects of within-day flow fluctuations are likely to be those associated with the availability of invertebrate prey including (1) minimum wetted area, (2) the proportion of the backwater's volume exchanged with the mainstem, and, to a lesser degree, (3) backwater temperature. Taken together, such effects could have important implications for the growth and survival of juvenile fish when flow fluctuations are sufficiently large.

\section{Harvey, M.D., R.A. Mussetter and E.J. Wick. 1993. A physical process-biological response model for spawning habitat formation for the endangered Colorado squawfish. Rivers 4:114-131.}

The Colorado squawfish (Ptychocheilus lucius), a federally listed endangered species, spawns at a limited number of sites within the lower Yampa River, Colorado, during the recessional limb of the annual snowmelt hydrograph. A three-level, physical process-biological response model for spawning habitat formation was developed from field measurements, hydraulic modeling (HEC-2), and analysis of a known spawning bar at RM 16.5. Sediment deposition and bar formation occur at discharges greater than 10,000 cfs, a discharge at which downstream hydraulic controls cause backwater and reduced transport capacity of the flows. Spawning habitat is formed by bar dissection and erosion at a range of flows between 400 and $5,000 \mathrm{cfs}$ when the local hydraulic energy is greatest because of reduced tailwater downstream, and sediment delivery to the chute channels is reduced by deposition in an upstream pool. The process-response model appears to be validated by fish-capture data at this, and another spawning bar at RM 18.5, on the Yampa River during both the 1991 and 1992 runoff seasons. 
Korman, J, S.M. Wiele and M. Torizzo. 2004. Modeling effects of discharge on habitat quality and dispersal of juvenile humpback chub (Gila cypha) in the Colorado River, Grand Canyon. Regulated Rivers 20:379-400.

A two-dimensional hydrodynamic model was applied to seven study reaches in the Colorado River within Grand Canyon to examine how operation of Glen Canyon Dam has affected availability of suitable shoreline habitat and dispersal of juvenile humpback chub (Gila cypha). Suitable shoreline habitat typically declined with increasing discharges above 226$425 \mathrm{~m}^{3} / \mathrm{s}$, although the response varied among modeled reaches and was strongly dependent on local morphology. The area of suitable shoreline habitat over cover types that are preferred by juvenile humpback chub, however, stayed constant, and in some reaches, actually increased with discharge. In general, changes in discharge caused by impoundment tended to decrease availability of suitable shoreline habitat from September to February, but increased habitat availability in spring (May-June). Hourly variation in discharge from Glen Canyon Dam substantially reduced the amount of persistent shoreline habitat at all reaches. Changes in suitable shoreline habitat with discharge were shown to potentially bias historical catch per unit effort indices of native fish abundance up to fourfold. Physical retention of randomly placed particles simulating the movement of juvenile humpback chub in the study reaches tended to decline with increasing discharge, but the pattern varied considerably due to differences in the local morphology among reaches and the type of swimming behavior modeled. Implications of these results to current hypotheses about the effects of Glen Canyon Dam on juvenile humpback chub survival in the mainstem Colorado River are discussed.

Mankin, J.B., R.H. Gardner, R.V. O’Neill and J.H. Carney. 1981. A comparison of sensitvity analysis and error analysis based on a stream ecosystem model. Ecological Modelling 12(3):173-190.

Changes in the water level in the Colorado River as a result of manipulations at Glen Canyon Dam are discussed. These uneven releases of water through the Dam cause man-made tides to surge along the banks of the river, disrupting the naturally alternating erosion and redeposition of silt, enabling exotic species of plants to flourish on the banks while killing others that have been established there for years, eliminating some populations of birds, and allowing fish and eggs to be stranded far from the water when the surge has gone by. Beaches are washed away. The shallowness of the water at times prohibits groups of white water enthusiasts from completing their trips. Plans are in the works for making changes which will increase the destruction already being seen. These plans are being laid in supposed answer to increasing electricity needs, but opponents of the plans suggest that existing power plants could be used for far less money than will be required to make the changes, and without doing further environmental damage.

Peterseni, J.H., D.L. Deangelas and C.P. Paukert. 2008. An overview of methods for developing bioenergetic and life history models for rare and endangered species. Transactions of the American Fisheries Society 137(1):244-253.

Many fish species are at risk to some degree, and conservation efforts are planned or underway to preserve sensitive populations. For many imperiled species, models could serve as 
useful tools for researchers and managers as they seek to understand individual growth, quantify predator-prey dynamics, and identify critical sources of mortality. Development and application of models for rare species however, has been constrained by small population sizes, difficulty in obtaining sampling permits, limited opportunities for funding, and regulations on how endangered species can be used in laboratory studies. Bioenergetic and life history models should help with endangered species-recovery planning since these types of models have been used successfully in the last 25 years to address management problems for many commercially and recreationally important fish species. In this paper we discuss five approaches to developing models and parameters for rare species. Borrowing model functions and parameters from related species is simple, but uncorroborated results can be misleading. Directly estimating parameters with laboratory studies may be possible for rare species that have locally abundant populations. Monte Carlo filtering can be used to estimate several parameters by means of performing simple laboratory growth experiments to first determine test criteria. Pattern-oriented modeling (POM) is a new and developing field of research that uses field-observed patterns to build, test, and parameterize models, Models developed using the POM approach are closely linked to field data, produce testable hypotheses, and require a close working relationship between modelers and empiricists. Artificial evolution in individual-based models can be used to gain insight into adaptive behaviors for poorly understood species and thus can fill in knowledge gaps.

\section{Peterson, J.H. and C.P. Paukert. 2005. Development of a bioenergetics model for humpback chub and evaluation of water temperature changes in the Grand Canyon, Colorado River. Transactions of the American Fisheries Society 134:960-974.}

The construction of Glen Canyon Dam above the Grand Canyon (Arizona) has reduced the water temperature in the Colorado River and altered the growth rate and feeding patterns of the federally endangered humpback chub Gila cypha. A bioenergetics model for humpback chub was developed and used to examine how warmer water temperatures in the lower Colorado River (achieved through a temperature control device [TCD] at Glen Canyon Dam) might influence their growth rate and food requirements. Parameter values for humpback chub were developed by Monte Carlo filtering and fitting to laboratory growth. Parameter bounds were established from the literature for Gila species, random parameter sets were selected within these bounds, and the growth of modeled humpback chub was compared with criteria from a laboratory growth experiment at $24^{\circ} \mathrm{C}$. This method of parameter estimation could be applied to other imperiled fishes where physiological studies are impractical. Final parameter values were corroborated by comparison with the growth rates of humpback chub from independent field and laboratory studies. Simulations indicated that increasing water temperatures from approximately $9^{\circ} \mathrm{C}$ to $16^{\circ} \mathrm{C}$ during summer and fall, the change expected from the TCD, may have a minimal effect on humpback chub growth rate unless food availability also increases with temperature. To evaluate the effects of increased temperatures on humpback chub in the lower Colorado River, it will be essential to monitor their growth rate, the invertebrate community, and the predators of humpback chub, which are also influenced by temperature changes. Bioenergetics models for humpback chub and their predators should be helpful tools for identifying potential scenarios and evaluating the complex interactions resulting from a TCD. 
Turner, D.S. and M.D. List. 2007. Habitat mapping and conservation analysis to identify critical streams for Arizona's native fish. Aquatic Conservation: Marine and Freshwater Ecosystems 17:737-748.

1) Arizona's native fish species are among the most imperiled fauna in North America. Knowing the current distribution of native fish and their habitat is critical to their management and conservation, but the last detailed mapping effort was more than 30 years ago and predated computer mapping techniques.

2) Current distribution of 34 native fish species was modeled by identifying perennial stream segments for which species presence had been documented. A composite of these single-species maps displays a pattern of species richness that can inform conservation, especially when overlaid with maps of management status or invasive species.

3) The map overlays suggest that conservation priorities should include Eagle Creek, the Verde River and its tributaries, Aravaipa Canyon, the Virgin River, and Black Draw, which together hold $63 \%$ of native fish species. Of the 32 streams which support 5 or more native species, 28 have at least one non-native fish species, indicating that a more aggressive program of removing non-natives may be critical to maintaining those native populations.

4) The U.S. Forest Service and Native American tribes administer the majority of occupied stream habitat (30 and $27 \%$, respectively). While private lands hold the third-highest amount of occupied habitat (19\%), they control streams occupied by the greatest total number of native species (30). Conservationists should work more with private land owners, while also coordinating efforts with the U.S. Forest Service and North American tribes.

Valdez, R.A. and D.W. Speas. 2007. A risk assessment model to evaluate risks and benefits to aquatic resources from a selective withdrawal structure on Glen Canyon Dam. Bureau of Reclamation, Salt Lake City, Utah.

A risk assessment was conducted to help evaluate possible responses by aquatic resources in Grand Canyon to a selective withdrawal structure (SWS) on Glen Canyon Dam. A mathematical model was used as a tool to quantify risks and benefits to fish, fish parasites, zooplankton, and macroinvertebrates from water temperature changes resulting from modification of 2 of the 8 power release units on the dam. All taxa present or with potential to access the area were inventoried for each of six regions, including lower Lake Powell, Glen Canyon Dam to Paria River, Paria River to Little Colorado River (LCR), LCR to Bridge Canyon, and Bridge Canyon to Pearce Ferry. Base scores were developed that described the presence or absence of each taxon and their position in the community for each region. Median, minimum, and maximum predicted temperatures were obtained from Bureau of Reclamation's GEMSS model for No Action (1990-2005) and a 2-unit SWS. Temperature degree days (TDD) were computed for spawning, incubation, and growth for fish and life history requirements for other taxa and compared with the predicted water temperatures to determine if the temperature change would benefit particular taxa. The TDDs were added to the base scores to derive a score for each 
taxon; higher scores indicate greater benefit to a taxon. Scores were calibrated for fish by comparing modeled fish composition with composition from four prior surveys reflecting predam temperatures (1958), cold temperatures during high flow fluctuations (1977-78), modified low fluctuating flows (1990-94), and low lake levels with warm releases (2003-04). Preliminary results show benefits to all native fishes, but also benefits to many nonnative fish species that may compete with or prey upon native species. Preliminary results also show more suitable conditions for warm-water fish parasites. The effect of cooling in the Lake Powell forebay is small on zooplankton populations, but primary producers and macroinvertebrates throughout Grand Canyon are likely to be affected by warmer water temperatures. We emphasize that these results are preliminary and that the primary intent of this document is to provide a documentation of a risk assessment model that could be used as a tool to evaluate effects of a SWS on aquatic resources in the Grand Canyon area.

\section{Walters, C., J. Korman, l.E. Stevens and B. Gold. 2000. Ecosystem modelling for evaluation of adaptive management policies in the Grand Canyon. Conservation Ecology 4(2):24.}

An Adaptive Environmental Assessment and Management workshop process was used to assist Grand Canyon scientists and managers in developing conceptual and simulation models for the Colorado ecosystem affected by Glen Canyon Dam. This model examines ecosystem variables and processes at multiple scales in space and time, ranging from feet and hours for benthic algal response to diurnal flow changes, to reaches and decades for sediment storage and dynamics of long-lived native fish species. Its aim is to help screen policy options ranging from changes in hourly variation in flow allowed from Glen Canyon Dam, to major structural changes for restoration of more natural temperature regimes. It appears that we can make fairly accurate predictions about some components of ecosystem response to policy change (e.g., autochthonous primary production, insect communities, riparian vegetation, rainbow trout population), but we are moderately or grossly uncertain about others (e.g., long-term sediment storage, response of native and non-native fishes to physical habitat restoration). Further, we do not believe that existing monitoring programs are adequate to detect responses of native fishes or vegetation to anything short of gross habitat changes. Some experimental manipulations (such as controlled floods for beach/habitat-building) should proceed, but most should await development of better monitoring programs and sound temporal baseline information from those programs.

\section{White, M.A., J.C. Schmidt and D.J. Topping, 2005. Application of wavelet analysis for monitoring the hydrologic effects of dam operations: Glen Canyon Dam and the Colorado River at Lees Ferry, Arizona. River Research and Applications 21(5):551-565.}

Wavelet analysis is a powerful tool with which to analyze the hydrologic effects of dam construction and operation on river systems. Using continuous records of instantaneous discharge from the Lees Ferry gauging station and records of daily mean discharge from upstream tributaries, we conducted wavelet analyses of the hydrologic structure of the Colorado River in Grand Canyon. The wavelet power spectrum (WPS) of daily mean discharge provided a highly compressed and integrative picture of the post-dam elimination of pronounced annual and sub-annual flow features. The WPS of the continuous record showed the influence of diurnal and weekly power generation cycles, shifts in discharge management, and the 1996 experimental 
flood in the post-dam period. Normalization of the WPS by local wavelet spectra revealed the fine structure of modulation in discharge scale and amplitude and provides an extremely efficient tool with which to assess the relationships among hydrologic cycles and ecological and geomorphic systems. We extended our analysis to sections of the Snake River and showed how wavelet analysis can be used as a data mining technique. The wavelet approach is an especially promising tool with which to assess dam operation in less well-studied regions and to evaluate management attempts to reconstruct desired flow characteristics.

Wiele, S.M. 1998. Modeling of flood-deposited sand distributions in a reach of the Colorado River below the Little Colorado River, Grand Canyon, Arizona. U.S. Geological Survey Water-Resources Investigations Report.

A release from Glen Canyon Dam during March- April 1996 was designed to test the effectiveness with which the riparian environment could be renewed with discharges greatly in excess of the normal powerplant-restricted maximum. Of primary concern was the rebuilding of sand deposits along the channel sides that are important to the flora and fauna along the river corridor and that provide the only camp sites for riverside visitors of the Grand Canyon National Park. Analysis of the depositional processes with a model of flow, sand transport, and bed evolution shows that the sand deposits formed along the channel sides early during the high flow were affected only slightly by the decline in suspended-sand concentrations over the course of the controlled flood. Modeling results suggest that the removal of a large sand deposit over several hours was not a response to declining suspended-sand concentrations. Comparisons of the controlled-flood deposits with deposits formed during a flood in January 1993 on the Little Colorado River that contributed sufficient sand to raise the suspended-sand concentrations to pre-dam levels in the main stem show that the depositional pattern as well as the magnitude is strongly influenced by the suspended- sand concentrations.

\section{Wolock, D.M. and G.J. McCabe. 1999. Estimates of runoff using water-balance and atmospheric General Circulation Models. Journal of the American Water Resources Association 35: 1341-1350.}

The effects of potential climate change on mean annual runoff in the conterminous United States (U.S.) are examined using a simple water-balance model and output from two atmospheric general circulation models (GCMs). The two GCMs are from the Canadian Centre for Climate Prediction and Analysis (CCC) and the Hadley Centre for Climate Prediction and Research (HAD). In general, the CCC GCM climate results in decreases in runoff for the conterminous U.S, and the HAD GCM climate produces increases in runoff. These estimated changes in runoff primarily are the result of estimated changes in precipitation. The changes in mean annual runoff, however, mostly are smaller than the decade-to-decade variability in GCMbased mean annual runoff and errors in GCM-based runoff. The differences in simulated runoff between the two GCMs, together with decade-to-decade variability and errors in GCM-based runoff, cause the estimates of changes in runoff to be uncertain and unreliable. 
Wright, S.A., C.R. Anderson and N. Voichick. 2009. A simplified water temperature model for the Colorado River below Glen Canyon Dam. River Research and Applications 25(6):675-686.

Glen Canyon Dam, located on the Colorado River in northern Arizona, has affected the physical, biological and cultural resources of the river downstream in Grand Canyon. One of the impacts to the downstream physical environment that has important implications for the aquatic ecosystem is the transformation of the thermal regime from highly variable seasonally to relatively constant year-round, owing to hypolimnetic releases from the upstream reservoir, Lake Powell. Because of the perceived impacts on the downstream aquatic ecosystem and native fish communities, the Glen Canyon Dam Adaptive Management Program has considered modifications to flow releases and release temperatures designed to increase downstream temperatures. Here, we present a new model of monthly average water temperatures below Glen Canyon Dam designed for first-order, relatively simple evaluation of various alternative dam operations. The model is based on a simplified heat-exchange equation, and model parameters are estimated empirically. The model predicts monthly average temperatures at locations up to $421 \mathrm{~km}$ downstream from the dam with average absolute errors less than 0.5 DGC for the dataset considered. The modeling approach used here may also prove useful for other systems, particularly below large dams where release temperatures are substantially out of equilibrium with meteorological conditions. We also present some examples of how the model can be used to evaluate scenarios for the operation of Glen Canyon Dam.

\subsection{SUPPORTING ARTICLES}

\section{Allendorf, F.W., D. Bayles, D.L. Bottom, K.P. Currens, C.A. Frissell, D. Hankin, J.A. Lichatowich, W. Nehlsen, P.C. Trotter and T.H. Williams. 1997. Prioritizing Pacific salmon stocks for conservation. Conservation Biology 11: 140-152.}

Over 300 native stocks of Pacific salmon, steelhead, and coastal cutthroat trout (Oncorhynchus spp.) are at risk of extinction in the Pacific Northwest. With only limited resources available for conservation and recovery, prioritization of these stocks may become necessary if meaningful measures are to be implemented. We propose criteria by which prioritization may be guided. First, we rank stocks for risk of extinction, either by population viability analysis or by a set of surrogate measures. Then we rank stocks for biological consequences of extinction, using sets of questions designed to establish the genetic and evolutionary consequences and the ecological consequences if a stock were to become extinct. Together, these rankings al- low stocks to be prioritized for a range of possible actions, with those stocks at highest risk and bearing the greatest biological consequences of extinction receiving attention first. Application of the prioritization process to 20 Pacific anadromous salmonid stocks worked as intended, although data limitations are considerable. The process is most likely to work successfully when applied to many stocks on which data exist, when several experts carry out the prioritization, and when the results are peer reviewed. 


\section{Ehrlich, P.R. and D.D. Murphy. 1987. Conservation lessons from long-term studies of checkerspot butterflies. Conservation Biology 1: 122-131.}

Long-term studies of checkerspot butterflies (Euphydras spp.) are used to draw conservation lessons with implications for the design and management of reserves for invertebrates. We discuss: 1) The importance of determining the structure of and patterns of mating within demographic units; 2) The lack of congruence between migration and gene flow; 3) The crucial role of habitat diversity in the protection of species which otherwise require only small areas of habitat; 4) The importance of identifying and preserving "reservoir" populations within metapopulations; 5) The necessity of identifying subtle habitat requirements; 6)The key role of environmental stochasticity in the extinction of small population; and 7) The difficulty of protecting metapopulations and of introducing populations into "empty" habitat patches. We conclude, among other things, that the size of reserves required to preserve herbivorous insects is often underestimated; that a " minimum viable metapopulation" approach to their conservation may be needed; that long-term studies of the biology of populations of sample invertebrates groups would greatly aid conservation biologists; and that more effort is needed to inform the public and decision makers about the need to conserve population as well as species.

\section{Hamman, R.L. 1987. Survival of razorback sucker cultured in earthen ponds. Progressive Fish-Culturist 49:187-189.}

Razorback sucker (Xyrauchen texanus) swim-up fry and fingerlings were successfully reared in earthen ponds at the Dexter, New Mexico, National Fish Hatchery. Swim-up fry (71,000/lb) were stocked in 0.34-1.08-acre ponds at the rate of 101,000-109,000 fry/acre; subfingerling fish (724/lb) were stocked in 0.86-0.98-acre ponds at the rate of 51,000-58,000 fingerlings/acre; fingerling fish (158/lb) were stocked in 0.98 -acre ponds at the rate of 26,00027,000 fingerlings/acre. Ponds were treated initially with organic and inorganic fertilizers, in addition to periodic addition of alfalfa pellets. The swim-up fry were supplementally fed a formulated trout feed. Survival ranged from 87.8 to $98.6 \%$ for swim-up fry and 92.7 to $95.8 \%$ for subfingerlings and averaged $96.2 \%$ for fingerlings.

Muth, R.T. and S.M. Meismer. 1995. Marking otoliths of razorback sucker embryos and larvae with fluorescent chemicals. Southwestern Naturalist 40:241-244.

Laboratory experiments were conducted to determine optimum treatments of alizarin complexone (ALC) or tetracycline hydrochloride (TC) for marking otoliths in late embryos or recently hatched larvae of razorback sucker (Xyrauchen texanus) through immersion in solutions of these chemicals. Once deposited in bone, ALC fluoresces red and TC fluoresces yellow when illuminated by ultraviolet light. Fish survival and mark quality were evaluated in different ALC or TC concentrations and immersion durations for (1) single treatment of embryos with either chemical, producing single marks and (2) single treatment of larvae with each chemical, producing double marks. Otoliths from all larvae in the single-mark or double-mark experiments had fluorescent marks. Embryo and larval survival decreased and mark quality increased as chemical concentrations and immersion durations increased. For best fish survival and mark quality, recommended ALC treatments are 12 to $30 \mathrm{~h}$ in 150 to $350 \mathrm{mg} / \mathrm{L}$ for embryos and 6 to $18 \mathrm{~h}$ in 12.5 to $50 \mathrm{mg} / \mathrm{L}$ for larvae. Recommended TC treatments are 18 to $30 \mathrm{~h}$ in 150 to 
$350 \mathrm{mg} / \mathrm{L}$ for embryos and 6 to $18 \mathrm{~h}$ in 150 to $350 \mathrm{mg} / \mathrm{L}$ for larvae. Rapid mass marking of otoliths in razorback sucker embryos or larvae has great potential for use in stock identification, assessment of stocking success, and life-history studies.

\section{Snyder, D.E. and S.M. Meismer. 1997. Effectiveness of light traps for capture and retention of larval and early juvenile Xyrauchen texanus and larval Ptychocheilus lucius and Gila elegans. Final report of Colorado State University Larval Fish Laboratory to U.S. National Park Service Cooperative Parks Study Unit, Fort Collins, Colorado.}

Light traps are used to capture the larvae of many fishes. To assess the potential of floating, low-intensity, quatrefoil-style light traps for capture of the larvae or early juveniles of endangered Colorado River basin fishes, provide guidelines for trap use, and better interpret field results, we conducted experiments in 1.2-m diameter tanks under light-excluding tents. For each capture trial, 50 laboratory-reared larvae or (for razorback sucker Xyrauchen texanus only) 25 juveniles were released into a tank and allowed to acclimate through simulated daylight, dusk, and full darkness before traps were set for 1,4 , or (for razorback sucker larvae only) $8 \mathrm{~h}$. In corresponding retention experiments, fish were placed in trap catch basins and allowed to calm before traps were placed in tanks. Mean capture percentages (MCPs) for larvae in 1 and 4-h trials were 13 to $36 \%$ for razorback sucker ( 33 to $44 \%$ in 8 -h trials), 3 to $15 \%$ for Colorado squawfish Ptychocheilus lucius, and 5 to $30 \%$ for bonytail Gila elegans. MCPs usually, but not always, increased with set duration for larvae. For early juvenile razorback suckers, maximum MCP, $51 \%$, occurred within $1 \mathrm{~h}$. Once in the trap, most larvae stayed; mean retention percentages (MRPs) were 85 to $99 \%$ for razorback sucker larvae in 1, 4, and 8 -h trials, and 95 to $99 \%$ for Colorado squawfish larvae in 1 and 4-h trials (bonytails were not tested for retention). Retention of juvenile razorback suckers was notably less with MRPs of 65 to $73 \%$. For fish in close proximity to the trap, these results suggest that the light traps tested are at least moderately effective in clear water for the capture and retention of razorback sucker and bonytail larvae and even better for the capture of early juvenile razorback suckers.

Additional experiments were conducted with razorback suckers. With trap lights off, few or no fish were captured and MRPs were lower, strikingly so for protolarvae with only $16 \%$ retention in 4-h trials. Light is critical for the effective capture and retention of fish larvae. Under simulated dusk, 1-h MCPs were lower than during night trials, but not significantly different. Setting traps prior to night fall might increase the ultimate number of fish collected but reduce catch per unit time. Under simulated dawn, 1-h MRPs dropped to $69 \%$ for protolarvae but remained $99 \%$ for postflexion mesolarvae. Traps should probably be retrieved before dawn to avoid significant losses of at least small larvae. In 1-h turbid-water trials, MCPs were 2.6 to 2.8 times greater for larvae but $70 \%$ less for juveniles in 50 to $75 \mathrm{FTU}$ water than in clear water. For fish in close proximity to the trap, effectiveness significantly increased for larvae in turbid water but decreased for early juveniles. Although maximum body width of the larger postflexion mesolarvae approximated $2 \mathrm{~mm}$, MCPs and MRPs for those larvae did not change significantly when 4-mm silt traps were used instead of 2-mm traps. However, early juveniles were unable to enter 2-mm traps. Maximum total length for capture of razorback suckers by 2-mm slit traps was between 20 and $27 \mathrm{~mm}$. MCPs for postflexion mesolarvae did not change significantly when tested in a comparable trap with 300 times greater light intensity at trap perimeter. MCPs for early juveniles dropped by over two-thirds to $19 \%$ in trials using a larger three-lobed light trap 
with comparable low-light intensity and to just $8 \%$ with 500 times greater light intensity. Dramatically increasing trap light intensity did not affect the capture of postflexion mesolarvae but significantly reduced the catch of early juveniles. Differences in trap design can affect the number of early juveniles captured.

\section{Welcomme, R.L. 1995. Relationships between fisheries and the integrity of river systems. Regulated Rivers 11:121-136.}

Human use of river systems has intensified considerably in the last century due to increasing population and the associated higher demand for water through industrial and agricultural technologies. This intensification process has impacted rivers and resident organisms. Natural rivers have rich and varied fish faunas adapted to the variable climate and morphology of such systems. Much of the diversity and resilience can be traced to the connectivity between two very different components, the channel and the floodplain. Fisheries in rivers are as diverse as the fish communities and are adjusted for capturing most species and life stages throughout the year. Fisheries reasonably conducted have proved sustainable with a high rate of catch correlated with the intensity of flooding in the same or preceding years. Fish communities react in a predictable manner to externally imposed stresses, whether eutrophication, induced by humans or natural environmental modification, or fishing, through successive loss of large species and their replacement by smaller, faster growing species. Generally, the overall weight of catch remains little affected by this process until excessive levels of exploitation are reached and the stock collapses. Damage to fish communities through overfishing and environmental modification is widespread. Improvement of the situation demands stricter management of riverine systems through the protection of the few that remain in a relatively pristine state, and those modified should be restored if social, political and economic conditions allow. Should this not be possible, approaches to the mitigation of externally imposed stresses should be sought and applied.

\section{CITATIONS INCLUDED IN BIBLIOGRAPHY}

Ackerman, M.W., D. Ward, T. Hunt, R.S. Rogers, D.R. Van Haverbeke, A. Morgan and C. Cannon. 2006. 2006 Grand Canyon long-term fish monitoring in the Colorado River, Diamond Creek to Lake Mead. Annual report to the U.S. Geological Survey, Grand Canyon Monitoring and Research Center, Flagstaff, Arizona.

Allen, E.J., J.M. Harris and L.J.S. Allen. 1992. Persistence-time models for use in viability analyses of vanishing species. Journal of Theoretical Biology 155: 33-53.

Allendorf, F.W., D. Bayles, D.L. Bottom, K.P. Currens, C.A. Frissell, D. Hankin, J.A. Lichatowich, W. Nehlsen, P.C. Trotter and T.H. Williams. 1997. Prioritizing Pacific salmon stocks for conservation. Conservation Biology 11: 140-152.

Arizona Game and Fish Department. 1996. Ecology of Grand Canyon backwaters. Final report to U.S. Bureau of Reclamation, Upper Colorado Region. Arizona Game and Fish Department, Phoenix. 
Arizona Game and Fish Department. 1996. Effects of an experimental flood on the aquatic biota and their habitats in the Colorado River, Grand Canyon, Arizona. Final report. Arizona Game and Fish Department, Phoenix. 94 pages.

Badame, P.V. 2008. Population estimates for humpback chub (Gila cypha) in Cataract Canyon, Colorado River, Utah, 2003-2005. Final report of Utah Division of Wildlife Resources to Upper Colorado River Endangered Fish Recovery Program, Lakewood, Colorado.

Baedecker, M.J. and L.C. Friedman, eds. 2000. Modeling and experimental flooding in the Grand Canyon. Pages 10-11. In M.J. Baedecker and L.C. Friedman, eds. U.S. Geological Survey National Research Program in the Hydrologic Sciences. U.S. Geological Survey Circular 1195.

Bartley, D., M. Bagley, G. Gall and B. Bentley. 1992. Use of linkage disequilibrium data to estimate effective size of hatchery and natural fish populations. Conservation Biology 6:365375 .

Benenati, E.P., J.P. Shannon, D.W. Blinn, K.P. Wilson and S.J. Hueftle. 2000. Reservoir-river linkages: Lake Powell and the Colordao River, Arizona. Journal of the North American Benthological Society 19(4):742-755.

Benenati, E.P., J.P. Shannon, J.S. Hagan and D.W. Blinn. 2001. Drifting fine particulate organic matter below Glen Canyon Dam in the Colorado River, Arizona. Journal of Freshwater Ecology 16(2):235-248.

Berry, C.R. 1988. Effects of cold shock on Colorado River squawfish larvae. Southwestern Naturalist 33(2):193-197.

Berry, C.R. and R. Pimentel. 1985. Swimming performances of three rare Colorado River fishes. Transactions of the American Fisheries Society 114:397-402.

Berry, D.R. 1984. Hematology of four rare Colorado River fishes. Copeia 3:790-793.

Bestgen, K. and L.W. Crist. 2000. Response of the Green River fish community to construction and re-regulation of Flaming Gorge Dam, 1962-1996. Final report of Colorado State University Larval Fish Laboratory to Upper Colorado River Endangered Fish Recovery Program, Lakewood, Colorado.

Bestgen, K.R. 1996. Growth, survival and starvation resistance of Colorado squawfish larvae. Environmental Biology of Fishes 46:197-209.

Bestgen, K.R. 1997. Interacting effects of physical and biological processes on recruitment of Colorado squawfish. Doctoral Dissertation, Chapter 4. Colorado State University, Fort Collins.

Bestgen, K. R., D. W. Beyers, J. A. Rice, and G. B. Haines. 2006. Factors affecting recruitment of young Colorado pikeminnow: Synthesis of predation experiments, field studies, 
and individual-based modelling. 2006. Transactions of the American Fisheries Society 135:1722-1742.

Bestgen, K.R. and J.M. Bundy. 1998. Environmental factors affect daily increment deposition and otolith growth in young Colorado squawfish. Transactions of the American Fisheries Society 127:105-117.

Bestgen, K.R. and M.A. Williams. 1994. Effects of fluctuating and constant temperatures on early development and survival of Colorado squawfish. Transactions of the American Fisheries Society 123:574-579.

Bestgen, K.R., D.W. Beyers, J.A. Rice and G.B. Haines. 2006. Factors affecting recruitment of young Colorado pikeminnow: Synthesis of predation experiments, field studies and individualbased modeling. Transactions of the American Fisheries Society 135:1722-1742.

Bestgen, K.R., R.T. Muth and M.A. Trammell. 1998. Downstream transport of Colorado squawfish larvae in the Green River drainage: temporal and spatial variation in abundance and relationships with juvenile recruitment. Final report of Colorado State University Larval Fish Laboratory to Upper Colorado River Endangered Fish Recovery Program, Lakewood, Colorado.

Beyers, D.W., J.A. Rice. and W.H. Clements. 1999. Evaluating biological significance of chemical exposure to fish using a bioenergetics-based stressor-response model. Canadian Journal of Fisheries and Aquatic Sciences 56:823-829.

Beyers, D.W., R.T. Muth and M.S. Farmer. 1994. Experimental evidence of competition between larvae of Colorado squawfish and fathead minnow. Final report of Colorado State University Larval Fish Laboratory to Upper Colorado River Endangered Fish Recovery Program, Lakewood, Colorado.

Blinn, D.W. and G.A. Cole. 1991. Algal and invertebrate biota in the Colorado River: Comparison of pre-and post-dam conditions. Pages 102-123 in Colorado River Ecology and Dam Management, Proceedings of a symposium, May 24-25, 1990. National Academy Press, Washington, DC.

Blinn, W., J.P. Shannon, L.E. Stevens and J.P. Carder. 1995. Consequences of fluctuating discharge for lotic communities. Journal of the North American Benthological Society 14(2):233-248.

Bowen, Z.K., M.C. Freeman and K.D. Bovee. 1998. Evaluation of generalized habitat criteria for assessing impacts of altered flow regimes on warmwater fishes. Transactions of the American Fisheries Society 127:455-468.

Bozek, M.A., L.J. Paulson and G.R. Wilde. 1990. Effects of ambient Lake Mohave temperatures on development, oxygen consumption and hatching success of the razorback sucker. Environmental Biology of Fishes 27:255-263. 
Brouder, M.J. and T.L. Hoffnagle. 1997. Distribution and prevalence of the Asian fish tapeworm, Bothriocephalus acheilognathi, in the Colorado River and tributaries, Grand Canyon, Arizona, including two new host records. Journal of the Helminthological Society of Washington 64(2):219-226.

Bulkley, R.V. and R. Pimental. 1983. Temperature preference and avoidance by adult razorback suckers. Transactions of the American Fisheries Society 112:601-607.

Bulow, F.J., J.R. Winningham and R.C. Hooper. 1979. Occurrence of copepod parasite Lernaea cyprinacea in a stream fish population. Transactions of the American Fisheries Society 108: $100-102$.

Canyon Long-Term Fish Monitoring Colorado River, Diamond Creek to Lake Mead. 2005 Annual report to Grand Canyon Monitoring and Research Center from U.S. Fish and Wildlife Service, Hualapai Tribeand SWCA Environmental Consultants, Flagstaff, Arizona.

Casagrandi, R. and M. Gatto. 1999. A mesoscale approach to extinction risk in fragmented habitats. Nature 400: 560-562.

Chao, A. 1989. Estimating population size for sparse data in capture-recapture experiments. Biometrics 45:427-438.

Chart, T.E., and L.D. Lentsch. 1999. Flow effects on humpback chub (Gila cypha) in Westwater Canyon. Final report of Utah Division of Wildlife Resources to Upper Colorado River Endangered Fish Recovery Program, Lakewood, Colorado.

Chart, T.E. and L.D. Lentsch. 2000. Reproduction and recruitment of Gila spp. and Colorado pikeminnow (Ptychocheilus lucius) in the middle Green River 1992-1996. Report C in Flaming Gorge Studies: Reproduction and recruitment of Gila spp. and Colorado pikeminnow (Ptychocheilus lucius) in the middle Green River. Final report of Utah Division of Wildlife Resources to Upper Colorado River Endangered Fish Recovery Program, Lakewood, Colorado.

Chart, T.E. D. P. Svendson and L.D. Lentsch. 1999. Investigation of potential razorback sucker (Xyrauchen texanus) and Colorado pikeminnow (Ptychocheilus lucius) spawning in the lower Green River, 1994 and 1995. Final report of Utah Division of Wildlife Resources to Upper Colorado River Endangered Fish Recovery Program, Lakewood, Colorado.

Childs, M.R., R.W. Clarkson and A.T. Robinson. 1998. Resource use by larval and early juvenile native fishes in the Little Colorado River, Grand Canyon, Arizona. Transactions of the American Fisheries Society 127:620-629.

Choudhoury, A., T.L. Hoffnagle and R.A. Cole. 2001. Parasites of native and nonnative fishes of the Little Colorado River, Grand Canyon, Arizona. Journal of Parasitology 90: 1042-1053. 
Christensen, N.S. and D.P. Lettenmaier. 2006. A multi-model ensemble approach to assessment of climate change impacts on the hydrology and water resources of the Colorado River basin. Hydrology and Earth System Sciences Discussions 3: 3727-3770.

Christensen, N.S., A.W. Wood, N. Voisin, D.P. Lettenmaier and R.N. Palmer. 2004. The effects of climate change on the hydrology and water resources of the Colorado River Basin. Climatic Change 62: 337-363.

Clarkson, R.W. 1993. Foods of young-of-year native fishes in the Little Colorado River, Arizona, and infestation patterns by Asian fish tapeworm Bothriocephalus acheilognathi. Proceedings of the Desert Fishes Council 24:27.

Clarkson, R.W. and M.R. Childs. 2000. Temperature effects of hypolimnial-release dams on early life stages of Colorado River Basin big-river fishes. Copeia 402-412.

Clarkson, R.W., A.T. Robinson and T.L. Hoffnagle. 1997. Asian tapeworm, Bothriocephalus acheilognathi, in native fishes from the Little Colorado River, Grand Canyon, Arizona. Great Basin Naturalist 57: 66-69.

Coggins, L.G. 2007. Abundance trends and status of the Little Colorado River population of humpback chub: an update considering 1989-2006 data. United States Geological Survey open file report 2007-1402.

Coggins, L.G., C. Walters, C. Paukert and S. Gloss. 2003. An overview of status and trend information for the Grand Canyon population of the humpback chub, Gila cypha. U.S. Geological Survery, Grand Canyon Monitoring and Research Center, Flagstaff, Arizona.

Cole, R. 2005. Exotic tapeworm found in endangered desert fishes. U.S. Geological Survey, Fisheries and Aquatics Bulletin 4(1):2-3.

Collins, K.P. and D.K. Shiozawa. 1996. The effects of fish predation on backwater invertebrate communities of the Green River, Utah (Ouray National Wildlife Refuge reach). Final report of Brigham Young University Department of Zoology to Upper Colorado River Endangered Fish Recovery Program, Lakewood, Colorado.

Colorado River, Grand Canyon, Arizona. Annals of the Association of American Geographers 89(2):238-266.

Converse, Y.K. 1995. Use of geomorphology to predict subadult humpback chub distribution in the Colorado River. Proceedings of the Desert Fishes Council.

Converse, Y.K., C.P. Hawkins, and R.A. Valdez. 1998. Habitat relationships of subadult humpback chub in the Colorado River through Grand Canyon: spatial variability and implications of flow regulation. Regulated Rivers: Research and Management 14(3):267-284. 
Converse, Y.K., L.D. Lentsch and R.A. Valdez. 1999. Evaluation of size-dependent overwinter growth and mortality of age-0 Colorado squawfish. Final report of Utah Division of Wildlife Resources to Upper Colorado River Endangered Fish Recovery Program, Lakewood, Colorado.

Day, K. S., K. D. Christopherson, and C. Crosby. 2000. Backwater use by young-of-year chub (Gila spp.) and Colorado pikeminnow (Ptychocheilus lucius) in Desolation and Gray Canyons of the Green River, Utah. Report B in Flaming Gorge studies: reproduction and recruitment of Gila spp. and Colorado pikeminnow (Ptychocheilus lucius) in the middle Green River. Final report of Utah Division of Wildlife Resources to Upper Colorado River Endangered Fish Recovery Program, Lakewood, Colorado.

Day, K.S., K.D. Christopherson and C. Crosby. 1999. An assessment of young-of-year Colorado pikeminnow Ptychocheilus lucius use of backwater habitats in the Green River, Utah. Report B in Flaming Gorge Studies: Assessment of Colorado pikeminnow nursery habitat in the Green River. Final report to Upper Colorado River Endangered Fish Recovery Program. Utah Division of Wildlife Resources, Salt Lake City, Utah.

DeMarais, B.D. and T.E. Dowling. 1993. Introgressive hybridization and evolution of Colorado River basin Gila (Teleostei: Cyprinidae). Proceedings of the Desert Fishes Council 24:67.

Didenko, A.V., S.A. Bonar and W.J. Matter. 2004. Standard weight (Ws) equations for four rare desert fishes. American Journal of Fisheries Management 24(2):697-703.

Douglas, M.E. 1993. An analysis of sexual dimorphism in an endangered cyprinid fish (Gila cypha Miller) using video image technology. Copeia 1993:334-343.

Douglas, M.E. and P.C. Marsh. 1993. Monthly population estimates of endangered humpback chub (Gila cypha) in the Little Colorado River of Arizona. Proceedings of the Desert Fishes Council 24:65-66.

Douglas, M.E. and P.C. Marsh. 1996. Endangered humpback chub (Gila cypha) as prey of introduced fishes in the Little Colorado River, Arizona. Section 2 in M.E. Douglas and P.C. Marsh, eds. Ecology and Conservation Biology of Humpback Chub (Gila cypha) in the Little Colorado River. Bureau of Reclamation, Salt Lake City, Utah.

Douglas, M.E. and P.C. Marsh. 1996. Population estimates/population movements of Gila cypha, an endangered cyprinid fish in the Grand Canyon region of Arizona. Copeia 1996:15-28.

Douglas, M.E. and P.C. Marsh. 1996. Survivability of an endangered species (Gila cypha) within the Grand Canyon region of Arizona. Section 4 in M.E. Douglas and P.C. Marsh, eds. Ecology and Conservation Biology of Humpback Chub (Gila cypha) in the Little Colorado River. Bureau of Reclamation, Salt Lake City, Utah.

Douglas, M.E., M.R. Douglas, J.M. Lynch and D.M. McElroy. 2001. Use of geometric morphometrics to differentiate Gila (Cyprinidae) within the Upper Colorado River basin. Copeia 2:389-400. 
Douglas, M.E., W.L. Minckley and H.M. Tyus. 1989. Qualitative characters, chubs of the genus Gila (Pisces: Cyprinidae) and the "art of seeing well". Copeia 3:653-662.

Douglas, M.E., W.L. Minckley and H.M. Tyus. 1998. Multivariate discrimination of Colorado Plateau Gila spp.: the art of seeing well revisited. Transactions of the American Fisheries Society $127: 163-173$.

Douglas, M.R. and M.E. Douglas. 2007. Genetic structure of humpback chub Gila cypha and roundtail chub G. robusta in the Colorado River ecosystem. Final report, Department of Fish, Wildlife and Conservation Biology, Colorado State University, Fort Collins, Colorado.

Dowling, T.E. and B.D. DeMarais. 1993. Evolutionary significance of introgressive hybridization in cyprinid fishes. Nature 362:444-446.

Dresser, Jr., T.J. 1996. Diet of adult humpback chub. Pages 59-65. In The effects of an experimental flood on the aquatic biota and their habitats in the Colorado River, Grand Canyon, Arizona. Arizona Game and Fish Department, Phoenix.

Elsdon, T. S., B. K. Wells, S. E. Campana, B. M. Gillanders, C. M. Jones, K. E. Limburg, D. H. Secor, S. R. Thorrold, and B. D. Walther. 2008. Otolith chemistry to describe movements and life-history parameters of fishes: hypotheses, assumptions, limitations, and inferences. Oceanography and Marine Biology: an Annual Review 46: 297-330.

Ehrlich, P.R. and D.D. Murphy. 1987. Conservation lessons from long-term studies of checkerspot butterflies. Conservation Biology 1: 122-131.

Fagan, W.F., C. Aumann, C.M. Kennedy and P.J. Unmack. 2005. Rarity, fragmentation, and the scale of dependence of extinction risk in desert fishes. Ecology 86(1):34-41.

Filbert, R.B. and C.P. Hawkins. 1995. Variation in condition of rainbow trout in relation to food, temperature and individual length in the Green River, Utah. Transactions of the American Fisheries Society 124:824-835.

Finney, S. 2006. Adult and juvenile humpback chub monitoring for the Yampa River population, 2003-2004. Final report of U.S. Fish and Wildlife Service to Upper Colorado River Endangered Fish Recovery Program, Lakewood, Colorado.

Freeman, M.C., Z.H. Bowen, K.D. Bove and E.R. Irwin. 2001. Flow and habitat effects on juvenile fish abundance in natural and altered flow regimes. Ecological Applications 11(1):179190.

Garrigan, D., P.C. Marsh and T.E Dowling. 2002. Long-term effective population size of three endangered Colorado River fishes. Animal Conservation 5(2):95-102. 
Gido, K.B., D.L. Propst and M.C. Molles. 1997. Spatial and temporal variation of fish communities in secondary channels of the San Juan River, New Mexico and Utah. Environmental Biology of Fishes 49:417-434.

Gloss, S.P. and L.G. Coggins. 2005. Fishes of Grand Canyon. Pages 33-49 in Gloss, S.P., J.E. Lovich and T.S. Melis, eds., The state of the Colorado River ecosystem in Grand Canyon. A report of the Grand Canyon Monitoring and Research Center 1991-2004. USGS Circular 1282. U.S. Geological Survey, Flagstaff, Arizona.

Gloss, S.P., J.E. Lovich and T.S. Melis, eds. 2005. The state of the Colorado River ecosystem in Grand Canyon: U.S. Geological Survey Circular 1282, Reston, Virginia. pp 220.

Goeking, S.A., J.C. Schmidt and M.K. Webb. 2003. Spatial and temporal trends in the size and number of backwaters between 1935 and 2000, Marble and Grand Canyons, Arizona. Department of Aquatic, Watershed and Earth Resources. Utah State University. Report prepared for U.S. Geological Survey, Grand Canyon Monitoring and Research Center, Flagstaff, Arizona.

Gorman, O.T. 1995. Habitat use by the endangered humpback chub (Gila cypha) in the Little Colorado River, Grand Canyon. Bulletin of the Ecological Society of America 76 (Suppl. 3):333.

Gorman, O.T. and D.M. Stone. 1999. Ecology of spawning humpback chub, Gila cypha, in the Little Colorado River near Grand Canyon, Arizona. Environmental Biology of Fishes 55:115133.

Gorman, O.T. and L. Coggins. 2000. Status and trends of native and non-native fishes of the Colorado River in Grand Canyon 1990-2000. Final report. U.S. Fish and Wildlife Service, Flagstaff, Arizona.

Gorman, O.T., D.M Stone, Z.M. Zdinak and V. Meretsky. 1995. Habitat use by the endangered humpback chub (Gila cypha) in the Little Colorado River, Arizona near Grand Canyon. Proceedings of the Desert Fishes Council 26:53.

Gorman, O.T., R.G. Bramblett, R.M. Hervin, D.R. Van Haverbeke and D.M. Stone. 2005. Distribution and abundance of native and non-native fishes of the Colorado River Ecosystem in Grand Canyon, Arizona. Page 78-94 in Proceedings of two symposia: restoring native fish to the lower Colorado River: interaction of native and non-native fishes. July 13-14, 1999. Las Vegas, Nevada. U.S. Fish and Wildlife Service, Southwest Region, Albuquerque, New Mexico.

Gorman, O.T., S.C. Leon and J.M. Seals. 1994. Habitat use by native fishes in the Little Colorado River in the vicinity of the Grand Canyon. Proceedings of the Desert Fishes Council 25:15.

Gorman, O.T., S.C. Leon and O.E. Maughan. 1993. Habitat use by humpback chub, Gila cypha, in the Little Colorado River and other tributaries of the Colorado River. Proceedings of the Desert Fishes Council 24:20-21. 
Grams, P.E., J.C. Schmidt and D.J. Topping. 2007. The rate and pattern of bed incision and bank adjustment on the Colorado River in Glen Canyon downstream from Glen Canyon Dam, 1956-2000. Bulletin of the Geological Society of America 119(5):556-575.

Granath, W.O., Jr. and G.W. Esch. 1983. Seasonal dynamics of Bothriocephalus acheilognathi in ambient and thermally altered areas of a North Carolina cooling reservoir. Proceedings of the Helminthological Society Washington 50: 205-218.

Grand, T., C.S.F. Railsback, J.W. Hayse and K.E. LaGory. 2006. A physical habitat model for predicting the effects of flow fluctuations in nursery habitats of the endangered Colorado pikeminnow Ptychocheilus lucius. River Research and Applications 22:1125-1142.

Haden, G.A., D.W. Blinn, J.P. Shannon and K.P. Wilson. 1999. Driftwood: an alternative habitat for macroinvertebrates in a large desert river. Hydrobiologia 397:179-186.

Haines, G.B. 1995. Effects of temperature on hatching success and growth of razorback sucker and flannelmouth sucker. Final report of U.S. Fish and Wildlife, Vernal, Utah, to Upper Colorado River Endangered Fish Recovery Program, Lakewood, Colorado.

Haines, G.B. and H.M. Tyus. 1990. Fish associations and environmental variables in age- 0 Colorado squawfish habitats, Green River, Utah. Journal of Freshwater Ecology 5:427-436.

Haines, G.B., D.W. Beyers and T. Modde. 1998. Estimation of winter survival, movement and dispersal of young Colorado squawfish in the Green River, Utah. Final report of U.S. Fish and Wildlife Service, Vernal, Utah, to Upper Colorado River Endangered Fish Recovery Program, Lakewood, Colorado.

Hamilton, S. J. and B. Waddell. 1994. Selenium in eggs and milt of razorback sucker (Xyrauchen texanus) in the middle Green River, Utah. Archives of Environmental Contamination and Toxicology 27:195-201.

Hamilton, S.J., R.T. Muth, B. Waddell and T.W. May. 1998. Selenium and other trace elements in wild larval razorback suckers from the Green River, Utah. Final report of U.S. Geological Survey Environmental and Contaminants Research Center to U.S. Bureau of Reclamation Irrigation Drainage Program, Denver, Colorado.

Hamman, R.L. 1981. Hybridization of three species of chub in a hatchery. Progressive Fish Culturist 43(3):140-141.

Hamman, R.L. 1982. Spawning and culture of humpback chub. Progressive Fish-Culturist $44: 213-216$.

Hamman, R.L. 1987. Survival of razorback sucker cultured in earthen ponds. Progressive FishCulturist 49:187-189. 
Hansen, S.P., A. Choudhury, D.M. Heisey, J.A. Ahumada, T.L. Hoffnagle and R.A. Cole. 2006. Experimental infection of the endangered bonytail chub (Gila elegans) with the Asian fish tapeworm (Bothriocephalus acheilognathi): impacts on survival, growth, and condition. Canadian Journal of Zoology 84(10):1383-1394.

Harpman, D.A. and A.J. Douglas. 2005. Status and trends of hydropower at Glen Canyon Dam. Pages 165-176 in Gloss, S.P., J.E. Lovich and T.S. Melis, eds., The state of the Colorado River ecosystem in Grand Canyon. A report of the Grand Canyon Monitoring and Research Center 1991-2004. USGS Circular 1282. U.S. Geological Survey, Flagstaff, Arizona.

Harvey, M.D., R.A. Mussetter and E.J. Wick. 1993. A physical process-biological response model for spawning habitat formation for the endangered Colorado squawfish. Rivers 4:114131.

Hedrick, P.W., D. Hedgecock and S. Hamelberg. 1995. Effective population size in winter-run chinook salmon. Conservation Biology 9:615-624.

Hendrickson, D. A. 1997. A preliminary study of utility of data obtainable from otoliths to management of humpback chub in the Grand Canyon. Final report to Arizona Game and Fish Department KR92-00310-LNR G20019-A. Abstract was excerpted from report.

Hendrickson, D.A. and E.B. Brothers. 1994. Utility of otoliths of Grand Canyon humpback chub Gila cypha for age determinations and as indicators of ecological history of individuals. Proceedings of the Desert Fishes Council 25:30-31.

Hickman, T.J. 1983. Effect of habitat alterations by energy resource developments in the Upper Colorado River basin on endangered fishes. Aquatic Resources Management of the Colorado River Ecosystem: Proceedings of the 1981 Symposium on the Aquatic Resources Management of the Colorado River Ecosystem November 16-18, 1981, Las Vegas, NV. Ann Arbor Science, Ann Arbor, MI. pp 537-550.

Hinck, J.E., V.S. Blazer, N.D. Denslow, K.R. Echols, T.S. Gross, T.W. May, PJ. Anderson, L.J. Coyle and D.E. Tillit. 2007. Chemical contaminants, health indicators and reproductive biomarker responses in fish from the Colorado River and its tributaries. Science of the Total Environment 378: 376-402.

Hoerling, M. and J. Eischeid. 2006. Past peak water in the Southwest. Southwest Hydrology $6(1)$.

Hoffnagle, T.L. 1996. Changes in water quality parameters and fish usage of backwaters during fluctuating vs. short-term steady flows in the Colorado River, Grand Canyon. Arizona Game and Fish Dept. Prepared for Glen Canyon Environmental Studies, U.S. Bureau of Reclamation.

Hoffnagle, T.L., A. Choudhury and R.A. Cole. 2006. Parasitism and body condition in humpback chub from the Colorado and Little Colorado rivers, Grand Canyon, Arizona. Journal of Aquatic Animal Health 18: 184-193. 
Hoffnagle, T.L., R.A. Valdez and D.W. Speas. 1999. Fish abundance, distribution, and habitat use. Pages 273-287 in R.H. Webb, J.C. Schmidt, G.R. Marzolf and R.A. Valdez, eds. The Controlled Flood in Grand Canyon. Geophysical Monograph 110, The American Geophysical Union, Washington, D.C.

Hoffnagle, T.L., W.R. Persons and G. Doster. 1994. Use of backwater areas by juvenile native fishes in the Colorado River. Proceedings of the Desert Fishes Council 25:33-34.

Holden, P.B. and C.B. Stalnaker. 1970. Systematic studies of the cyprinid genus Gila in the Upper Colorado River Basin. Copeia 1970:409-420.

Houde, E.D. 1987. Fish early life dynamics and recruitment variability. American Fisheries Society Symposium 2:17-29.

Howard, A. and R. Dolan. 1981. Geomorphology of the Colorado River in the Grand Canyon. Journal of Geology 89:269-298.

Hunt, T.A. 2008. The effects of capture by trammel nets on native Arizona fishes. Master's Thesis. Northern Arizona University, Flagstaff, Arizona.

Hurt, C. and P. Hedrick. 2004. Conservation genetics in aquatic species: general approaches and case studies in fishes and springsnails of arid lands. Aquatic Sciences 66(4):402-413. 55 Irving, D. and T. Modde. 2000. Home-range fidelity and use of historical habitat by adult Colorado squawfish (Ptychocheilus lucius) in the White River, Colorado and Utah. Western North American Naturalist 60:16-25.

Jackson, J.A. 2008. Population estimate for the humpback chub (Gila cypha) and roundtail chub (Gila robusta) in Western Canyon, Colorado River, Utah 2003-2005. Draft report Utah Division of Wildlife Resources, Moab, Utah.

Johnson, J.E. and R.T. Hines. 1999. Effect of suspended sediment on vulnerability of young razorback suckers to predation. Transactions of the American Fisheries Society 128:648-655.

Johnson, R.R. and S.W. Carothers. 2005. External threats: the dilemma of resource management on the Colorado River in Grand Canyon National park, USA. Environmental Management 11(1):99-107.

Junk, W.J., P.B. Bailey and R.E. Sparks. 1989. The flood pulse concept in river-floodplain systems. Canadian Special Publication of Fisheries and Aquatic Sciences 106:110-127.

Kaeding, L.R. and M.A. Zimmerman. 1983. Life history and ecology of the humpback chub in the Little Colorado and Colorado Rivers of the Grand Canyon. Transactions of the American Fisheries Society 112:577-594. 
Kaeding, L.R., B.D. Burdick, P.A. Schrader and C.W. McAda. 1990. Temporal and spatial relations between the spawning of humpback chub and roundtail chub in the upper Colorado River. Transactions of the American Fisheries Society 119:135-144.

Karp, C.A. and H.M. Tyus. 1990. Humpback chub (Gila cypha) in the Yampa and Green Rivers, Dinosaur National Monument, with observations on roundtail chub (G. robusta) and other sympatric fishes. Great Basin Naturalist 50:257-264.

Keeler-Foster, C.L., I.B. Spies, V. Bondu-Hawkins and P. Bentzen. 2004. Development of microsatellite markers in bonytail (Gila elegans) with cross-species amplification in humpback chub (Gila cypha). Molecular Notes 4(1):23-25.

Kennedy, T.A. 2007. A Dreissena risk assessment for the Colorado River ecosystem. U.S. Geological Survey open file report 2007-1085.

Kennedy, T.A. and S.P. Gloss. 2005. Aquatic ecology: the role of organic matter and invertebrates. Pages 87-102 in Gloss, S.P., J.E. Lovich and T.S. Melis, eds., The state of the Colorado River ecosystem in Grand Canyon. A report of the Grand Canyon Monitoring and Research Center 1991-2004. USGS Circular 1282. U.S. Geological Survey, Flagstaff, Arizona.

Korman, J.M. and S.E. Campana. 2009. Effects of hydropeaking on nearshore habitat use and growth of age- 0 rainbow trout in a large regulated river. Transactions of the American Fisheries Society 138(1):76-87.

Korman, J., M. Kaplinski and J. Buszowski. 2006. Effects of air and mainstem water temperatures, hydraulic isolation and fluctuating flows from Glen Canyon Dam on water temperatures in shoreline environments of the Colorado River in Grand Canyon. Final report to U.S. Geological Survey, Grand Canyon Monitoring and Research Center, Flagstaff, Arizona.

Korman, J., M. Kaplinski, J.E. Hazel III and T.S. Melis. 2005. Effects of the experimental fluctuating flows from Glen Canyon Dam in 2003 and 2004 on the early life history stages of rainbow trout in the Colorado River. Final report to Grand Canyon Monitoring and Research Center, Flagstaff, Arizona.

Korman, J., S.M. Wiele and M. Torizzo. 2004. Modeling effects of discharge on habitat quality and dispersal of juvenile humpback chub (Gila cypha) in the Colorado River, Grand Canyon. Regulated Rivers 20:379-400.

Kubly, D.M. 1990. The endangered humpback chub (Gila cypha) in Arizona: a review of past studies and suggestions for future research. Arizona Game and Fish Department, Phoenix, Arizona.

LaGory, K.E., J.W. Hayse, and D. Tomasko. 2003. Recommended priorities for geomorphology research in endangered fish habitats of the Upper Colorado River Basin. Final report of Argonne National Laboratory to Upper Colorado River Endangered Fish Recovery Program, Lakewood, Colorado. 
Leibfried, W.C. and R.A. Valdez. 1995. Food habits and electivity indices of the endangered humpback chub, Gila cypha form the Colorado River in Grand Canyon National Park. Proceedings of the Desert Fishes Council, Flagstaff, Arizona.

Leibfried, W.C., H. Johnstone, S. Rhodes and M. Lauretta. 2005. Feasibility study to determine the efficacy of using a weir in Bright Angel Creek to capture brown trout. Final report to Grand Canyon Monitoring and Research Center from SWCA Environmental Consultants, Flagstaff, Arizona.

Lorenzen, K. 1996. The relationship between body weight and natural mortality in fish: a comparison of natural ecosystems and aquaculture. Journal of Fish Biology 49:627-647.

Lupher, M.L. and R.W. Clarkson. 1994. Temperature tolerance of humpback chub (Gila cypha) and Colorado squawfish (Ptychocheilus lucius). Proceedings of the Desert Fishes Council 25:38.

Mabey, L.W. and D.K. Shiozawa. 1993. Planktonic and benthic microcrustaceans from floodplain and river habitats of the Ouray Refuge on the Green River, Utah. Department of Zoology, Brigham Young University, Provo, Utah.

Mankin, J.B., R.H. Gardner, R.V. O’Neill and J.H. Carney. 1981. A comparison of sensitvity analysis and error analysis based on a stream ecosystem model. Ecological Modelling 12(3):173-190.

Marsh, P.C. 1985. Effect of incubation temperature on survival of embryos of native Colorado River fishes. Southwestern Naturalist 30:129-140.

Marsh, P.C. 2005. Immiscibility of native and nonnative species. Pages 59-63 in Proceedings of two symposia: restoring native fish to the lower Colorado River: interaction of native and nonnative fishes. July 13-14, 1999. Las Vegas, Nevada. U.S. Fish and Wildlife Service, Southwest Region, Albuquerque, New Mexico.

Marsh, P.C. and M.E. Douglas. 1995. Humpback chub as food of non-native fishes in the Little Colorado River. Proceedings of the Desert Fishes Council, Flagstaff, Arizona.

Marsh, P.C. and M.E. Douglas. 1997. Predation by introduced fishes on endangered humpback chub and other native species in the Little Colorado River, Arizona. Transactions of the American Fisheries Society (Bethesda) 126(2):343-346

Marsh, P.C., C.A. Pacey and W.L. Minckley. 1999. Resource use attributes of Colorado River fishes and implication for management of native and non-native species. Proceedings of the Desert Fishes Council 30:24.

Masslich, W.J., B.R. Cowdell and R.A. Valdez. 1993. Radiotelemetry studies of humpback chub Gila cypha in the Colorado River, Grand Canyon, Arizona. Proceedings of the Desert Fishes Council 24:68-69. 
McGuinn-Robbins, D.K. 1995. Comparisons in the number and area of backwaters associated with the Colorado River in Glen, Marble and Grand Canyons, Arizona. Draft report to Glen Canyon Environmental Studies, U.S. Bureau of Reclamation. Arizona Game and Fish Department, Phoenix, Arizona.

McKinney, T. and D.W. Speas. 2001. Observations of size-related aymmetries in diet and energy intake of rainbow trout in a regulated river. Environmental Biology of Fishes 61(4):435444.

McKinney, T. and W.R. Persons. 1999. Rainbow Trout and Lower Trophic Levels in the Lee's Ferry Tailwater Below Glen Canyon Dam, Arizona: A Review. Arizona Game and Fish Department report to U.S. Geological Survey, Grand Canyon Monitoring and Research Center, Flagstaff, Arizona.

McKinney, T., R.S. Rogers and W.R. Persons. 1999. Effects of flow reductions on aquatic biota of the Colorado River below Glen Canyon Dam, Arizona. North American Journal of Fisheries Management 19(4):984-991.

Meffe, G.K. and W.L. Minckley. 1987. Persistence and stability of fish and invertebrate assemblages in a repeatedly disturbed Sonoran Desert stream. American Midland Naturalist. 117:177-191.

Meretsky, V.J., R.A. Valdez, M.E. Douglas, M.J. Brouder, O.T. Gorman and P.C. Marsh. 2000. Spatiotemporal variation in length-weight relationships of endangered humpback chub: implications for conservation and management. Transactions of the American Fisheries Society 129:419-428.

Mills, L.S. and F.W. Allendorf. 1996. The one-migrant-per-generation rule in conservation and management. Conservation Biology 10:1509-1518.

Minckley, C.O. 1996. Observations on the biology of the humpback chub in the Colorado River Basin, 1908-1990. Doctoral Dissertation. Northern Arizona University, Flagstaff, Arizona.

Minckley, W.L. 1995. Translocation as a tool for conserving imperiled fishes: Experiences in western United States. Biological Conservation 72(2):297-309.

Minckley, W.L. and B.D. DeMarais. 2000. Taxonomy of chubs (Teleostei, Cyprinidae, genus Gila) in the American Southwest with comments on conservation. Copeia (1):251-256.

Minckley, W.L., P.C. Marsh, J.E. Deacon, T.E. Dowling, P.W. Hedrick, W.J. Mathews and G. Mueller. 2003. A conservation plan for native fishes of the Lower Colorado River. Bioscience 53(3):219-234.

Mueller, G.A. 2005. Predatory fish removal and native fish recovery in the Colorado River mainstem: what have we learned? Fisheries 30(9):10-19. 
Mueller, G.A., J. Carpenter and D. Thornbrugh. 2006. Bullfrog tadpole (Rana catesbeiana) and red swamp crayfish (Procambarus clarkii) predation on early life stages of endangered razorback sucker (Xyrauchen texanus). The Southwestern Naturalist 51(2):258-261.

Muth, R.T. and D. E. Snyder. 1995. Diets of young Colorado squawfish and other small fish in backwaters of the Green River, Colorado and Utah. Great Basin Naturalist 55:95-104.

Muth, R.T. and E.J. Wick. 1997. Field studies on larval razorback suckers in Canyonlands National Park and Glen Canyon National Recreation Area, 1993-1995. Final report of Colorado State University Larval Fish Laboratory to U.S. National Park Service, Rocky Mountain Region, Denver, Colorado.

Muth, R.T. and S.M. Meismer. 1995. Marking otoliths of razorback sucker embryos and larvae with fluorescent chemicals. Southwestern Naturalist 40:241 244.

Muth, R.T., L.W. Crist, K.E. LaGory, J.W. Hayse, K.R. Bestgen, T.P. Ryan, J.K. Lyons and R.A. Valdez. 2000. Flow and temperature recommendations for endangered fishes in the Green River downstream of Flaming Gorge Dam. Final report to Upper Colorado River Endangered Fish Recovery Program, Lakewood, Colorado.

National Park Service. 2009, August 12. Humpback chub translocation experiment in Shinumo Creek [Press release]. Available at http://www.nps.gov/grca/naturescience/cynsk-v12.htm.

Olden, J.D., L. Poff and K.R. Bestgen. 2008. Trait synergisms and the rarity, extirpation, and extinction risk of desert fishes. Ecology 89(3):847-856.

Orchard, K.L., and J.C. Schmidt. 2000. A geomorphic assessment of the availability of potential humpback chub habitat in the Green River in Desolation and Gray Canyons, Utah. Report A in Flaming Gorge studies: reproduction and recruitment of Gila spp. and Colorado pikeminnow (Ptychocheilus lucius) in the middle Green River. Final report of Utah Division of Wildlife Resources to Upper Colorado River Endangered Fish Recovery Program, Lakewood, Colorado.

Papoulias, D. and W.L. Minckley. 1990. Food limited survival of larval razorback sucker, Xyrauchen texanus, in the laboratory. Environmental Biology of Fishes 29:73-78.

Papoulias, D. and W.L. Minckley. 1992. Effects of food availability on survival and growth of larval razorback suckers in ponds. Transactions of the American Fisheries Society 121:340-355.

Patten, D.T., D.A. Harpman, M.I. Voita and T.J. Randle. 2001. A managed flood on the Colorado River: background, objectives, design, and implementation. Ecological Applications 11(3):635-643.

Paukert, C.P. 2004. Comparison of electrofishing and trammel netting variability for sampling native fishes. Journal of Fish Biology 65(6):1643-1652. 
Paukert, C.P. and J.H. Petersen. 2007. Comparative growth and consumption potential of rainbow trout and humpback chub in the Colorado River, Grand Canyon, Arizona, under different temperature scenarios. The Southwestern Naturalist 52(2):234-242.

Paukert, C.P., D.L. Ward, P.J. Sponholtz and K.D. Hilwig. 2005. Effects of repeated hoopnetting and handling of bonytail chub. Journal of Freshwater Ecology 20:649-653.

Paukert, C.P., L.G. Coggins, Jr. and C.E. Flaccus. 2006. Distribution and movement of humpback chub in the Colorado River, Grand Canyon, based on recaptures. Transactions of the American Fisheries Society 135:539-544.

Peterseni, J.H., D.L. Deangelas and C.P. Paukert. 2008. An overview of methods for developing bioenergetic and life history models for rare and endangered species. Transactions of the American Fisheries Society 137(1):244-253.

Peterson, J.H. and C.P. Paukert. 2005. Development of a bioenergetics model for humpback chub and evaluation of water temperature changes in the Grand Canyon, Colorado River. Transactions of the American Fisheries Society 134:960-974.

Pimentel, R. and R.V. Bulkley. 1983. Concentrations of total dissolved solids preferred or avoided by endangered Colorado River fishes. Transactions of the American Fisheries Society 112(5):595-600.

Pine, W. E., III, K. H. Pollock, J. E. Hightower, T. J. Kwak, J. A. Rice. 2003. A review of tagging methods for estimating fish population size and components of mortality. Fisheries 28:10-23.

Pollock, K. H., H. Jiang, H. and J. E. Hightower. 2004. Combining radio-telemetry and fisheries tagging models to estimate fishing and natural mortality rates. Transactions of the American Fisheries Society, 133:639-648.

Portz, D. and Tyus H. 2004. Fish humps in two Colorado River fishes: a morphological response to cyprinid predation? Environmental Biology of Fishes 71(3):233-245.

Powell, K. 2002. Open the floodgates!--A second attempt to restore the altered environment of the Grand Canyon, by letting the Colorado River run free. Nature 420(6914):356-358.

Program Director's Office. 2006. Evaluation of population estimates for Colorado pikeminnow and humpback chub in the Upper Colorado River Basin. Upper Colorado River Endangered Fish Recovery Program, Lakewood, Colorado.

Rakowski, C.L. and J.C. Schmidt. 1999. The geomorphic basis of Colorado pikeminnow nursery habitat in the Green River near Ouray, Utah. Report A in Flaming Gorge Studies: Assessment of Colorado pikeminnow nursery habitat in the Green River. Final report to Upper Colorado River Endangered Fish Recovery Program. Utah Division of Wildlife Resources, Salt Lake City, Utah. 
Robinson, A.T. 1993. Feeding behavior and ecology of young-of-the-year native fish in the Little Colorado River of the Grand Canyon. Proceedings of the Desert Fishes Council 24:39.

Robinson, A.T. and M.R. Childs. 2001. Juvenile growth of native fishes in the Little Colorado River and in a thermally modified portion of the Colorado River. North American Journal of Fisheries Management 21:809-815.

Robinson, A.T. D.M. Kubly, R.W. Clarkson and E.D. Creef. 1996. Factors limiting the distributions of native fishes in the Little Colorado River, Grand Canyon, Arizona. Southwestern Naturalist 41(4):378-387.

Robinson, A.T., R.W. Clarkson and R.E. Forrest. 1998. Dispersal of larval fishes in a regulated river tributary. Transactions of the American Fisheries Society 127:722-786.

Rogers, R.S., D.L. Speas and A.S. Makinster. 2003. Grand Canyon Long-term Nonnative Fish Monitoring, 2003 Annual report submitted to Grand Canyon Monitoring and Research Center Cooperative Agreement 02WRAG0030, October 2003.

Rogers, R.S., W.R. Persons and T. McKinney. 2003. Effects of a 31,000-cfs spike flow and low steady flow on benthic biomass and drift composition in the Lees Ferry tailwater. Cooperative Agreement 1425-98-FC-40-22690 (mod3). Arizona Game and Fish Department, Flagstaff, Arizona.

Rosenfeld, M.J. and J.A. Wilkinson. 1989. Biochemical genetics of the Colorado River Gila complex (Pisces: Cyprinidae). Southwestern Naturalist 34:232-244.

Rubin, D.M., D.J. Topping, J.C. Schmidt, J. Hazel, M. Kaplinski and T.S. Melis. 2002. Recent sediment studies refute Glen Canyon Dam hypothesis. Transactions American Geophysical Union 83(25):273.

Rubin, D.M., J.M. Nelson and D.J. Topping. 1998. Relation of inversely graded deposits to suspended-sediment grain-size evolution during the 1996 flood experiment in Grand Canyon. Geology 2692):99-102.

Ruppert, J.B. and R.T. Muth. 1997. Effects of electrofishing fields on captive juveniles of two endangered cyprinids. North American Journal of Fisheries Management 17:314-320.

Ruppert, J.B., R.T. Muth and T.P. Nesler. 1993. Predation on fish larvae by adult red shiner, Yampa and Green Rivers, Colorado. Southwestern Naturalist 38:397-399.

Schmidt, J.C. 1994. Compilation of historic hydrologic and geomorphic data for the upper Colorado River basin. Annual report of Utah State University Department of Geography and Earth Resources to Upper Colorado River Endangered Fish Recovery Program, Lakewood, Colorado. 
Schmidt, J.C. and J. Brim Box. 2004. Application of a dynamic model to assess controls on age-0 Colorado pikeminnow distribution in the middle Green River, Colorado and Utah. Annals of the Association of American Geographers, Vol. 94 (3):458-476.

Schmidt, J.C. and D.M. Rubin. 1995. Regulated streamflow, fine-grained deposits, and effective discharge in canyons with abundant debris fans. Pages 177-195 in J. E. Costa, A. J. Miller, K. W. Potter, and P. R. Wilcock, editors. Natural and anthropogenic influences in fluvial geomorphology. AGU Geophysical Monograph 89.

Schmidt, J.C., D.J. Topping, P.E. Grams and J.E. Hazel. 2004. System wide changes in the distribution of fine sediment in the Colorado River corridor between Glen Canyon Dam and Bright Angel Creek, Arizona. Final report of the Fluvial Geomorphology Laboratory, Utah State University, Logan, Utah. pp 99.

Schmidt, J.C., K.L. Orchard and S.P. Holman. 1996. Spatial and temporal patterns of habitat availability in Desolation and Gray Canyons. 1995 Annual report and 1996 field progress report, Department of Geography and Earth Resources, Utah State University. Logan.

Schmidt, J.C., R.H. Webb, R.A. Valdez, G.R. Marzolf and L.E. Stevens. 1998. Science and values in river restoration in the Grand Canyon. BioScience 48: 735-747.

Schmidt, J.C., S.J. Topping, D.M. Rubin, J.E. Hazel and M. Kaplinski. 2007. Streamflow and sediment data collected to determine the effects of low summer steady flows and habitat maintenance flows in 2000 on the Colorado River between Lees Ferry and Bright Angel Creek, Arizona. U.S. Geological Survey, Reston, Virginia, pp 86.

Schultz. A.A., O.E. Maughan, S.A. Bonar and W.J. Matter. 2003. Effects of flooding on abundance of native and nonnative fishes downstream from a small impoundment. North American Journal of Fisheries Management 23:503-511.

Seager, R., M. Ting, I. Held, Y. Kushnir, J. Lu, G. Vecchi, H. Huang, N. Harnik, A. Leetmaa, N. Lau, C. Li, J. Velez and N. Naik. 2007. Model projections of an imminent transition to a more Arid Climate in Southwestern North America. Science.10:1126.

Seals, J.M., O.T. Gorman and S.C. Leon. 1994. Stream fish habitat studies in the Little Colorado River: a microhabitat approach. Proceedings of the Desert Fishes Council 25:14-15.

Shaffer, M.L. 1981. Minimum population sizes for species conservation. Bioscience 31:131134.

Shannon, J.P., D.W. Blinn, G.A. Haden, E.P. Benenati and K.P. Wilson. 2001. Food web implications of $\sigma 13 \mathrm{C}$ and $\sigma 15 \mathrm{~N}$ variability over $370 \mathrm{~km}$ of the regulated Colorado River USA. Isotopes in Environmental and Health Studies 37(3):179-191.

Shannon, J.P., D.W. Blinn, P.L. Benenati and K.P. Wilson. 1996. Organic drift in a regulated desert river. Canadian Journal of Fisheries and Aquatic Sciences 53(6):1360-1369. 
Shannon, J.P., D.W. Blinn, T. McKinney, E.P. Benenati, K.P. Wilson and C. O’Brien. 2001. Aquatic food base response to the 1996 test flood below Glen Canyon Dam, Colorado River, Arizona. Ecological Applications 11(3): 672-685.

Sharber, N.G. and S.W. Carothers. 1987. Submerged, electrically shielded live tank for electrofishing boats. North American Journal of Fisheries Management 7:450-453. 135 Shaver, M.L., J.P. Shannon, K.P. Wilson, P.L. Benenati and D.W. Blinn. 1997. Effects of suspended sediment and desiccation on the benthic tailwater community in the Colorado River, USA. Hydrobiologia 357(1-3):63-72.

Simpfendorfer, C. A., M. R. Heupel, and A. B Collins. 2008. Variation in the performance of acoustic receivers and its implication for positioning algorithms in a riverine setting. Canadian Journal of Fisheries and Aquatic Sciences 65:482-492.

Snyder, D.E. 1976. Terminologies for intervals of larval fish development. Pages 41-60 in J. Boreman, editor. Great Lakes fish egg and larvae identification, proceedings of a workshop. U.S. Fish and Wildlife Service FWS/OBS-76/23.

Snyder, D.E. and S.M. Meismer. 1997. Effectiveness of light traps for capture and retention of larval and early juvenile Xyrauchen texanus and larval Ptychocheilus lucius and Gila elegans. Final report of Colorado State University Larval Fish Laboratory to U.S. National Park Service Cooperative Parks Study Unit, Fort Collins, Colorado.

Speas, D W. 2004. Effects of low steady summer flows on rainbow trout in the Lee's Ferry tailwater, 2000. Report to U.S. Geological Survey, Grand Canyon Monitoring and Research Center, Flagstaff, Arizona.

Speas, D.W., W.R. Persons, R.S. Rogers, D.L. Ward, A.S. Makinster and J.E. Slaughter, IV. 2004. 2001 Fish Investigations in the Lee's Ferry Tailwater. Report to U.S. Geological Survey, Grand Canyon Monitoring and Research Center, Flagstaff, Arizona.

Stanford, J.A. 1994. Instream flows to assist the recovery of endangered fishes of the Upper Colorado River basin: review and synthesis of ecological information, issues, methods and rationale. U.S. Fish and Wildlife Service, Denver, Colorado. FLBS Open File Report 130-93.

Stevens, L.E., J.C. Schmidt, J.C. Ayers, T.J. Brown and T. Bryan. 1995. Flow regulation, geomorphology, and Colorado River marsh development in the Grand Canyon, Arizona.

Stevenson, D.K. and Campana, S.E. (Editors). 1992. Otolith microstructure examination and analysis. Canadian Special Publication of Fisheries and Aquatic Sciences 117.

Stone, D.M. 1999. Ecology of humpback chub (Gila cypha) in the Little Colorado River, near Grand Canyon, Arizona. Master's thesis, Northern Arizona University, Flagstaff. 
Stone, D.M. 2004. Differential detection of ingested items evacuated from genus Gila cyprinids by two nonlethal alimentary tract lavage techniques. Journal of Freshwater Ecology 19:559-565.

Stone, D.M. 2005. Effect of baiting on hoop net catch rates of endangered humpback chub. North American Journal of Fisheries Management 25(2):640-645.

Stone, D.M. and O.T. Gorman. 2005. Ontogenesis of endangered humpback chub (Gila cypha) in the Little Colorado River, Arizona. The American Midland Naturalist 155:123-135.

Stone, D.M., D.R. Van Haverbeke, D.L. Ward and T.A. Hunt. 2007. Dispersal of nonnative fishes and parasites in the intermittent Little Colorado River, Arizona. Southwestern Naturalist 52(1):130-137.

Suttkus, R.D. and G.H. Clemmer. 1977. The humpback chub, Gila cypha, in the Grand Canyon area of the Colorado River. Occasional Papers of the Tulane University Museum of Natural History, New Orleans, Louisiana 1:1-30.

Thieme, M.L., C.C. Mivor, M.J. Brouder and T.L. Hoffnagle. 2001. Effects of pool formation and flash flooding on relative abundance of young-of-year flannelmouth suckers in the Paria River, Arizona.

Thompson, J.M., E.P. Bergersen, C.A. Carlson and L.R. Kaeding. 1991. Role of size, condition, and lipid content in the overwinter survival of age-0 Colorado squawfish. Transactions of the American Fisheries Society 120:346-353.

Topping, D.J., D.M. Rubin and L.E. Vierra, Jr. 2000. Colorado River sediment transport 1. Natural sediment supply limitation and the influence of Glen Canyon Dam. Water Resources Research 36:515-542.

Topping, D.J., D.M. Rubin and T.S. Melis. 2007. Coupled changes in sand grain size and sand transport driven by changes in the upstream supply of sand in the Colorado River: relative importance of changes in bed-sand grain size and bed-sand area. Sedimentary Geology 202(3):538-561.

Trammel, M. and R. Valdez. 2003. Native fish monitoring activities in the Colorado River within Grand Canyon during 2001. SWCA, Inc., Flagstaff, Arizona, to Grand Canyon Monitoring and Research Center, Flagstaff, Arizona.

Trammell, M. A. and T. E. Chart. 1999. Colorado pikeminnow young-of-year habitat use, Green River, Utah, 1992-1996. Report C in Flaming Gorge Studies: Assessment of Colorado pikeminnow nursery habitat in the Green River. Utah Division of Wildlife Resources, Final report to Upper Colorado River Endangered Fish Recovery Program, Lakewood, Colorado.

Trammell, M., R. Valdez, S. Carothers and R. Ryel. 2002. Effects of a low steady summer flow experiment on native fishes of the Colorado River in Grand Canyon, Arizona. SWCA 
Environmental Consultants. Final report to U.S. Geological Survey, Grand Canyon Monitoring and Research Center, Flagstaff, Arizona.

Turner, D.S. and M.D. List. 2007. Habitat mapping and conservation analysis to identify critical streams for Arizona's native fish. Aquatic Conservation: Marine and Freshwater Ecosystems $17: 737-748$.

Tyus, H.M. 1991. Movements and habitat use of young Colorado squawfish in the Green River, Utah. Journal of Freshwater Ecology 6:43-51.

Tyus, H.M. 1992. An instream flow philosophy for recovering endangered Colorado River fishes. Rivers 3:27-36.

Tyus, H.M. and C.A. Karp. 1989. Habitat use and streamflow needs of rare and endangered fishes, Yampa River, Colorado and Utah. U.S. Fish and Wildlife Service Biological Report 89:1-27.

Tyus, H.M. and C.A. Karp. 1991. Habitat use and streamflow needs of rare and endangered fishes, Green River, Utah. U.S. Fish and Wildlife Service, Vernal, Utah.

Tyus, H.M. and C.W. McAda. 1984. Migration, movements and habitat preferences of Colorado squawfish, Ptychocheilus lucius, in the Green, White and Yampa Rivers, Colorado and Utah. Southwestern Naturalist 29:289-299.

Tyus, H.M. and G.B. Haines. 1991. Distribution, habitat use and growth of age-0 Colorado squawfish in the Green River basin, Colorado and Utah. Transactions of the American Fisheries Society 120:79-89.

Tyus, H.M. and J.F. Saunders. 1996. Nonnative fishes in the Upper Colorado River Basin and a strategic plan for their control. Final report of University of Colorado Center for Limnology to Upper Colorado River Endangered Fish Recovery Program, Lakewood, Colorado.

Tyus, H.M. and J.F. Saunders, III. 2000. Non-native fish control and endangered fish recovery: lessons from the Colorado River. Fisheries 25(9):848-855.

Tyus, H.M. and W.L. Minckley. 1988. Migrating Mormon crickets, Anabrus simplex (Orthoptera: Tettigoniidae), as food for stream fishes. Great Basin Naturalist 48:25-30. 61

Tyus, H.M., J.L. Cooper and R.H. Hamre. 1991. Management of Colorado River fishes. USDA Forest Service, Washington, D.C.

U.S. Bureau of Reclamation. 1999. Glen Canyon Dam modification to control downstream temperatures. Plan and draft environmental assessment. U.S. Bureau of Reclamation, Upper Colorado Region, Salt Lake City, Utah. 
U.S. Bureau of Reclamation. 2002. Proposed experimental releases from Glen Canyon Dam and removal of non-native fish. U.S. Department of the Interior, Bureau of Reclamation, Upper Colorado Region, Salt Lake City, Utah.

U.S. Bureau of Reclamation. 2007. Biological assessment on the operation of Glen Canyon Dam and proposed experimental flows for the Colorado River below Glen Canyon Dam during the years 2008-2012. U.S. Bureau of Reclamation, Upper Colorado River Region, Salt Lake City, Utah.

U.S. Bureau of Reclamation. 2007. Biological assessment of the Colorado River interim guidelines for lower basin shortages and coordinated operations for Lake Powell and Lake Mead, final environmental impact statement. U.S. Bureau of Reclamation, Boulder Canyon Operations Office, Boulder City, Nevada.

U.S. Fish and Wildlife Service. 1994. Determination of critical habitat for four endangered Colorado River fishes. Federal Register 59(54):13374-13400.

U.S. Fish and Wildlife Service. 1994. Final rule, determination of critical habitat for the Colorado River endangered fishes: razorback sucker, Colorado squawfish, humpback chub and bonytail chub. Federal Register 59:13374-13400.

U.S. Fish and Wildlife Service. 2002. Recovery goals: amendment and supplement to the humpback chub recovery plan. Mountain-Prairie Region, Denver, Colorado.

U.S. Fish and Wildlife Service. 2007. Final biological opinion for the proposed adoption of Colorado River interim guidelines for lower basin shortages and coordinated operations for Lake Powell and Lake Mead. Consultation number 22410-2006-F-0224. U.S. Fish and Wildlife Service, Phoenix, Arizona.

U.S. Fish and Wildlife Service. 2008. Final biological opinion on the operation of Glen Canyon Dam. U.S. Fish and Wildlife Service, Phoenix, Arizona.

U.S. Fish and Wildlife Service. 2009. A plan for the captive maintenance of humpback chub from the Yampa River population. Upper Colorado River Endangered Fish Recovery Program, Lakewood, Colorado.

U.S. Geological Survey. 2006. Grand Canyon humpback chub population stabilizing. U.S. Geological Survey Fact Sheet 2006-3109.

U.S. Geological Survey. 2007. Grand Canyon humpback chub population improving. U.S. Geological Survey Fact Sheet 2007-3113.

U.S. Geological Survey. 2007. Science Plan for Potential 2008 Experimental High Flow at Glen Canyon Dam, Grand Canyon Monitoring and Research Center, Flagstaff, Arizona. pp 104. 
Upper Colorado River Endangered Fish Recovery Program. 2008. A plan for the captive maintenance of humpback chub from the Yampa River. Draft report, Upper Colorado River Endangered Fish Recovery Program, Lakewood, Colorado.

Valdez, R.A. 1993. Use of scales to determine emigration of juvenile humpback chub Gila cypha from the Little Colorado River in Grand Canyon, Arizona. Proceedings of the Desert Fishes Council 24:61.

Valdez, R.A. 1994. Effects of interim flows from Glen Canyon Dam on the aquatic resources of the lower Colorado River from Diamond Creek to Lake Mead: Phase I. Bio/West, Inc., Final report to Glen Canyon Environmental Studies.

Valdez, R.A. and D.W. Speas. 2007. A risk assessment model to evaluate risks and benefits to aquatic resources from a selective withdrawal structure on Glen Canyon Dam. Bureau of Reclamation, Salt Lake City, Utah.

Valdez, R.A. and R.J. Ryel. 1995. Life history and ecology of the humpback chub (Gila cypha) in the Colorado River, Grand Canyon, Arizona. Final report of Bio/West, Inc., Logan, Utah, to U.S. Bureau of Reclamation, Salt Lake City, Utah.

Valdez, R.A. and R.J. Ryel. 1997. Life history and ecology of the humpback chub in the Colorado River in Grand Canyon, Arizona. Final report TR-250-08. BIO/WEST, Inc., Logan, Utah.

Valdez, R.A. and R.T. Muth. 2005. Ecology and conservation of native fish in the Upper Colorado River Basin. American Fisheries Society Symposium 45:157-204.

Valdez, R.A. and S.W. Carothers. 1998. The aquatic ecosystem of the Colorado River in Grand Canyon. Final report of SWCA, Inc., Flagstaff, Arizona, to U.S. Bureau of Reclamation, Upper Colorado Region, Salt Lake City, Utah.

Valdez, R.A. and T.L. Hoffnagle. 1999. Movement, habitat use and diet of adult humpback chub. Pages 297-307 in R.H. Webb, J.C. Schmidt, G.R. Marzolf and R.A. Valdez (eds.). The controlled flood in Grand Canyon. Geophysical Monograph 110. American Geophysical Union, San Francisco, California.

Valdez, R.A., B.R. Cowdell and E. Pratts. 1995. Effects of interim flows from Glen Canyon Dam on the aquatic resources of the lower Colorado River from Diamond Creek to Lake Mead: Phase II, Bio/West, Inc., Final report to Glen Canyon Environmental Studies.

Valdez, R.A., P.B. Holden and T.B. Hardy. 1990. Habitat suitability index curves for humpback chub of the Upper Colorado River Basin. Rivers 1:31-42.

Valdez, R.A., S.W. Carothers, M.E. Douglas, M. Douglas, R.J. Ryel, K.R. Bestgen and D.L. Wegner. 2000. Research and implementation plan for establishing a second population of 
humpback chub in Grand Canyon, Final report to U.S. Department of the Interior, U.S. Geological Survey, Grand Canyon Monitoring and Research Center, Flagstaff, Arizona.

Valdez, R.A., T.L. Hoffnagle, C.D. McIvor, T. McKinney and W.C. Leibfried. 2001. Effects of a test flood on fishes of the Colorado River in Grand Canyon, Arizona. Ecological Applications 11:686-700.

Valdez, R.A., W.J. Masslich and W. Leibfried. 1993. Present distribution of humpback chub Gila cypha in the mainstem Colorado River, Grand Canyon, Arizona. Proceedings of the Desert Fishes Council 24:66.

Valdez, R.A., W.J. Masslich, L. Crist and W. Leibfried. 1992. Investigations of the life history and ecology of the humpback chub (Gila cypha) in the Grand Canyon. Proceedings of the Desert Fishes Council 23:15.

Valdez, R.A., W.J. Masslich, W. Leibfried, A. Wasowicz, B. Cowdell, R. VanHaverbeke, M. Yard, T.M. Trinca and L.I. Brown. 1992. Characterization of the life history and ecology of the humpback chub in the Grand Canyon. Annual report TR 250-05 of BIO/WEST, Inc. to U.S. Bureau of Reclamation, Salt Lake City, Utah.

Van Haverbeke, D.R. and L.G. Coggins, Jr. 2002. Stock assessment and fisheries monitoring activities in the Little Colorado River within Grand Canyon during 2001. Document number USFWS-AZFRO-FL-02-002. U.S. Fish and Wildlife Service, Flagstaff, Arizona. 82 pages.

Van Haverbeke, D.R. and R.L. Simmonds, Jr. 2004. Feasibility of developing a program to augment the population of humpback chub (Gila Cypha) in Grand Canyon. USFWS-AZFROFL-03-007. U.S. Fish and Wildlife, Arizona Fishery Resources Office, Flagstaff.

Van Steeter, M.M. and J. Pitlick. 1998. Geomorphology and endangered fish habitats of the upper Colorado River, 1. Historic changes in streamflow, sediment load and channel morphology. Water Resources Research 34:287-302.

Vernieu, W.S., S.J. Hueffle and S.P. Gloss. 2005. Water quality in the Lake Powell and the Colorado River. Pages 1991-2004 in Gloss, S.P., J.E. Lovich and T.S. Melis, eds., The state of the Colorado River ecosystem in Grand Canyon. A report of the Grand Canyon Monitoring and Research Center 1991-2004. USGS Circular 1282. U.S. Geological Survey, Flagstaff, Arizona.

Walters, C. and J. Korman. 1999. Linking recruitment to trophic factors: revisiting the Beverton-Holt recruitment model from a life history and multispecies perspective. Reviews in Fish Biology and Fisheries 9(2):187-202.

Walters, C., J. Korman, L.E. Stevens and B. Gold. 2000. Ecosystem modelling for evaluation of adaptive management policies in the Grand Canyon. Conservation Ecology 4(2):24.

Waples, R.S. 1990. Conservation genetics of Pacific salmon. II. Effective population size and the rate of loss of genetic variability. Journal of Heredity 81:267-276. 
Waples, R.S., G.A. Winans, F.M. Utter and C. Mahnken. 1990. Genetic approaches to the management of Pacific salmon. Fisheries 15(5):19-25.

Ward, D.L. 2007. Removal and quantification of Asian tapeworm from bonytail chub using praziquantel. North American Journal of Aquaculture 69(3):207-210.

Ward, D.L. and S.A. Bonar. 2003. Effects of cold water on susceptibility of age-0 flannelmouth sucker predation by rainbow trout. Southwestern Naturalist 48:43-46.

Ward, D.L. and S.A. Bonar. 2003. Effects of cold water on susceptibility of age-0 flannelmouth sucker predation by rainbow trout. Southwestern Naturalist 48:43-46.

Ward, D.L., O.E. Maughan, S.A. Bonar and W.J. Matter. 2002. Effects of temperature, fish length and exercise on swimming performance of age-0 flannelmouth sucker. Transaction of the American Fisheries Society 131:492-497.

Ward, J.V. and J.A. Stanford. 1995. Ecological connectivity in alluvial river ecosystems and its disruption by flow regulation. Regulated Rivers: Research \& Management 11(1):105-119.

Wasowicz, A. and R.A. Valdez. 1995. Historic and present distribution and abundance of humpback chub in Grand Canyon, Arizona. Proceedings of the Desert Fishes Council 26:57.

Webb, R.H., D.L. Wegner, E.D. Andrews, R.A. Valdez and D.T. Patten. 1999. Downstream effects of Glen Canyon dam on the Colorado River in Grand Canyon: a review. Geophysical Monograph 110:1-21.

Webb, R.H., P.G. Griffiths, C.S. Magirl and T.C. Hanks. 2005. Debris flows in Grand Canyon and the rapids of the Colorado River. Pages 139-152 in Gloss, S.P., J.E. Lovich and T.S. Melis, eds., The state of the Colorado River ecosystem in Grand Canyon. A report of the Grand Canyon Monitoring and Research Center 1991-2004. USGS Circular 1282. U.S. Geological Survey, Flagstaff, Arizona.

Webb, R.H., P.G. Griffiths, T.S. Melis and D.R. Hartley. 2000. Sediment delivery by ungaged tributaries of the Colorado River in Grand Canyon, Arizona. Water Resources Investigations Report, U.S. Geological Survey no. 4055, pp 78.

Webb, R.H., R. Hereford and G.J. McCabe. 2005. Climatic fluctuations, drought and flow in the Colorado River. Pages 57-68 in S.P. Gloss, Lovich, J.E. and Melis, T.S. (eds.). The state of the Colorado River ecosystem in the Grand Canyon: U.S. Geological Survey Circular 1282.

Weiss, J. 1992. The relationship between flow and backwater fish habitat of the Colorado River in Grand Canyon. Draft report. Glen Canyon Environmental Studies, Bureau of Reclamation, Flagstaff. pp 13. 
Welcomme, R.L. 1995. Relationships between fisheries and the integrity of river systems. Regulated Rivers 11:121-136.

White, M.A., J.C. Schmidt and D.J. Topping. 2005. Application of wavelet analysis for monitoring the hydrologic effects of dam operations: Glen Canyon Dam and the Colorado River at Lees Ferry, Arizona. River Research and Applications 21(5):551-565.

Wick, E.J., J.A. Hawkins and T.P. Nesler. 1991. Occurrence of two endangered fishes in the Little Snake River, Colorado. Southwestern Naturalist 36:251-254.

Wiele, S.M. 1998. Modeling of flood-deposited sand distributions in a reach of the Colorado River below the Little Colorado River, Grand Canyon, Arizona. U.S. Geological Survey WaterResources Investigations Report, pp 26.

Wiele, S.M., J.B. Graf and J.D. Smith. 1996. Sand deposition in the Colorado River in the Grand Canyon from flooding of the Little Colorado River. Water Resources Research 32:357996.

Wieringa, M.J. and A.G. Morton. 1996. Hydropower, adaptive management and biodiversity: Environmental Management 20(6):831-840.

Williams, J.E., D.B. Bowman, J.E. Brooks, A.A. Echelle, R.J. Edwards, D.A. Hendrickson and J.J. Landye. 1985. Endangered aquatic ecosystems in North American deserts, with a list of vanishing fishes of the region. Journal of the Arizona-Nevada Academy of Sciences.

Wolock, D.M. and G.J. McCabe. 1999. Estimates of runoff using water-balance and atmospheric General Circulation Models. Journal of the American Water Resources Association 35: $1341-1350$.

Wolz, E.R. and D.K. Shiozawa. 1995. Soft sediment benthic macroinvertebrate communities of the Green River at the Ouray National Wildlife Refuge, Uintah County, Utah. Great Basin Naturalist 55:213-224.

Wright, S.A., C.R. Anderson and N. Voichick. 2009. A simplified water temperature model for the Colorado River below Glen Canyon Dam. River Research and Applications 25(6):675-686.

Wright, S.A., T.S. Melis, D.J. Topping and D.M. Rubin. 2005. Influence of Glen Canyon Dam operations on downstream sand resources of the Colorado River in Grand Canyon. Pages 17-31 in Gloss, S.P., J.E. Lovich and T.S. Melis, eds., The state of the Colorado River ecosystem in Grand Canyon. A report of the Grand Canyon Monitoring and Research Center 1991-2004. USGS Circular 1282. U.S. Geological Survey, Flagstaff, Arizona.

Wyodoski, R.S. and E.J. Wick. 1998. Ecological value of floodplain habitats to razorback suckers in the upper Colorado River basin. Final report of U.S. Fish and Wildlife Service and U.S. National Park Service to Upper Colorado River Endangered Fish Recovery Program, Lakewood, Colorado. 